UNIVERSIDADE DE SÃO PAULO

EESC $\cdot$ USP

ESCOLA DE ENGENHARIA DE SÃO CARLOS

SISTEMA DE GERÊNCIA DE PAVIMENTOS APLICADO A VIA PERMANENTE METROFERROVIÁRIA AUXILIADO POR UM SISTEMA DE INFORMAÇÕES GEOGRÁFICAS

Igor Baria

São Carlos

2015 



\title{
Igor Baria
}

\section{SISTEMA DE GERÊNCIA DE PAVIMENTOS APLICADO A VIA PERMANENTE METROFERROVIÁRIA AUXILIADO POR UM SISTEMA DE INFORMAÇÕES GEOGRÁFICAS}

\author{
Tese apresentada à Escola de \\ Engenharia de São Carlos da \\ Universidade de São Paulo como parte \\ dos créditos para obtenção do título de \\ Doutor em Ciências no Programa de Pós- \\ Graduação em Engenharia de \\ Transportes.
}

Área de Concentração: Infraestrutura de Transportes.

Orientador: Professor Associado José Leomar Fernandes Júnior.

\section{São Carlos}


Autorizo a reprodução e divulgação total ou parcial deste trabalho, por qualquer meio convencional ou eletrônico, para fins de estudo e pesquisa, desde que citada a fonte.

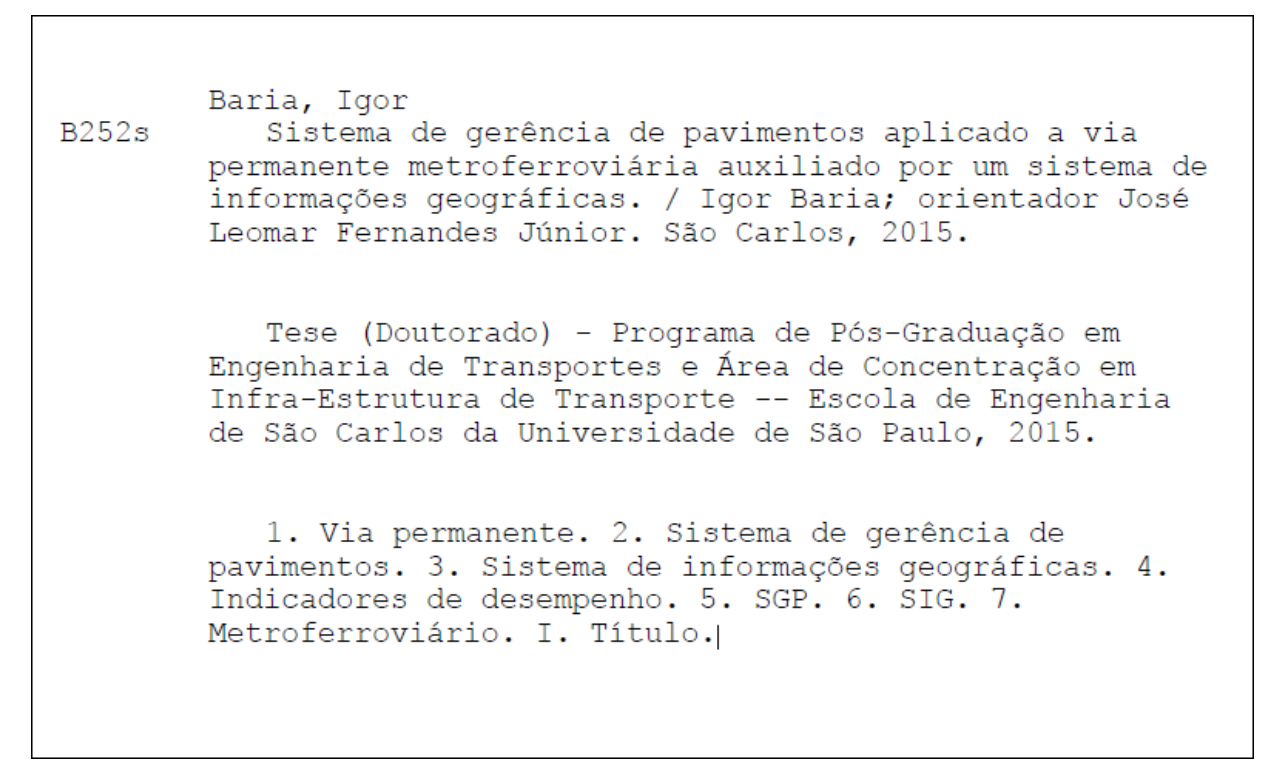




\section{UNIVERSIDADE DE SÃO PAULO}

\section{ESCOLA DE ENGENHARIA DE SÃO CARLOS}

Tese submetida ao corpo docente do Programa de Pós-Graduação em Engenharia de Transportes da Escola de Engenharia de São Carlos da Universidade de São Paulo, sob orientação do Professor Associado José Leomar Fernandes Júnior e aprovada conforme Folha de Julgamento.

\section{FOLHA DE JULGAMENTO}

Candidato: Engenheiro IGOR BARIA.

Tífulo da tese: "Sistema de geréncia de pavimentos aplicado a via permanente metroferroviória auxiliado por um sistema de informações geográficas"

Data da defesa: 16/07/2015

Comissão Julgadora:

Resultado:

Prof. Titular José Leomar Fernandes Júnior (Orientador)

(Escola de Engenharia de São Carlos/EESC)

APROVADO

Profa. Dra. Cira Souza Pîtombo

(Escola de Engenharia de São Carlos/EESC)

Aprovado

Profa. Dra. Ana Paula Camargo Larocca

(Escola de Engenharia de São Carlos/EESC)

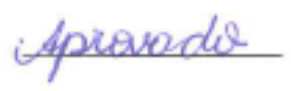

Prof. Dr. Rudney da Conceiçāo Queiroz

(Faculdades Logatti/FIAR)

APROVADD

Prof. Dr. Ernesto Ferreira Nobre Júnior

APROVA DO

(Universidade Federal do Ceará/UFC)

Coordenador do Programa de Pós-Graduaçāo em Engenharia de Transportes:

Prof. Associado Paulo Cesar Lima Segantine

Presidente da Comissāo de Pós-Graduaçāo:

Prof. Associado Paulo Cesar Lima Segantine 



\section{DEDICATÓRIA}

À minha amada Rita, minha alma gêmea, companheira fiel de todos os momentos da minha vida, maior apoiadora de meus estudos e maior responsável pelos meus sucessos.

A meu avô Vincas Dzetulionis, figura marcante de minha infância, que sempre dizia: "ao final de um dia de trabalho deveríamos descansar a cabeça em uma pedra e os pés no travesseiro, afinal os pés só ficam cansados por que a cabeça não pensou o suficiente para que o trabalho fosse mais leve".

A meus pais, Izabel e Ari, por ensinarem-me o caminho do conhecimento, cada um à sua maneira, e me apoiarem neste caminho, também cada um à sua maneira.

Às minhas filhas, Natália e Giovana, razão de meus esforços. 


\section{AGRADECIMENTOS}

A Deus, por permitir que tudo seja realizado.

À minha esposa Rita, por compreender a necessidade da minha ausência para a conclusão deste trabalho, mas, mais que compreender a ausência, incentivar-me a cada vez buscar mais qualificação e conhecimento, "Vi" agradece.

Às minhas filhas Natália e Giovana, pelo seu apoio em todos os momentos. Labai ačiu mergaitès.

À Universidade de São Paulo, pela minha aceitação no programa de Pós-graduação.

Meus sinceros e prestimosos agradecimentos ao Prof. José Leomar Fernandes Junior, da Universidade de São Paulo, que me aceitou como seu orientado, e conduziu sua orientação com espírito educador, dinâmico e incentivador, e imbuído de uma paciência quase incomensurável.

Meus mais sinceros agradecimentos aos professores da Universidade de São Paulo pelos ensinamentos transmitidos em sala de aula.

Externo os meus agradecimentos às secretárias do Departamento de Engenharia de Transportes (STT), Heloísa, Beth e D. Magaly que sempre atenderam com muito profissionalismo, atenção e dedicação as solicitações que encaminhei e pela paciência em aguardar o desenrolar dos prazos.

Aos colegas Milton Gióia, Luis Eduardo Argenton e Décio Bin, por serem apoiadores deste trabalho.

Aos profissionais do Metrô SP, CPTM, e demais operadoras de transporte, que sempre me receberam com boa vontade para dirimir minhas dúvidas.

Aos colegas que ansiaram e torceram calorosamente pelo término desta etapa.

À família, que sempre está ao lado, olhando por nós.

Aos demais amigos que sempre me acompanham meus sinceros agradecimentos! 
Lietuvškai Patarlè

Kas skaito ir rašo duonos neprašo

Ditado Lituano

Quem lê e escreve pão não pede

Aqueles que passam por nós, não vão sós, não nos deixam sós. Deixam um pouco de si, levam um pouco de nós.

Antoine de Saint-Exupéry O último esforço da razão é reconhecer que existe uma infinidade de coisas que a ultrapassam.

Blaise Pascal. 



\section{RESUMO}

BARIA, Igor. Sistema De Gerência de Pavimentos Aplicado a Via Permanente Metroferroviária Auxiliado por um Sistema de Informações Geográficas. 2015. 269 p. Tese (Doutorado). Escola de Engenharia de São Carlos, Universidade de São Paulo, São Carlos, 2015 .

Esta pesquisa tem em sua linha principal a avaliação da infraestrutura da via permanente dos sistemas de transporte público urbano sobre trilhos. A avaliação é alcançada a partir da proposta de utilização de um sistema de gerência de pavimentos (SGP), aliado a um sistema de informações geográficas (SIG) e a um banco de dados relacional que suporte operações geográficas. 0 trabalho também sugere um conjunto de indicadores, para o gerenciamento da manutenção da via permanente. A pesquisa foi realizada a partir de uma pesquisa bibliográfica extensa sobre os assuntos relacionados para identificar soluções semelhantes que tenham sido implantadas. A pesquisa bibliográfica não identificou nenhum trabalho que tenha abordado este tema voltado ao transporte público urbano sobre trilhos, contudo foram identificadas linhas de pesquisa voltadas ao transporte de carga que compartilham do mesmo objetivo, utilizar um SIG para a gerência do ativo. Também foram identificados sistemas de suporte a decisão para ferrovias, sem o módulo de informações geográficas. A utilização de modelos de degradação, análise do ciclo de vida e análise de confiabilidade, disponibilidade, manutenabilidade e segurança são usadas, e estudadas, com relativa frequência na literatura especializada, usando a ferrovia como exemplo de aplicação. Os resultados alcançados por esses estudos foram incorporados nesta pesquisa. A partir de um método qualitativo o SIG e o banco de dados relacional foram escolhidos. Os indicadores de manutenção foram estudados e escolhidos a partir da literatura e experiência do autor. Utilizando (i) dados de operação e manutenção de um sistema de transporte metroferroviário, (ii) os resultados dos trabalhos identificados na pesquisa bibliográfica e (iii) o referencial teórico consultado, foram calculados os tempos médios entre falhas, a evolução de degradação de componentes da via permanente e o intervalo adequado de manutenção, utilizando recursos do banco de dados. Estes cálculos serviram de entrada para elaboração de mapas temáticos. Os mapas temáticos contêm informações sobre o nível de degradação da via e quais as manutenções a serem realizadas. 0 sistema também fornece os custos envolvidos em cada uma das operações de manutenção. Estas informações são primordiais para que o gestor do ativo possa escolher a opção que apresente o melhor custo-benefício, com base em informações apuradas, melhorando a qualidade de sua decisão.

Palavras-chave: Via permanente. Sistema de gerência de pavimentos. Sistema de Informações geográficas. Indicadores de desempenho. SGP. SIG. Metroferroviário. 


\section{ABSTRACT}

BARIA, Igor. Pavement Management System Supported by Geographic Information System to Mass Transit Railtrack. 2015. 269 p. Thesis (PhD). Escola de Engenharia de São Carlos, Universidade de São Paulo, São Carlos, 2015.

This research has the goal assess the permanent way infrastructure of urban public transport systems on rails. This assessment is result of a proposal to use a pavement management system (PMS), coupled with a geographic information system (GIS) and a relational database that supports geographical operations. The research also suggests a set of indicators for the management of the maintenance of the permanent way. The survey ran from an extensive literature to identify similar solutions deployed. The literature review did not identify any work that has addressed this issue back to urban public transport on rails. Were identified lines of research aimed at cargo transport that shares the same goal, using a GIS for asset management. In addition, decision support systems have been identified for railways, without geographical information module. It is easy to find use of degradation patterns, life cycle analysis and reliability analysis, availability, maintainability and safety in the literature, using the railway as example. The results achieved by these studies were included in this study. From a qualitative method, GIS and relational database were chosen. Maintenance indicators were chosen using the literature and the author's experience as basis. Data operation and maintenance of a metro system, the results of the work identified in the literature and a technical and theoretical framework from literature served as line to calculate the mean time between failures, the rate of degradation of permanent way components and the appropriate maintenance period. These calculations served as input in database for the preparation of thematic maps in the GIS. Thematic maps contain information about the track degradation level and the maintenance needed to be performed. The system also provides the costs of each maintenance step. The information generated by the system can help the manager to choose the option with best tradeoff, improving the decision quality.

Keywords: Permanent way. Pavement management system. Geographical Information System. Maintenance Performance indicators. SGP. SIG. Subway. 


\section{SUMÁRIO}

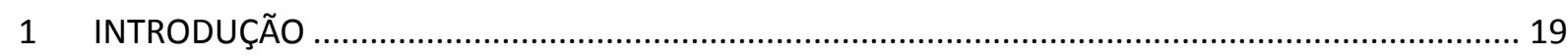

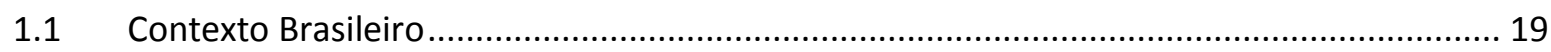

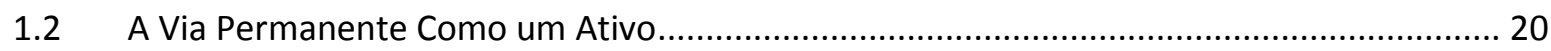

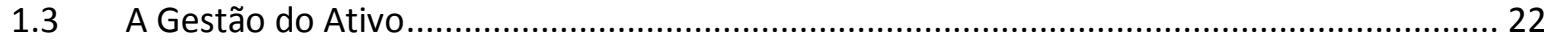

1.4 Definição do Problema ............................................................................................... 24

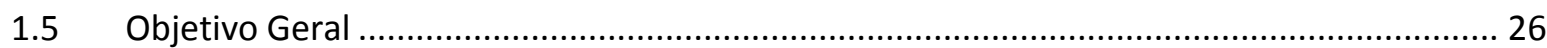

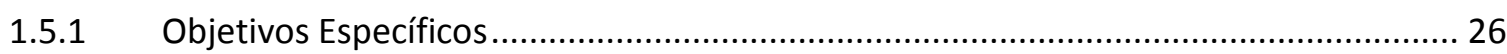

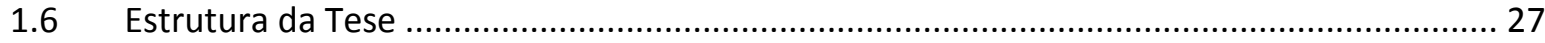

$1.7 \quad$ Escopo e Delimitações do Estudo ................................................................................ 28

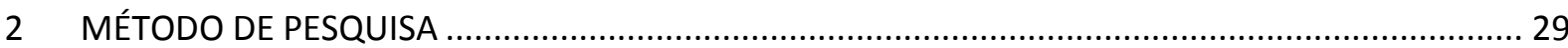

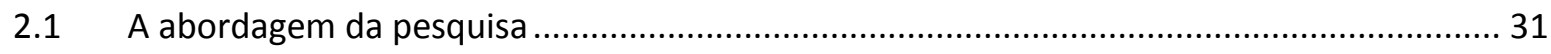

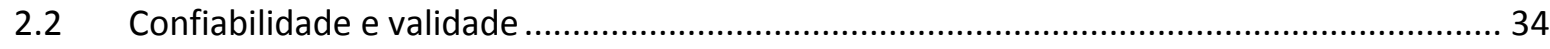

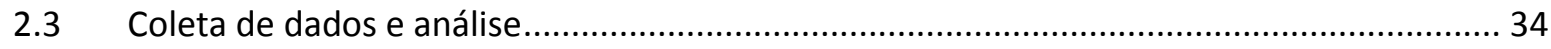

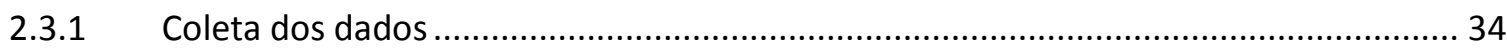

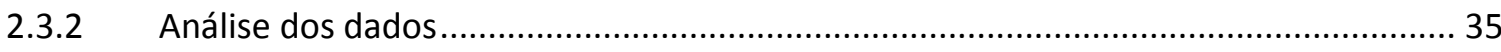

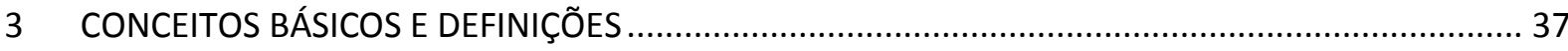

3.1 Sistemas de Gerência de Pavimentos ………................................................................... 37

3.1.1 Características do Sistema de Gerência de Pavimentos ............................................... 37

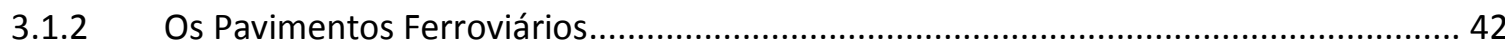

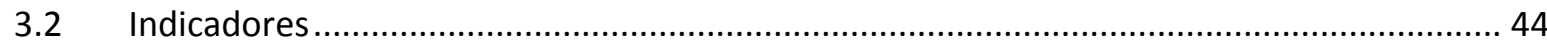

3.3 Confiabilidade, Disponibilidade, Manutenibilidade e Segurança. ........................................ 49

3.3.1 Parâmetros de análise de confiabilidade, disponibilidade, manutenibilidade e

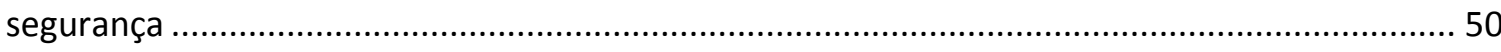

3.3.2 Fatores que Afetam análise de confiabilidade, disponibilidade, manutenibilidade e

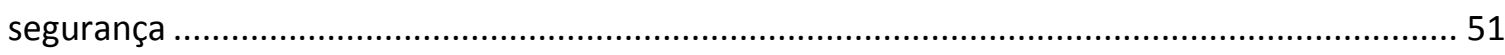

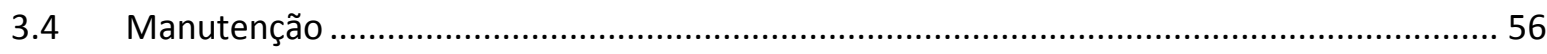

3.4.1 Planejamento da Manutenção da Infraestrutura ....................................................... 58

3.4.2 Análise de confiabilidade, disponibilidade, manutenibilidade e segurança para a Manutenção 
3.4.3 Confiabilidade, Disponibilidade, Manutenibilidade e Segurança na Fase de Operação e

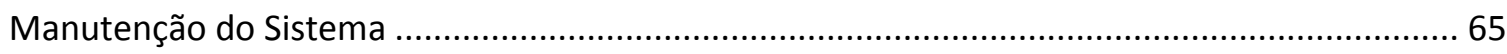

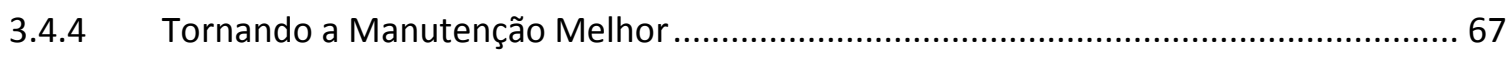

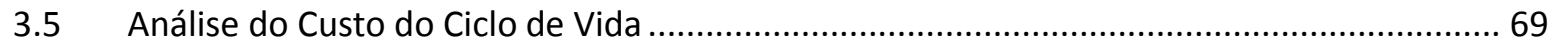

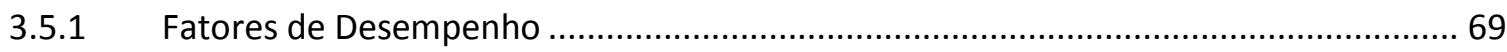

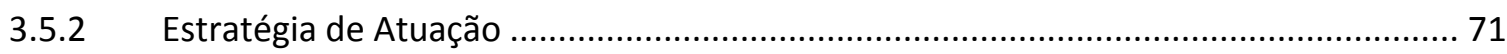

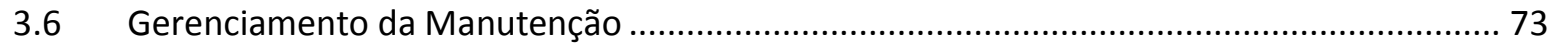

3.6.1 Gestão de Manutenção na Via Permanente .................................................................. 73

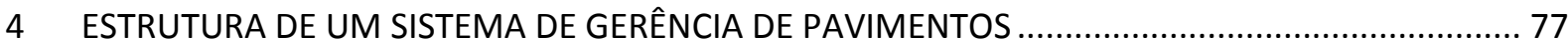

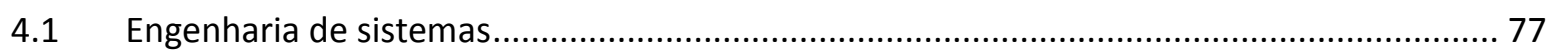

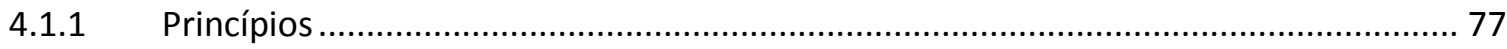

4.1.2 Engenharia de sistemas: orientação ao processo ……................................................... 78

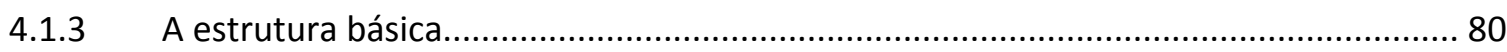

4.2 Estrutura geral de um sistema de gerência de pavimentos.................................................. 84

4.2.1. Aplicando engenharia de sistemas ao comportamento do pavimento ................................ 86

4.2.2 Engenharia de sistemas aplicada ao projeto de pavimento …...................................... 87

4.2.3 Comportamento e desempenho do pavimento …......................................................... 88

4.2.4 O Sistema de Gerência de Pavimentos não toma decisões ........................................... 88

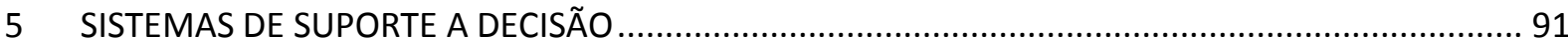

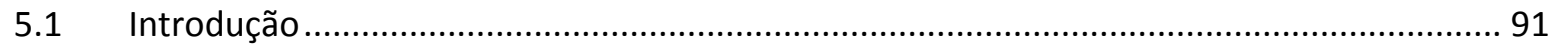

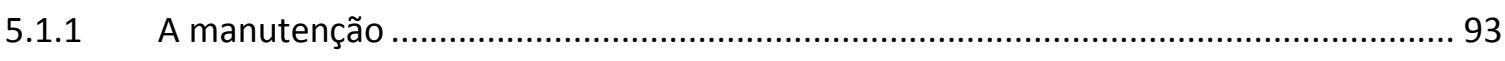

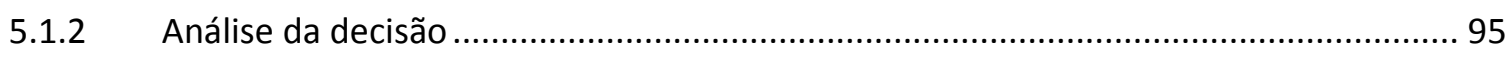

5.2 Quadro para análise do desempenho em longo prazo ......................................................... 96

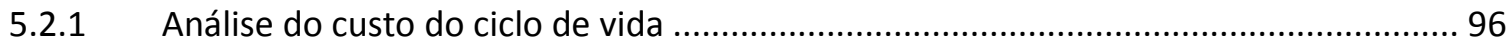

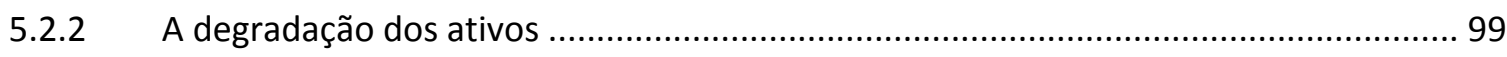

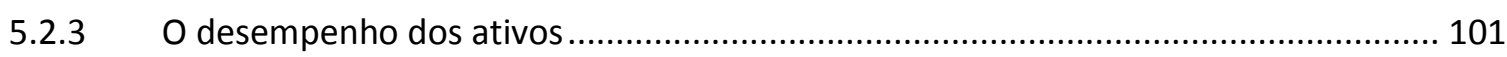

5.3 Os Sistemas de Suporte à Decisão na Prática ...................................................................... 103

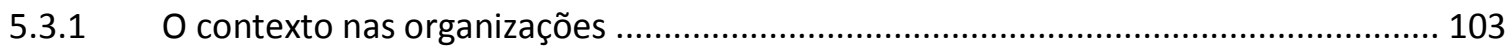

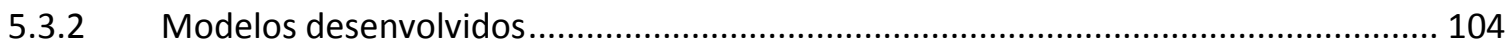

5.4 Implantação de Um Sistema de Suporte à Decisão ……….............................................. 107

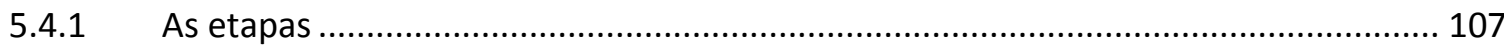

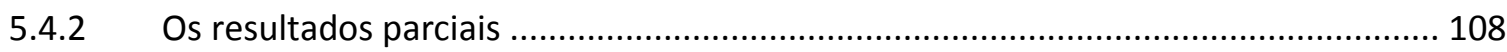

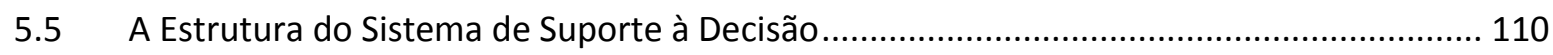




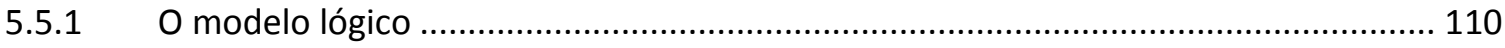

5.5.2 A composição das atividades de manutenção no sistema de suporte à decisão ....... 114

5.6 Desenvolvimento das Regras de Decisão........................................................................ 117

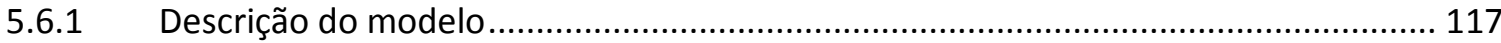

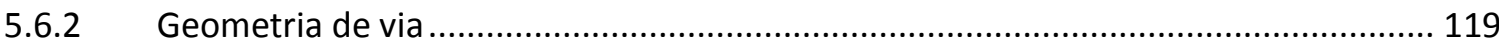

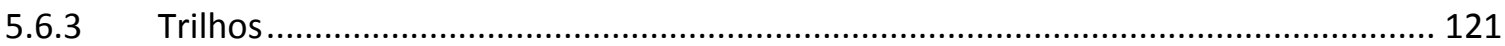

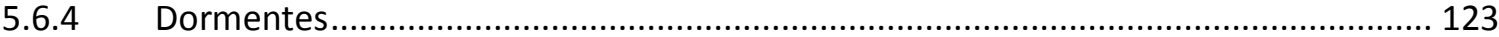

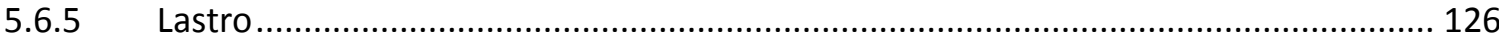

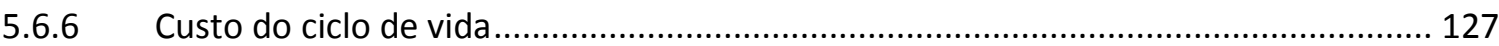

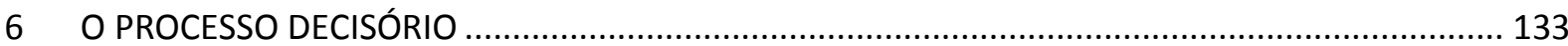

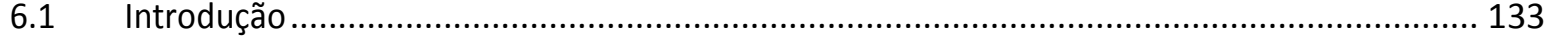

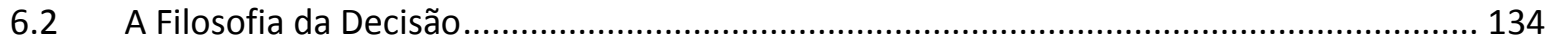

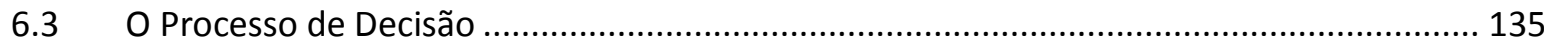

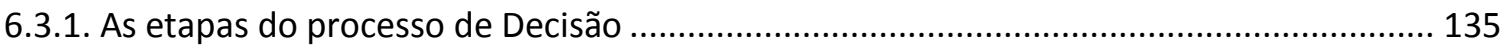

6.3.2 A incerteza e a engenharia de sistemas ................................................................... 137

6.3.3 Breve descrição de sistemas ................................................................................. 138

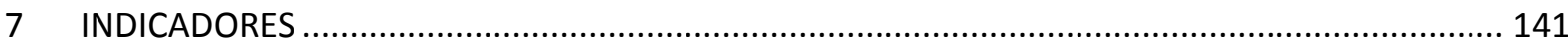

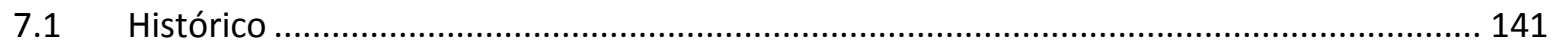

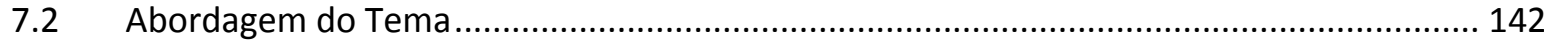

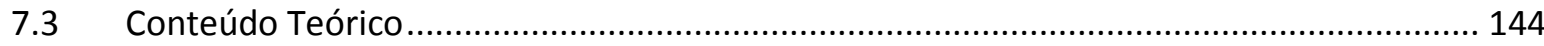

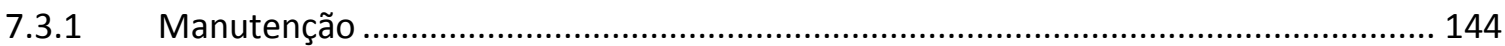

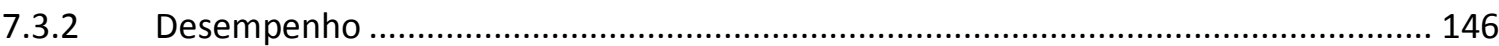

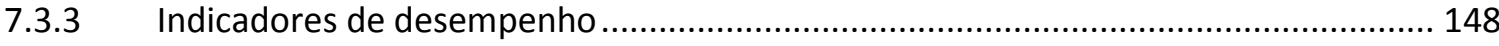

7.3.4 Indicadores de desempenho da manutenção.......................................................... 151

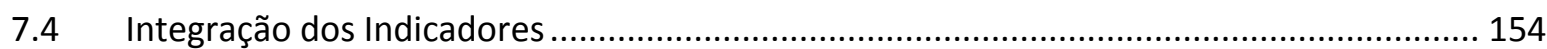

7.4.1 Implantação de um sistema de indicadores................................................................ 155

7.4.2 Desempenho global de equipamentos ……............................................................. 158

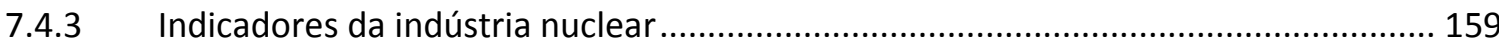

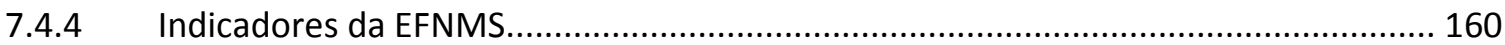

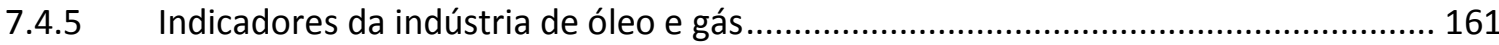

7.4.6 Indicadores da indústria de manufatura e processos ............................................... 162

7.4.7 Indicadores da indústria de utilidades .................................................................... 163

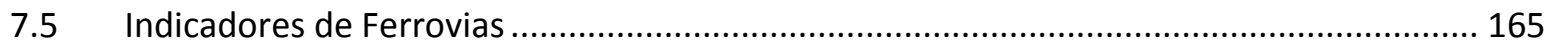


7.5.1 Indicadores na Bankvert (Suécia) …………............................................................ 165

7.5.2 Indicadores na Rede Ferroviária Italiana (RFI) …....................................................... 165

7.5.3 Indicadores na Queensland Rail (Austrália) ............................................................... 166

7.6 Indicadores Sugeridos para Gestão de Via Permanente.................................................... 167

8 SISTEMA DE INFORMAÇÕES GEOGRÁFICAS E GERENCIADOR DE BANCO DE DADOS ................. 169

8.1 Breve Descrição do Conceito de Livre e Código Aberto...................................................... 169

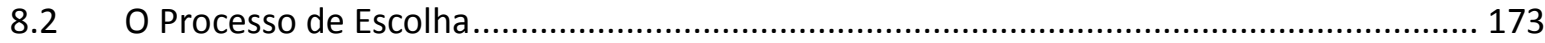

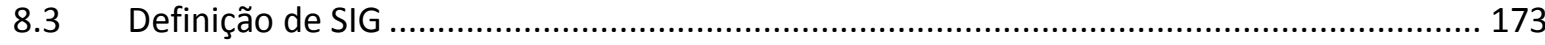

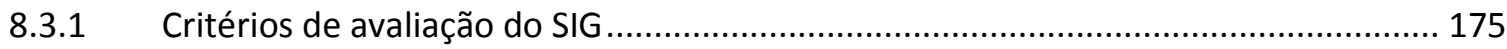

8.4 Escolha do Sistema Gerenciador de Banco de Dados ......................................................... 178

8.4.1 Definição de banco de dados .................................................................................. 179

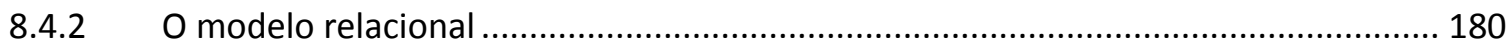

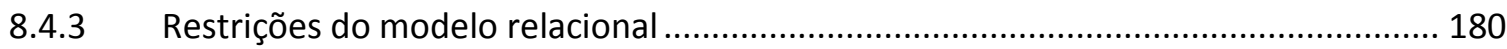

8.4.4 Fatores determinantes na escolha de um banco de dados ...................................... 181

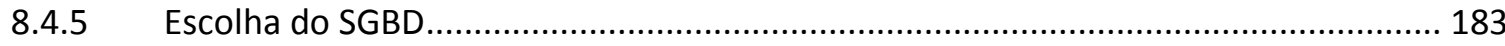

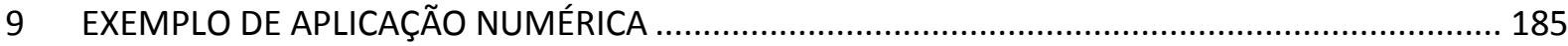

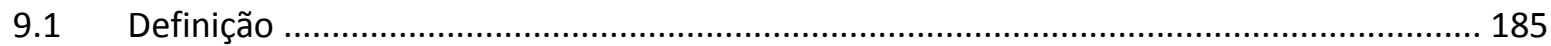

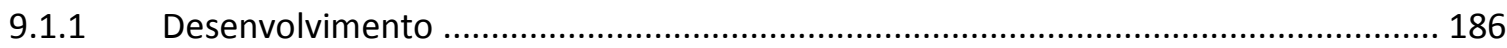

9.2 O Estudo de Caso Objeto do Trabalho …..................................................................... 187

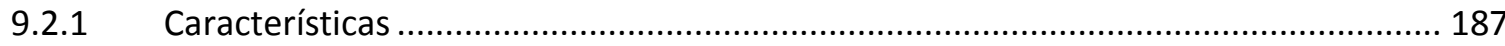

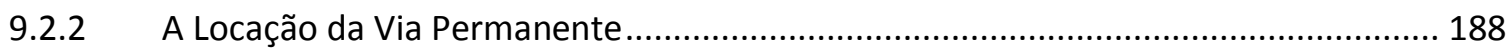

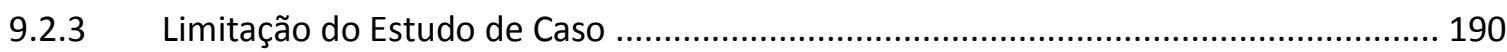

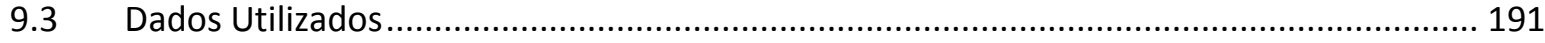

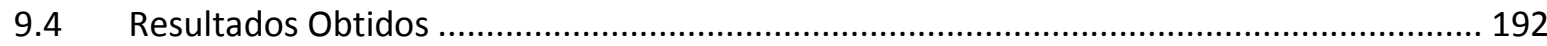

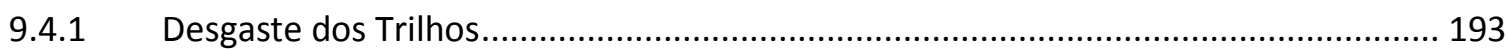

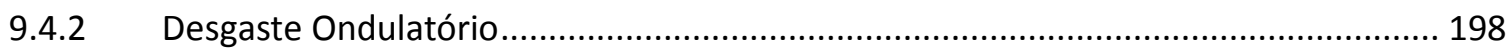

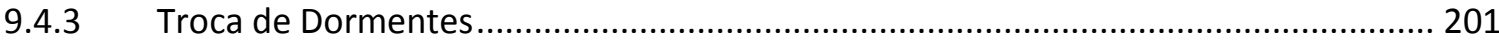

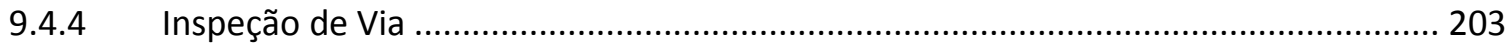

9.4.5 Correção Geométrica da Via - Socaria de Via ............................................................ 206

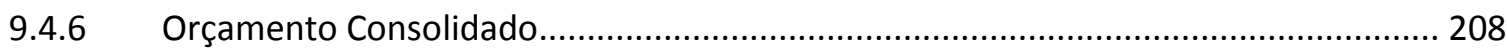

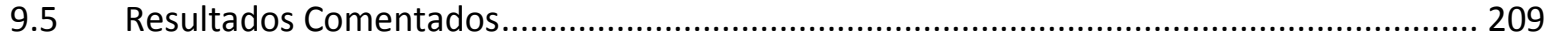

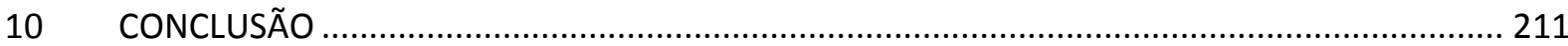

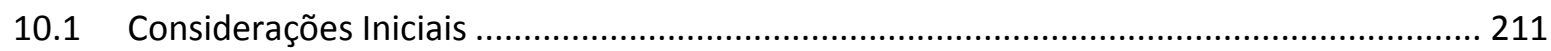




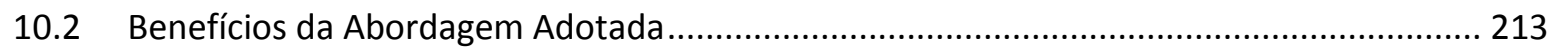

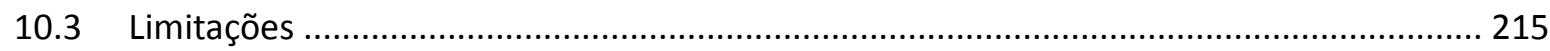

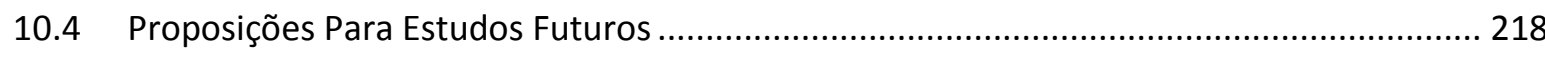

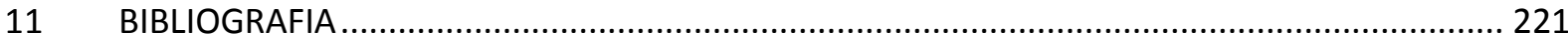

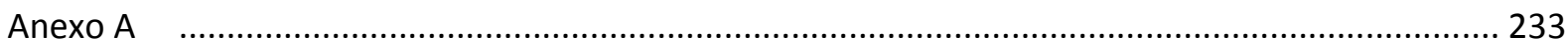





\section{INTRODUÇÃO}

O sistema de transporte metroferroviário é um dos modos de transporte público mais usado no mundo, com a vantagem de ter um impacto positivo na sociedade como um todo. Com o avanço da tecnologia, mudança contínua do ambiente de negócios e crescentes demandas dos usuários, este modo de transporte tem que atualizar suas atividades operacionais constantemente.

A implantação de uma linha ferroviária, ou metroviária, com o objetivo de servir como meio de transporte para a população de grandes cidades, é um investimento na ordem de bilhões de reais. Grande parte deste investimento está na infraestrutura necessária a este empreendimento, que envolve a instalação das estações e da via permanente, que respondem, em geral, por 2/3 do custo total da obra, o 1/3 restante é relativo a sistemas e material rodante.

\subsection{Contexto Brasileiro}

No Brasil existem, atualmente, cerca de $140 \mathrm{~km}$ de linhas em sistemas de transporte público urbano sobre trilhos que atendem às populações metropolitanas em 
São Paulo, Brasília, Rio de Janeiro, Teresina, Recife, Belo Horizonte, Porto Alegre, João Pessoa e Salvador. Estes sistemas transportam diariamente aproximadamente 9 milhões de pessoas, com metade desta demanda sendo atendida somente em São Paulo.

Este ativo, o sistema de transportes, precisa ser conservado com boas técnicas e dentro de padrões de qualidade mínimos para que as condições de custo e usabilidade sejam atendidas e para que seja oferecido um transporte adequado à população destas cidades.

Considerando que os custos de implantação são altos, uma política de conservação desta infraestrutura é primordial. A vida útil destas instalações deve ser prolongada, com um custo de conservação o mais baixo possível, buscando o desejado equilíbrio, o ponto ideal de intervenção para que custo seja mínimo e a utilização a máxima possível.

\subsection{A Via Permanente Como um Ativo}

Uma rede segura e confiável, com capacidade e disponibilidade suficiente, é um requisito primordial para que o equilíbrio entre capacidade e disponibilidade seja alcançado. Para cumprir este requisito de forma eficaz, é preciso examinar as várias fases do ciclo de vida (criação, projeto, fabricação, instalação, operação e manutenção, e eliminação). Uma vez que a infraestrutura está instalada, é muito difícil modificar o projeto inicial. Por conseguinte, o desempenho da infraestrutura depende em grande medida das decisões de manutenção e de renovação tomadas durante o seu ciclo de vida.

A fase de concepção do sistema deve considerar não só o custo, mas também aspectos como confiabilidade, disponibilidade, manutenibilidade e segurança (RAMS, do inglês Reliability, Availability, Maintainability and Safety) e Custo do Ciclo de Vida (LCC, do inglês Life Cycle Costs), no que diz respeito aos avanços tecnológicos e mudanças necessárias. Após a instalação, durante a fase de operação e manutenção, análise do custo do ciclo de vida e análise de confiabilidade, disponibilidade, manutenibilidade e segurança são ferramentas adequadas para a tomada de decisões eficazes e eficientes.

Cada um dos componentes de infraestrutura, com as suas características de vida e degradação, influenciará na qualidade e confiabilidade do sistema. Com o objetivo de manter a qualidade da infraestrutura a um nível aceitável, dois aspectos da qualidade da 
infraestrutura precisam ser considerados: a medição da qualidade da infraestrutura numa base contínua bem como os meios para alcançar a qualidade necessária, quando a qualidade cai abaixo dos níveis estabelecidos. A qualidade é medida a partir de vários parâmetros como, por exemplo, a confiabilidade do serviço, o nível de utilização da via, a acessibilidade, a segurança do sistema e a rentabilidade.

Os elevados custos de operação e manutenção tendem a agir como uma barreira para a obtenção de um desempenho financeiro favorável nas operações, interferindo no equilíbrio entre mínimo custo de manutenção com máxima utilização do ativo.

Com o aumento das necessidades da infraestrutura em termos de carga por eixo, tonelagem anual bruta, velocidade, advindas da necessidade crescente de passageiros transportados, existe uma tendência do aparecimento de mais falhas, que requerem mais manutenção. Ao mesmo tempo, existe a exigência de mais disponibilidade da infraestrutura para atividades operacionais, diminuindo o tempo para executar as manutenções necessárias. Assim, o balanceamento desta equação, que demonstra um sistema complexo, requer a disponibilidade de mais recursos financeiros, materiais e de mão de obra, impactando diretamente no orçamento anual. Para aperfeiçoar as atividades de manutenção em termos de custo-benefício e análise de confiabilidade, disponibilidade, manutenibilidade e segurança, é necessária uma abordagem de análise sistemática.

Esta configuração de um sistema complexo exige a utilização de um método que permita uma abordagem organizada dos diversos aspectos ligados à manutenção do sistema. A estrutura da via permanente é uma estrutura complexa submetida a diferentes combinações de carga e a diversas condições ambientais. Além dessa complexidade temos a caracterização do material utilizado na construção e reparo, que não é homogêneo, variando o desempenho da via permanente e suas inter-relações. Assim, é necessário um quadro teórico, uma estrutura de requisitos aplicável ao problema geral de manutenção da via permanente.

A fim de minimizar os efeitos que as falhas representam para os sistemas metroferroviários, as decisões devem ser avaliadas de forma sistemática. 0 gestor tem um papel claramente definido e é desafiado a aumentar o desempenho do sistema com diminuição de recursos. Devido ao aumento nos custos de operação e manutenção, os gestores devem adequar seu orçamento, enquanto a confiabilidade e disponibilidade do sistema devem ser aumentadas, sem colocar em risco a segurança do tráfego. 


\subsection{A Gestão do Ativo}

Uma vez que, no cenário atual, a maioria das decisões de manutenção e renovação é baseada nas experiências do passado e nas estimativas de especialistas, surge à necessidade de uma abordagem sistemática.

O exame das técnicas disponíveis para analisar tais relações complexas mostra que os conceitos de engenharia de sistemas (que são aplicados na eletrônica, comunicações e indústria aeroespacial) são apropriados para análise da estrutura da via permanente.

O uso de engenharia de sistemas não leva, por si só, a uma solução nova e definitiva do problema de manutenção organizada da via permanente, mas fornece um meio de organizar os vários segmentos do problema em um quadro compreensível, utilizando uma estrutura de requisitos possível de ser seguida.

O gerenciamento destes ativos, os sistemas de transporte, é estudado em profundidade em uma subárea da engenharia que trata dos sistemas de gerenciamento de pavimentos. O sistema de gerenciamento de pavimentos (SGP), de uma forma não estruturada, é utilizado em rodovias e ferrovias desde há muito tempo, no entanto a sua formalização foi idealizada por Haas; Hudson; Zaniewski, (1994), utilizando a engenharia de sistemas como referência para estruturar um SGP.

Com as crescentes exigências para melhorar o desempenho, de forma rápida, os gestores concentram-se nos orçamentos de curto prazo, ou apenas em melhorias de desempenho sem levar em consideração os efeitos de longo prazo.

Apesar de uma quantidade substancial de pesquisa ter sido realizada nos últimos anos, os processos de degradação dos componentes ferroviários ainda não são suficientemente compreendidos. Isto reflete de maneira negativa na tentativa de traduzilos em relações quantitativas inequívocas quando pese entre decisões de investimento e de manutenção e os efeitos de longo prazo na qualidade do sistema (FERREIRA; MURRAY, 1997).

Os envolvidos no negócio de transporte têm preferência por um retorno de curto prazo nos investimentos e por melhorias de desempenho rápidas, preferência essas que podem entrar em conflito com a natureza das ferrovias e com a destinação ótima de 
gastos. 0 tempo de vida longo dos componentes e seus altos custos de instalação indicam que as decisões têm um alto grau de irreversibilidade. Além disso, as consequências da baixa qualidade inicial e de manutenção preventiva insuficiente, muitas vezes, só aparecem vários anos depois, entendendo como consequência níveis de custo altos e baixa confiabilidade do sistema.

Depois de atingir certos níveis de degradação, somados a atrasos na manutenção, configura-se uma situação de degradação progressiva levando à destruição do ativo e do capital investido. Embora o gestor deva ser capaz de incorporar esses efeitos na tomada de decisão, seja de forma implícita ou explícita, há muitos fatores que o impedem.

A visão de longo prazo, geralmente, é um ponto discordante entre a concepção e a manutenção, geralmente criando um conflito nas fronteiras organizacionais e institucionais, tais como os orçamentos atribuídos, procedimentos operacionais padrão, as relações estabelecidas com outros atores e regulamentações externas. A maioria desses limites têm uma longa história, e os tomadores de decisão geralmente consideram apenas mudanças incrementais.

Cabe aqui uma breve análise sobre a preferência em retornos de curto prazo e aumentos significativos de desempenho em intervalos curtos de tempo.

Quanto a retornos de curto prazo é opinião do autor que este tipo de retorno sempre é associado a um risco alto. Então, considerando que riscos altos não devem ser assumidos quando no processo temos pessoas envolvidas, parece que a adoção deste tipo de preferência é pouco, ou quase nada, indicada.

Aumentos significativos de desempenho demandam adoção de novas tecnologias que, geralmente, têm um alto custo de aquisição e implantação, necessidades de interdição das vias para a sua total implantação, necessidade de tempos de operação para teste dos sistemas e demais interferências na operação do sistema. Isto é totalmente contraditório com a exigência de mais tempo de operação para atender às crescentes demandas de passageiros nos sistemas.

Assim, as duas preferências são mutuamente excludentes quando comparadas com as exigências do sistema, governo e usuários. Parece que a adoção de modelos que busquem melhoria contínua, com um pequeno passo de cada vez, são mais adequados a 
atender as diversas exigências, e, ao mesmo tempo, entregar as preferências de maneira paulatina.

\subsection{Definição do Problema}

Este trabalho terá em sua linha principal a avaliação da infraestrutura dos sistemas de transporte público urbano sobre trilhos, especificamente a via permanente, com o intuito de propor um SGP, aliado a um sistema de informações geográficas (SIG). 0 trabalho também sugere um conjunto de indicadores, para o gerenciamento da manutenção da via permanente, que atenda os operadores de transporte público urbano sobre trilhos no Brasil.

Gestores de infraestrutura de via permanente enfrentam crescentes exigências dos operadores, do governo, bem como dos passageiros para assegurar um serviço de transporte seguro, confiável e confortável. Para alcançar estes objetivos, a qualidade da via permanente precisa ser melhorada e mantida.

As atividades de manutenção têm objetivos que estão, ou deveriam estar ligados às metas e objetivos corporativos. Os fatores críticos de sucesso incluem as orientações para as diretivas (objetivos) a serem alcançadas (confiabilidade, segurança e conforto); métodos para estabelecer e mensurar a relação entre a confiabilidade operacional, a condição da via permanente e os trabalhos de manutenção realizados; métodos para medir a rentabilidade das operações de manutenção. Portanto, há uma necessidade de desenvolver modelos eficazes de suporte à decisão com indicadores que podem ajudar a alcançar os objetivos globais.

Os modelos de suporte à decisão ajudam na determinação: dos tempos e tipos de manutenção, de quais ações de manutenção devem ser realizadas, de como estas ações serão realizadas e de qual ação garantirá a manutenção da segurança do sistema.

A análise dos parâmetros de confiabilidade, disponibilidade, manutenibilidade e segurança ajuda na identificação de diferentes alternativas de atuação. Esta análise também fornece uma garantia de desempenho com o qual o sistema pode garantir que os objetivos envolvendo a infraestrutura sejam alcançados. A análise do custo do ciclo de vida ajudará na melhoria da relação custo-benefício das ações de manutenção derivadas 
da análise dos parâmetros de confiabilidade, disponibilidade, manutenibilidade e segurança. Estimativas de custos através do ciclo de vida ajudam a prever os custos das ações de manutenção ao longo de toda a vida útil da via permanente, e não apenas no curto prazo.

Tendo o arcabouço até aqui apresentado como referência para o trabalho, é necessário responder as seguintes perguntas:

- Qual é o problema?

- Por que este problema é relevante?

- Qual é a relação com outros problemas?

O problema aqui abordado é a falta de um sistema integrado de gerenciamento da manutenção da via permanente que produza um planejamento baseado no histórico de manutenções realizadas, defeitos observados e falhas ocorridas. 0 uso de um sistema de informações geográficas facilitará a visualização da forma como os dados relacionam-se. O desejo de que o sistema possa atender, de forma única, a todos os operadores de transporte público sobre trilhos no quesito indicadores de manutenção, contribuiria para uma relação custo-benefício vantajosa para as organizações.

A relevância deste estudo está contida: (i) na aplicação do conceito de espacialidade na via permanente, com a utilização do SIG, e (ii) na proposta de estabelecimento de um conjunto único de indicadores para todos os operadores, permitindo a troca de experiências e avaliações com base nas melhores práticas adotadas e em sistemas de gerenciamento consagrados.

A relação deste estudo com outros problemas está baseada no fato de existirem iniciativas de utilização de um sistema de gerência de pavimentos e um sistema de informações geográficas no gerenciamento de pavimentos rodoviários, como documentado em (CHEETHAM; BECK, 1994), (ELHANDI, 2009), (FLINTSCH et al., 2004), (HAAS; HUDSON; ZANIEWSKI, 1994), (HUANG, 2004), (INTERNATIONAL GULF CONFERENCE ON ROADS; AL-QADI, 2009), (SHAHIN, 2005).

De fato, existem algumas iniciativas no gerenciamento de uma via permanente, contudo voltadas a transporte de carga, descritas em (ESVELD, 2001); (FERREIRA; MURRAY, 1997); (GULER; AKAD; ERGUN, 2004). 
Assim, o desenvolvimento de um estudo que contemple as características citadas neste texto parece preencher uma lacuna com possibilidades razoáveis de aplicabilidade e de discussão no meio acadêmico.

\subsection{Objetivo Geral}

O objetivo geral deste trabalho reside na proposta de desenvolvimento de um sistema de gerência de pavimentos (SGP), aliado a um sistema de informações geográficas (SIG), que possibilite o gerenciamento da manutenção de uma via permanente com base em indicadores de manutenção que sejam acordados entre os operadores de transporte público urbano sobre trilhos no Brasil.

\subsubsection{Objetivos Específicos}

- Especificar um sistema de informações geográficas (SIG) de uso livre e sem custo de aquisição, dentro da iniciativa chamada de software livre (FOSS, do inglês Free Open Source Software);

- Especificar um banco de dados adequado à manipulação das informações que são necessárias no gerenciamento da via permanente, que seja de uso livre e sem custo de aquisição;

- Estabelecer uma plataforma que permita, a qualquer tempo, a migração do SIG e dados para um sistema operacional de uso livre e sem custo de aquisição;

- Estabelecer um banco de dados com os indicadores de desempenho da via permanente em uma mesma base de maneira que permita aos operadores a comparação de seus resultados e a troca de experiências;

- Utilizar um método de classificação dos indicadores com o objetivo de obter um conjunto adequado de indicadores que atenda às necessidades dos operadores de transporte;

- Desenvolver as funções de desgaste e tempo de vida de componentes da via permanente em função de carga e frequência de trens. 


\subsection{Estrutura da Tese}

Esta tese é estruturada em capítulos, e segue uma estrutura que procura dar um sequenciamento lógico nos assuntos abordados e na conjugação dos assuntos para a formação da ideia central. Os capítulos, apesar de não receberem o nome usual, seguem a estruturação básica exigida pelas normas de edição de teses da EESC.

O capítulo inicial, a introdução, procura criar as bases do estudo, apresentando o contexto nacional sobre os sistemas de transporte público sobre trilhos, o problema que é a inspiração para o estudo, os objetivos a serem alcançados e as delimitações do trabalho.

O capítulo 2 trata da metodologia da pesquisa aplicada para consecução do estudo e a relevância dos dados necessários para o estudo. Uma vez que o objetivo deste estudo é gerar novos conhecimentos e compreensão sobre os modelos de manutenção e gestão da manutenção, o foco desta pesquisa pode ser descrito como exploratório.

Nos capítulos 3 a 7 apresenta-se uma revisão da literatura sobre os assuntos abordados nesta tese.

A gerência de pavimentos é apresentada e a sua conexão com a engenharia de sistemas. Os sistemas de suporte a decisão são descritos, bem como é apresentado um breve relato sobre a teoria da decisão. Os indicadores são apresentados e suas características são exploradas de maneira a estabelecer um fundamento adequado sobre o desenvolvimento e implantação dos indicadores e sistemas de indicadores.

O capítulo 8 faz um relato sobre os sistemas de informação geográfica e sobre bancos de dados geográficos. Neste capítulo são definidos o sistema de informação geográfica e o banco de dados geográfico a serem utilizados no estudo de caso.

O capítulo 9 é aplicação numérica dos conceitos apresentados nos capítulos 3 a 8 . Este capítulo terá como produto a apresentação de um mapa da via permanente com as ações de manutenção necessárias, dentro das limitações estabelecidas no estudo.

O capítulo 10 apresenta a discussão sobre os resultados alcançados, as dificuldades encontradas na elaboração do trabalho e as sugestões para trabalhos futuros. 


\subsection{Escopo e Delimitações do Estudo}

A infraestrutura metroferroviária é constituída por diversos subsistemas, como o sistema de via permanente, de sinalização e de telecomunicações, e o sistema de energia. Nesta pesquisa considerou-se apenas o sistema de via permanente. Embora a análise de confiabilidade, disponibilidade, manutenibilidade e segurança e análise do custo do ciclo de vida sejam aplicáveis em todas as fases do ciclo de vida do sistema, desde a concepção até o seu encerramento, esta tese utiliza-os somente na fase de manutenção e operação do sistema.

A tese apresenta diferentes modelos para a manutenção da via permanente. No entanto, os modelos não consideram o efeito interativo dos diferentes sistemas (vias, sinalização, tração, etc.) de uns sobre os outros e como isto influencia a política de manutenção. Os modelos de manutenção fornecem ao gestor o devido suporte na tomada de decisões sobre a inspeção e manutenção, de modo a atingir as metas para a infraestrutura de via permanente.

Esta tese se concentra na manutenção e atividades relacionadas com a manutenção de um ponto de vista do gestor da infraestrutura, com foco em indicadores de desempenho de manutenção com a visualização destes indicadores por meio de um sistema de informações geográficas. É importante que as conclusões e os resultados possam ser implantados sem que haja qualquer alteração nas organizações de maneira que não sejam requeridos novos procedimentos ou regras. 


\section{MÉTODO DE PESQUISA}

A pesquisa pode ser definida de muitas maneiras. Geralmente é definida como um processo através do qual as perguntas são feitas e respondidas de forma sistemática. Como uma forma de crítica, a pesquisa pode incluir a questão de saber se estamos ou não fazendo as perguntas certas (DANE, 1990). Em outras palavras, a pesquisa é uma análise sistemática da informação observada, realizada para encontrar respostas para os problemas.

A metodologia da pesquisa é o elo entre o pensamento e as provas (SUMSER, 2001). Para realizar uma pesquisa, é essencial escolher uma metodologia clara. Isto fornece um quadro para a integração dos diferentes aspectos do estudo. 0 estudo de metodologias de pesquisa permite ao pesquisador o conhecimento e as habilidades que são necessárias para resolver os problemas e enfrentar os desafios de um ambiente de tomada de decisão (COOPER; SCHINDLER, 2006).

Há muitas formas de realizar uma pesquisa, porém a finalidade da pesquisa pode ser classificada em três categorias principais: objetivo exploratório (para explorar um novo tópico), o propósito descritivo (para descrever um fenômeno) e o propósito explicativo (para explicar por que algo ocorre). Os detalhes estão descritos na Tabela 2.1. 
Tabela 2.1 - Diferentes tipos de Propósitos em Pesquisa (COOPER; SCHINDLER, 2006)

\begin{tabular}{|c|c|c|}
\hline Exploratória & Descritiva & Explanatória \\
\hline $\begin{array}{l}\text { Familiarizar-se com fatos } \\
\text { básicos, padrões e } \\
\text { interesses. } \\
\text { Criar uma imagem geral } \\
\text { das condições. } \\
\text { Formular e focar em } \\
\text { questões para futuras } \\
\text { pesquisas. } \\
\text { Gerar novas ideias, } \\
\text { conjecturas ou hipóteses. } \\
\text { Determinar a viabilidade de } \\
\text { realização da pesquisa } \\
\text { Desenvolver técnicas para } \\
\text { medição e localização de } \\
\text { dados de falha. }\end{array}$ & $\begin{array}{l}\text { Fornecer uma análise } \\
\text { detalhada, uma imagem de } \\
\text { alta precisão. } \\
\text { Localizar novos dados que } \\
\text { contradigam dados do } \\
\text { passado. } \\
\text { Criar um conjunto de } \\
\text { categorias ou classificar } \\
\text { tipos. } \\
\text { Esclarecer uma sequência } \\
\text { de etapas ou fases. } \\
\text { Documentar um processo } \\
\text { casual ou um mecanismo. } \\
\text { Relatório detalhado sobre } \\
\text { um contexto ou situação }\end{array}$ & $\begin{array}{l}\text { Testar teoria de } \\
\text { previsões ou princípio. } \\
\text { Elaborar e enriquecer } \\
\text { explicação de uma } \\
\text { teoria. } \\
\text { Estender uma teoria } \\
\text { para novos assuntos ou } \\
\text { temas. } \\
\text { Reforçar ou refutar uma } \\
\text { explicação ou predição. } \\
\text { Questões de princípios } \\
\text { gerais ou ligações. } \\
\text { Determinar qual de } \\
\text { várias explicações é a } \\
\text { melhor. }\end{array}$ \\
\hline
\end{tabular}

Dependendo da quantidade de conhecimento que precisa ser adquirido sobre um determinado problema ou área do problema, o foco da pesquisa varia. As metodologias utilizadas na presente pesquisa são descritivas e exploratórias.

Uma vez que o objetivo deste estudo é gerar novos conhecimentos e compreensão sobre os modelos e gestão da manutenção da via permanente, o foco desta pesquisa pode ser descrito como exploratório.

A investigação pode ser fundamental ou aplicada em sua natureza, dependendo do tipo de conhecimento procurado sobre uma determinada área e a solução pretendida. A investigação fundamental visa alargar o conhecimento de um assunto particular, de modo que as iniciativas de futuras pesquisas podem basear-se no conhecimento alargado. Esta pesquisa foi concebida para resolver problemas de natureza prática, com impacto direto sobre decisões estratégicas em manutenção de via permanente.

A estratégia de pesquisa varia de acordo com as perguntas da pesquisa. Neste estudo as perguntas concentram-se em "como" e "qual". Os acontecimentos de comportamento não foram abordados, e os eventos contemporâneos devem ser levados em consideração; assim, o estudo de caso foi adotado como estratégia principal de investigação para este estudo (YIN, 2002). Outras estratégias de pesquisa que poderiam 
ter sido usadas, como o experimento, levantamento, análise de arquivo, ou estudo da história, como mostra a Tabela 2.2.

Tabela2.2 - Estratégias de Pesquisa, adaptado de Yin (2002).

\begin{tabular}{llcc}
\hline \hline Estratégia & Questão Central & $\begin{array}{c}\text { Controle de } \\
\text { Comportamento } \\
\text { dos Eventos }\end{array}$ & $\begin{array}{c}\text { Foco dos Eventos } \\
\text { Contemporâneos }\end{array}$ \\
\hline Experimento & Como, porquê & $\mathrm{Sim}$ & $\mathrm{Sim}$ \\
Pesquisa & $\begin{array}{l}\text { Quem, o quê, porquê, } \\
\text { quantos, quanto custa }\end{array}$ & Não & $\mathrm{Sim}$ \\
Análise de Arquivo & $\begin{array}{l}\text { Quem, o quê, porquê, } \\
\text { quantos, quanto custa, }\end{array}$ & Não & $\mathrm{Sim}$ \\
Estudo da História & Como, porquê & Não & Não \\
Estudo de Caso & Como, porquê & Não & Sim \\
\hline \hline
\end{tabular}

O objetivo deste estudo é descrever modelos de manutenção, modelos de predição, sistemas de informações geográficas e bancos de dados com o objetivo de criar um sistema capaz de responder as questões fundamentais de manutenção de vias.

\subsection{A abordagem da pesquisa}

A pesquisa pode ser dividida em três formas de condução, dependendo da quantidade de conhecimento que existe sobre um determinado problema na área de estudo (RICHARDSON; PERES, 1999; AHREN, 2005).

A pesquisa pode também ser dividida em estudos quantitativos e qualitativos (AHREN, 2005;RICHARDSON; PERES, 1999). Estudos quantitativos visam estudar e analisar o problema com métodos estatísticos, ou seja, utilizando números. A pesquisa qualitativa tem como objetivo estudar e analisar problemas com métodos de análise verbal. 0 quadro abaixo (Tabela 2.3) resume as principais características de cada uma das pesquisas. 
Tabela 2.3 - Principais Características das Pesquisas.

\begin{tabular}{l|l}
\hline \multicolumn{1}{c|}{ Quantitativa } & \multicolumn{1}{c}{ Qualitativa } \\
\hline Medição de fatos objetivos & Constrói realidade social, meios culturais. \\
Foco em variáveis & Foco em processos interativos e eventos \\
Confiabilidade & Autenticidade \\
Independe de valores & Valores são presentes e explícitos \\
Independente do contexto & Circunscrito em uma situação \\
Muitos casos & Poucos casos \\
Análise estatística & Análise situacional \\
O pesquisador não se envolve & Pesquisador é envolvido \\
\hline \hline
\end{tabular}

Todas as atividades de investigação começam com um problema que precisa ser explicado e entendido. Se a pesquisa tem como objetivo resolver problemas práticos relacionados então a pesquisa é chamada de aplicada. Por outro lado, se o objetivo é obter e ampliar o conhecimento para uso futuro então é chamada de pesquisa de investigação fundamental (RICHARDSON; PERES, 1999).

A fim de descrever a abordagem da pesquisa é importante recapitular o propósito da pesquisa, objetivos e limitações.

O objetivo geral deste trabalho é o desenvolvimento de um sistema de gerência de pavimentos (SGP), aliado a um sistema de informações geográficas (SIG), que possibilite o gerenciamento da manutenção da via permanente usando indicadores de manutenção que sejam aplicáveis entre os operadores de transporte público urbano sobre trilhos no Brasil.

A abordagem da pesquisa pode ser indutiva ou dedutiva (RUBIN; BABBIE, 2013):

- Na abordagem indutiva, o pesquisador começa com observações, procura padrões nessas observações, e cria conclusões preliminares;

- Na abordagem dedutiva, o pesquisador começa com hipóteses, que podem vir a partir de uma teoria ou de tentativas de conclusão, e depois testá-los.

Na presente pesquisa tanto a abordagem dedutiva como indutiva foram aplicadas. Uma abordagem indutiva foi utilizada para desenvolver um processo de aplicação de 
gestão de ativos na manutenção da infraestrutura ferroviária, ao passo que foi aplicada uma abordagem dedutiva para desenvolver os modelos de degradação. Ambas as metodologias de pesquisa, qualitativa e quantitativa, foram aplicados nesta pesquisa.

A abordagem desta pesquisa pode ser classificada como indução ou dedução (DANE, 1990). A dedução pode ser aplicada para gerar hipóteses baseadas em teorias existentes, cujos resultados são obtidos por conclusões lógicas. A indução utiliza observações, uma base de conhecimento e dados empíricos para explicar e desenvolver teorias. A abordagem envolve inferir algo sobre um grupo ou classe de objetos a partir de nosso conhecimento sobre um ou alguns membros do grupo ou classe.

Com base nos fins de pesquisa, objetivos e limitações deste estudo a abordagem escolhida pode ser descrita da seguinte forma:

- Pesquisa descritiva: compreender a natureza dos indicadores, identificar os modelos de degradação e descrever como eles podem ser aplicados na gestão da manutenção e na tomada de decisão;

- Pesquisa aplicada: os resultados podem ser utilizados pelo gestor da infraestrutura de transporte público urbano sobre trilhos em um sistema de suporte a decisão com visualização a partir de um sistema de informações geográficas.

Esta tese é uma pesquisa aplicada com a finalidade de aplicar modelos de predição (degradação) e técnicas de gerenciamento de manutenção no contexto da infraestrutura ferroviária para desenvolver modelos de decisão de manutenção. 0 problema de pesquisa tem uma aplicação direta na indústria ferroviária e é resolvido usando abordagens indutiva e dedutiva. 0 conhecimento adquirido a partir da literatura existente e de experiência acumulada ao longo de anos de trabalho em manutenção de sistemas de vias é aplicado para delinear um modelo de manutenção de infraestrutura ferroviária, de modo a tornar o planejamento eficaz e com risco minimizado. 


\subsection{Confiabilidade e validade}

De acordo com Lewis (1996), a confiabilidade significa confiança ou coerência. Isto sugere que as mesmas coisas são repetidas ou ocorrem em condições idênticas ou muito similares. Confiabilidade significa que os métodos de aplicação de um estudo, tais como procedimentos de coleta de dados, podem ser aplicados por pessoas distintas com o mesmo resultado. A validade é concernente se o estudo realmente obtém a informação pretendida. Refere-se à quão bem uma ideia sobre a realidade se encaixa com a realidade atual (ANDREWS, 2009).

\subsection{Coleta de dados e análise}

\subsubsection{Coleta dos dados}

Dados podem ser definidos como os fatos apresentados para os pesquisadores sobre o ambiente estudado. Os dados podem ser divididos em primários e secundários. Os dados coletados pelo pesquisador, com a finalidade de estudo através de várias experiências, ou gravação de dados no local são chamados de dados primários. Os dados primários são procurados por sua proximidade com a verdade e controle sobre erro. Os dados coletados por outras pessoas ou organizações e utilizados pelos pesquisadores são chamados dados secundários. Eles têm pelo menos um nível de interpretação inserido entre o evento e sua gravação (COOPER; SCHINDLER, 2006).

Dados de falha, degradação e manutenção dos sistemas foram coletados a partir de bases de dados do Metrô SP. Desta maneira o resultado obtido é real e é possível de ser utilizado sem necessidade de adaptações, ficando em consonância com os objetivos deste trabalho.

Pesquisadores geram informações através da análise de dados coletados. A análise dos dados é um passo importante no processo de pesquisa e geralmente envolve a redução dos dados acumulados a um tamanho administrável, o desenvolvimento de resumos, busca de padrões, e aplicação de técnicas estatísticas. Além disso, o pesquisador 
deve interpretar estes resultados à luz das questões da pesquisa ou determinar se os resultados são consistentes com as hipóteses e teorias (COOPER; SCHINDLER, 2006).

\subsubsection{Análise dos dados}

A ferrovia é um sistema reparável; assim, as técnicas de análise de confiabilidade para sistemas reparáveis devem ser aplicadas para a análise de dados de falha. A primeira etapa da análise é verificar se os dados estão de forma independente e identicamente distribuídos.

A análise de dados de confiabilidade e disponibilidade é feita com base no pressuposto de que os tempos entre falhas (MTBF, do inglês Medium Time Between Failures) e tempos até o reparo (TTRs, do inglês Time To Repair) são independentes e identicamente distribuídos no domínio do tempo. Além disso, também se supõe que eles sejam independentes um do outro e formam duas séries independentes. Isto significa que os intervalos entre falhas (TBFs) e o tempo até o reparo (TTR) são livres de tendências e de correlações em série. Em tal situação, o registro dos dados de intervalo entre falhas (TBFs) e tempo até o reparto (TTRs) são válidos para a montagem das várias distribuições para representar a população das TBFs e TTRs.

A discussão acima sugere que, antes que qualquer análise de confiabilidade seja iniciada, o teste para as tendências e correlações da série deve ser feito para verificar se a habitual suposição habitual, de que os conjuntos de dados são independentes e identicamente distribuídos, é respeitada, ou não (DHILLON, 1999.; RAUSAND, 2004; STAPELBERG, 2009).

Um sistema ferroviário é um sistema que permite reparo e pode ser restaurado por um método diferente da simples substituição. Depois do reparo, o sistema pode ser classificado em um dos seguintes estados possíveis (ASCHER, 1984):

- Tão bom como novo (AGAN);

- Tão ruim quanto desgastado (ABAO);

- Melhor do que o antigo, mas pior que o novo;

- Melhor do que o novo;

- Pior do que o desgastado. 
Observe-se que esta classificação é relativa e serve apenas como um referencial. A avaliação depende diretamente dos parâmetros de manutenção adotados.

Tomemos como exemplo o processo de socaria de via. Este processo tem como objetivo restabelecer as condições originais de geometria da via com base em valores de projeto, a partir de alarmes que são disparados durante o processo de inspeção da geometria de via. Estes alarmes são particulares para cada ferrovia. Podemos ter situações em que em uma ferrovia uma diferença de $10 \mathrm{~mm}$ no alinhamento da via é um alarme, que exige atuação da manutenção, enquanto que em outra ferrovia este alarme só é disparado quando o alinhamento ultrapassa 50mm.

Assim, dado o desgaste do lastro, a acomodação natural do terreno e a necessidade de ajustes intermediários que não provoquem variações bruscas na geometria, o processo não é totalmente eficaz. 0 estado do sistema após a manutenção será melhor do que velho, mas pior do que novo. Da mesma forma o esmerilhamento de trilhos pode tornar o contato roda-trilho tão bom quanto novo (e em alguns casos até melhor que o novo), mas dependendo da técnica e dos cuidados aplicados no esmerilhamento podemos recair na situação de melhor que o antigo, mas pior que o novo.

Nesta tese, os dados de inspeção e de manutenção foram utilizados para estimar as distribuições de probabilidade dos tempos de degradação. Como o ponto de ocorrência da degradação entre duas inspeções ou entre a falha funcional e a última inspeção é incerto, a distribuição de probabilidade de degradação pode ser estimada considerandose os dados do intervalo até a degradação. 


\section{CONCEITOS BÁSICOS E DEFINIÇÕES}

A literatura existente sobre SGPs, SIGs, indicadores, métodos de classificação e sistemas de suporte a decisão é extensa. Este capítulo apresentará as principais referências e a conexão do referencial com a tese em desenvolvimento.

\subsection{Sistemas de Gerência de Pavimentos}

Grande parte do material sobre gerência de pavimentos refere-se a pavimentos rodoviários, desta maneira a apresentação dos textos será seguida de uma ligação entre o pavimento rodoviário e o pavimento ferroviário.

\subsubsection{Características do Sistema de Gerência de Pavimentos}

A principal diferença entre o pavimento rodoviário e o pavimento ferroviário está na configuração de cada um deles. Enquanto o pavimento rodoviário é basicamente uma infraestrutura, um conjunto de camadas de solo, pedra britada, concreto e uma camada de acabamento, como mostra a Figura 3.1, o pavimento ferroviário é composto de uma infraestrutura e de uma superestrutura.

Em pavimentos rodoviários as cargas de roda são aplicadas em pequenas áreas e a magnitude de cada uma das cargas em cada área é uma constante independente da rigidez do sistema de camadas. Em pavimentos ferroviários, as cargas dos rodeiros são 
distribuídas através dos trilhos e dormentes a uma área extensa e a carga no dormente mais crítico e na roda com a maior carga depende fortemente da rigidez do sistema em camadas (HUANG, 2004).

O pavimento ferroviário tem em sua infraestrutura o suporte para a carga do material rodante. Esta infraestrutura pode ser uma via em lastro ou uma via em lajes de concreto, como é muito comum em linhas de metrô. A superestrutura é composta dos elementos que recebem o trilho (trilhos ou placas), dos elementos de fixação dos trilhos e do trilho propriamente dito. Estas configurações de montagem de uma via permanente podem ser vistas nas Figuras 3.2a, 3.2b, 3.2c, 3.3 e 3.4.

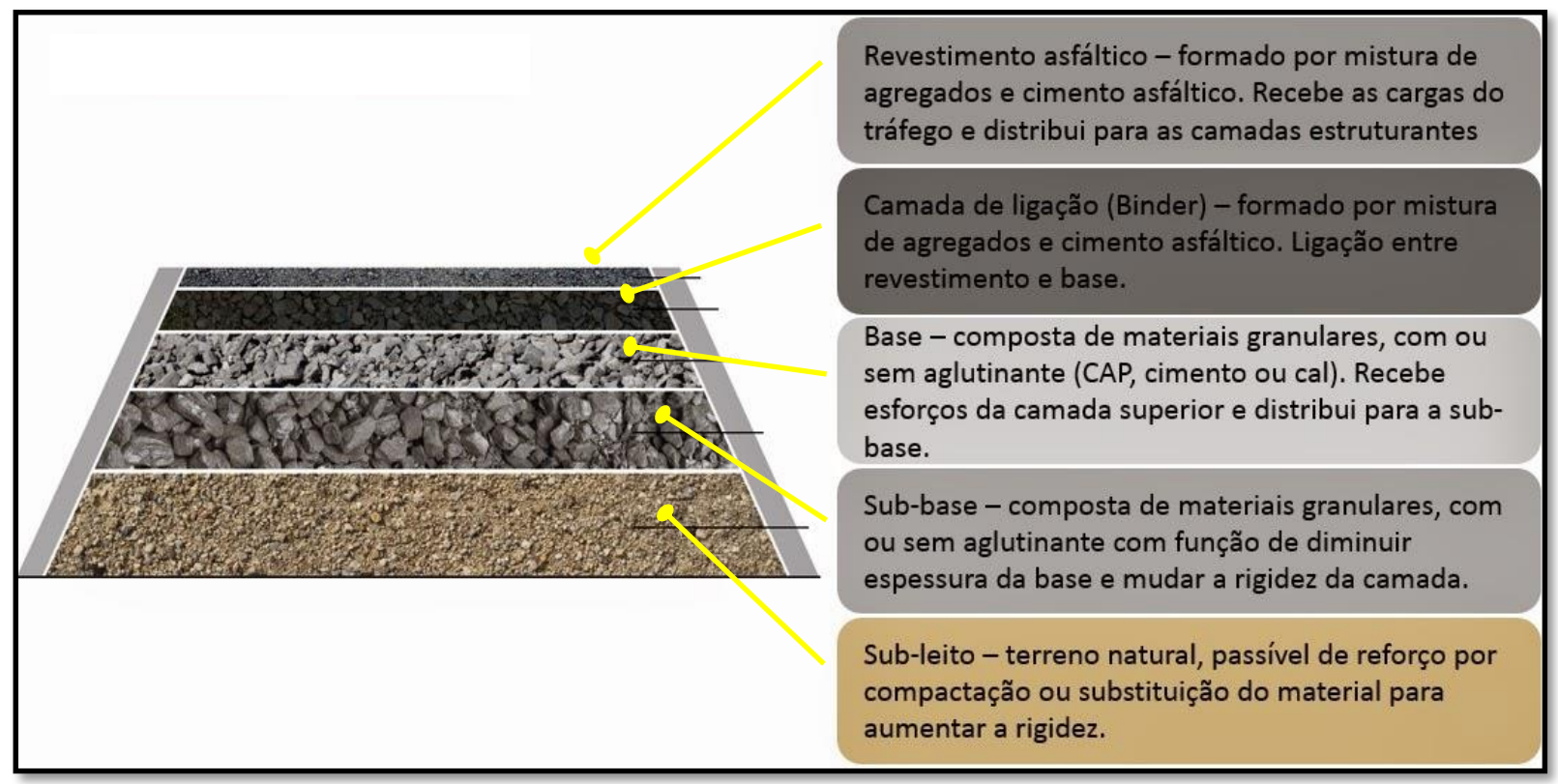

Figura 3.1 - Composição dos pavimentos flexíveis (Fonte: www.asfaltodequalidade.com.br)

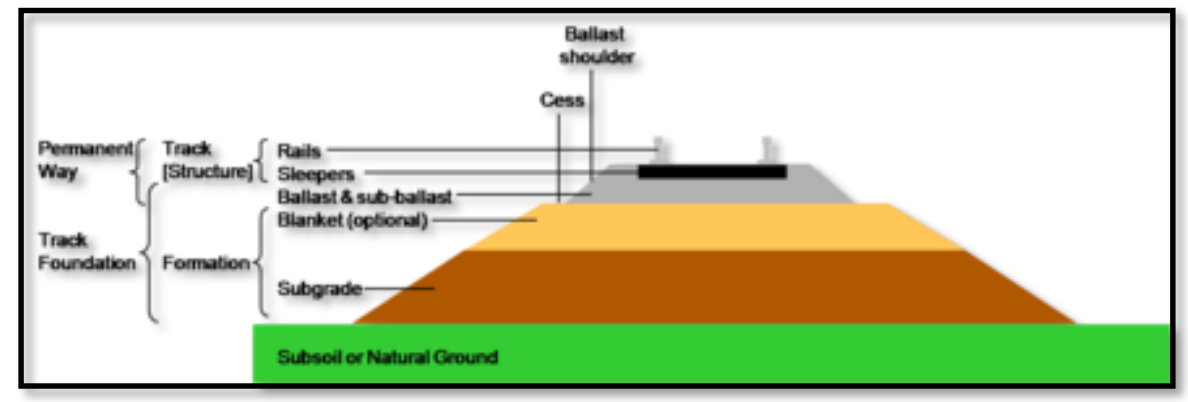

Figura 3.2.a - Via permanente montada em lastro de pedra britada - Estrutura Básica (Fonte: www.icivilengineer.com). 


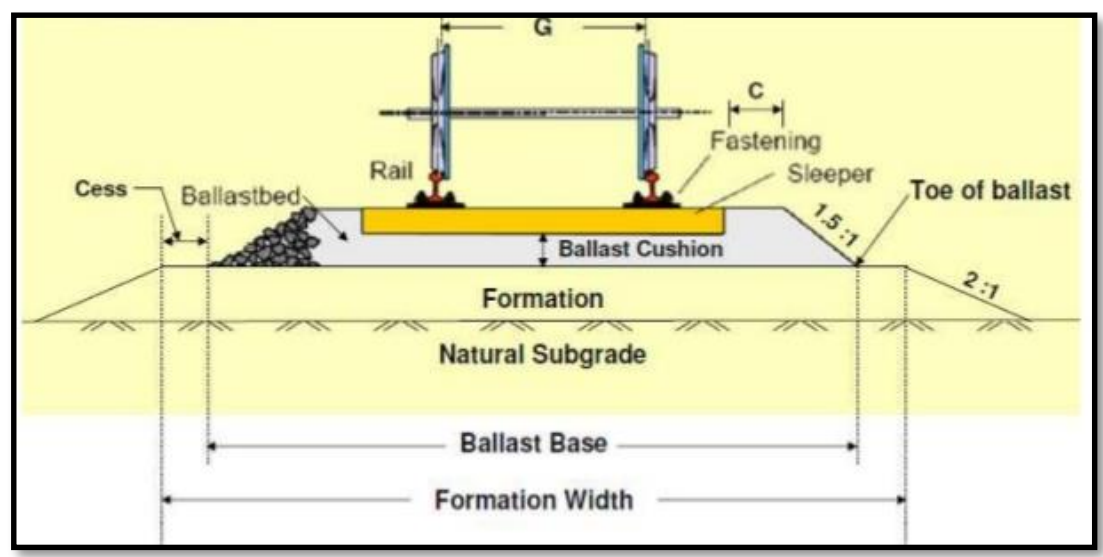

Figura 3.3.b - Via permanente montada em lastro de pedra britada - Consideração da Estrutura (Fonte: www.railway-technical.com/track.shtml).

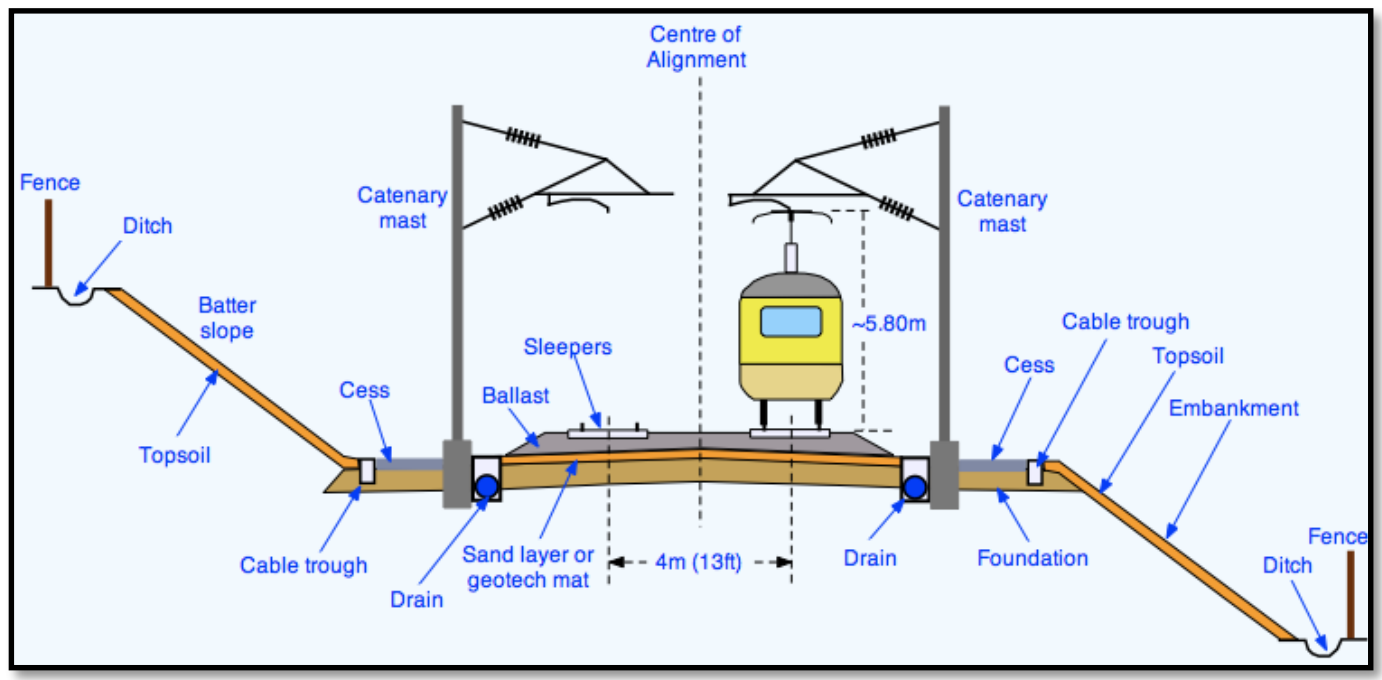

Figura 3.4.c - Via permanente montada em lastro de pedra britada - Perfil Típico (Fonte: www.railway-technical.com/track.shtml).

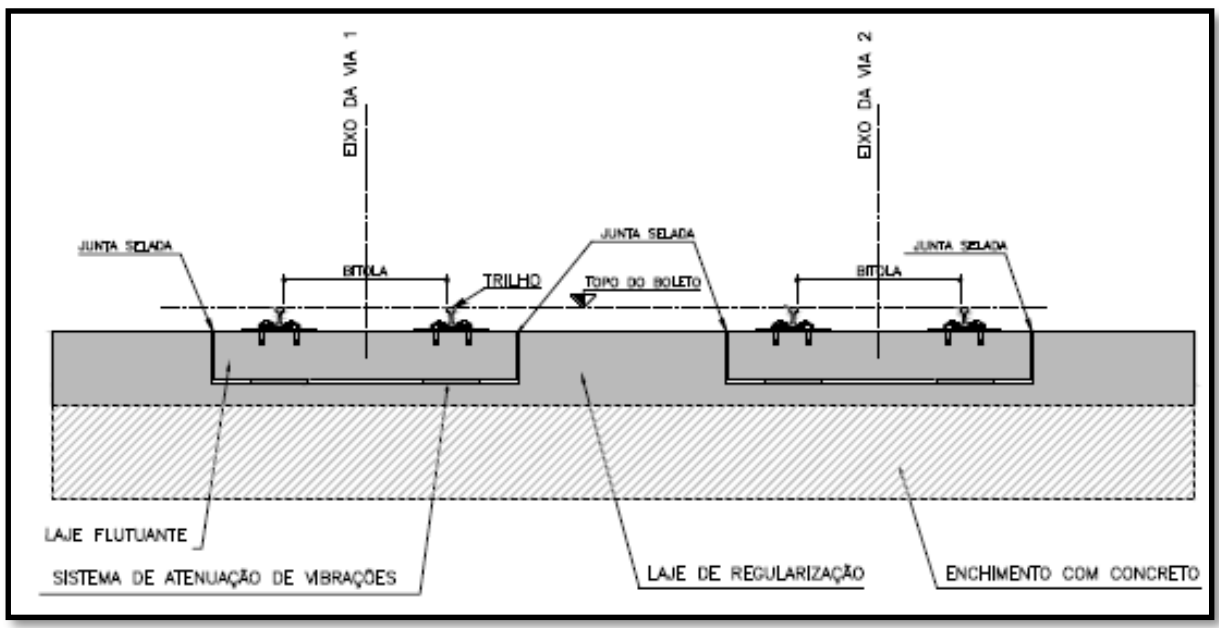

Figura 3.5 - Via permanente montada em sistema de lajes flutuantes (Fonte: Metrô SP). 


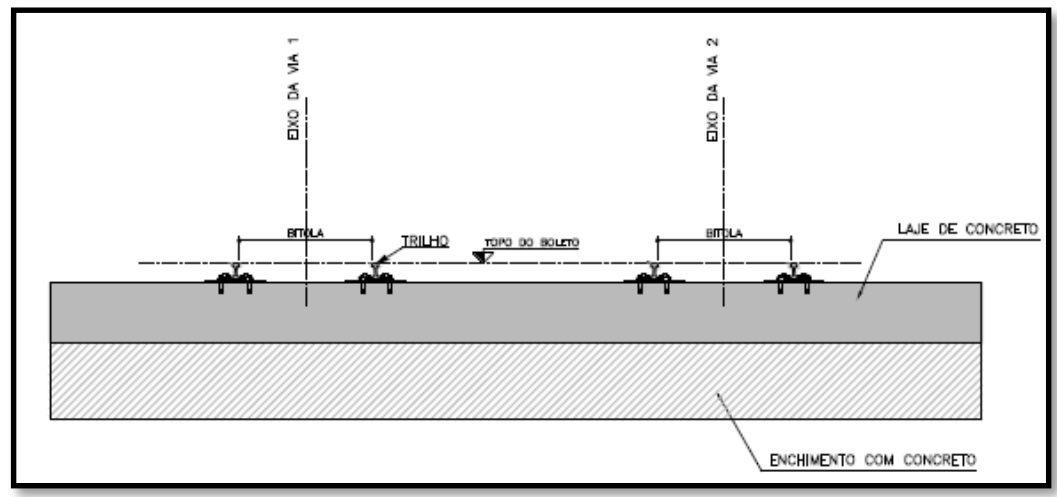

Figura 3.6 - Via permanente montada em laje de concreto (Fonte: Metrô SP).

A principal função de um SGP é o de auxiliar as autoridades de trânsito em encontrar as melhores estratégias para manter os pavimentos em um nível de serviço aceitável a um custo mínimo. Não é incorreto dizer que pavimentos construídos com materiais de baixa qualidade não são totalmente habilitados a utilizar-se de todas as vantagens apresentadas no seu gerenciamento por um SGP.

Muito embora nestas situações não seja possível eliminar as deficiências de projeto do pavimento com o uso de um SGP, a sua utilização pode minimizar os impactos que estas deficiências causarão e, ainda, poderá auxiliar as autoridades em tomar as providências necessárias de uma maneira objetiva e consistente (INTERNATIONAL GULF CONFERENCE ON ROADS; AL-QADI, 2009).

Os SGP têm sido definidos, pela AASHTO, como um conjunto de ferramentas e métodos que auxiliam os decisores em encontrar as melhores estratégias para avaliar e manter os pavimentos com um nível de serviço aceitável em um determinado período de tempo (SHAHIN, 2005).

Os SGPs permitem uma abordagem racional e efetiva em termos de custo para as operações de manutenção. SGPs que avaliam várias alternativas utilizam-se, para avaliar o desempenho futuro, do impacto esperado pelas ações de manutenção ou reabilitação. Também são fornecidas as informações necessárias sobre os recursos financeiros necessários bem como as justificativas necessárias para implantação dos programas de manutenção (HUANG, 2004).

Da mesma forma, a aplicação do SGP, devidamente desenvolvido para uma ferrovia, poderá alcançar estas facilidades apresentadas. As questões que envolvem a 
superestrutura e a infraestrutura poderão ser tratadas de maneira que as respostas obtidas do SGP sejam adequadas para que os decisores tenham as informações necessárias para a escolha da melhor alternativa em termos de manutenção.

Ainda, segundo Ibraheem (2012), um SGP é a chave para alcançar a melhor decisão na manutenção de pavimentos. O SGP armazena as informações do inventário dos pavimentos, as condições e desempenho e as alternativas de investimento aplicadas. A utilização de um SGP permite que as autoridades envolvidas no processo decisório tenham a habilidade de planejar adequadamente a manutenção de autoestradas, estradas e ruas pavimentadas.

Um SGP consiste, basicamente, de dois componentes. Um banco de dados que contém as séries históricas da condição qualitativa do pavimento, estrutura do pavimento e tráfego de veículos diário, mensal e anual. 0 segundo componente é um conjunto de ferramentas que permite determinar situações atuais e futuras do pavimento, projetar os recursos financeiros necessários e identificar e priorizar os trabalhos necessários.

A seleção da correta ação de manutenção, no tempo certo, é de fundamental importância para o efetivo gerenciamento dos pavimentos. A estratégia de manutenção será influenciada pelo tipo, grau de severidade, extensão das irregularidades encontradas e rugosidade do pavimento. A escolha do tratamento correto para o pavimento depende da extensão e frequência com que estas irregularidades ocorrem (IBRAHEEM, 2012).

Da mesma forma, em um pavimento ferroviário, as questões que envolvem o aparecimento de defeitos, a condição da pista de rolamento em termos de ondulações e toda a história deste pavimento, inclusive a concepção de projeto, influenciarão na escolha adequada da ação de manutenção.

As atividades de gerenciamento de pavimento são conduzidas em dois níveis distintos: nível de rede e nível de projeto (HAAS et al., 1994). O nível de rede abrange uma visão generalizada da infraestrutura como, por exemplo, de um estado providenciando o planejamento e orçamento gerais. 0 nível de projeto tem o foco em um limitado trecho da rede, no entanto providenciando planos de manutenção mais detalhados (HUANG, 2004). 


\subsubsection{Os Pavimentos Ferroviários}

Os procedimentos de manutenção adotados no ramo ferroviário são tradicionalmente baseados no conhecimento e experiência adquiridos nas empresas e adotados individualmente, com o objetivo de prover um nível de serviço elevado para a segurança da infraestrutura (ZIO et al., 2007).

O gerenciamento de uma ferrovia tem o objetivo de fazer uma avaliação qualitativa, definindo se a via permanente está em uma condição ótima, boa, ruim, etc... E uma avaliação quantitativa, definindo limites para atuação da manutenção. Estas avaliações, combinadas, são a base de um sistema baseado em regras e padrões, para que decisões possam ser tomadas para a manutenção e renovação da ferrovia (ESVELD, 2001).

Segundo Esveld (2001), os custos de manutenção da via permanente são uma grande parte do total gasto com a manutenção da infraestrutura do sistema. Qualquer redução no custo tem um impacto positivo na eficiência geral do gerenciamento da infraestrutura. Desta maneira, é uma das prioridades do responsável por esta manutenção que a mantenha no nível de serviço desejado, dentro de um período determinado, ao menor custo possível.

O processo para determinar se, quando, aonde e como fazer a intervenção, alocando os recursos de maneira ótima e minimizando os custos é uma tarefa complexa, pois diferentes seções da via permanente tendem a comportar-se de maneira diferente sobre o efeito das cargas transportadas.

Igualmente, decidir sobre ações de manutenção ou renovação também é um processo complexo, pois elas estão inter-relacionadas. Seja no campo das decisões que envolvem parâmetros técnicos tanto como as decisões que envolvem questões financeiras, os planos de manutenção ou renovação envolvem uma grande quantidade de informações técnicas e econômicas, um extenso conhecimento e, além de tudo, experiência nestas operações.

A Figura 3.5 mostra quais são as variáveis que existem em um sistema de gerenciamento de via permanente. 


\section{Sistema de Gerenciamento de Manutenção de Via}

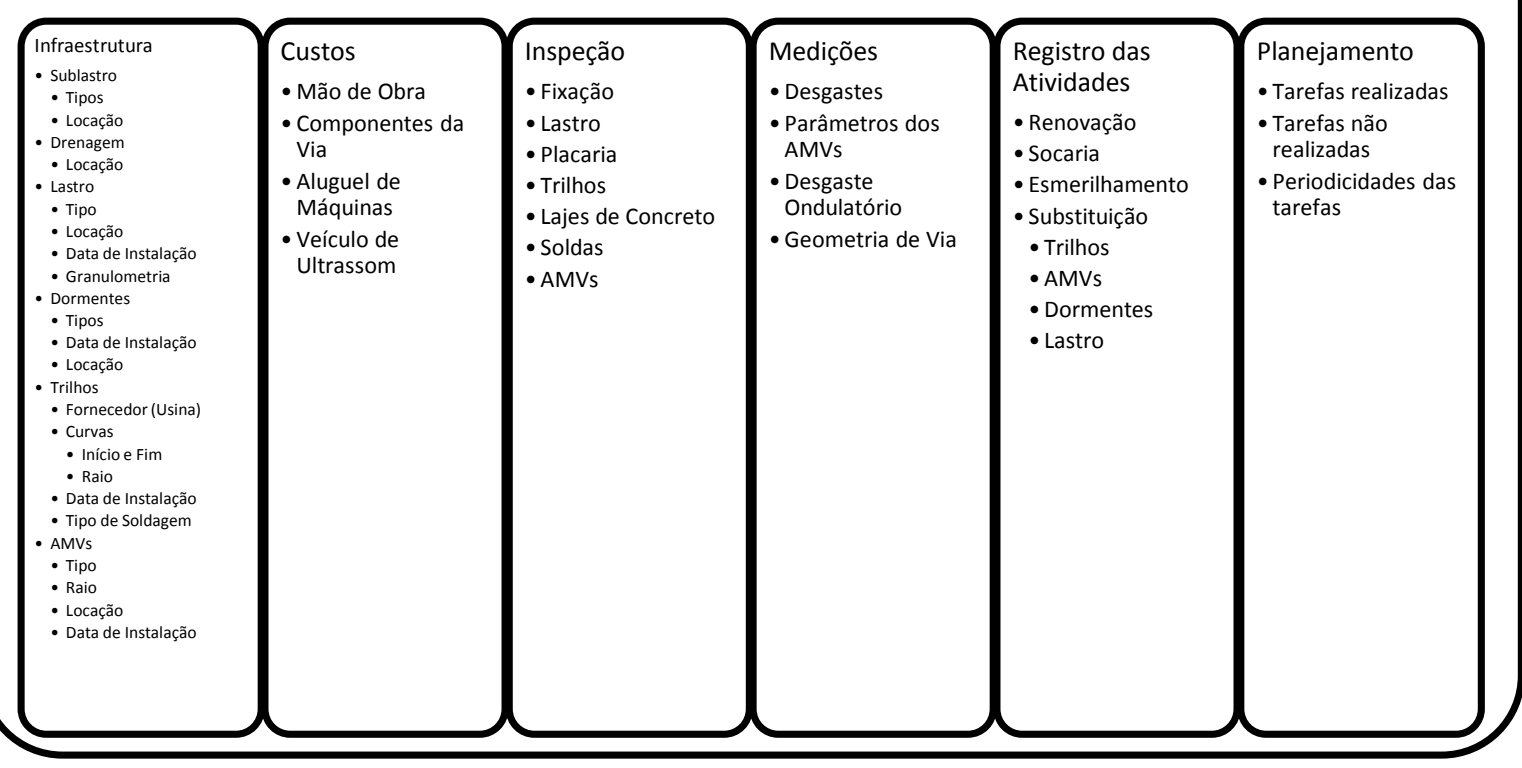

Figura 3.7 - Uma visão geral de um SGP aplicado em Ferrovia. Adaptado de (ESVELD, 2001).

A definição dos procedimentos de inspeção e manutenção sempre buscou assegurar um nível elevado de segurança para a infraestrutura, enquanto as questões financeiras recebiam um grau de importância menos elevado. Com a competição verificada em todos os setores da economia é necessário que haja uma racionalização dos custos em nome da segurança (ZIO et al., 2007).

Neste sentido, a adoção de um sistema que permita visualizar a situação da via permanente, com indicadores adequados, é uma ferramenta muito adequada para a racionalização dos custos e, ainda assim, prover um nível de serviço adequado de acordo com um processo decisório ajustado às necessidades de operação da via.

O processo decisório geralmente compreende duas partes: as permutas possíveis nas ações de manutenção e aumento do desempenho do sistema. As permutas podem ser conduzidas com ações de manutenção semelhantes com um orçamento definido ou entre diferentes ações de manutenção que são complementares. A permuta pode, ao mesmo tempo, verificar os benefícios econômicos da mudança de recursos de uma ação para outra e qual o impacto no nível de serviço. 0 aprimoramento do sistema lida com o 
desenvolvimento de um subconjunto de ações que atendam restrições orçamentárias (LI; SINHA, 2004).

A aquisição de dados é o primeiro passo no desenvolvimento de um SGP, e o banco de dados torna-se a parte principal do SGP. Existem três tipos de dados que devem estar contidos no banco de dados de um SGP: inventário do pavimento (dados construtivos, materiais utilizados, data de instalação, etc.), pesquisa das condições do pavimento (inspeções periódicas com registro dos defeitos encontrados) e registro das ações de reparo tomadas (INTERNATIONAL GULF CONFERENCE ON ROADS; AL-QADI, 2009).

As tecnologias de informação espacial, tais como os SIGs, são particularmente apropriados para integrar dados do pavimento e permitem a apresentação dos dados de operação e manutenção do pavimento usando relacionamento espacial para relatar objetos e eventos de maneira geométrica e geográfica. Em diferentes estágios o gerenciamento de pavimentos envolve relações entre objetos e eventos, localizados em diferentes posições espacialmente localizadas. Esta característica de possuírem uma coordenada espacial mostra que a utilização de tecnologia espacial aparece como uma alternativa válida. A tecnologia espacial pode auxiliar e melhorar a análise de situações e eventos no processo decisório (IBRAHEEM, 2012).

\subsection{Indicadores}

Os valores aplicados na manutenção da infraestrutura ferroviária americana em 2006 estão em torno de US\$ $10.6 \mathrm{Bi}$, indicando que a parcela de capital investido representa uma das maiores do mercado (GORMAN; KANET, 2010). Esta parcela significativa de investimento justifica que existam indicadores apropriados para a execução de uma manutenção adequadamente planejada e implantada.

O transporte de milhões de passageiros anualmente também aponta para a necessidade de um conjunto de indicadores que leve o nível de qualidade do serviço prestado a um patamar que seja minimamente aceitável, ou seja, que a oferta do serviço atenda às expectativas mínimas dos usuários, sem atrasos e interrupções do sistema de transporte. De fato, garantir a segurança dos usuários no sistema é o ponto mais importante no estabelecimento destes indicadores. 
Assim, o estabelecimento de indicadores deve seguir uma lógica que não permita, ou não deveria permitir, que a infraestrutura como um todo e seus diversos componentes alcancem os limites técnicos estabelecidos como limítrofes para um determinado nível de serviço esperado.

A infraestrutura ferroviária mostra-se como um sistema complexo. A operação do sistema e a escolha da infraestrutura que suportará esta operação influenciam-se mutuamente. A qualidade do material rodante influencia o desgaste e fadiga da infraestrutura e, por consequência, o plano de manutenção. Um aspecto importante na infraestrutura ferroviária é que seus componentes tem um ciclo de vida longo e uma vez instalados é custoso e complicado a modificação do projeto original.

Decisões sobre o projeto e manutenção terão um impacto de longa duração no desempenho da infraestrutura. Caso as ações de manutenção sejam reduzidas ao longo do tempo, os componentes podem ter a sua vida útil esgotada rapidamente e o resultado disto serão custos elevados de manutenção (ZOETEMAN, 2001).

A definição dos tempos corretos de manutenção em uma infraestrutura ferroviária é um fator crucial para a realização eficaz e eficiente dos planos de trabalho (manutenção ou renovação), uma vez que isto incrementa a vida útil da infraestrutura e de seus componentes. As realizações dos trabalhos em prazo que extrapola os limites definidos, levando ao envelhecimento do sistema, coloca em risco a segurança do sistema além de fazer com que o custo destes trabalhos cresça de forma exponencial.

A redução de custos e processos de manutenção ajustados, por sua vez, aumenta a eficiência do sistema. Os modernos sistemas de gerenciamento de pavimentos ferroviários requerem que exista um conceito de diagnóstico embutido que designe uma abordagem baseada na condição da infraestrutura, ou seja, na análise de criticidade e urgência de atuação nos componentes principais. É possível alcançar um gerenciamento eficiente e eficaz escolhendo adequadamente as ações de manutenção e renovação, bem como a distribuição temporal e espacial destas ações (GULER , 2012).

Segundo Shyr (1993), a vida útil de uma infraestrutura é determinada por dois índices, o nível de desgaste e a taxa de fadiga. Os defeitos de fadiga, quando não detectados e removidos, podem levar a quebras de componentes e causar acidentes graves, como, por exemplo, descarrilamentos. 0 verdadeiro mecanismo da fadiga permanece em 
investigação no meio acadêmico, e, como resultado, a predição deste tipo de defeito não tem um nível de acerto razoável.

Muito embora estes dois índices desempenhem um papel importante na definição das políticas de manutenção, e, de fato, são os fenômenos físicos responsáveis pela degeneração dos sistemas, é importante que os componentes sejam avaliados não somente como um sistema único, mas individualmente também. Esta avaliação individual, associada a uma visão sistêmica, auxilia na definição das regras que norteiam o plano de manutenção e renovação de um pavimento ferroviário. A Tabela 3.1 mostra os principais indicadores individuais para definição de planos de manutenção e renovação.

Tabela 3.1 - Indicadores de manutenção para pavimento ferroviário.

\begin{tabular}{|c|c|c|}
\hline Lastro & Dormentes e Fixação & $\begin{array}{l}\text { Esmerilhamento e } \\
\text { Lubrificação }\end{array}$ \\
\hline $\begin{array}{l}\text { Tipo } \\
\text { Idade e limites de idade } \\
\text { Histórico de socaria } \\
\text { Condição do sublastro }\end{array}$ & \multirow{6}{*}{$\begin{array}{l}\text { Tipo } \\
\text { Carga e carga acumulada } \\
\text { Bitola } \\
\text { Condição física } \\
\text { Número dormentes } \\
\text { danificados } \\
\text { Regras de substituição }\end{array}$} & $\begin{array}{l}\text { Classe da via } \\
\text { Aceleração transversal } \\
\text { Desgaste Ondulatório } \\
\text { Nível de ruído }\end{array}$ \\
\hline Quantidade de lastro sujo & & Número de trens \\
\hline Geometria da via & & Número de defeitos no trilho \\
\hline $\begin{array}{l}\text { Profundidade mínima } \\
\text { aceitável }\end{array}$ & & Raio de curvatura \\
\hline $\begin{array}{l}\text { Valores de referência - } \\
\text { ensaios }\end{array}$ & & Carga e carga acumulada \\
\hline Frequência de defeitos & & $\begin{array}{l}\text { Parâmetros estatísticos } \\
\text { Soldas de trilho rebaixadas }\end{array}$ \\
\hline Trilhos & Socaria & Renovação \\
\hline $\begin{array}{l}\text { Tipo } \\
\text { Velocidade } \\
\text { Carga e carga acumulada } \\
\text { Raios de curvatura } \\
\text { Classe da Via } \\
\text { Parâmetros estatísticos } \\
\text { Número de defeitos } \\
\text { Limites de desgaste } \\
\text { Impacto } \\
\text { Soldas de trilho rebaixadas }\end{array}$ & $\begin{array}{l}\text { Histórico de socaria } \\
\text { Geometria da via } \\
\text { Análise da geometria } \\
\text { Limite de defeitos } \\
\text { Aceleração lateral }\end{array}$ & $\begin{array}{l}\text { Substituição de dormentes } \\
\text { Substituição da fixação } \\
\text { Substituição dos Trilhos } \\
\text { Condição do sublastro } \\
\text { Análise de custos }\end{array}$ \\
\hline
\end{tabular}

Deve ser observado que estes indicadores podem variar na sua utilização, dependendo dos limites aceitáveis de um determinado comportamento da via ou limites técnicos de componentes bem como as regras de manutenção para cada operador de um sistema de transporte público sobre trilhos. Não obstante, um dos objetivos deste 
trabalho é o de criar um conjunto único de indicadores para utilização pelos operadores no Brasil, porém algumas características podem levar a adoção do conjunto único e mais alguns indicadores que sejam adequados a uma particularidade de uma determinada via ou pavimento ferroviário.

O equilíbrio entre as intervenções de manutenção e o custo das intervenções deve ser equilibrado de maneira que a manutenção permaneça com um custo aceitável e, ao mesmo tempo, não haja queda no nível de serviço devido a periodicidade adotada para as intervenções. Neste sentido, traçando um paralelo entre Zorita et al.(2010), que mencionam que o fio de contato é o único componente, no sistema de alimentação elétrica da tração dos trens, que não possui redundância por motivos econômicos e técnicos e, portanto, a manutenção deste componente deve ser tal que permita alta disponibilidade, aumente a sua vida útil, ou, pelo menos, aumente o tempo médio entre falhas, dado que o reparo sempre é oneroso podemos aplicar este raciocínio a todos os componentes da via permanente. A Figura 3.6 identifica como as intervenções e variáveis do sistema influenciam nos indicadores de desempenho dos componentes e da via permanente como um todo.

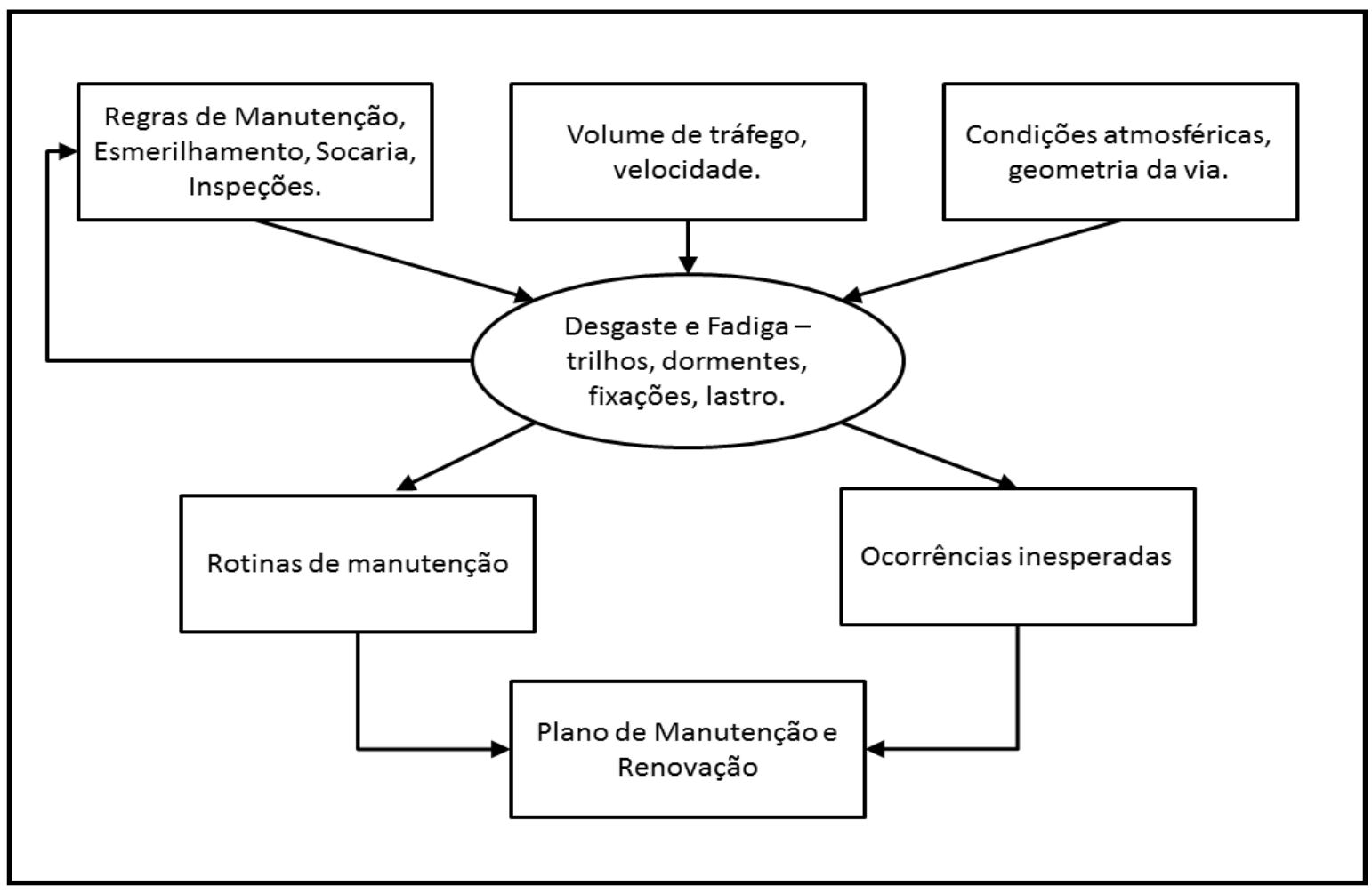

Figura 3.8 - Influência de fenômenos físicos e variáveis do sistema nos indicadores de manutenção (Fonte:Autor). 
Na Figura 3.6 é mostrado que os indicadores de manutenção (as regras de manutenção) são alimentados pelo comportamento da infraestrutura. Estas regras são dinâmicas e devem ser adequadas ao longo do tempo para que incorporem o envelhecimento da infraestrutura ou novos comportamentos em função de modernização dos componentes. Um exemplo prático desta situação é com relação à fixação dos trilhos: a adoção de um sistema de fixação com um nível de confiabilidade acima do existente pode permitir que as inspeções nos trechos de via permanente tenham a sua periodicidade alterada.

De uma forma geral, o comportamento dos componentes da via permanente que são submetidos a desgaste, e as respectivas ações de manutenção e renovação são mostrados na Figura 3.7. A linha pontilhada mostra que ações de manutenção podem postergar o momento de substituição de um componente. A diferença entre os limites de manutenção e operacional representa o tempo que existe entre os dois limites, de maneira que haja possibilidade de planejamento e execução das ações necessárias para substituição do componente.

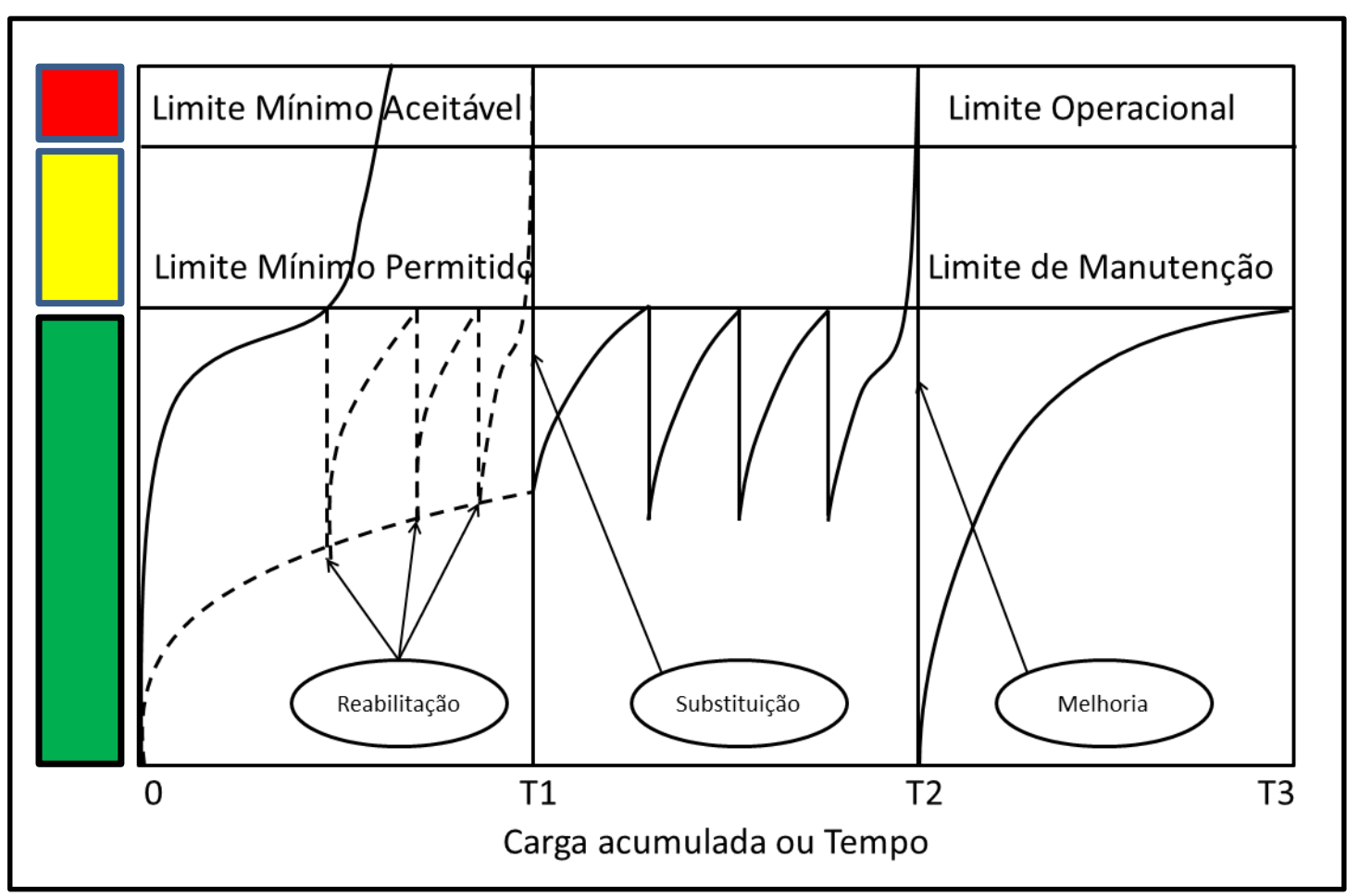

Figura 3.9 - Comportamento de componentes e ações de manutenção. Adaptado de HAAS; HUDSON; ZANIEWSKI (1994). 
Considerando as questões de desgaste e fadiga, além das ações climáticas, na via permanente, a adoção de indicadores, que permitam uma avaliação das condições da infraestrutura, é uma ferramenta valorosa para os decisores de todos os níveis.

Para que seja adotado um programa de manutenção com indicadores em número adequado para a sua utilização é importante que a via permanente seja subdividida em seções identificadas individualmente, e cada uma destas seções tenha o tratamento necessário.

Os indicadores para as seções são idênticos, contudo a característica geométrica de cada seção leva a uma interpretação individual do indicador. Por exemplo, em uma curva com superelevação a interpretação do desgaste de um trilho é diferente para a interpretação de um trecho em reta. Da mesma forma o comportamento de placas, ou do lastro, devem ser considerados dentro do contexto global, no entanto levando em consideração a característica individual da seção.

A melhoria da infraestrutura como um todo, desde o nível de componente, até o sistema completo é essencial para que as empresas ferroviárias estejam inseridas no mercado e possam competir com outros meios de transporte.

\subsection{Confiabilidade, Disponibilidade, Manutenibilidade e Segurança.}

Confiabilidade e gestão da manutenção estão atraindo interesse no mundo corporativo. A busca em se manter competitiva e prestar serviços adequados às necessidades dos clientes é, em parte, responsável por esse interesse. Uma empresa não pode adotar uma estratégia de resposta rápida se o seu sistema não está disponível ou não for confiável (MADU, 2005). As disciplinas de engenharia de confiabilidade e engenharia de manutenção são relativamente novas. Engenharia de confiabilidade e engenharia de manutenção não são apenas partes do processo de projeto de engenharia, mas também as funções necessárias no custeio do ciclo de vida, na análise custo-benefício, nos estudos de capacidade operacional, na alocação de recursos para reparação e 
instalação, na determinação de estoque e necessidades de peças de reposição, nas decisões de substituição, e no estabelecimento de programas de manutenção preventiva.

A primeira norma europeia (EN 50126) para o sistema ferroviário, sob a ótica da engenharia de confiabilidade, foi publicada em 1999 pelo CENELEC e define Confiabilidade, Disponibilidade, Manutenibilidade e Segurança (RAMS, do inglês Reliability, Availability, Maintainability \& Safety)) como uma característica de operação de longo prazo de um sistema. Os estados padrões de análise de confiabilidade, disponibilidade, manutenibilidade e segurança são conseguidos através da aplicação de conceitos de engenharia, métodos, ferramentas e técnicas ao longo do ciclo de vida do sistema.

A CENELEC (1999) define os elementos básicos análise de confiabilidade, disponibilidade, manutenibilidade e segurança como:

- Confiabilidade: a probabilidade de que um item pode executar uma função requerida, submetido a condições especificadas, para um determinado intervalo de tempo.

- Disponibilidade: a capacidade de um item estar em um estado capaz de executar uma função requerida, submetido a determinadas condições, a um dado instante de tempo ou durante um dado intervalo de tempo, assumindo que os recursos externos necessários são fornecidos.

- Manutenção: a probabilidade de que uma dada ação de manutenção de um ativo, para um item submetido a determinadas condições de utilização, pode ser realizada dentro de um intervalo de tempo estabelecido, indicando quando a manutenção é realizada sob tais condições estabelecidas e utilizando procedimentos e recursos especificados.

- Segurança: o estado de um sistema livre do risco inaceitável de dano.

\subsubsection{Parâmetros de análise de confiabilidade, disponibilidade, manutenibilidade e} segurança

No caso da infraestrutura metroferroviária, existem três sistemas distintos, a saber: a via permanente, o sistema de sinalização e comunicação, e o sistema de energia. Estes sistemas possuem um efeito combinado sobre a degradação da infraestrutura. 
Cada sistema é sujeito à degradação devido a fatores internos e externos. Todos estes aspectos devem ser considerados para estimar a confiabilidade, disponibilidade, manutenibilidade e segurança da infraestrutura, o que faz com que o cálculo seja complexo. Para estimar estes aspectos ao nível de infraestrutura, devem-se avaliar as características ao nível subsistema e componente. Em geral, os parâmetros de confiabilidade e manutenção são estimados tanto no nível de componente como do sistema, enquanto que a disponibilidade e segurança são calculados apenas sobre o nível do sistema.

\subsubsection{Fatores que Afetam análise de confiabilidade, disponibilidade, manutenibilidade e segurança}

Para conseguir um sistema confiável, os fatores que podem influencia-lo precisam ser identificados, os seus efeitos devem ser avaliados, e as causas destes efeitos precisam ser gerenciadas durante todo o ciclo de vida do sistema. O sistema metroferroviário é influenciado de três maneiras:

- Condições do sistema: as fontes de falhas são introduzidas internamente no sistema, em qualquer fase do ciclo de vida do sistema. Estas falhas são impostas pelo projeto e fabricação dos componentes ou do sistema.

- Condições de funcionamento: as fontes de falhas resultam do método pelo qual o sistema é operado. Essas falhas também são impostas pelas condições ambientais.

- Condições de manutenção: as fontes de falhas são causadas por ações de manutenção. Falhas na infraestrutura podem ser causadas não só pelas ações de manutenção na infraestrutura, mas também pela manutenção do material rodante.

Essas possíveis fontes de falha podem interagir, conforme mostrado na Figura 3.8. Na figura a confiabilidade não é explicitamente mostrada, mas é dada por meio do grupo de falhas internas e externas no sistema. Os fatores que influenciam análise de confiabilidade, disponibilidade, manutenibilidade e segurança, como mostrados na figura, são genéricos e podem ser aplicados em todas as instalações industriais. As devidas 
adaptações devem ser procedidas para aplicação no setor de transporte. A Tabela 3.3 identifica os fatores específicos que afetam a análise de confiabilidade, disponibilidade, manutenibilidade e segurança da via permanente. 


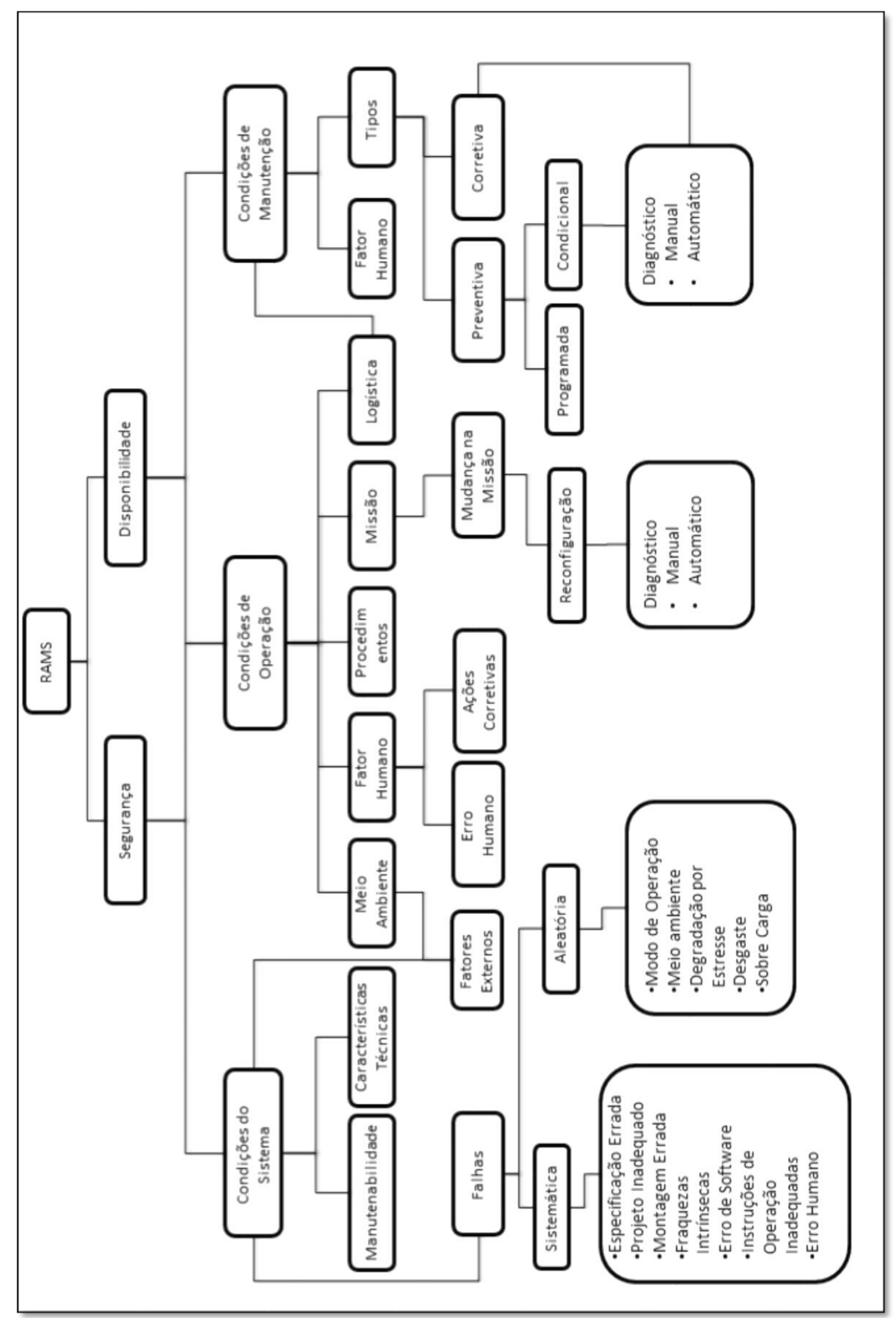

Figura 3.10 - Fontes de Falha e Conexão com Confiabilidade, Disponibilidade, Segurança e Manutenibilidade (Fonte: CENELEC, 1999). 
Tabela 3.2 - Fatores que afetam a qualidade da via.

\begin{tabular}{|c|c|c|}
\hline & Parâmetros Físicos & Parâmetros Técnicos \\
\hline \multirow{6}{*}{ 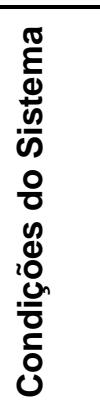 } & $\begin{array}{l}\text { Curvatura da Via (Curva de } \\
\text { transição, raio). }\end{array}$ & Estresse da Via. \\
\hline & Gradiente da via (início, fim e valor). & Estresse da Via. \\
\hline & Trilho (tipo, soldado, com tala). & Elasticidade. \\
\hline & Lastro (tipo, tamanho). & Rigidez, amortecimento. \\
\hline & Fixação. & Amortecimento. \\
\hline & Sublastro (condição geológica). & Rigidez, amortecimento. \\
\hline \multirow{4}{*}{ 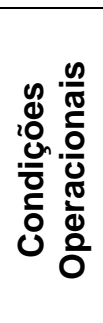 } & $\begin{array}{l}\text { Carregamentos (tonelagem bruta } \\
\text { anual, carga máxima por eixo). }\end{array}$ & $\begin{array}{l}\text { Tensão de flexão, tensão de cisalhamento e } \\
\text { tensão de contato. }\end{array}$ \\
\hline & Meio ambiente (temperatura). & Tensão térmica. \\
\hline & Velocidade dos trens. & Tensão lateral e vertical. \\
\hline & $\begin{array}{l}\text { Condições do material rodante } \\
\text { (rodas desgastadas). }\end{array}$ & Tensão dinâmica e tensão de contato. \\
\hline \multirow{5}{*}{ 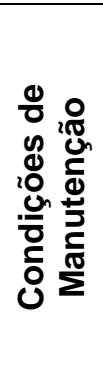 } & Esmerilhamento. & Taxa de desgaste. \\
\hline & Socaria. & Mudança na rigidez da via. \\
\hline & Lubrificação. & Mudança no coeficiente de atrito. \\
\hline & $\begin{array}{l}\text { Substituição dos componentes de } \\
\text { via. }\end{array}$ & Periodicidade de substituição. \\
\hline & $\begin{array}{l}\text { Substituição corretiva de } \\
\text { componentes. }\end{array}$ & Taxa de falhas dos componentes. \\
\hline
\end{tabular}

Os fatores mencionados afetam as características de qualidade da via da mesma forma que a qualidade dos dados afeta a exatidão da estimativa dos parâmetros de vida. Muitos tipos de dados são relevantes para a estimativa e previsão da confiabilidade, e para cálculo da disponibilidade e da manutenibilidade. Nem todos dados são recolhidos, e a falta de informação é, por vezes, um problema grave em uma análise (BLISCHKE; MURTHY, 2003).

Por exemplo, a fim de estimar o efeito do material rodante nas características da via permanente, é preciso conhecer a tensão de flexão, a tensão de cisalhamento e a pressão de contato transmitida pela carga. Da mesma forma, é necessário conhecer os tipos de via e o espaçamento entre as fixações para determinar a tensão de flexão, rigidez e amortecimento da via. 
As condições do sistema são relacionadas com a concepção e fabricação dos componentes da via, enquanto que as condições de funcionamento são ligadas às operações do material rodante. Na maioria dos casos, é difícil mudar as condições do sistema e de operação e manutenção, embora possam ocorrer mudanças nas condições de funcionamento (por exemplo, alterações na carga por eixo) que podem mudar devido a fatores externos (nova modalidade de tarifação, novas possibilidades de conexão no sistema, etc.).

A fim de identificar as ações de manutenção relevantes para a via permanente, é fundamental ter uma boa compreensão dos modos de falha e suas causas. Modo de Falha, Efeitos e Análise de Criticidade (FMECA) atua como uma ferramenta para revelar estes mecanismos de falha. Para dar suporte a essa tarefa, quatro tipos de falha são definidos, a saber:

- O componente é submetido à degradação progressiva que pode ser observada por um instrumento adequado;

- O componente é submetido à degradação progressiva que não pode ser observada;

- O componente é submetido a uma degradação súbita, que pode ser observada por um instrumento adequado;

- O componente é sujeito à degradação de choque, que conduz de imediato à falha e interrupção da função do componente.

Esta classificação é particularmente útil quando os parâmetros de confiabilidade estão sendo avaliados, uma vez que estes parâmetros têm interpretações diferentes para as quatro categorias de progressões de falha. Os modos de falha da via e os seus limites correspondentes podem ser categorizadas como indicado abaixo (ESVELD, 2001). Os limites podem ser definidos por unidade de comprimento da via.

- Condição geométrica da via (desvio-padrão no alinhamento longitudinal, vertical e bitola);

- Porcentagem de lastro bom e lastro ruim em uma amostra;

- Condição da fixação (porcentagem de elementos de fixação soltos);

- Condição dos dormentes (percentual de dormentes em níveis ruim, médio e bom);

- Defeitos no trilho (número de defeitos devido à fadiga, número de trilhos quebrados, número de soldas defeituosas, e desgaste ondulatório); 
- Desgaste dos trilhos (desgaste vertical e lateral do boleto do trilho);

Medir a condição de infraestrutura é pré-requisito para o planejamento de manutenção de via. Além disso, a segurança e a disponibilidade em serviço só podem ser alcançadas pelo cumprimento de todos os requisitos de confiabilidade e manutenabilidade, pelo controle contínuo da manutenção, pelas atividades de manutenção e operação em longo prazo e pelo controle da influência do ambiente que envolve o sistema.

\subsection{Manutenção}

O objetivo da manutenção e da gestão da manutenção é o de maximizar a disponibilidade de um dado sistema com custos mínimos, reduzindo a probabilidade de equipamento ou sistema apresentar falha (LEVITT, 2009). A gestão da manutenção pode, a partir de uma visão holística, ser descrita como a gestão dos recursos de manutenção disponíveis, ou seja, recursos humanos, financeiros, materiais, e informações, para garantir uma saída desejada em termos de alta integridade dos ativos. A gestão também inclui o gerenciamento de entradas inesperadas, bem como saídas indesejáveis.

A evolução da manutenção e da gestão da manutenção começou no período posterior à Segunda Guerra Mundial, quando então a política de manutenção dominante era a de "quebrou, consertou" (KELLY, 2006). Este é chamado de a primeira geração de Manutenção (MOUBRAY, 1997).

Durante os anos 1960, as questões de segurança tornaram-se mais importantes, bem como a melhoria da eficiência do trabalho, assim uma estratégia de manutenção preventiva emergiu; isso é chamado de Segunda Geração de Manutenção (MOUBRAY, 1997). Esta mudança de estratégia também permitiu começar a controlar o desempenho de manutenção, os custos de produção e disponibilidade de ativos.

A terceira geração de Manutenção (MOUBRAY, 1997), surgiu durante a década de 1970, com uma estratégia preventiva desenvolvida a níveis mais elevados devido aos avanços e s necessidades dos gerentes em prever o valor futuro da manutenção; assim a 
estratégia de manutenção baseada em condição evoluiu.

A evolução da manutenção atingiu hoje a quarta geração, em que a manutenção é encarada de um ponto de vista mais holístico, com a integração do gerenciamento de ativos com a produção (DUNN, 2003). A manutenção não é mais vista apenas como um centro de custo, ela também cria valor para o negócio (LIYANAGE; KUMAR, 2002, LIYANAGE; KUMAR, 2003)

A manutenção, segundo a Norma Europeia 13306, edição de 2010, é necessária devido à falta de confiabilidade e perda da qualidade. A manutenção é uma "combinação de todas as ações técnicas, administrativas e de gestão durante o ciclo de vida de um produto, destinado a mantê-lo, ou restaurá-lo, para um estado em que ele pode executar a função desejada" (EN 13306:2010).

A manutenção é muitas vezes encarada como um processo, ou seja, o estabelecimento de uma meta e estratégia, a criação do programa, o planejamento, a execução e a análise de melhoria contínua. As atividades de manutenção em si são realizadas tanto como manutenção corretiva depois de uma falha, ou manutenção preventiva para reduzir a probabilidade de avarias futuras (SWANSON, 2001).

Tradicionalmente, a manutenção preventiva é realizada com base no tempo. Uma abordagem de manutenção preditiva é frequentemente utilizada quando é possível monitorar o estado do equipamento, dando a oportunidade de executar a manutenção apenas quando existe a necessidade. Os benefícios desta estratégia são os intervalos de manutenção prolongada e custos de manutenção reduzidos (SWANSON, 2001). Contudo, por vezes, é mais rentável adotar uma estratégia de esperar o equipamento falhar. Isto deve ser adotado para equipamentos baratos, cuja falha é fácil de detectar e que não tem qualquer efeito sobre o processo de produção.

A fim de acompanhar e avaliar a gestão da manutenção e as atividades realizadas, bem como avaliar se o processo de manutenção suporta os objetivos gerais do negócio, o uso de sistemas de geração de indicadores é um requisito importante para o desempenho (WIREMAN, 2005). Na década de 1960, o foco principal era a economia, equipamentos e questões organizacionais, mas hoje a saúde, segurança e questões ambientais são igualmente importantes (KUMAR; AKERSTEN, 2008). 


\subsubsection{Planejamento da Manutenção da Infraestrutura}

A manutenção é definida como a combinação de todas as ações técnicas e administrativas, incluindo as ações de supervisão, destinadas a manter um item ou restaurá-lo para um estado onde ele pode executar uma função requerida (BEN-DAYA, 2009). A manutenção tem sido tratada com uma abordagem reativa, "de combate a incêndios". No entanto, com as metas de confiabilidade para ativos tornando-se cada vez mais importantes, várias abordagens de manutenção preventiva e outros métodos estão sendo desenvolvidos.

Todas as decisões relacionadas à manutenção de infraestrutura ferroviária são tomadas a fim de manter um equilíbrio entre os aspectos econômicos e de segurança. 0 objetivo é encontrar um processo de manutenção eficaz para aumentar a disponibilidade da via e, ao mesmo tempo, permitir o aumento da velocidade do material rodante, mesmo em condições de restrição.

Os diferentes componentes do sistema via permanente são estrutural e economicamente interdependentes. Efeitos de escala estão envolvidos na sua manutenção e renovação, enquanto que a sua degradação é normalmente relacionada com a utilização. Dado que a operação do sistema tem que ser continuada e os orçamentos são limitantes, todos os tipos de restrições têm que ser considerados no planejamento de manutenção de infraestrutura. Os conceitos do processo de planejamento de manutenção são desenvolvidos nas seguintes etapas (ZOETEMAN, 2006):

- Geração de estratégias de manutenção de ativos individuais (por exemplo, manutenções corretiva ou preventiva, baseadas no tempo ou condição. As estratégias são distintas com base na importância individual do equipamento para todo o sistema de produção);

- Definição de regras de agrupamento, que aperfeiçoam as freqüências de atividades com base em efeitos de escala ou de escopo;

- Definição de regras de atribuição de janelas de tempo de manutenção para manter as programações de manutenção com base nas oportunidades que ocorrem no curto ou médio prazo. 
No início dos anos 1980, iniciaram-se os estudos de pré-requisitos para o planejamento da manutenção da via (FAZIO; PRYBELLA, 1980). Medidas de qualidade da via e modelos de deterioração são destacadas como áreas-chave para a estruturação de um processo de planejamento. Três ferramentas são indicadas para melhorar a eficiência da manutenção: sistemas de inspeção automatizados, bases de dados e sistemas de planejamento de manutenção (ZAREMBSKI, 1998). A falta de integração entre essas ferramentas impede a total utilização do potencial de cada uma delas, conforme mostra a Figura 3.9.

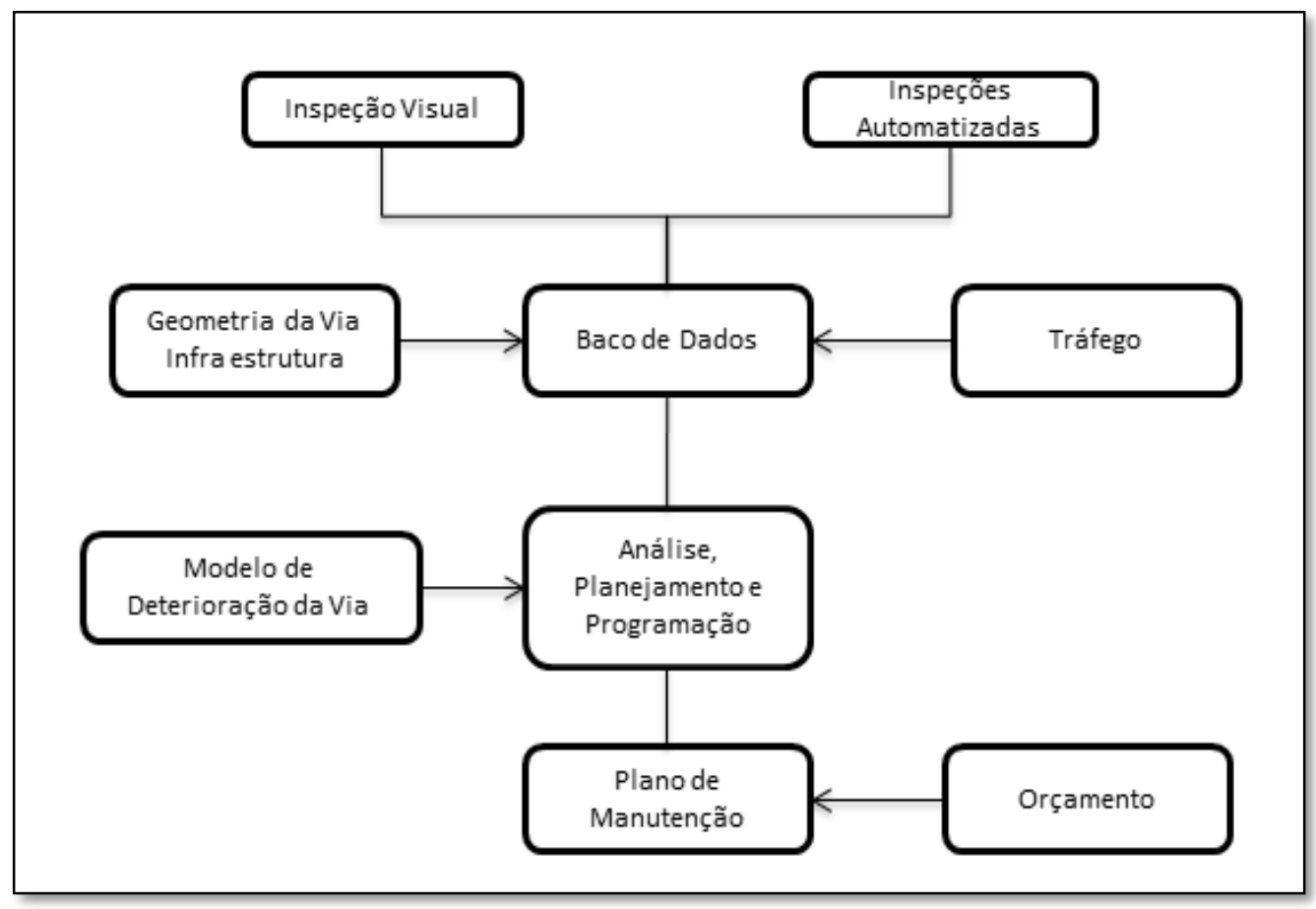

Figura 3.11 - Visão Geral do Planejamento da Manutenção. (Fonte: adaptado de Fazio; Prybela, 1980)

As diferentes fontes de dados precisam ser ligadas em um banco de dados geral para fins de planejamento. A adição de modelos de degradação da via podem auxiliar na avaliação do estado da infraestrutura ao longo do tempo. 0 planejamento das atividades de manutenção será afetado pelas condições da via. Isto requer um conhecimento 
detalhado de cada componente da via e a sua relação com os outros componentes, bem como o padrão de degradação de cada componente.

Assim, a tarefa do planejamento de manutenção de infraestrutura pode ser descrita como encontrar respostas para as seguintes perguntas:

- Quais são as condições atuais da infraestrutura? (Índices de qualidade da via);

- O que será necessário em curto e em longo prazo para a consecussão das atividades de manutenção? (Previsão de ações de manutenção);

- 0 que deve ser feito primeiro? (Priorização das atividades de manutenção).

A Tabela 3.2 ilustra o efeito da estratégia de esmerilhamento da Canadian Pacific Railway sobre a confiabilidade do trilho. Como mostra a tabela, a estratégia de esmerilhamento iniciada com esmerilhamento preventivo aumenta a vida do trilho consideravelmente. 0 esmerilhamento corretivo exige a remoção de uma camada mais espessa, enquanto o preventivo é mais frequente e menos invasivo.

A taxa de remoção em esmerilhamento é o parâmetro que controla a vida do trilho, porque, quando o desgaste atinge o limite de manutenção / segurança do trilho, ele é substituido. Sem esmerilhamento temos um cenário em que a vida do trilho é determinada principalmente por RCF (Roling Contact Fatigue - Fadiga de Contato). A Tabela 3.2 também apresenta uma comparação da vida do trilho devido à fadiga em três cenários de esmerilhamento. A vida em fadiga do trilho é atingida quando o número de defeitos em uma seção específica da via atinge seu limite.

Tabela 3.3 - Vida do Trilho X Esmerilhamento X Estratégias

\begin{tabular}{lccc}
\hline \hline Critério de Desgaste & $\begin{array}{c}\text { Sem } \\
\text { Esmerilhamento }\end{array}$ & $\begin{array}{c}\text { Esmerilhamento } \\
\text { Corretivo }\end{array}$ & $\begin{array}{c}\text { Esmerilhamento } \\
\text { preventivo }\end{array}$ \\
\hline $\begin{array}{l}\text { Taxa de Desgaste do } \\
\text { Trilho em mm/MTBT }\end{array}$ & 0,04 & 0,06 & 0,03 \\
Vida do Trilho em MTBT & 469 & 367 & 844 \\
$\begin{array}{l}\text { Vida do trilho devido à } \\
\text { fadiga em MTBT }\end{array}$ & 331 & 496 & 1322 \\
\hline \hline
\end{tabular}


A diferença entre a vida devido ao desgaste do trilho e a vida devido à fadiga está ilustrada na Figura 3.10. À medida que a taxa de desgaste, ou de remoção de material devido esmerilhamento aumenta, a vida do trilho se aproxima do limite de manutenção / segurança. No entanto, o aumento na taxa de remoção de material devido ao esmerilhamento aumenta a vida devido à fadiga, já que o esmerilhamento remove os defeitos devido à fadiga antes de estes tornarem-se críticos. Assim, a estratégia de esmerilhamento é vista como um parâmetro importante que afeta a confiabilidade da via. A figura também ilustra a chamada "taxa ótima de desgaste".

A "taxa ótima de desgaste" é a taxa de esmerilhamento que a estratégia preventiva deve atingir, a fim de alcançar a máxima segurança para os trilhos. Como mostrado na figura, quando a taxa de desgaste está abaixo da taxa mágica, a vida trilho é determinada pela vida devido à fadiga, enquanto que quando a taxa de desgaste é maior que a taxa mágica, a vida trilho é determinada pelo desgate do trilho.

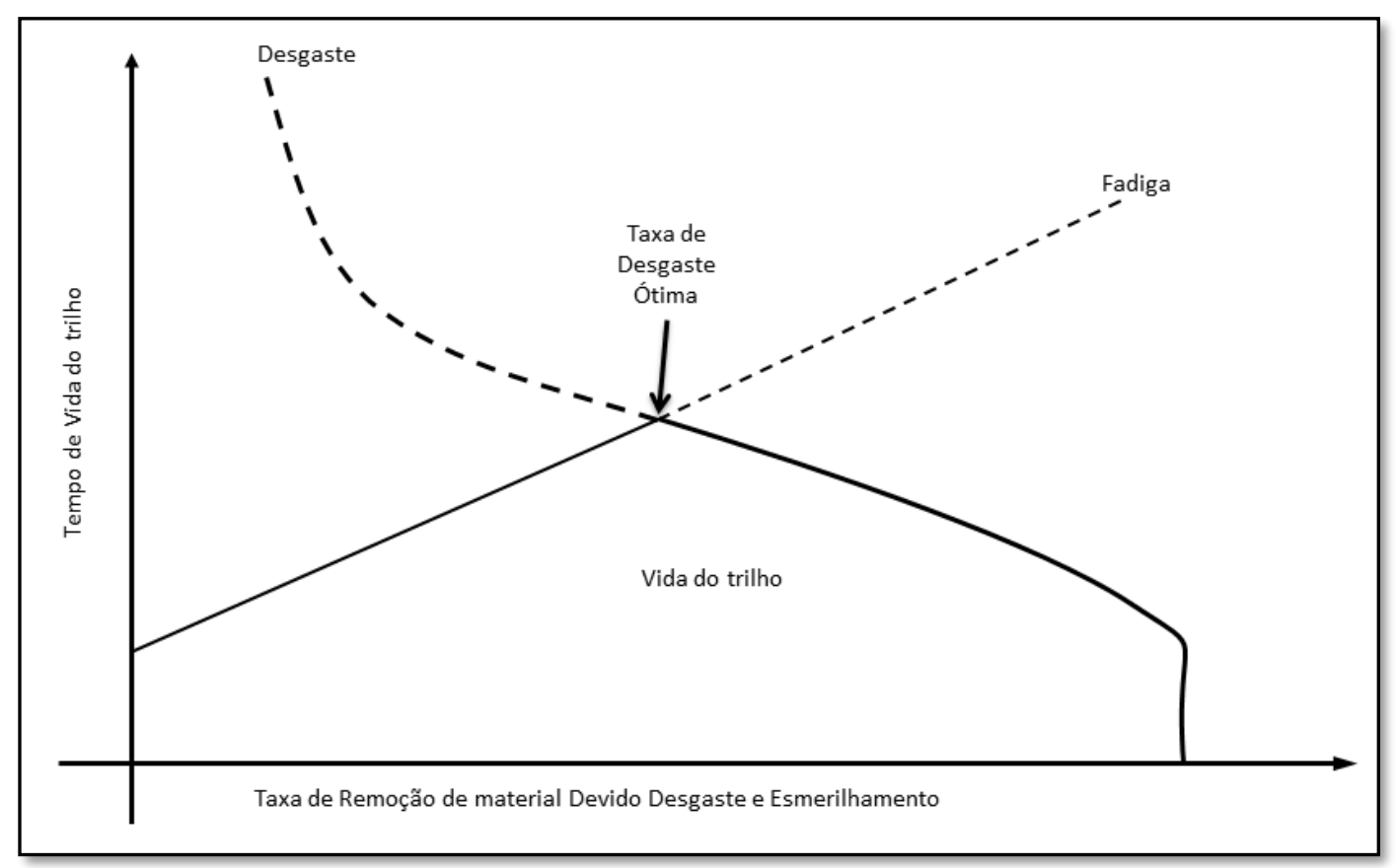

Figura 3.12 - Relação entre a vida do trilho, desgaste e RCF (Fonte: MAGEL et al., 2004).

A fim de avaliar os efeitos da manutenção sobre a confiabilidade dos trilhos, é necessário considerar o seu efeito combinado sobre o sistema. Como descrito acima, o esmerilhamento afeta a confiabilidade do trilho. No entanto, para realizar uma análise 
eficaz da confiabilidade, os efeitos combinados de outras condições de manutenção, por exemplo, lubrificação, substituições de componentes, etc, devem ser levados em conta.

Por exemplo, a lubrificação reduz o desgaste do trilho, especialmente nas curvas da via, e, assim, aumenta a confiabilidade do trilho. No entanto, ao mesmo tempo, a lubrificação é um fator incrementador de defeitos de RCF, que são removidos por esmerilhamento. A fim de cumprir os objetivos acima referidos, a análise de confiabilidade, disponibilidade, manutenibilidade e segurança irá desempenhar um papel importante no planejamento de manutenção.

\subsubsection{Análise de confiabilidade, disponibilidade, manutenibilidade e segurança para a Manutenção}

A análise de confiabilidade, disponibilidade, manutenibilidade e segurança é um processo que utiliza a informação de falha de um sistema, a fim de desenvolver as distribuições de probabilidade do sistema para efetuar a sua análise funcional. A análise de confiabilidade, disponibilidade, manutenibilidade e segurança destinada à via permanente baseia-se nos seguintes elementos:

- Banco de dados com informações sobre confiabilidade, disponibilidade, manutenabilidade e segurança do sistema;

- Modos de falha;

- Métodos e ferramentas para análise da confiabilidade, disponibilidade, manutenabilidade e segurança do sistema.

A utilização da falha e dados de manutenção são fatores importantes na análise de confiabilidade, disponibilidade, manutenibilidade e segurança e na gestão do sistema. Há várias dimensões com relação à coleta de dados de análise de confiabilidade, disponibilidade, manutenibilidade e segurança. Deve-se verificar que os dados estão sendo coletados de maneira a atender todos os tipos de análise de confiabilidade, disponibilidade, manutenibilidade e segurança necessárias para o sistema. Outro aspecto importante é que os dados devem englobar todo o ciclo de vida do sistema e, mais importante ainda, a fase de manutenção. A Figura 3.11 mostra o uso de uma base de dados de confiabilidade, disponibilidade, manutenibilidade e segurança como fonte de dados 
para a análise da confiabilidade, disponibilidade, manutenibilidade e segurança, para a fase de operação e manutenção do ciclo de vida do sistema.

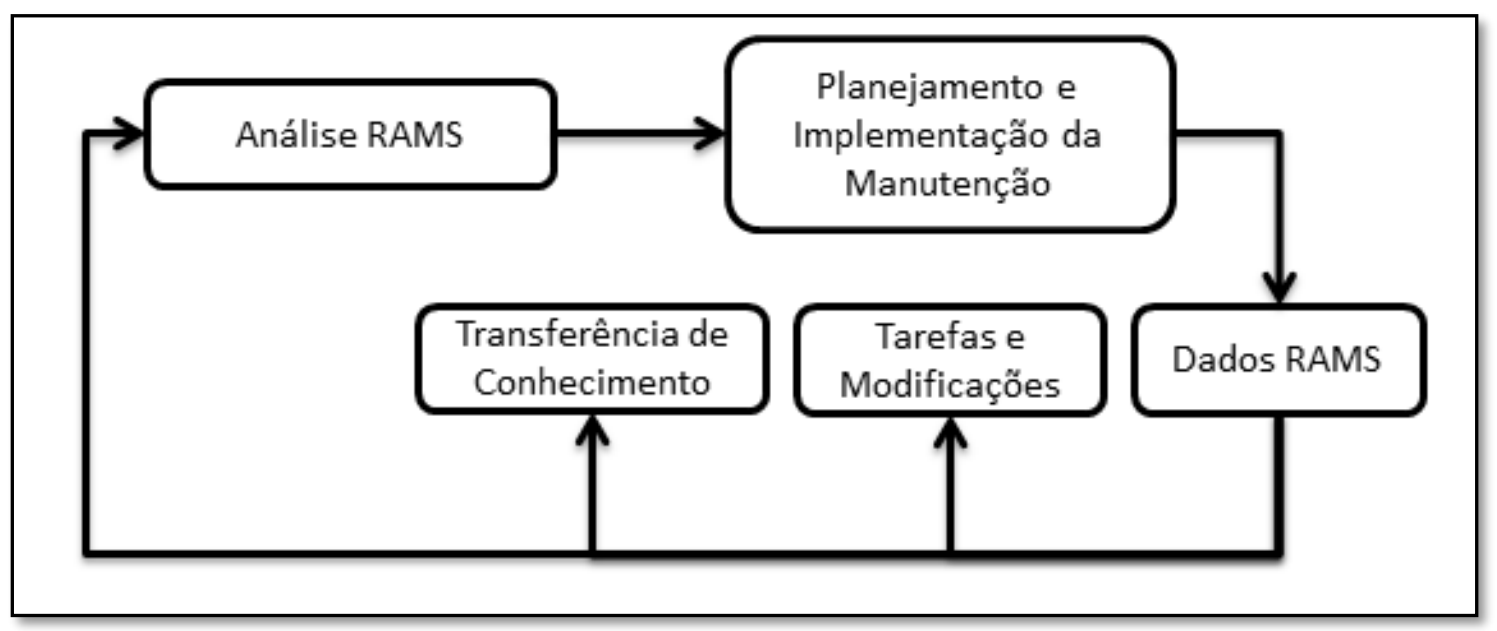

Figura 3.13 - Processo retroalimentado mostrando a utilização dos dados RAMS em análise RAMS (Fonte: adaptado de Esveld, 2001)

Para uma análise de confiabilidade, disponibilidade, manutenibilidade e segurança efetiva, os bancos de dados de tráfego e geometria da via devem ser considerados juntamente com as bases de dados de falhas e manutenção, como mencionado acima. Portanto, a via tem de ser dividida em segmentos de análise homogéneos no que diz respeito a curvas, qualidade, superelevação, a densidade do tráfego, etc Os dados a seguir também são uma parte da base de dados de confiabilidade, disponibilidade, manutenibilidade e segurança, juntamente com os dados de falha (ESVELD, 2001).

a) Perfil da Via e Dados Operacionais

i) Curvas (início e fim da km, curvas de transição, raio, etc...);

ii) Cargas (carga anual - milhões de toneladas brutas transportadas - MTBT, carga máxima por eixo, data a partir da qual os dados são válidos, etc...);

iii) Velocidades (perfil de velocidade dos trechos, data a partir da qual a velocidade é válida, etc...);

iv) Rampas (início, fim e valor).

Nota: MTBT é a soma de todas as cargas aplicadas na via, pelo material rodante, em um período, geralmente um ano. Ela é calculada com base na carga por eixo 
multiplicado pelo número de viagens ocorrido no período em que se deseja verificar a carga acumulada. Também é uma referência utilizada para estimar o tempo de vida de equipamentos de via. Por exemplo, um jacaré pode ter a vida estimada em 140 MTBT.

b) Infraestrutura

i) Subleito (condições geológicas, diversos parâmetros monitorados, etc...);

ii) Lastro (tipo de lastro, data de instalação, espessura de lastro, etc...);

iii) Dormentes (tipo de leito da via, espaçamento dos dormentes, data de instalação dos dormentes, o tipo de fixação e data de instalação);

iv) Trilhos (tipo do trilho, tipo de união, tipo de solda, data de instalação, histórico de instalação dos trilhos, tonelagem acumulada nos trilhos).

c) Histórico de Trabalho

i) Renovações, esmerilhamento e socaria (início e fim da km, tipo);

ii) Histórico das restrições de velocidade (data de início e fim das restrições temporárias da velocidade e taxa de redução da velocidade);

iii) Histórico de manutenção do trecho (tipo e data).

É comum que as ferrovias tenham sistemas independentes para cada uma das fases da análise de confiabilidade, disponibilidade, manutenibilidade e segurança. Assim, há a necessidade de integrar as diferentes bases de dados para uma análise de confiabilidade, disponibilidade, manutenibilidade e segurança eficiente e para o adequado planejamento de manutenção. Em um estudo abrangente, é necessário investigar o efeito de degradação e da falha na via nos outros sistemas de infraestrutura ferroviária, por exemplo, os sistemas de sinalização. É evidente que para alcançar a meta de disponibilidade da infraestrutura ferroviária em geral, é preciso garantir a disponibilidade de todos os sistemas que fazem parte da infraestrutura. 


\subsubsection{Confiabilidade, Disponibilidade, Manutenibilidade e Segurança na Fase de Operação e Manutenção do Sistema}

O ciclo de vida do sistema é uma sequência de fases, cada uma contendo tarefas, abrangendo a vida total de um sistema desde a sua conceituação até a eliminação. 0 ciclo de vida fornece uma estrutura para planejamento, gestão, controle e monitoramento de todos os aspectos de um sistema, incluindo a análise de confiabilidade, disponibilidade, manutenibilidade e segurança. Assim, o sistema avança pelas fases, a fim de entregar o produto certo ao preço certo dentro dos prazos acordados.

Um ciclo de vida do sistema que é adequado no contexto da operação ferroviária é mostrado na Figura 3.12. O ramo de cima para baixo (na lateral esquerda) é geralmente chamado de projeto e desenvolvimento e é um processo de aprimoramento contínuo que termina com a fabricação de componentes do sistema. Já o ramo de baixo para cima (do lado direito) está relacionado com a montagem, instalação, comissionamento e, em seguida, a operação de todo o sistema.

A representação "V" pressupõe que as atividades de comissionamento estão intrinsecamente ligadas às atividades de projeto e desenvolvimento. Isto é fato, na medida em que o inicialmente concebido tem que ser verificado em relação aos requisitos. Portanto, as atividades de validação para o comissionamento em várias fases de um sistema são baseadas na especificação do sistema e devem ser planejadas nas fases anteriores, ou seja, começando nas fases de concepção e desenvolvimento correspondentes do ciclo de vida. 


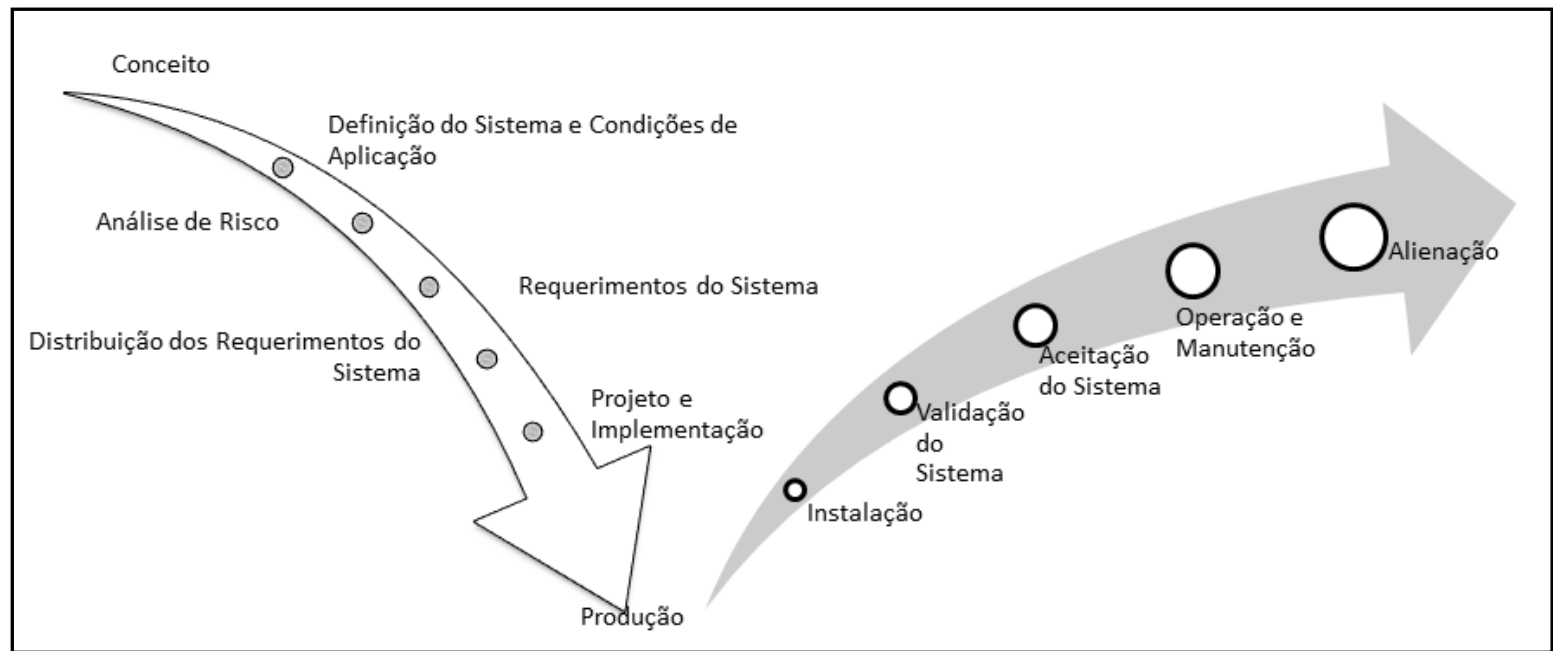

Figura 3.14 - Representação do ciclo de vida de confiabilidade, disponibilidade, manutenibilidade e segurança (IEC 62278, 2002).

A Figura 3.13 ilustra o processo de análise dos parâmetros para a infraestrutura ferroviária na fase de operação e manutenção do ciclo de vida do sistema. É um processo de melhoria contínua em toda a operação e manutenção do sistema. As fontes de falhas são devidas ao próprio sistema, as atividades de operação de trem ou de manutenção indevida realizada na via.

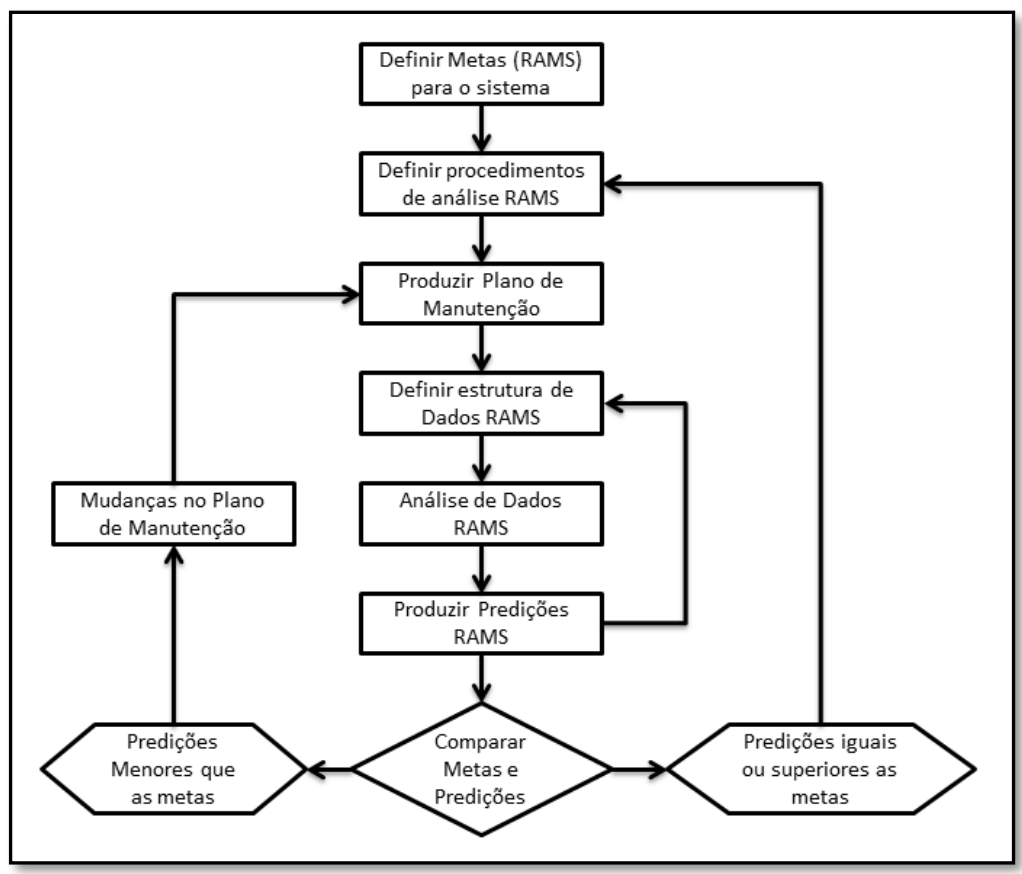

Figura 3.15 - Processo RAMS na fase de operação e manutenção de um sistema (Fonte: Adaptado de Joanovic, 2006) 
O objetivo básico na fase de operação e manutenção é monitorar os parâmetros de controle, a fim de cumprir as metas estabelecidas para a infraestrutura. Os indicadores de desempenho para verificar os objetivos são os parâmetros de controle. Se as metas não forem cumpridas os procedimentos de manutenção são alterados a fim de cumprir as metas. Se as condições estabelecidas de operação do sistema mudarem durante a fase de operação e manutenção, mudanças nos procedimentos de manutenção são necessárias para atender às metas estabelecidas com a análise dos parâmetros.

A análise RAMS da infraestrutura não deve ser realizada sem considerar as características operacionais do material rodante. Para que se tenha uma medida realista da disponibilidade da infraestrutura, é necessário considerar a demanda operacional.

A disponibilidade é a probabilidade de que um sistema estará em um estado de funcionamento sob uma determinada demanda (KUMAR; AKERSTEN, 2008). No caso da via, a disponibilidade é definida como uma unidade de comprimento da via disponível quando os trens utilizam-se do sistema. Para alcançar a disponibilidade da secção de via, devem ser consideradas as seguintes medidas:

- A manutenção corretiva via deve ser reduzida. Como as falhas podem ocorrer ao acaso, quanto menor o número de falhas, maior é a disponibilidade;

- Todas as ações preventivas de manutenção e renovação na pista devem ser realizadas nos períodos disponíveis para a manutenção;

- Os planos de manutenção da via precisam considerar esta janela de manutenção para obter o máximo de todas as ações de manutenção.

\subsubsection{Tornando a Manutenção Melhor}

Como a infraestrutura ferroviária é um ativo de alto custo, com uma vida útil longa, deve ser garantida a relação entre o custo e a eficácia das decisões de projeto e de manutenção de longo prazo.

A Figura 3.14 representa o custo do ciclo de vida (LCC) baseado nos requisitos da infraestrutura, que por sua vez são baseados em um cenário operacional específico. As 
restrições de orçamento e da política de manutenção desempenham um papel importante na escolha das estratégias alternativas de manutenção. A Figura 3.14 mostra como a análise dos parâmetros de manutenção afeta o custo do ciclo de vida em vários estágios.

A estratégia de manutenção com o menor custo no ciclo de vida é considerada como a solução de baixo custo para ser utilizada nas tarefas de manutenção da via permanente. A estratégia de manutenção pode ser uma ação de manutenção simples (por exemplo, esmerilhamento) ou um conjunto de ações de manutenção. Para uma decisão eficaz sobre qual a estratégia de manutenção, é importante ter em conta o conjunto de ações de manutenção para os cálculos do custo do ciclo de vida, e como as ações de manutenção são relacionadas e dependentes.

Ao considerar a estratégia de manutenção com o menor custo do ciclo de vida, como a solução de baixo custo, é importante considerar os índices na análise dos parâmetros de manutenção associados a essa estratégia de manutenção particular. Portanto, ao não considerar a estratégia de manutenção com o menor custo do ciclo de vida como a melhor solução, uma compensação entre os objetivos estabelecidos pelos parâmetrois de manutenção e o valor do custo do ciclo de vida é necessário a fim de alcançar uma estratégia de manutenção efetiva.

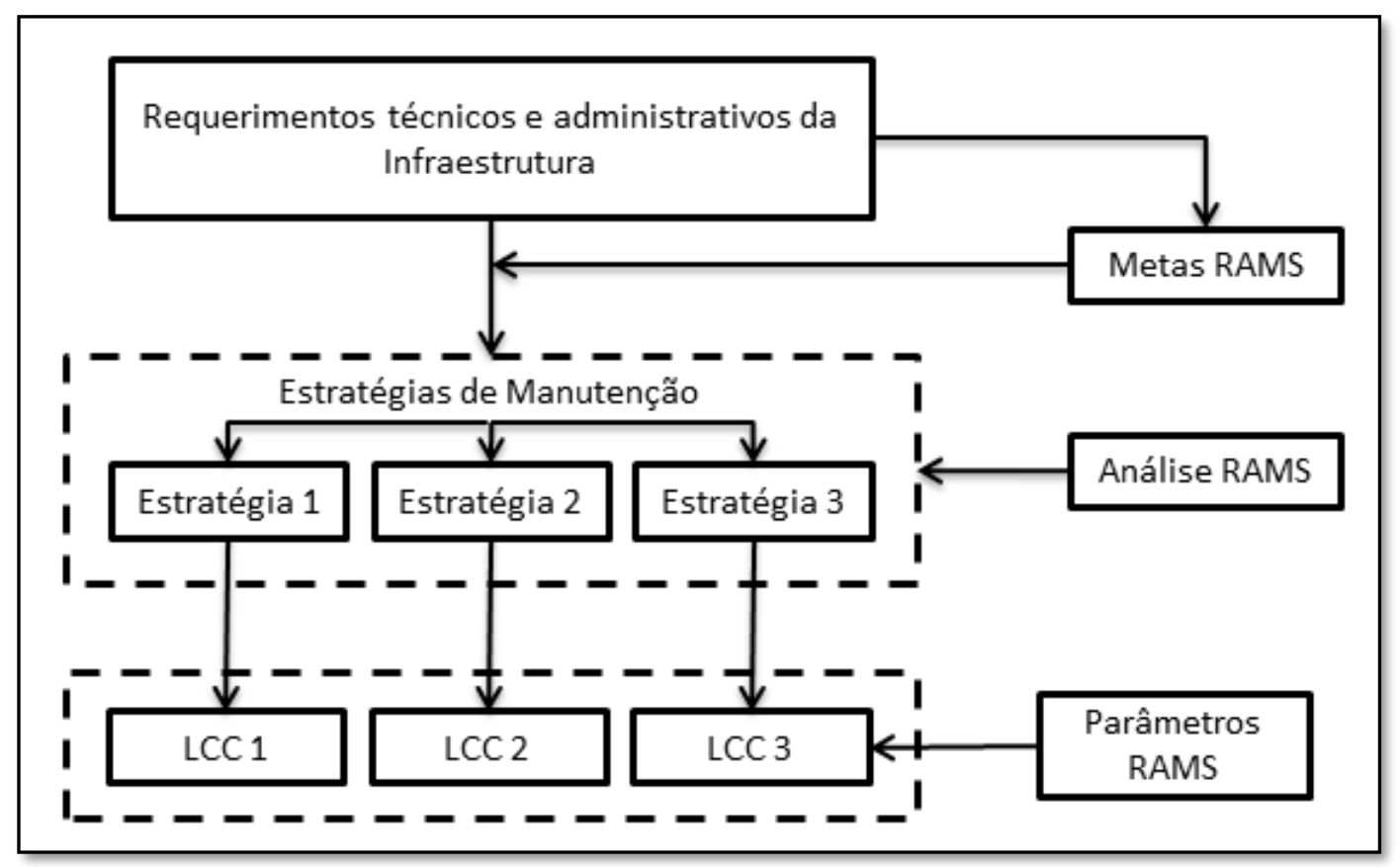

Figura 3.16 - Decisões de manutenção baseadas em custo do ciclo de vida (Adaptado de Joanovic, 2006) 


\subsection{Análise do Custo do Ciclo de Vida}

0 aumento dos requisitos de eficiência e eficácia promove um ambiente em mudança para a gestão da infraestrutura. Para garantir os melhores resultados em longo prazo para os sistemas metroferroviários, os efeitos das decisões devem ser avaliados sistematicamente (ZOETEMAN, 2001a).

\subsubsection{Fatores de Desempenho}

Os três parâmetros que influenciam o desempenho da infraestrutura da via são (PUTALLAZ; RIVIER, 2003): a capacidade, conteúdo e qualidade, conforme Figura 3.15. A capacidade da infraestrutura pode ser expressa em termos de traçados utilizáveis durante um determinado intervalo de tempo. 0 conteúdo da infraestrutura refere-se ao tempo de vida útil médio remanescente de seus componentes. Finalmente, a qualidade da infraestrutura representa a qualidade da geometria e de componentes da via. 0 gerenciamento da infraestrutura resume-se a definição desses três parâmetros no seu nível mais adequado, a fim de maximizar a eficiência. Ajustes podem, e devem ser feitos para que a capacidade seja atingida através de uma política de investimento, o conteúdo seja alcançado através de uma política de renovação, e a qualidade através de uma política de manutenção.

Estes três parâmetros não podem ser ajustados de forma independente. Uma infraestrutura antiga (baixo conteúdo) exige mais manutenção (para aumentar a qualidade), ao passo que uma via com geometria inadequada (baixa qualidade) aumenta o desgaste da infraestrutura. Da mesma forma, mais intervenções (manutenção e renovação) exigem posses da via (menos capacidade), enquanto que mais tráfego (alta capacidade) induz desgaste da infraestrutura. 


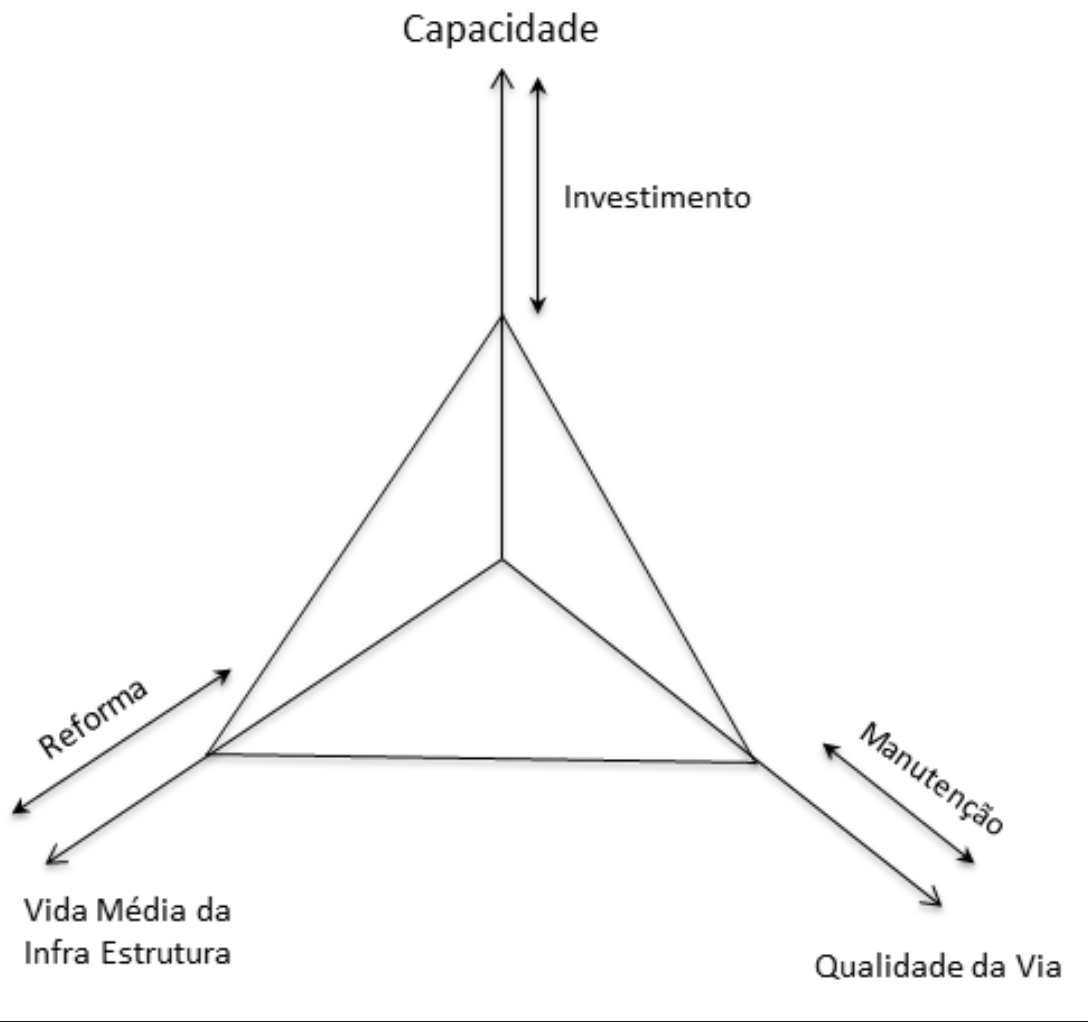

Figura 3.17 - Os três parâmetros básicos de uma infraestrutura que influenciam o desempenho (Putallaz, 2003).

Os fatores que influenciam o desempenho da infraestrutura, e seus relacionamentos, precisam ser identificados a fim de serem capazes de estimar os custos do ciclo de vida da infraestrutura. 0 fator determinante causador de falhas e a consequente manutenção é a degradação do ativo. A degradação da via depende de muitos fatores, tais como a qualidade inicial da construção, a qualidade da superestrutura e as cargas sob as quais a via está imposta.

Além da degradação de ativos, há outros fatores que também influenciam o custo de ciclo de vida, tais como os parâmetros de manutenção para a via, a quantidade de manutenção preventiva, o custo da mão de obra, materiais e máquinas, bem como as características operacionais da linha. 0 gerente de infraestrutura pode controlar alguns desses fatores diretamente (por exemplo, a estratégia de manutenção), ou com cooperação dos usuários da via (por exemplo, a qualidade do material rodante) e do governo (por exemplo, subsídios negociados) (ZOETEMAN, 2001a). 
O desempenho da infraestrutura é influenciado por fatores como o nível de segurança, conforto do usuário, ruído, as vibrações, a confiabilidade, disponibilidade e os custos de propriedade (ver Figura 3.16). As normas de segurança e ruído influenciam indiretamente os custos do ciclo de vida, uma vez que determinam as tolerâncias e os limites para os parâmetros de projeto e de manutenção. 0 projeto físico influencia a degradação de ativos, juntamente com outras condições, tais como a intensidade de tráfego, carga por eixo, a qualidade da infraestrutura e a eficácia da manutenção realizada. A qualidade geométrica da via determina o volume necessário de manutenção e de renovação, assim como a escolha da estratégia de manutenção.

\subsubsection{Estratégia de Atuação}

A estratégia de manutenção também tem um impacto direto sobre o custo do ciclo de vida. Os modelos de custos utilizados nos sistemas de apoio à decisão e sistemas de gestão de manutenção devem ser capazes de fornecer os meios para avaliar e comparar os custos e benefícios de diferentes estratégias e opções de manutenção. A fim de realizar uma análise econômica, é necessário fazer ajustes nos custos para garantir que eles são medidos nas mesmas unidades e representam custos reais (LARSSON, 2004). 0 custo do ciclo de vida pode ser apresentado de três formas: i) o valor presente total (TPV), ii) a taxa interna de retorno (TIR), e iii) o equivalente ou renda anual (ANN ) (ZOETEMAN, 2001a). 


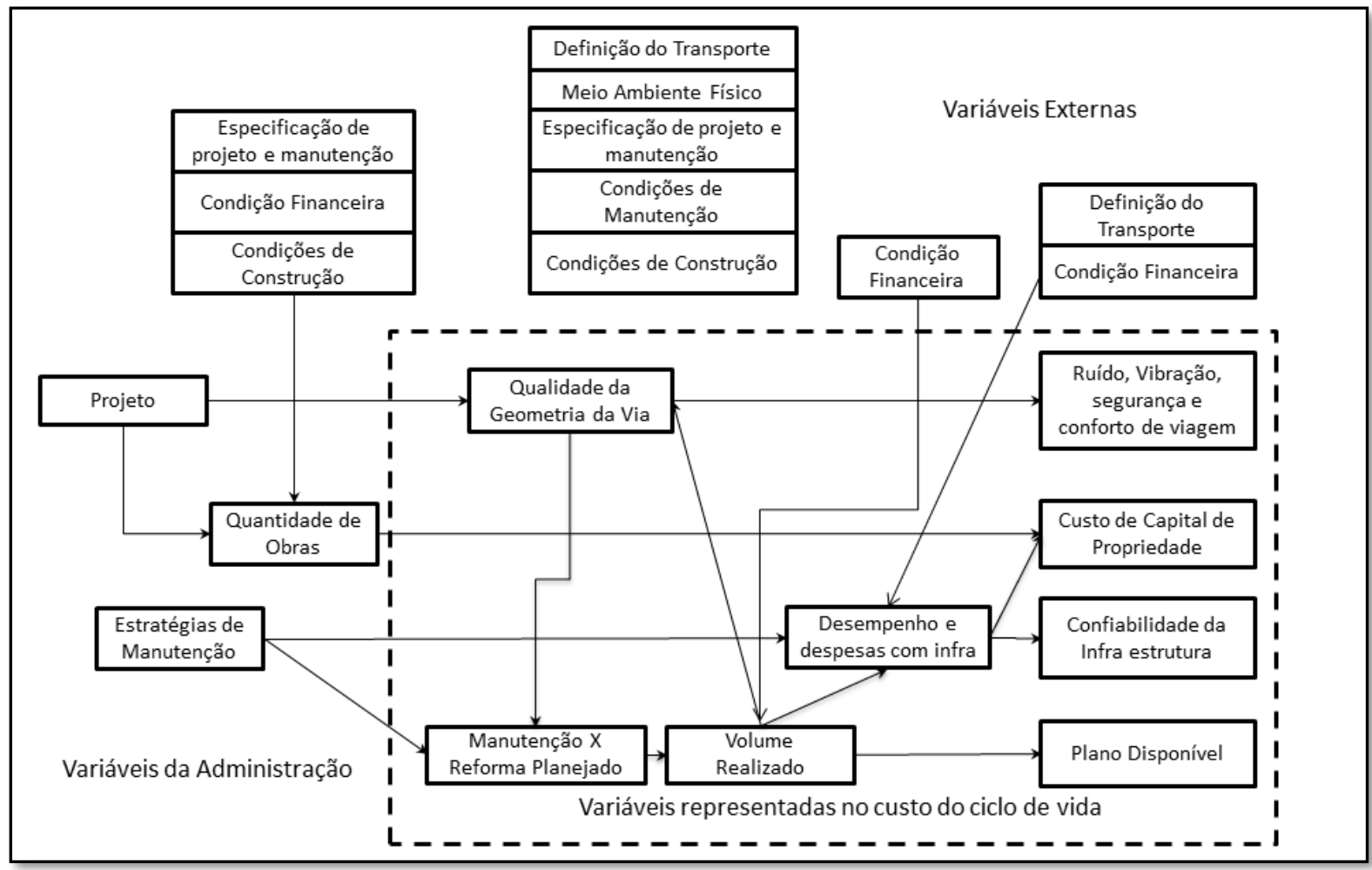

Figura 3.18 - Fatores que influenciam o desemepnho da infraestrutura de via (Zoeteman, 2001).

O custo do ciclo de vida da infraestrutura depende, principalmente, de dois aspectos: a configuração da rede e a complexidade de utilização da rede. Complexidade é um parâmetro predominante para o investimento e custos de manutenção.

Além deste aspecto outros devem ser considerados no custo do ciclo de vida, como curvatura, carga por eixo e velocidade média.

A utilização de redes (por exemplo, o conjunto de vias do Metrô de Barcelona forma uma rede) tem um forte impacto sobre o custo de manutenção e sobre a vida técnica dos componentes até a substituição. Alguns dos principais indicadores são:

- Frequência média de trens por ano na rede;

- Tonelagem bruta média por ano na rede.

É difícil generalizar o custo do ciclo de vida por quilômetro de via devido à variabilidade em termos de complexidade e utilização. Algumas linhas da rede são mais carregadas que outras, e isto leva a maior quantidade de trens circulando e, em consequência, maior carga acumulada. 
A análise dos dados mostrou que os gastos de manutenção podem ser ajustados de acordo com as frequências de trem, em particular, por causa da forte correlação entre os tempos de acesso à via e os custos de manutenção. Despesas de renovação estão ajustadas de acordo com a tonelagem bruta, que tem um grande impacto sobre o desgaste da via.

\subsection{Gerenciamento da Manutenção}

A estratégia de gestão de ativos é a abordagem que faz uso da gestão da manutenção e do plano de manutenção para cada item do sistema. Esta estratégia determina o que é planejado e os trabalhos da manutenção programada que devem ser realizados, e considera os potenciais problemas que podem exigir uma resposta reativa não programada (KELLY, 2006). A estratégia de gestão de ativos deve ser entendida antes que a gestão da manutenção seja concluída. Isto permite vislumbrar o quanto da atividade de manutenção será necessária, o que será realizado, quais peças de reposição serão utilizadas, etc.

\subsubsection{Gestão de Manutenção na Via Permanente}

Os gestores tentam alcançar o sucesso e o equilíbrio na gestão de custos e qualidade. Isto é essencial porque os passageiros tornam-se cada vez mais exigentes quanto à qualidade apresentada e como ela é percebida. Portanto, os gestores buscam qualidade com o menor custo, sem que haja interferência nos parâmetros de segurança. O caminho para atingir este objetivo é através da gestão de manutenção adequada.

Os dados necessários para um Sistema de Gestão de Manutenção de Via podem ser exemplificados conforme listado abaixo (ESVELD, 2001):

- Mensurações;

- Planejamento;

- Infraestrutura;

- Inspeções; 
- O trabalho realizado;

- Custos.

No entanto, as dificuldades de antecipação exata da manutenção a ser realizada levam a um planejamento de manutenção que não é preciso. Além disso, o montante do financiamento atribuído para o trabalho de manutenção varia de um grau muito alto, para a alta administração, para um grau muito baixo par as equipes de manutenção e operação. Consequentemente, a seleção da estratégia de manutenção ideal passa a ser um desafio. Uma abordagem sistemática para a determinação da deterioração de componentes da via é necessária para avaliar completamente o estado do sistema e componentes. Isso exige avaliações adequadas das condições da via, o estabelecimento de um sistema padronizado de avaliação da condição, assim como o desenvolvimento e atualização regular de modelos de previsão para os vários componentes da via.

Esveld (2001) discutiu a ideia de gestão racional para a infraestrutura. Esta gestão visa à avaliação quantitativa e qualitativa de maneira objetiva, após o qual, com base nos objetivos do sistema, em regras e normas, possam ser tomadas decisões sobre a manutenção e renovação da infraestrutura. Esta ideia é resumida da seguinte forma:

- Ser menos dependente do know-how individual;

- Criar condições de trabalho ideais com a economia empresarial disponível;

- Assumir a responsabilidade e relatar à gestão.

Portanto, um sistema de gestão de manutenção eficaz requer a gestão dos parâmetros de manutenção e custo do ciclo de vida integrados ao gerenciamento de ativos do sistema. Assim, a efetividade de um sistema é a sua capacidade de realizar um trabalho para o qual foi destinado. A efetividade pode ser definida como uma função da disponibilidade operacional do sistema, a confiabilidade operacional e capacidade (BEN-DAYA, 2009). Os termos são explicados: 
- A disponibilidade operacional da infraestrutura é definida como a probabilidade de que a infraestrutura será operacionalmente disponível durante o tráfego de trens.

- A segurança operacional é a probabilidade de que, durante a operação de tráfego de trens, a infraestrutura não sofrerá quaisquer falhas.

- Capacidade é a capacidade da infraestrutura para atender seus objetivos necessários.

A eficácia do sistema pode ser definida como:

Eficácia = disponibilidade operacional * segurança operacional * capacidade

Quanto maior for essa eficácia do sistema, melhor será a infraestrutura, para que seja possível alcançar os seus objetivos.

A Figura 3.17 ilustra a relação entre gestão de manutenção, desempenho de ativos e manutenção de ativos. A gestão de ativos da via diz respeito a dois aspectos importantes, ou seja, o desempenho dos ativos e a manutenção de ativos. A eficácia do sistema e o custo efetivo atuam como indicadores para o desempenho de ativos. A manutenção dos ativos diz respeito às atividades que vão desde ações de manutenção de pequena escala até a construção de uma nova infraestrutura. 


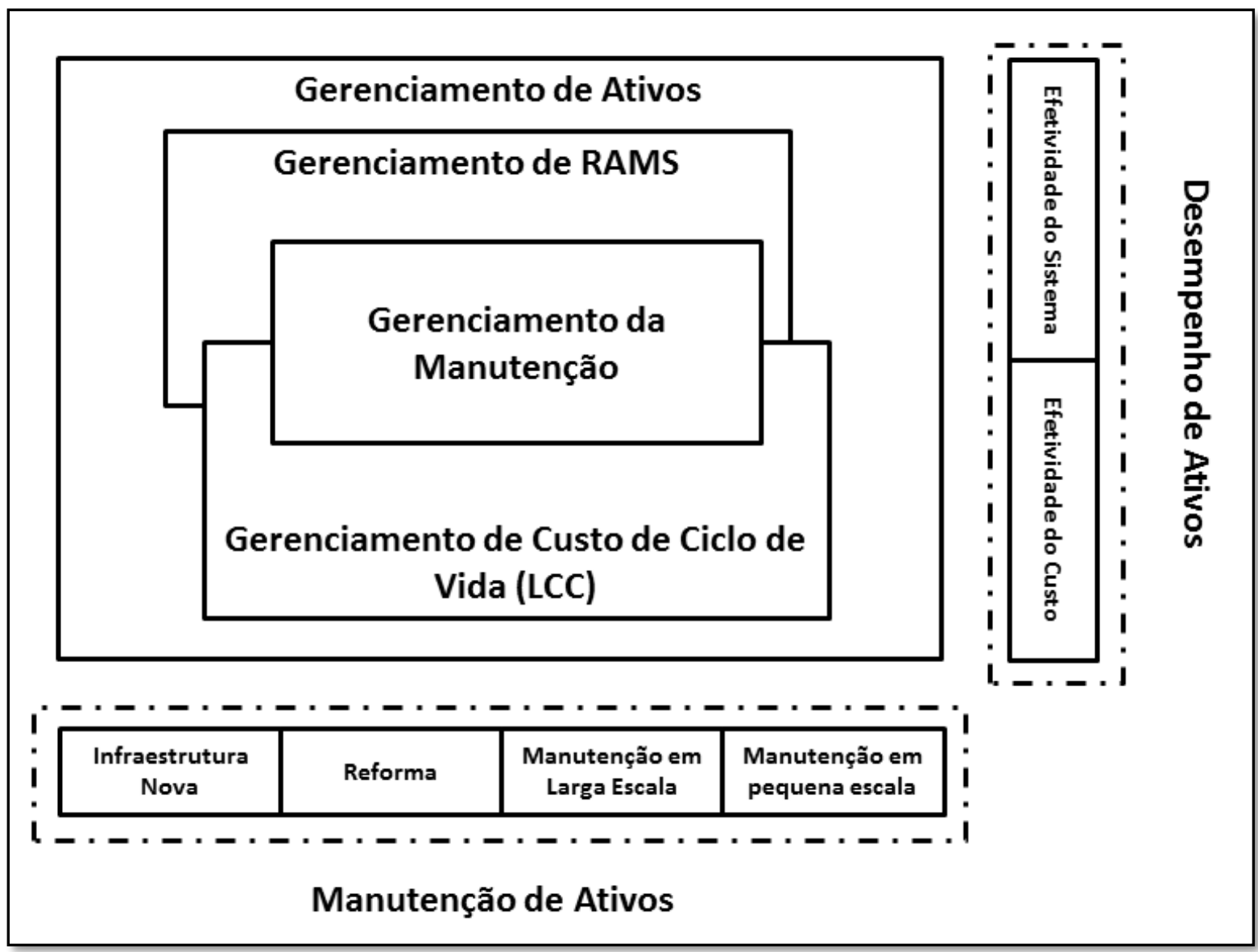

Figura 3.19 - Fatores de influência no gerenciamento da manutenção (Fonte: adaptado de Zoeteman, 2001).

Há uma estreita relação entre a manutenção de ativos e desempenho de ativos. Assim como a manutenção eficaz dos ativos aumenta o desempenho, o desempenho dos ativos atua como uma ferramenta de decisão para a manutenção. 


\section{ESTRUTURA DE UM SISTEMA DE GERÊNCIA DE PAVIMENTOS}

\subsection{Engenharia de sistemas}

\subsubsection{Princípios}

A engenharia de sistemas é uma tecnologia de gestão. A tecnologia é a organização, aplicação e entrega de conhecimento científico e de outras formas de conhecimento para a melhoria de um dado grupo. Esta é uma definição funcional da tecnologia como sendo uma atividade fundamentalmente humana. A tecnologia envolve uma extensão de um ou mais processos naturais humanos. Por exemplo, o computador digital é uma tecnologia em que se aumenta a capacidade de um ser humano para executar os cálculos e, em formas mais avançada, para processar a informação.

A gestão envolve a interação da organização com o ambiente. A finalidade da administração é permitir que as organizações interajam melhor com seus ambientes, de modo a atingir metas e objetivos. Consequentemente, uma tecnologia de gestão envolve a interação de tecnologia com as organizações, que são seres humanos envolvidos tanto com a evolução como com a utilização de tecnologias, e com o ambiente. A Figura 4.1 ilustra estas interações conceptuais. 


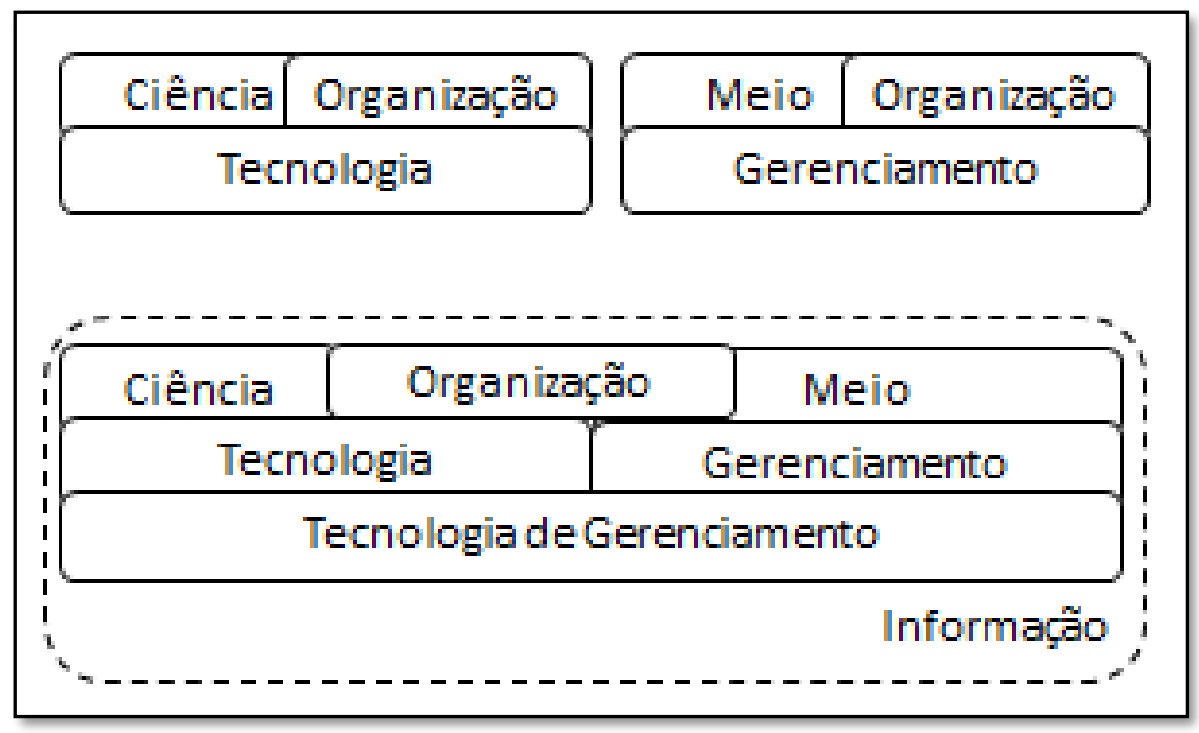

Figura 4.1 - Interações conceituais (Fonte: o autor)

Informação é o meio que permite as interações mostradas nesta figura. A informação é uma porção importante que se assume disponível para a tecnologia de gestão, a engenharia de sistemas. Estas noções iniciais de engenharia de sistemas, junto com as de direção técnica e com os sistemas de gestão de desenvolvimento tecnológico, são as que levam ao sucesso de um projeto de engenharia de sistemas. Sugere-se a seguinte definição: "a engenharia de sistemas é a tecnologia de gestão que controla o processo de ciclo de vida de um sistema. Isto resulta na definição, desenvolvimento e implantação de um sistema que é de alta qualidade, confiável e de custo eficaz no atendimento às necessidades do usuário" (SAGE; ARMSTRONG, 2000).

\subsubsection{Engenharia de sistemas: orientação ao processo}

Esta noção de orientação ao processo de engenharia de sistemas e gestão de sistemas é apresentada aqui. A Figura 4.2 ilustra a visão do conhecimento de engenharia de sistemas, que compreende o seguinte:

- Princípios do conhecimento, que geralmente representam a abordagem formal do conhecimento na solução de problemas, geralmente utilizado em situações novas, ou em ambientes não estruturados; 
- Práticas de conhecimento, que representam a sabedoria e experiências acumuladas que levaram ao desenvolvimento de políticas operacionais regulamentadas para problemas bem estruturados;

- Perspectivas de conhecimento, que representam o ponto de vista em relação às direções e realidades futuras na área tecnológica em estudo.

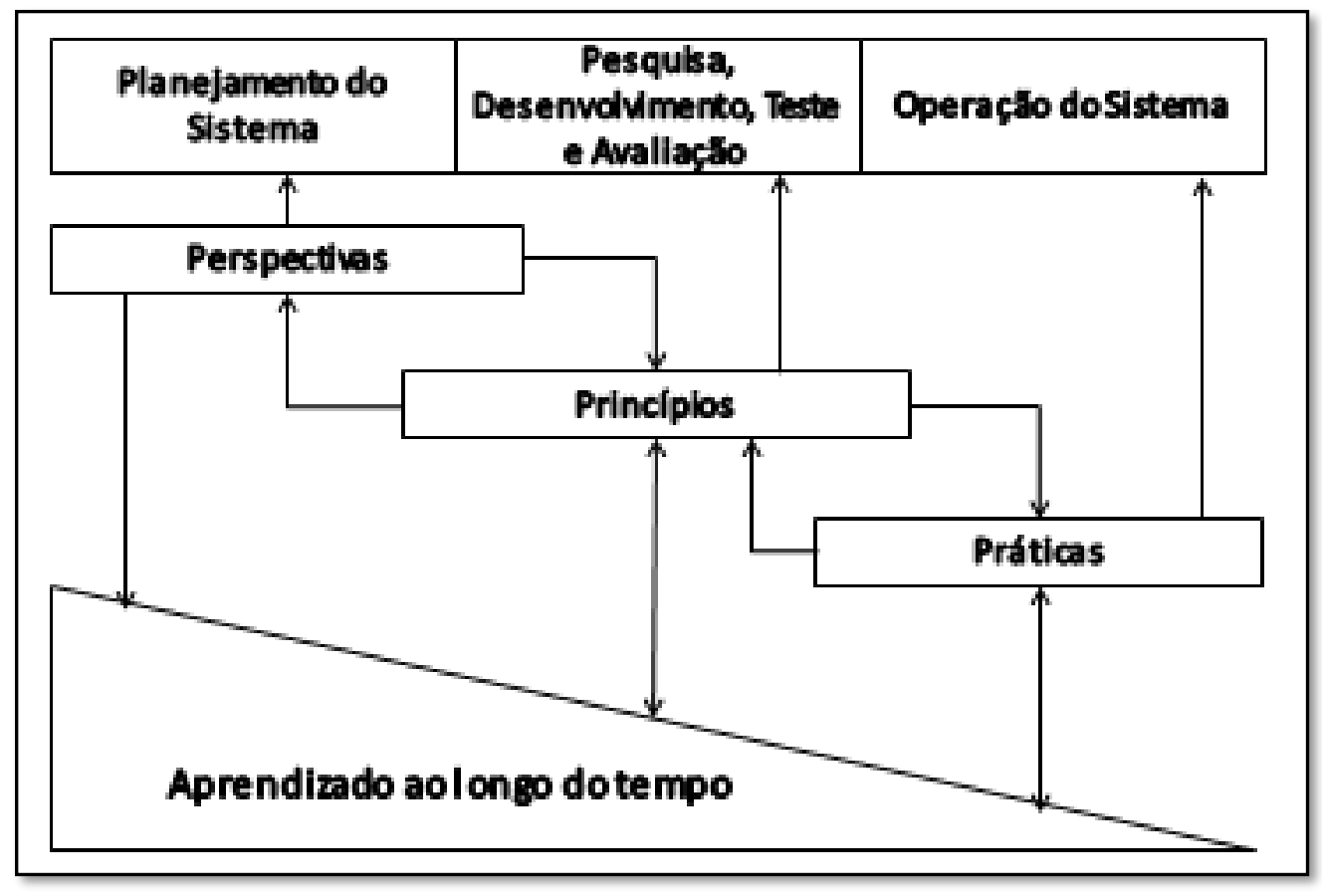

Figura 4.2 - Engenharia de Sistemas - Visão (Fonte: o autor).

Claramente, uma forma de conhecimento leva a outra. Perspectivas de conhecimento podem criar o incentivo à pesquisa, que leva à descoberta de novos princípios. Como princípios de conhecimento emergem e são refinados, eles geralmente são incorporados na forma de práticas de conhecimento.

As práticas de conhecimento são, geralmente, a principal influência dos sistemas que podem ser adquiridos. Estes tipos de conhecimento interagem entre si, tal como sugerido na Figura 4.2, que ilustra a forma de como estes tipos de conhecimento fornecem suporte um ao outro. De uma forma não exclusiva, cada um suporta um dos principais ciclos de vida associados à engenharia de sistemas. 
A Figura 4.2 ilustra também uma série de retroalimentações que estão associadas com a aprendizagem para permitir a melhoria contínua do desempenho ao longo do tempo. Isso apoia a visão, e uma premissa maior deste texto, que é um grave erro considerar esses ciclos de vida isoladamente.

O uso do termo conhecimento é proposital. Ele tem sido considerado essencial para a engenharia e gestão de sistemas para distinguir dados e informações. A informação é geralmente definida como dados que são importantes para a tomada de decisão. Para obter as informações a serem utilizadas com sucesso no processo de tomada de decisão, é necessário associar o contexto e ambiente. As informações resultantes, realçadas pelo contexto e ambiente, resultam em conhecimento. A gestão adequada da informação e do conhecimento é necessária para engenharia e gestão de sistemas de alta qualidade.

Com base no uso apropriado dos três tipos de conhecimento representados na Figura 4.2, é possível realizar o planejamento tecnológico e desenvolvimento de sistemas, e o planejamento e desenvolvimento do sistema de gestão, que levam a um novo produto ou serviço. São necessários os três tipos de conhecimento. 0 ambiente associado a este conhecimento precisa ser gerenciado, e isto é o que geralmente se pretende com o uso da gestão do conhecimento. Além disso, a aprendizagem que resulta desses esforços é necessária, tanto em uma base organizacional como individual.

Preocupações associadas com a definição, desenvolvimento e implantação de sistemas sempre foram abordadas, de modo que eles possam ser usados de maneira eficiente e eficaz. Muitas vezes, a prática da "tentativa e erro" tem sido a forma de alcançar este objetivo. Quando a escala ou escopo é grande, então, geralmente, não é possível para os engenheiros de sistemas agirem também como os usuários de sistemas, e é necessária uma abordagem mais formal (ROUSE; SAGE, 2009).

\subsubsection{A estrutura básica}

Os esforços na definição, desenvolvimento e implantação representam o nível de macroestrutura da engenharia de sistemas, como mostrado na Figura 4.3. Cada um deles precisa ser empregado para cada um dos três ciclos de vida ilustrados na Figura 4.2. E dentro de cada vida fase do ciclo, há uma série de passos, como ilustrado na Figura 4.4. 
Assim, vemos que a descrição relativamente simples de engenharia de sistemas cada vez mais complexa.

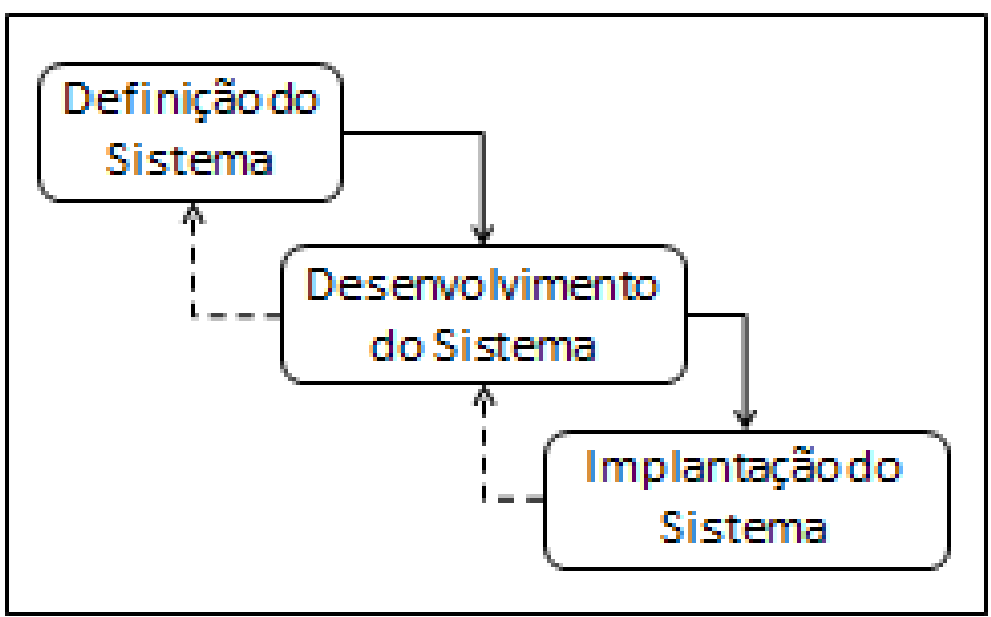

Figura 4.3 - Macroestrutura da Engenharia de Sistemas (Fonte: o autor).

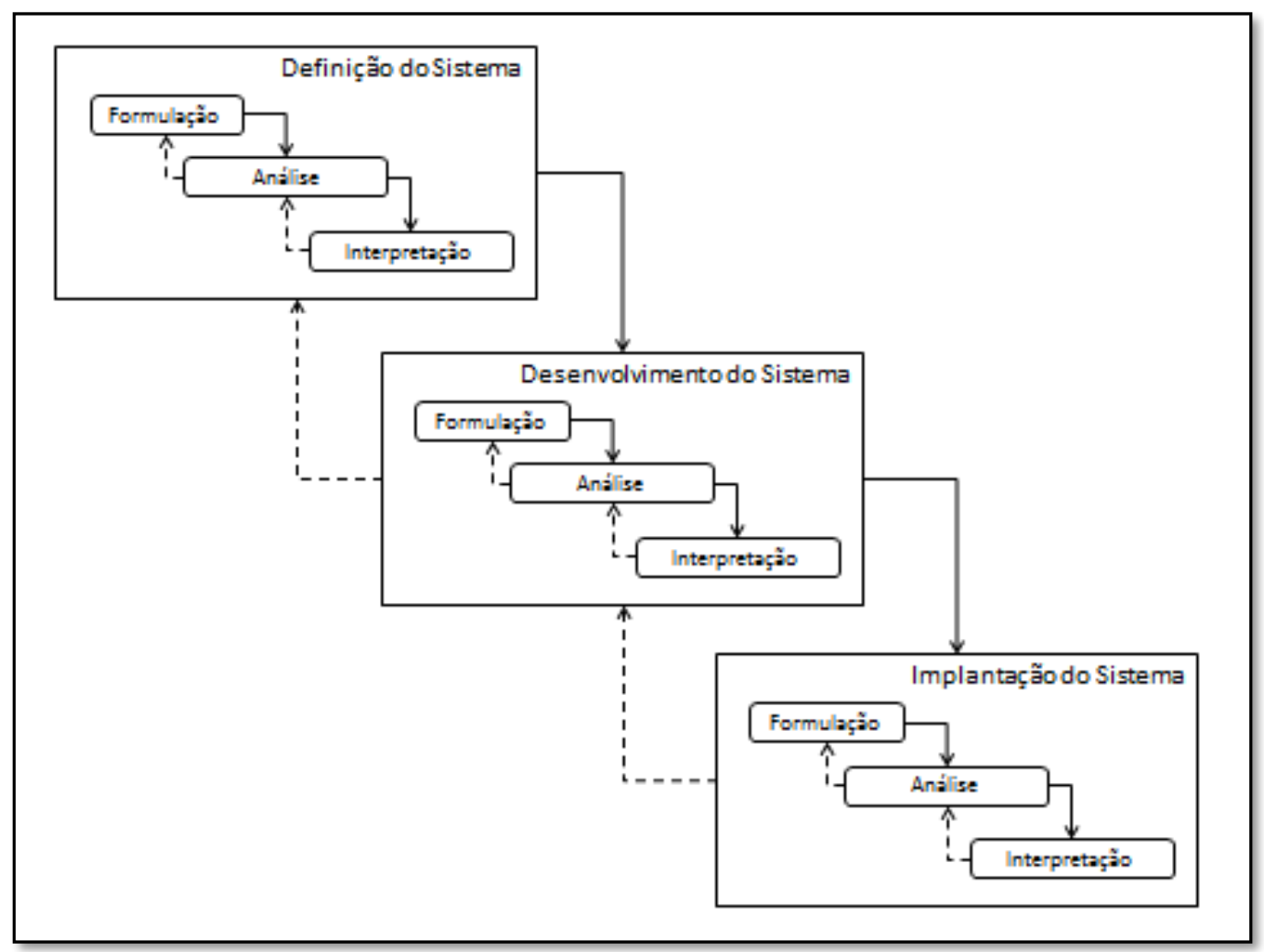

Figura 4.4 - Desdobramento das Fases da Engenharia de Sistemas (Fonte: adaptado de Blanchard; Fabrycky, 2010). 
Assim, os esforços contemporâneos em engenharia de sistemas tem um foco sobre o seguinte (BLANCHARD; FABRYCKY, 2010):

- Ferramentas, métodos e tecnologias para a engenharia de sistemas;

- Metodologia de sistemas para o processo de definição do ciclo de vida com métodos e tecnologias que permitam o uso apropriado destas ferramentas;

- Abordagens do gerenciamento de sistemas que permitem a incorporação adequada da engenharia de sistemas e evolução do processo dentro das organizações.

Desta forma, a gestão e engenharia de sistemas deve fornecer o apoio necessário para empreendimentos da engenharia convencional associados à aplicação dos princípios da física e ciência dos materiais para realizar o projeto detalhado e implantação de produtos em várias áreas de especialidade para o aperfeiçoamento da humanidade.

A Figura 4.5 ilustra essa relação conceitual entre os três níveis de engenharia de sistemas e mostra como os vários membros de uma equipe de engenharia de sistemas devem aplicar-se ao definir, desenvolver e implantar um sistema em evolução. Cada um desses três níveis de sistemas é necessariamente associado a ambientes adequados, a fim de assegurar um processo de engenharia de sistemas adequado, incluindo a interação com o cliente durante a definição do sistema. 0 uso de métodos e ferramentas adequados, bem como a metodologia de sistemas e estruturas de gerenciamento permite que a engenharia de sistemas seja eficiente e eficaz na interação humana.

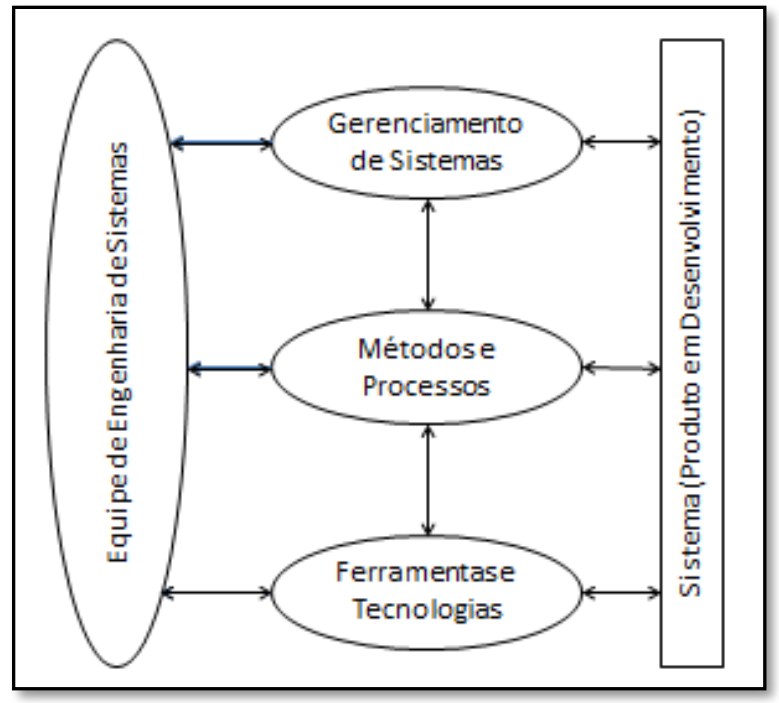

Figura 4.5 - Interação entre os três níveis da Engenharia de Sistemas (Fonte: adaptado de Blanchard; Fabrycky, 2010). 
O gerenciamento do sistema e a integração são importantes na determinação da eficácia, eficiência e funcionalidade geral de projetos de sistemas. Para atingir um elevado grau de funcionalidade, um sistema deve ser produzido, usado, mantido, retrabalhado e modificado durante todas as fases do ciclo de vida. Este ciclo de vida começa com a concepção e identificação, prossegue através de especificação dos requisitos do sistema e arquiteturas para a instalação do sistema final, execução operacional, implantação, avaliação e manutenção ao longo da vida produtiva. É importante notar que um sistema que é produzido por uma organização pode muito bem ser utilizado como um processo, ou para suportar um processo, por outro organismo.

Estudos indicam que há dificuldades associadas à produção de sistemas funcionais, confiáveis e sérios quando em grande escala e escopo expandido:

- É muito difícil identificar as necessidades dos utilizadores para um grande sistema;

- Sistemas grandes são caros;

- A capacidade do sistema é muitas vezes menor do que o prometido e esperado;

- As entregas do sistema são muitas vezes atrasadas;

- 0 excesso de custos em grandes sistemas ocorre frequentemente;

- A manutenção de grande sistema é complexa e sujeita a erros;

- A documentação de grande sistema é inadequada e insuficiente;

- Os grandes sistemas são muitas vezes complicados de usar e a interação humana é geralmente falha;

- Os novos subsistemas individuais muitas vezes não podem ser integrados com sistemas existentes;

- Os sistemas de grande porte geralmente não podem ser transferidos para um novo ambiente ou modificados para atender às crescentes necessidades dos clientes;

- Os riscos imprevistos muitas vezes se materializar;

- Pode não haver gestão de risco ou gestão de crises associadas com o uso de um sistema;

- Os sistemas de grande porte geralmente sofrem em termos de confiabilidade, disponibilidade e facilidade de manutenção;

- $\quad$ desempenho de grandes sistemas é muitas vezes de baixa qualidade; 
- Os sistemas de grande porte geralmente não são executados de acordo com as especificações;

- É difícil identificar métricas de desempenho adequadas para um grande sistema que permita a determinação do custo e eficácia do sistema;

- Muitas vezes há falta de comunicação entre a gestão do programa, os projetistas e os clientes ou patrocinadores do programa;

- $\quad$ sistema de especificações muitas vezes não capta adequadamente as necessidades e exigências do usuário;

- Os sistemas de grande podem perder a sustentabilidade ao longo do tempo;

- Sistemas de grande podem ser rejeitados pelos usuários como não adequados às suas necessidades.

\subsection{Estrutura geral de um sistema de gerência de pavimentos}

Como parte do desenvolvimento do sistema de gerência de pavimentos no nível do projeto, o processo de concepção foi estruturado e seus componentes foram identificados mais especificamente em 1965-1967, como mostrado na Figura 4.6. Esta versão detalhada foi simplificada na Figura 4.7 como um resumo da representação. Os componentes da Figura 4.6 são discutidos como se segue:

- Entradas. Entradas, incluindo diferentes variáveis, além de objetivos, devem ser confirmadas;

- Modelos. A necessidade de uma análise da alternativa foi identificada. Um modelo simples da resposta do pavimento mostra, por exemplo, como um gráfico simples não trata adequadamente os materiais de pavimentação;

- Comportamento - Perigos. A maioria dos modelos de pavimento calcula ou prevê o comportamento do pavimento, como estresse ou tensão. Diante da de previsão de resposta, se levado ao extremo o resultado será uma falha. Modelos de previsão para o pavimento, e, portanto, para trincas e outras falhas de pavimento, são essenciais;

- Desempenho - Função de Saída. Falhas acumuladas reduzem a manutenção do pavimento, e o histórico de manutenção define o desempenho do pavimento;

- Segurança. Resistência ao deslocamento e outras saídas de segurança são importantes; 
- Custos. Análise econômica do ciclo de vida é uma parte vital do processo de gestão de pavimento;

- Critérios de Decisão. São intimamente ligadas à economia. As decisões sobre as despesas admissíveis em relação aos benefícios resultantes são relacionadas a uma escolha particular. Esses fatores devem ser explicitamente definidos e considerados na análise;

- Comparar - Melhorar. Selecionar as alternativas ou a melhor estratégia é um passo importante no processo de tomada de decisão;

- Implantação. A construção das alternativas ou estratégias selecionadas e a manutenção periódica e reabilitação, quando necessário, constitui a implantação da solução.

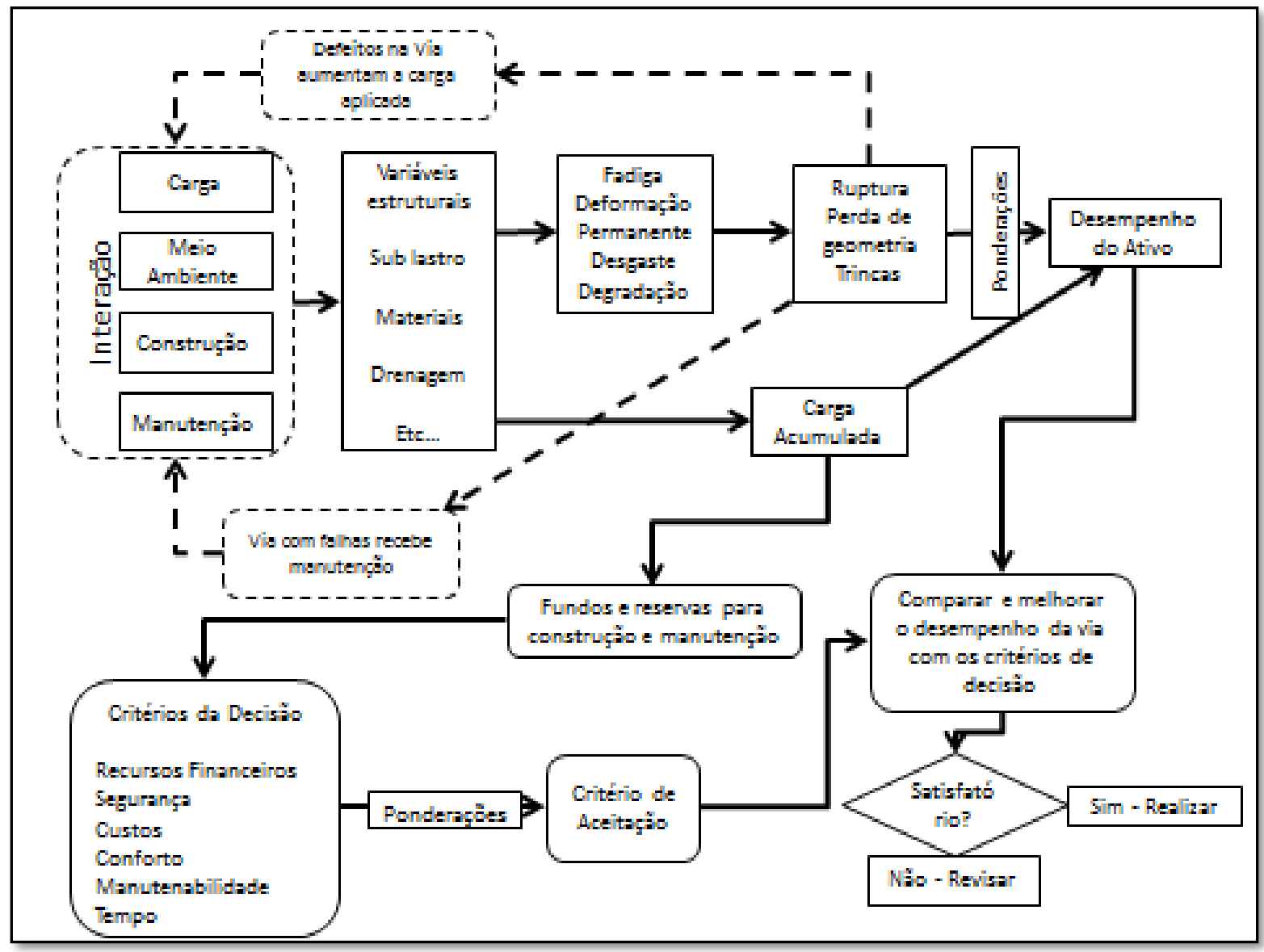

Figura 4.6 - Estrutura do Sistema de Gerência de Pavimentos(HAAS; HUDSON; ZANIEWSKI, 1994). 


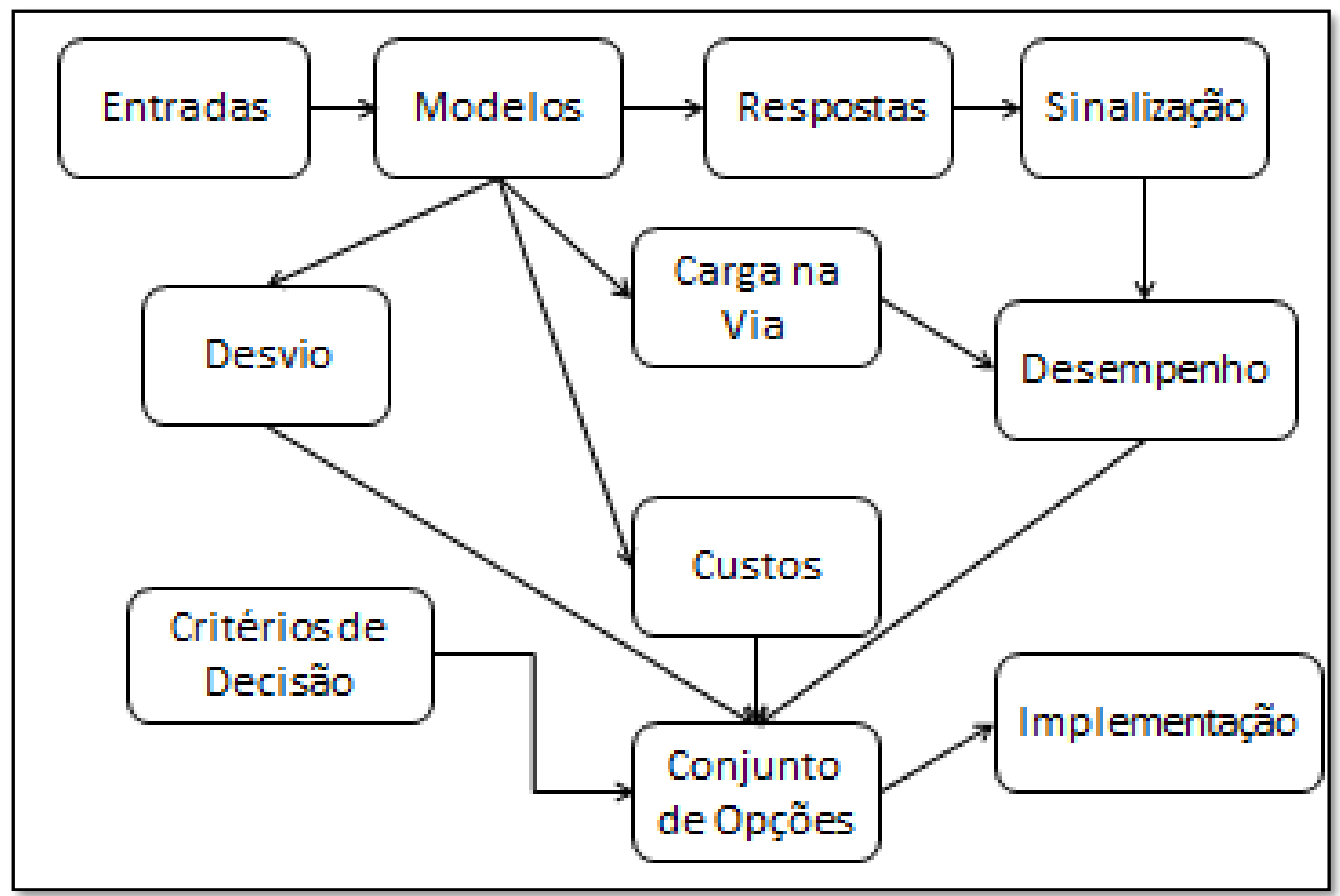

Figura 4.7 - Estrutura Simplificada do Sistema de Gerência de Pavimentos (Fonte: adaptado de Haas; Hudson; Zaniewski, 1994).

\subsubsection{Aplicando engenharia de sistemas ao comportamento do pavimento}

Um pavimento é uma estrutura complexa que é submetida a diferentes combinações de carga e a diversas condições ambientais. Somando-se a essa complexidade temos a caracterização do material, que não é homogêneo, variando o desempenho do pavimento e suas inter-relações. Devido a isso é necessário um quadro teórico, uma estrutura de requisitos aplicável ao problema geral de dimensionamento de pavimentos.

O exame das técnicas disponíveis para analisar tais relações complexas mostra que os conceitos de engenharia de sistemas (que são aplicados na eletrônica, comunicações e indústria aeroespacial) são apropriados para análise da estrutura dos pavimentos. 0 uso de engenharia de sistemas não leva, por si só, a uma solução nova e definitiva do problema de projeto de pavimento, mas fornece um meio de organizar os vários segmentos do 
problema em um quadro compreensível, utilizando uma estrutura de requisitos possível de ser seguida (HAAS; HUDSON; ZANIEWSKI, 1994).

Os aspectos científicos e de engenharia relativos ao tema sistemas geralmente abrange um amplo espectro de atividades:

1. Uso de observações físicas ou medições para caracterizar o comportamento do sistema;

2. Definição de modelos matemáticos que descrevem ou aproximam-se do fenômeno físico observado no sistema;

3. Desenvolvimento de um sistema que se encaixe no que foi prescrito matematicamente por meio de modelos;

4. Realização física do projeto.

Assim, é essencial que os engenheiros de sistemas sejam capazes de formular um sistema por meio de um modelo matemático ou físico, ou, na sua falta, devem ser capazes, de alguma forma, de simular o fenômeno físico observado e recolher as respostas necessárias para formação de um modelo empírico.

\subsubsection{Engenharia de sistemas aplicada ao projeto de pavimento}

O projeto de pavimentos tendo a engenharia de sistemas como referência envolve diferentes características:

1. As variáveis de entrada e de saída devem ser identificadas e descritas quantitativamente;

2. Os métodos de seleção de materiais de construção e técnicas de construção devem ser aprovados;

3. As saídas (respostas) do sistema para todas as possíveis entradas ocorridas em serviço devem ser mensuradas, e se não for possível no próprio sistema devem, de alguma forma, ser simuladas;

4. A qualidade da resposta ou a medida de desempenho do sistema deve ser julgada por critérios adequados; 
5. Alterações do sistema devem ser permitidas a fim de atingir condições o mais próximo possível das condições ótimas.

A fim de tratar quantitativamente os recursos externos ao sistema, é necessário definir os termos e as operações de forma precisa. A entrada para o sistema consiste de volume de tráfego, meio ambiente e manutenção. 0 efeito do tráfego é transmitido, através das cargas de roda, esforços, tensões e deformações na superfície do pavimento. A distribuição espacial e a variação temporal (dinâmica e cíclica) devem ser representadas. A entrada ambiental consiste, entre outras coisas, da difusão do calor e do nível de umidade para o sistema.

Estas entradas devem, também, ser representadas como funções de espaço e tempo. Em certos casos, uma entrada de produto químico pode ocorrer, por exemplo, o uso de sais de degelo. A resposta do sistema consiste na geração de um estado mecânico identificado por deformação e tensão interna. 0 estado mecânico é mais facilmente descrito em termos de tensão e deformação.

\subsubsection{Comportamento e desempenho do pavimento}

O exame do projeto do pavimento representado na Figura 4.6 ilustra as complexas inter-relações que necessariamente existem entre (1) materiais que compõem a estrutura, (2) manifestações de comportamento do pavimento, e (3) o desempenho do pavimento. Esforços têm sido realizados para desenvolver modelos melhorados que relacionem o comportamento do pavimento ao histórico de manutenção e a sua idade (o desempenho). Deve-se compreender que a avaliação de materiais e uma modelagem mecanicista da estrutura do pavimento são essenciais a gestão do pavimento.

\subsubsection{O Sistema de Gerência de Pavimentos não toma decisões}

Provavelmente não haverá situação em que se possa confiar unicamente em modelos quantitativos para tomadas de decisão em engenharia. 0 julgamento qualitativo 
é um elemento importante em todas as atividades humanas; assim, o método, ou o computador, utilizado nos sistemas não tomam decisões; em vez disso, ele processa as informações para uso pelos tomadores de decisão. Assim, a responsabilidade pela tomada de decisões sempre será das pessoas envolvidas no processo, e não de um sistema especialista ou computador.

O conjunto de ferramentas propostas neste trabalho, a saber: (1) um sistema de suporte a decisão (DSS, do inglês Decision Support System), (2) um sistema de informações geográficas (SIG) e (3) um banco de dados geográfico, formam a base de um sistema de gerência de pavimentos destinado a gerência de um pavimento ferroviário, ou seja, da via permanente.

Da mesma forma, o conjunto de ferramentas aqui proposto servirá como auxílio ao gestor para a tomada de decisões. Muitas restrições nem sempre podem ser incorporadas ao sistema de gerência de pavimentos, seja pela impossibilidade de quantificar um critério que é fundamental na decisão, seja por situações momentâneas, cenário político, restrições inesperadas, etc... Assim, sempre caberá ao gestor a decisão final sobre qual será a política adotada para aquela situação particular de maneira que os objetivos da manutenção e os objetivos e estratégias da organização sejam alcançáveis. 


\section{SISTEMAS DE SUPORTE A DECISÃO}

Este capítulo apresenta as características de um sistema de suporte, ou apoio, à decisão (DSS, do inglês Decision Support System) para gerenciamento da manutenção e renovação da via metroferroviária, analisa os seus componentes e sugere métodos para auxiliar os gestores na gestão da manutençã. A opinião de especialistas de manutenção de via e uma pesquisa abrangente na literatura foram utilizadas para vislumbrar o sistema de apoio à decisão proposto.

\subsection{Introdução}

As redes de transporte metroferroviário são utilizadas com muita frequência e desempenham um papel importante no transporte de milhares de pessoas. As condições operacionais estão cada vez mais rigorosas de maneira a facilitar os serviços de transporte, aumentar a densidade de trens por hora, oferecer mais horas operacionais e ter a pontualidade melhorada. Estas condições conflitam com a programação e execução de manutenção eficiente e podem, em longo prazo, levar a um aumento da necessidade de manutenção e renovação.

As regulamentações implicam cada vez mais restrições, relacionadas à segurança ferroviária, segurança do trabalho e os níveis de ruído. Além dos requisitos de desempenho crescente, os gestores de infraestrutura são frequentemente confrontados com ativos usados, atrasos na manutenção e dificuldade de acesso aos sistemas para a 
construção e modernização (por exemplo, para aumentar a capacidade das vias e instalação de nova tecnologia).

O sistema metroferroviário mostra-se um sistema complexo. Em primeiro lugar, as operações e a infraestrutura influenciam-se de vários modos. A qualidade dos trens (material rodante) influencia o desgaste da infraestrutura e, portanto, as quantidades de manutenção e renovação necessárias. Aqui no caso estudado, a única infraestrutura avaliada é a via permanente, no entanto um material rodante com problemas pode gerar vibrações que danificam as estruturas civis, pontes e demais estruturas que recebam esta vibração indesejada.

Em segundo lugar, as falhas de infraestrutura, como também as manutenções bens planejadas, tendem a influenciar a confiabilidade das operações. Um aspecto importante da infraestrutura metroferroviária é que os ativos têm expectativa de vida longa e uma vez instalado é muito caro e complicado alterar o projeto inicial. Decisões em projeto e manutenção, assim, passam a ter um impacto duradouro. Se, por exemplo, a manutenção preventiva é reduzida sistematicamente, os ativos podem desgastar-se de forma rápida e isso pode resultar em custos elevados de manutenção (JOVANOVIC, 2004).

Os trilhos sofrem a ação de forças de atrito causada por trens e os efeitos do meio ambiente. Assim, as vias exigem manutenção regular, a fim de funcionar corretamente. Existem várias operações de manutenção que visam aumentar a vida útil do trilho, embora, em alguns casos, nenhuma dessas operações seja suficiente e toda a seção da via precisa ser renovada.

As áreas responsáveis pela manutenção utilizam diferentes proporções de manutenção regular e de renovação, com pouco consenso sobre qual a melhor combinação entre as ações (GRIMES; BARKAN, 2006).

O momento certo de realizar a manutenção ou renovação das vias é crucial para que um trabalho eficiente e adequado seja planejado, aumentando a vida útil dos componentes da via. Considerando a realização de manutenção e renovação muito tarde certamente existe uma condição insegura. Como a via envelhece os custos de manutenção e de renovação de aumentam.

0 aumento da demanda por transporte metroferroviário requer o aporte de recursos financeiros para serem utilizados na manutenção de via. A redução de custos e 
melhor controle dos processos de manutenção, portanto, aumentam a eficiência do sistema. 0 sistema de gestão da infraestrutura exige o conceito de diagnóstico, ou seja, uma abordagem baseada na condição, bem como a análise de criticidade e urgência de todos os principais componentes de infraestrutura.

A via permanente e os aparelhos de mudança de via (AMVs) estão sujeitos à fatores que agem na alteração da geometria da via e nos materiais da via de uma forma exponencial, imputados pela ação do material rodante e de variações ambientais. Estes fatores causam o deslocamento lateral e longitudinal da via e, assim, os componentes da via estão expostos à fadiga, corrugação, desgaste, abrasão, defeitos e danos. Além disso, nas curvas de raio pequeno, muitas vezes a corrugação apresenta-se a taxas muito altas.

É muito importante determinar estas degradações nos estágios iniciais, porque o estado das vias determina a segurança e conforto do transporte. Há uma série de pesquisas sobre a deterioração linha férrea. As pesquisas têm especialmente focado em acomodação do lastro, desgaste de trilhos e desgaste e fadiga de superfície de trilhos. Esta diversidade demonstra que a degradação da via é um processo complexo. Estes modelos de degradação foram revistos e discutidos por Öberg (2006). Geralmente os modelos de degradação podem ser categorizados conforme segue:

- Modelos de degradação devido ao deslocamento lateral;

- Modelos de degradação devido ao desgaste e fadiga de contato;

- Modelos Generalizados de degradação;

- Modelos de degradação em função da mudança de condições do tráfego;

- Planejamento auxiliado por computador e ferramentas de predição.

\subsubsection{A manutenção}

A política de manutenção, incluindo a modelagem e aperfeiçoamento, tem como objetivo a realização da manutenção preventiva ou corretiva de maneira a minimizar o custo total de intervenções e/ou maximizar o tempo de vida do ativo (BARROS, 1998).

Portanto, os gestores precisam de ferramentas de análise e planejamento da manutenção que lhes permitam analisar sistematicamente e melhorar as necessidades orçamentais, minimizar os custos totais para os níveis necessários de confiabilidade, 
manutenibilidade, disponibilidade e segurança do sistema, e garantir a qualidade dos ativos ferroviários em longo prazo.

Os seguintes componentes podem ser distinguidos para a gestão da manutenção:

a. Registro de ativos. O primeiro passo na gestão da manutenção é o de estabelecer um cadastro completo de ativos que é capaz de ligar medições da qualidade da infraestrutura, histórico de manutenção e dados de transporte (tonelagem) com a localização de ativos e o ativo específico.

b. Conceitos de manutenção. Os padrões de degradação e de falhas e métodos de reparação devem ser conhecidos (MTTR, do inglês Medium Time To Repair e MTBF, do inglês Medium Time Between Failures), a fim de planejar tarefas de inspeção e manutenção. Conceitos de manutenção são desenvolvidos através de uso do Modo de Falha Análise de Efeitos (FMEA) (MOUBRAY, 1997)

c. Análise de custo do ciclo de vida (LCC, do inglês Life Cycle Costs). Para obter a relação custo-benefício ideal entre investimento e manutenção, deve ser aplicada a análise de custo do ciclo de vida. Conceitos de manutenção, pareceres de peritos adicionais e os dados empíricos são as fontes de informação. Um sistema de apoio à decisão deve facilitar a estimativa dos custos do ciclo de vida em diferentes condições operacionais, a fim de testar a robustez da solução escolhida (ZOETEMAN, 2001b).

d. Planejamento de trabalho assistido por computador. Um sistema de planejamento deve auxiliar na priorização e programação das atividades de manutenção e renovação em médio prazo, bem como o planejamento de materiais e recursos, de pessoal e máquinas.

O desenvolvimento do registro de ativos é difícil de realizar. No entanto, devido ao aumento da pressão para reduzir os orçamentos é essencial a transparência das decisões de manutenção para melhorar a qualidade. É necessária uma abordagem que possa apoiar os tomadores de decisão de forma adequada. Neste trabalho, o conceito e utilização de um sistema de apoio à decisão (DSS), com base de cálculo de custos do ciclo de vida (LCC) é discutido, o que deve ajudar os decisores na análise dos custos de infraestrutura e desempenho esperados. 
A análise do custo do ciclo de vida fornece os conceitos teóricos necessários para equilibrar os custos em curto prazo e longo prazo e o desempenho. A análise do custo do ciclo de vida é definida como uma avaliação econômica de um item, sistema ou instalação e suas alternativas de projeto, considerando todos os custos significativos sobre a vida econômica, expressa em termos de unidades monetárias equivalentes (ASIEDU; GU, 1998).

\subsubsection{Análise da decisão}

Apesar da importância da tomada de decisões a formação nesta área de conhecimento ainda é pequena. Assim, contamos com a experiência para acumular conhecimento tácito e qualitativo sobre decisões. No entanto, a experiência é, por vezes, ineficiente, e agrega junto com as boas práticas, os maus hábitos. (HAMMOND; KEENEY; RAIFFA, 2002)

A tomada de decisão é uma das coisas difíceis na vida. A tomada de decisão verdadeira não ocorre quando define-se exatamente o que fazer, mas quando ainda não é conhecido o que fazer (MCNAMEE; CELONA, 2001). Quando valores conflitantes devem ser equilibrados, situações complexas carecem de classificação, a incerteza é real e devese lidar com esta questão, é quando o ponto de tomada de decisão é alcançado.

A análise de decisão é uma disciplina normativa, o que significa que ela descreve como as pessoas devem, logicamente, tomar decisões. Especificamente, corresponde como as pessoas tomam decisões em situações simples e mostra como esse comportamento deve, logicamente, ser estendido a situações mais complexas (WATSON, 1987).

De uma forma generalizada, estes conceitos básicos da tomada de decisão foram levados em consideração na proposta do sistema de suporte a decisão descrita neste trabalho. 


\subsection{Quadro para análise do desempenho em longo prazo}

\subsubsection{Análise do custo do ciclo de vida}

As decisões de manutenção só podem ser tomadas de forma responsável, quando os custos e desempenho de decisões alternativas são consideradas em longo prazo, com base no ciclo de vida. Isto também inclui a disponibilidade e confiabilidade, uma vez que o desempenho da infraestrutura influencia os custos e receitas das operações.

De acordo com a análise do custo do ciclo de vida, a ação que deve ser tomada é aquela que resulta em menores custos totais durante o tempo de vida de uma unidade de produção, em nosso caso a via permanente de um sistema metroferroviário. As decisões tomadas durante a concepção, construção, manutenção e operação de uma via tem impacto sobre os custos e receitas durante a vida econômica residual.

A fim de tornar estes custos e receitas comparáveis, ou seja, para expressá-los em unidades monetárias equivalentes, os fluxos de caixa que ocorrem durante o ciclo de vida analisado são descontados a um ano-base, no qual a decisão será tomada.

Na teoria do custo do ciclo de vida os custos totais de propriedade e operação são o critério utilizado para avaliar alternativas, ou seja, diferentes projetos ou estratégias de manutenção. Existem três formas diferentes de apresentar estes custos:

- 0 valor presente total (TPV, do inglês Total Present Value), que é a soma de todos os fluxos de caixa descontados. No método do custo do ciclo de vida refere-se essencialmente com respeito aos custos; receitas podem ser expressas como custos negativos. Quanto maior o valor presente, menos atrativo o investimento em comparação com investimentos alternativos ou estratégias de manutenção.

- A taxa interna de retorno (TIR) mostra a rentabilidade de um investimento em relação aos investimentos alternativos ou estratégias de manutenção.

- 0 equivalente anual ou anuidade (ANN) é a soma dos juros e amortizações, que tem de ser pago a cada ano para financiar os investimentos e a manutenção. Com a anuidade, projetos de diferentes expectativas de vida podem ser comparados. 
A fim de tomar uma decisão correta, todos os custos (e receitas) afetados pela decisão devem ser considerados. Esses custos podem ser classificados da seguinte forma:

a) Custos tangíveis e intangíveis. Custos tangíveis são pagos em dinheiro, por exemplo, os custos de construção e manutenção (mão de obra, materiais e máquinas). Intangíveis, ou custos ocultos, são aqueles que não são pagos diretamente por parte do autor, são o resultado de perda de qualidade, redução dos serviços de transporte, redução dos níveis de segurança e conforto, e poluição sonora. Estes custos devem ser refletidos em regimes de desempenho e padrões de manutenção.

b) Custos iniciais (capital investido) e custos de funcionamento. Os custos iniciais são os realizados para a aquisição, instalação ou construção. Os custos de funcionamento são gerados durante o período de funcionamento da ferrovia. Pode ser feita uma distinção adicional entre os custos anuais, tais como inspeções, pequenas ações de manutenção e custos intermitentes ou periódicas, como revisões e renovações.

c) Custos de propriedade e de operação. Em uma divisão dos custos uma pode haver uma distinção entre os custos sofridos pelo proprietário da infraestrutura, geralmente o governo e os custos sofridos pelos operadores.

A teoria do custo do ciclo de vida pressupõe que se todos esses custos são identificados para todas as ações, então a ação com os menores custos de ciclo de vida deve ser escolhida. Um pré-requisito para a comparação é que as soluções fornecem o serviço desejado e atendem as normas técnicas (por exemplo, parâmetros de projeto para a linha de alta velocidade são muito mais rigorosos do que os de uma linha convencional).

Na prática, outros fatores também podem influenciar uma decisão. Outros critérios que não os custos do ciclo de vida serão considerados nos processos de tomada de decisão. Regulamentos relativos à segurança, ruído e vibrações, o conforto do usuário e as condições de trabalho são óbvias limitações a serem considerados no desenvolvimento de alternativas de uma decisão. Além disso, o orçamento disponível pode, por exemplo, fazer o gestor a optar por um projeto com menores custos de construção. 
No entanto, mesmo se o orçamento é um obstáculo, na avaliação das diferentes alternativas ainda é possível que o tomador de decisão selecione a segunda melhor alternativa com o menor impacto negativo no custo do ciclo de vida.

A análise do custo do ciclo de vida é considerada uma abordagem adequada para aumentar a qualidade das decisões de manutenção: pode mobilizar o conhecimento do estado da arte a fim de estabelecer hipóteses sobre as ações futuras de manutenção de uma forma transparente. Os tomadores de decisão são capazes de escolher uma estratégia de concepção ou de manutenção com a melhor garantia de ser o melhor custo-benefício e suposições podem ser monitorados sistematicamente a fim de refinar ainda mais os projetos e estratégias de manutenção.

Uma questão importante é a confiabilidade dos dados utilizados para estimar as necessidades de manutenção e taxas de falha. Pressupostos tem que ser feitos sobre as futuras condições operacionais da via e a deterioração dos ativos ferroviários. A solução de projeto ou manutenção deve ser robusta, ou seja, continuar a ser a alternativa preferida em diversas condições, como mais, ou menos, transporte do que o esperado; uma taxa de juros maior, ou menor; e uma degradação mais rápida, ou mais lenta dos ativos. Basicamente dois métodos podem ser utilizados para testar a robustez:

- Análise de sensibilidade. Na análise de sensibilidade os valores de entrada são sistematicamente variados, com percentagens de 10\%, 20\% e 30\%, para mais e para menos. Os parâmetros de entrada mais sensíveis são identificados pela percentagem de desvio dos resultados.

É importante ter uma estimativa precisa sobre o valor provável destas variáveis. A desvantagem de uma análise de sensibilidade é que as interações usam apenas uma variável de cada vez e possíveis interações entre os fatores não são diretamente reveladas (FLANAGAN, 1989).

- Análise de incertezas. Se os custos de ciclo de vida são determinados por uma série de variáveis de risco, a análise de sensibilidade pode ser insuficiente. A análise de incerteza é uma abordagem mais sofisticada, onde os parâmetros de entrada do modelo são considerados variáveis aleatórias, a partir do qual as amostras são recolhidas. 
A simulação de Monte Carlo é uma técnica para aproximar uma distribuição normal (probabilística) dos resultados: a chance de um resultado específico pode ser deduzida para um nível de confiança desejado (FLANAGAN, 1989). Análise de incerteza também é discutida em, por exemplo, Ellingham e Fawcett (2006), Clemen e Reilly (2000), Nutt e Wilson (2010).

\subsubsection{A degradação dos ativos}

Com o objetivo de estimar os custos do ciclo de vida, os fatores que influenciam o desempenho da infraestrutura ferroviária devem ser identificados, bem como as suas relações. 0 fator mandatório da manutenção e ocorrência de falhas é a degradação do ativo.

Existem diferentes modos de degradação: equipamentos elétricos, por exemplo, podem falhar instantaneamente, enquanto os ativos em que o desgaste é devido ao contato mecânico, como o contato roda-trilho, degradam obedecendo a uma determinada regra. Na Figura 5.1 um padrão de degradação teórico é mostrado. Com a quantidade de toneladas transportadas na via, medido em milhões de toneladas brutas, ou MGT, o desgaste da pista aumenta e é necessária a adoção de uma ação de reabilitação. 


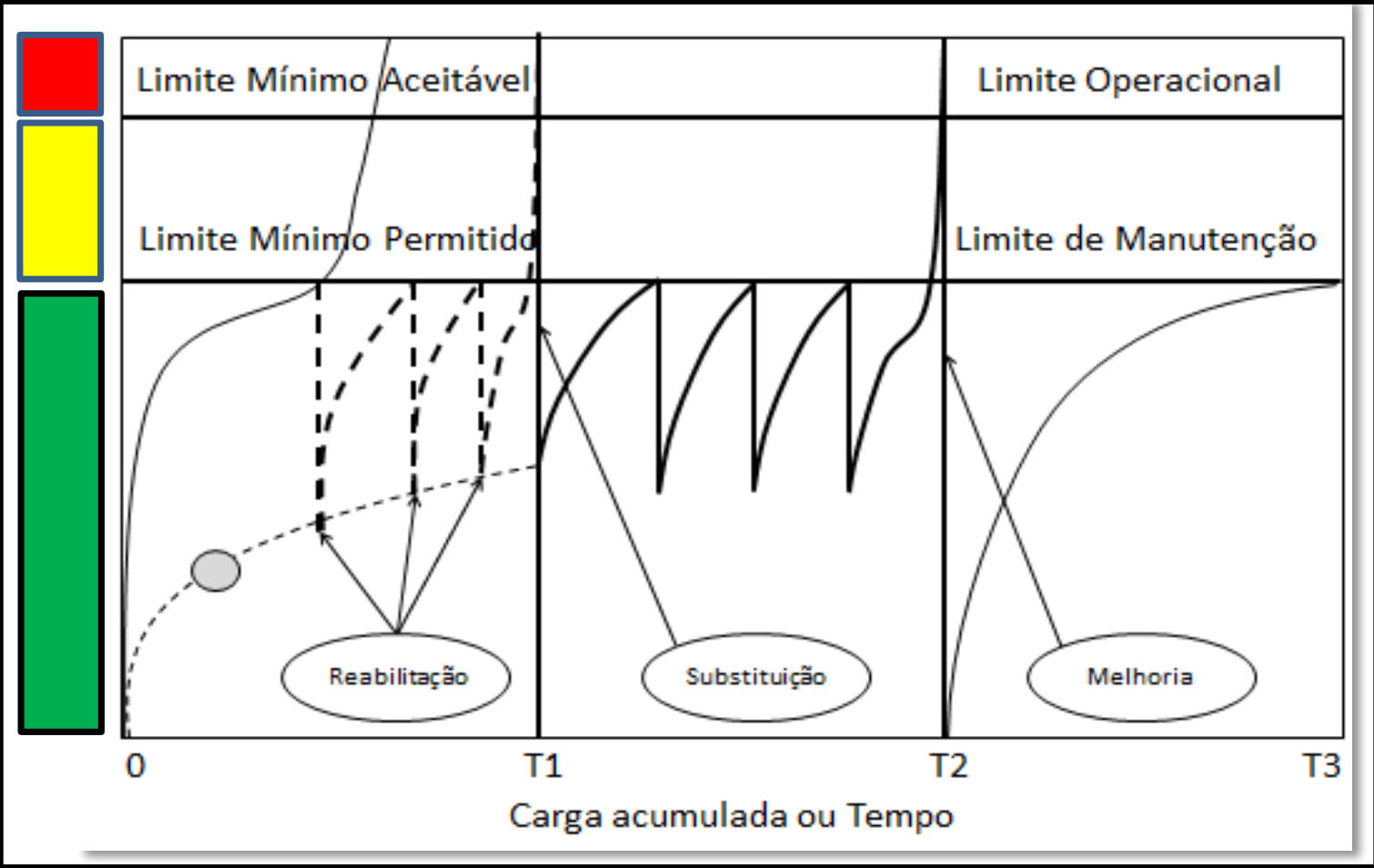

Figura 5.1 - Degradação hipotética de um sistema

O gestor dos ativos utiliza um limite de manutenção com base em sua experiência considerando que a deterioração será progressiva uma vez que este limite assumido seja ultrapassado. A linha pontilhada mostra que a substituição do trilho pode ser adiada por manutenção periódica. Depois de algum tempo a eficácia da manutenção tornou-se demasiada baixa (diminuindo intervalo de manutenção) e uma substituição é necessária. Essa substituição deve ser planejada antes que as condições do trilho ultrapassem o limite operacional, que é definido para garantir a segurança e confiabilidade do transporte.

A degradação da via depende de fatores diversos, tais como a qualidade inicial da construção, a qualidade do sublastro, e as cargas sobre a via. Dados históricos podem fornecer estimativas sobre as taxas de degradação reais e a eficácia das atividades de manutenção em condições específicas (ZAALBERG, 1998).

Além da degradação dos ativos, há outros fatores que também influenciam os custos do ciclo de vida, tais como os padrões de confiabilidade aplicados, a quantidade de manutenção preventiva, os custos de mão de obra, materiais e máquinas, e as características operacionais da linha. 0 gestor pode gerenciar alguns desses fatores diretamente (por exemplo, estratégia de manutenção) ou com a cooperação dos 
operadores (por exemplo, a qualidade do material rodante) e do governo (por exemplo, algum tipo de subvenção). Fatores exógenos, como a condição do solo e da taxa de juros, também influenciarão os custos do ciclo de vida.

\subsubsection{O desempenho dos ativos}

Na Figura 5.2 um modelo conceitual é apresentado (ZOETEMAN, 2001b). 0 desempenho da infraestrutura é definido, nesta figura, como o nível de segurança, o conforto do usuário, ruído, vibrações, confiabilidade, disponibilidade e os custos de propriedade.

As normas de segurança e de ruído indiretamente influenciam os custos do ciclo de vida, uma vez que determinam as tolerâncias e os limites para os parâmetros de projeto e manutenção. Outros parâmetros funcionais, como velocidade máxima, intervalo mínimo entre trens e carga máxima por eixo, são restrições para o projeto ou estratégias de manutenção.

O projeto determina diretamente quais são os custos de propriedade (quantidade de investimento). Este investimento também é determinado pela acessibilidade do local de construção. 0 projeto também influencia a degradação de ativos (qualidade inicial), em conjunto com outras condições, tais como intensidades de tráfego e cargas por eixo, a qualidade da infraestrutura e da eficácia da manutenção realizada. 


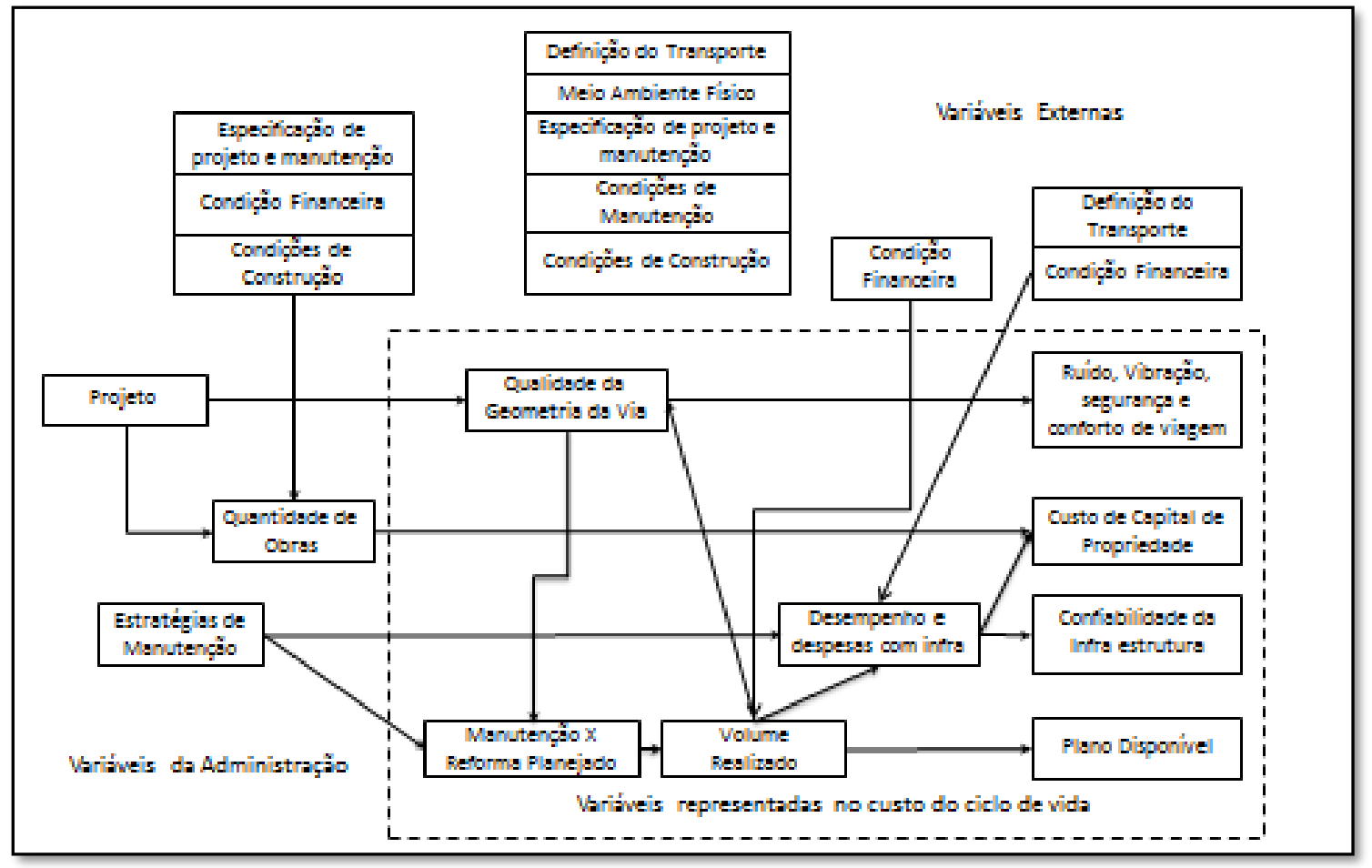

Figura 5.2 - Fatores de influência no desempenho da via permanente

A diminuição da qualidade determina o volume necessário de manutenção e renovação. A estratégia de manutenção escolhida influencia na quantidade de manutenção preventiva e corretiva ao longo da vida do ativo. Um fator que determina o volume de manutenções é o orçamento anual disponível: um atraso nas manutenções pode resultar em um declínio mais rápido da qualidade da infraestrutura.

Além disso, a estratégia de manutenção também tem um impacto direto sobre os custos do ciclo de vida através dos custos da organização para restaurar falhas (gestão de incidentes). Posteriormente, a organização de gerenciamento de incidentes, o volume de manutenções realizado, e o projeto da via, determinam os minutos de atraso causados por falhas de infraestrutura (confiabilidade reduzida). Se for o caso, os minutos de atraso podem ser convertidos em penalidades usando um regime de pagamento por desempenho. Por fim, as penalidades de desempenho, os custos de manutenção e de renovação, e os custos de construção devem compensar os custos totais de propriedade. 


\subsection{Os Sistemas de Suporte à Decisão na Prática}

\subsubsection{O contexto nas organizações}

Sistemas de suporte, ou apoio, à decisão são tecnologias que ajudam os tomadores de decisão a obter o conhecimento na quantidade disponível, no momento preciso, com os custos e com os cenários mais precisos possíveis relativos a uma tomada de decisão. Estes sistemas ajudam os gestores a tomar a melhor decisão com relação a limitações financeiras e outras restrições impostas pelo problema em questão.

Os parágrafos anteriores descrevem a relação entre os produtos principais da tomada de decisão estratégica, projeto e manutenção, e o desempenho da infraestrutura em termos de custos de ciclo de vida. 0 projeto e a manutenção ainda são processos separados em muitas organizações. Este fenômeno de "mundos separados" também acontece para as diferentes disciplinas técnicas de um sistema complexo, como a via permanente, a tração e a sinalização.

Dentro dessas "ilhas", com uma organização hierárquica baseada em habilidades, o grupo diretivo foi o responsável pela tomada de decisões operacionais e táticas. As decisões foram baseadas no conhecimento tácito destes peritos e também em procedimentos detalhados e normas técnicas, prescrevendo os parâmetros de projeto e as frequências de manutenção. A tomada de decisão teve um foco técnico forte, impulsionada pela segurança do sistema, que sempre tinha que ser garantida.

As normas e procedimentos técnicos para os processos de desenvolvimento e manutenção básicos não se tornaram supérfluos, mas a exigência de desempenho levou a especificações funcionais, tais como níveis de confiabilidade, disponibilidade e facilidade de manutenção. É necessário um nível estratégico de tomada de decisões, superando os processos de projeto e manutenção técnica, onde os projetos físicos e estratégias de manutenção são selecionados com base no desempenho exigido. Este nível de tomada de decisão estava confuso e mal desenvolvido. No entanto, com base na teoria de gestão da manutenção, um modelo estratégico para a criação e manutenção de tomada de decisão pode ser elaborado (BEN-DAYA, 2009; DHILLON, 1999; KELLY, 2006). 


\subsubsection{Modelos desenvolvidos}

Shen e Grivas (1996) apresentaram um sistema de apoio à decisão para a conservação de infraestrutura civil. O sistema visa fornecer ajuda para as decisões relacionadas com as três tarefas principais de manutenção e reabilitação de infraestrutura: a observação de sintomas, diagnóstico da condição, e identificação de tratamento.

Jo et al. (2011) apresentou um quadro integrado de apoio à decisão que ajuda os órgãos públicos a identificar locais de acidentes e desenvolver projetos de melhoria de segurança de baixo custo. Funções de desempenho de segurança, o método bayesiano empírico, e o potencial para melhorar a segurança, são incorporados ao sistema para identificar locais perigosos em rodovias. Projetos de segurança de baixo custo são priorizados com base no custo do ciclo de vida (LCC) e em modelos ideais de alocação de recursos.

Halfawy, Dridi e Baker (2008) desenvolveram uma abordagem integrada para o planejamento de renovação dos sistemas de infraestrutura municipal. 0 artigo discute a aplicação da abordagem proposta para implantar um sistema de apoio à aecisão (DSS, do inglês Decision Support System) baseado em um sistema de informações geográficas (SIG) para auxiliar no planejamento de renovação de redes de esgoto.

Um sistema de suporte à decisão (DSS) é um sistema baseado em computador que representa e processa o conhecimento de forma a permitir que a tomada de decisão seja mais produtiva, ágil, inovadora e confiável (BURSTEIN; HOLSAPPLE, 2008). Ao longo dos anos, verifica-se que o processo de tomada de decisão foi representado por um conjunto de regras "se for isso, então faça assim, senão execute desta forma", dependendo da natureza do sistema de suporte à decisão.

As regras são desenvolvidas por especialistas para um sistema conhecido como sistema especialista, definido como: um sistema que usa o conhecimento humano, com apoio computacional, para resolver um problema que necessita de competência humana (TURBAN; DELEN, 2010). A qualidade do sistema de suporte à decisão depende tanto da qualidade como da extensão do conhecimento incluído (YEHIA et al., 2008). 
Observa-se um desenvolvimento considerável de sistemas de suporte à decisão (DSS) em planejamento de manutenção e renovação de via permanente, não apenas pelas organizações ferroviárias, mas também por institutos especializados e universidades.

Essas pesquisas, realizadas nos EUA, Canadá, Japão e Europa, são apresentadas na Tabela 5.1. As informações mais detalhadas podem ser encontradas no relatório ERRI D 187/RP1, do European Rail Research Institute. A maioria dos sistemas apresentados na Tabela 5.1 tem foco em soluções para problemas muito precisos. Estes sistemas de planejamento estão em processo de desenvolvimento ou em processo de avaliação dentro das ferrovias (GULER, 2012).

Tabela 5.1 - Adaptado de GULER (2012)

\begin{tabular}{ll}
\hline \multicolumn{1}{c}{ Sistema } & \multicolumn{1}{c}{ Organizador do Sistema } \\
\hline System Dynamics & Ferrovia Alemã (DB) \\
Mini-MARPAS, RRNPV & Ferrovia Britânica (BR) \\
TMS, REPOMAN & Burlington Northern Railroad (BN - Canadá) \\
SMIS, Micro LABOCS II & Ferrovia Japonesa (JR) \\
GEV & Ferrovia Federal Suiça (SBB) \\
BINCO & Ferrovia Holandesa (NS) \\
DOMO, KOMPLAN & Ferrovia Polonesa (PKP) \\
OOP, TIMON & Ferrovia Francesa (SNCF) \\
PATER & Ferrovia Hungara (MAV) \\
Track Management Model & BHP \\
Rail Management Model & BHP / HK-MTRC \\
TRACS & AAR/MIT \\
RAILER & US Army Constructions Engineering Research Lab \\
ECOTRACK & ERRI/UIC \\
RAMSYS & Mermec Industries \\
\hline \hline
\end{tabular}

O Instituto BHP idealizou dois modelos para ferrovias de carga. 0 modelo calcula os ciclos de manutenção recomendados e os custos operacionais associados e determina as condições da via em termos do Índice de Qualidade Ponderada da Via (TQI). Este índice foi desenvolvido para indicar a qualidade da via baseado no efeito de vários parâmetros de geometria da via e nos custos e danos relacionados.

O sistema Railer (UZARSKI; DARTER; THOMPSON, 1993), desenvolvido pelo Exército dos EUA, estabeleceu índices de condição para trilhos, fixações, dormentes, lastro 
e componentes da via. Os índices foram baseados em dados obtidos a partir de um painel de especialistas em via que avaliaram uma variedade de condições da via utilizando classificações numéricas.

Uzarski e McNeil (1994) apresentaram uma visão geral de tecnologias para sistemas de avaliação de ferrovia e de apoio à decisão para manutenção de via. Eles afirmaram que a pesquisa e desenvolvimento de tecnologias para a coleta de dados e dos sistemas de suporte à decisão (DSS) baseados em computador não são amplamente relatados na literatura, devido à natureza da indústria. Eles descreveram uma variedade de sistemas e questões e, consequentemente, eles afirmaram que os sistemas de suporte à decisão (DSS) esforçam-se para mudar a tomada de decisão em manutenção na via permanente de uma arte para uma ciência.

O ERRI (do inglês European Research Rail Institute) e UIC (do francês Union Internationale des Chemins de fer) iniciaram um projeto de sistema de suporte à decisão (DSS) para manutenção de vias com o apoio de especialistas, que reuniram os seus conhecimentos e experiências para a concepção e desenvolvimento do sistema. 0 produto final, chamado Ecotrack, foi criado em 1998. O principal objetivo era fornecer uma ferramenta com a finalidade de minimizar os custos do ciclo de vida (LCC) (GULER, 2012).

A Universidade de Tecnologia de Delft desenvolveu e utilizou um sistema de apoio às decisões (DSS) para analisar os impactos das decisões de longo prazo de projeto e de manutenção. 0 sistema combina e processa dados de construção, manutenção e operação, a fim de fazer estimativas de custos totais do ciclo de vida (LCC). 0 sistema incluiu o desempenho da infraestrutura (disponibilidade e confiabilidade) nessas estimativas, provando ser uma ferramenta útil para testar a robustez de decisões de projeto e de manutenção e focando a discussão sobre os fatores de custo (ZOETEMAN, 2001a).

O sistema RAMSYS é uma plataforma de software integrada para a gestão de todos os dados relacionados com a manutenção da infraestrutura ferroviária. Ele suporta a gestão de todos os dados relacionados com a infraestrutura ferroviária e manutenção do material rodante (ativos, defeitos, histórico de trabalho, medidas, dados operacionais, etc.), permitindo a manutenção preditiva e baseada em condição bem como a renovação no momento adequado (JOVANOVIC; EVREN; GULER, 2011). 


\subsection{Implantação de Um Sistema de Suporte à Decisão}

\subsubsection{As etapas}

Existem diversas formas de estabelecer um programa de implantação de sistema de suporte a decisão. A teoria de gestão da manutenção sugere um esquema de estágios, partindo do geral e seguindo para o específico, em uma estrutura semelhante a estrutura top-down utilizada na formação de indicadores.

No primeiro estágio a funcionalidade e desempenho exigidos são determinados. Com base na demanda prevista, análise global da qualidade da infraestrutura existente e tecnologia disponível, um nível de desempenho tem de ser determinado, que satisfaça estas demandas. Esta etapa geralmente é realizada pelo Governo e é especialmente aplicável para novos projetos de infraestrutura e modernização. Os produtos desta etapa são especificações funcionais, tais como confiabilidade necessária e disponibilidade, e um regime de desempenho, seja uma empresa pública ou privada.

Durante a segunda etapa, o gestor da infraestrutura estuda as consequências das especificações funcionais em detalhe. São identificados confiabilidade, custos da tecnologia disponível e as condições significativas para o financiamento, construção e manutenção. Os resultados desta etapa são um indicador sobre a viabilidade dos requisitos de desempenho entregues e uma primeira lista das possíveis alternativas de projeto ou manutenção.

Durante a terceira etapa de uma análise extensa e quantitativa das alternativas viáveis é realizada. As expectativas sobre os custos de construção, as necessidades de manutenção e taxas de insucesso são realizadas, a fim de estimar os custos do ciclo de vida para o período de gestão considerado. O resultado desta etapa é uma lista de alternativas já ponderadas, com as suas estimativas de custo do ciclo de vida e uma especificação dos riscos. Novamente, isso pode proporcionar novas sugestões para modificar os requisitos de desempenho quando causam riscos, ou custos, altos. 
Durante a quarta etapa é feita a escolha da alternativa a ser implantada com base nas preferências de risco do gestor da infraestrutura e dos seus credores, bem como à concessão acordada de riscos entre Governo e gestor.

Durante cada uma das etapas do processo de tomada de decisão, os tomadores de decisão têm a necessidade de obter uma visão quantitativa sobre o impacto de uma decisão específica sobre os custos do ciclo de vida. Como a Figura 5.2 mostrou, os custos do ciclo de vida são o resultado de um conjunto complexo de condições (em parte incerta). O número de fatores afetados e a incerteza envolvida exigem uma análise de diferentes cenários (condições futuras), em que o conceito de um sistema de apoio à decisão (DSS) pode contribuir de maneira efetiva.

\subsubsection{Os resultados parciais}

Com a sua capacidade de estimar os custos do ciclo de vida de projetos distintos, estratégias de manutenção e as condições operacionais, o sistema de suporte à decisão pode ajudar a alcançar diversos objetivos, que são:

- A avaliação dos diferentes projetos ou estratégias de manutenção, a fim de selecionar a solução mais robusta e eficaz em termos de custos de uma forma sistemática e transparente;

- Analisar os impactos das condições operacionais e financeiros (restritivas) para a manutenção dos ativos, a fim de discuti-las com outras partes interessadas;

- Apoiar o desenvolvimento de planos de manutenção que visam diminuir os custos do ciclo de vida do sistema ferroviário;

- Treinar os envolvidos nas decisões de projeto e de manutenção de maneira a melhorar o processo decisório.

As saídas do sistema de suporte à decisão são estimativas sobre os custos totais durante um período determinado (custos de ciclo de vida) e estimativas sobre a confiabilidade e disponibilidade do sistema. Na Figura 5.2, as relações na área demarcada pela linha pontilhada são modeladas dentro do sistema de suporte à decisão. Os limites orçamentais não são uma restrição modelada no sistema de suporte à decisão: é de 
responsabilidade do usuário selecionar essas alternativas de decisão para serem analisadas e verificar quais são viáveis, considerando também o orçamento disponível para construção e manutenção.

Os resultados finais - custos de ciclo de vida, confiabilidade e disponibilidade - são calculados em uma série de etapas, de acordo com a Figura 5.3. Nesta figura os processos de cálculo são mostrados como retângulos. No lado esquerdo e direito os dados necessários para os cálculos são mostrados. As setas a tracejado indicam a utilização de dados de uma tabela de dados para o cálculo, enquanto as outras setas indicam a sequência no cálculo.

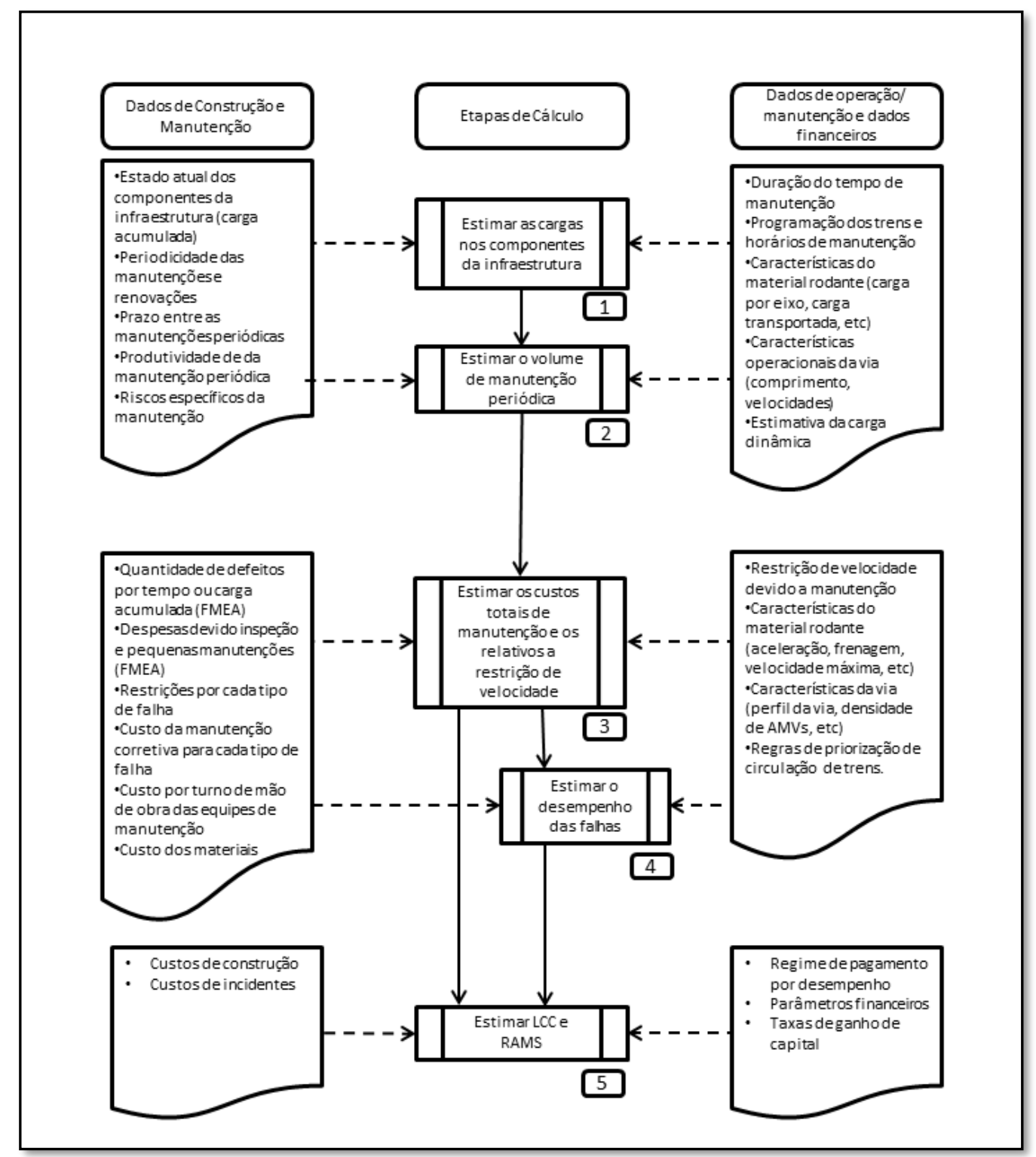

Figura 5.3 - Estrutura sugerida de um DSS apoiado em análise custo do ciclo de vida (Fonte: Zoeteman, 2006). 
As tabelas dos dados são refletidas em uma coleção de dados. Muitas fontes de dados podem ser utilizadas, como dados empíricos (por exemplo, testes de laboratório, simulação de computador, informações de fornecedores, de histórico da manutenção e de custo de manutenção) e opiniões de especialistas sobre, por exemplo, o número esperado de falhas. As ferramentas de análise e planejamento de manutenção tornaram-se disponíveis apenas recentemente e em uma escala limitada de maneira que os dados sobre falhas, degradação da via e histórico de trabalho, dificilmente estão disponíveis ou tem o nível de confiança necessário. Em especial o entendimento da degradação dos componentes da infraestrutura é um processo ainda em desenvolvimento e que, por vezes, envolve conceitos e modelagens complexas, fato que torna a sua compreensão assunto, ainda, no campo de especialistas.

\subsection{A Estrutura do Sistema de Suporte à Decisão}

\subsubsection{O modelo lógico}

O desenvolvimento de modelos é parte deste trabalho, porém de uma forma ainda primária e tímida, já que a avaliação de degradação é parte de grandes projetos de pesquisa com os prazos de entrega de muitos anos. A maior parte de dados de entrada do sistema de suporte à decisão, portanto, depende de pareceres de peritos. Abaixo é descrito o processo do cálculo para estimar os dados de entrada do sistema de suporte à decisão.

\section{Processo de Cálculo 1: Estimativa das cargas sobre a infraestrutura.}

A degradação da qualidade é uma função do tempo (em anos) e de carga na pista (toneladas brutas acumuladas ou o número de passagens de trens). Como a Figura 5.2 mostrou, uma série de fatores influencia a degradação. Esta taxa de degradação por componente de infraestrutura se reflete na tonelagem ou limiar de manutenção com base no tempo. Como um exemplo, a aplicação de um tipo mais pesado do trilho pode reduzir a velocidade de desgaste. Se o desgaste é o fator determinante, principalmente em curvas ou em seções com operações de carga por eixo pesados, um trilho mais pesado pode 
suportar mais toneladas. Um limite superior é definido de modo a refletir a taxa de degradação mais baixa.

Para o cálculo da tonelagem bruta uma programação de trens de referência é utilizada. A programação pode ser especificada para diferentes intervalos de tempo, a fim de expressar o crescimento do tráfego, ou o declínio. Contém o número esperado de trens, bem como o número de horas de funcionamento por dia. Esta programação também é utilizada para o cálculo do tempo anual de viagens programadas, que é a soma dos tempos de percurso para todos os trens em uma secção particular da via. A programação também revela o tempo disponível de acesso à via que não afeta a qualidade dos serviços de transporte.

\section{Processo de Cálculo 2: Estimativa do volume de manutenção periódica.}

Esta etapa consiste em uma estimativa da manutenção periódica. Limites para cada atividade de manutenção são especificados, bem como as cargas acumuladas. 0 tempo de vida residual e, portanto, os momentos de grande revisão ou renovação são deduzidos de cada componente da infraestrutura. Pode ser configurado para considerar o trabalho durante em múltiplos anos. Além disso, o tomador de decisão pode identificar as atividades mais improváveis de acontecerem, assim o eventual impacto deve ser estudado com os riscos específicos. A contribuição nos custos do ciclo de vida é mostrada separadamente. Finalmente, o número de turnos é calculado com base nas taxas de produtividade para cada atividade.

Processo de Cálculo 3: Estimar os custos totais de manutenção e horas de acesso à via.

Com base no número de acessos por ano os custos totais para a manutenção periódica podem ser calculados com base nos custos por quilômetro, com relação a materiais, e um custo por turno de trabalho, considerando mão de obra e máquinas.

A manutenção diária e as falhas são relacionadas com a tonelagem acumulada em serviço ou o tempo de vida do componente. 0 usuário pode definir os custos por tonelada ou por ano para inspeção, manutenção e reparação de pequenas falhas. A manutenção diária e a reparação em pequenas falhas são tarefas diferentes, razão pela qual as 
estimativas resumidas são usadas. Modo de Falha Análise de Efeitos (FMEA) é a técnica a ser utilizada para estimar a quantidade de manutenção diária e a ocorrência de falhas.

Processo de Cálculo 4: Estimativa do desempenho em função de falha.

Em alguns casos, os gestores de infraestrutura são penalizados ou recompensados por seu desempenho baseado nos minutos de atraso causados por falha dos ativos da infraestrutura. Dependendo dos detalhes do regime de desempenho, uma etapa intermediária é a conversão da restrição de velocidade e tempo de acesso não planejados em minutos de atraso e em cancelamento de viagem. Um modelo que estima os minutos de atraso cumulativos e cancelamentos pode ser incluído, com base no desempenho dos trens e uma série de suposições sobre o impacto de uma restrição de velocidade e acesso à via. Dividindo o total de minutos de atraso pelo total de tempo de viagem programado em um intervalo de tempo especificado podemos calcular a confiabilidade. Uma análise mais avançada do atraso pode ser feita com, por exemplo, um modelo de simulação dedicada, ou usando um método analítico. Assim, a localização de chaves e o número de paradas do trem podem influenciar o atraso cumulativo.

\section{Etapa de Cálculo 5: Estimar os custos do ciclo de vida}

Na última etapa a estimativa da confiabilidade e disponibilidade e os custos totais (custo do ciclo de vida) são calculados. Dependendo da situação os custos de construção são incluídos no fluxo de caixa. Outra opção é a de incluir ou excluir os riscos específicos. Finalmente, os custos de financiamento são calculados com base na taxa de juros. Os custos do ciclo de vida das diferentes soluções de projeto ou de manutenção são apresentados como indicador de desempenho.

Para cada cálculo um modelo, que consiste em um conjunto de equações, é utilizado.

Os parâmetros apresentados na Tabela 5.2 foram utilizados para desenvolver as regras de manutenção. 0 sistema de suporte à decisão proposto calcula alguns dos parâmetros com base nos segmentos de via analisados. Estes dados são utilizados dentro das regras de manutenção, no entanto, alguns dados intermediários podem ser produzidos no processo. Regras simples foram definidas para cada tipo de manutenção, 
usando os dados relevantes. Por exemplo: IF Dados da Via (1) $\geq$ Valor Limite (1) OR Dados da Via (2) $\geq$ Valor Limite (2) OR Dados da Via (3) $\geq$ Valor Limite (3), THEN Realize a Manutenção tipo Y na Data Calculada. A estrutura lógica do sistema do modelo desenvolvido é ilustrada na Figura 5.4. Geralmente, o objetivo principal é o de identificar os requisitos de $M \& R$ com vista a classificá-las em algumas categorias. Da mesma forma, o sistema de suporte à decisão proposto fornece as análises de algumas etapas que são primeiro estágio, segundo estágio, Consistência, Melhoria e Avaliação.

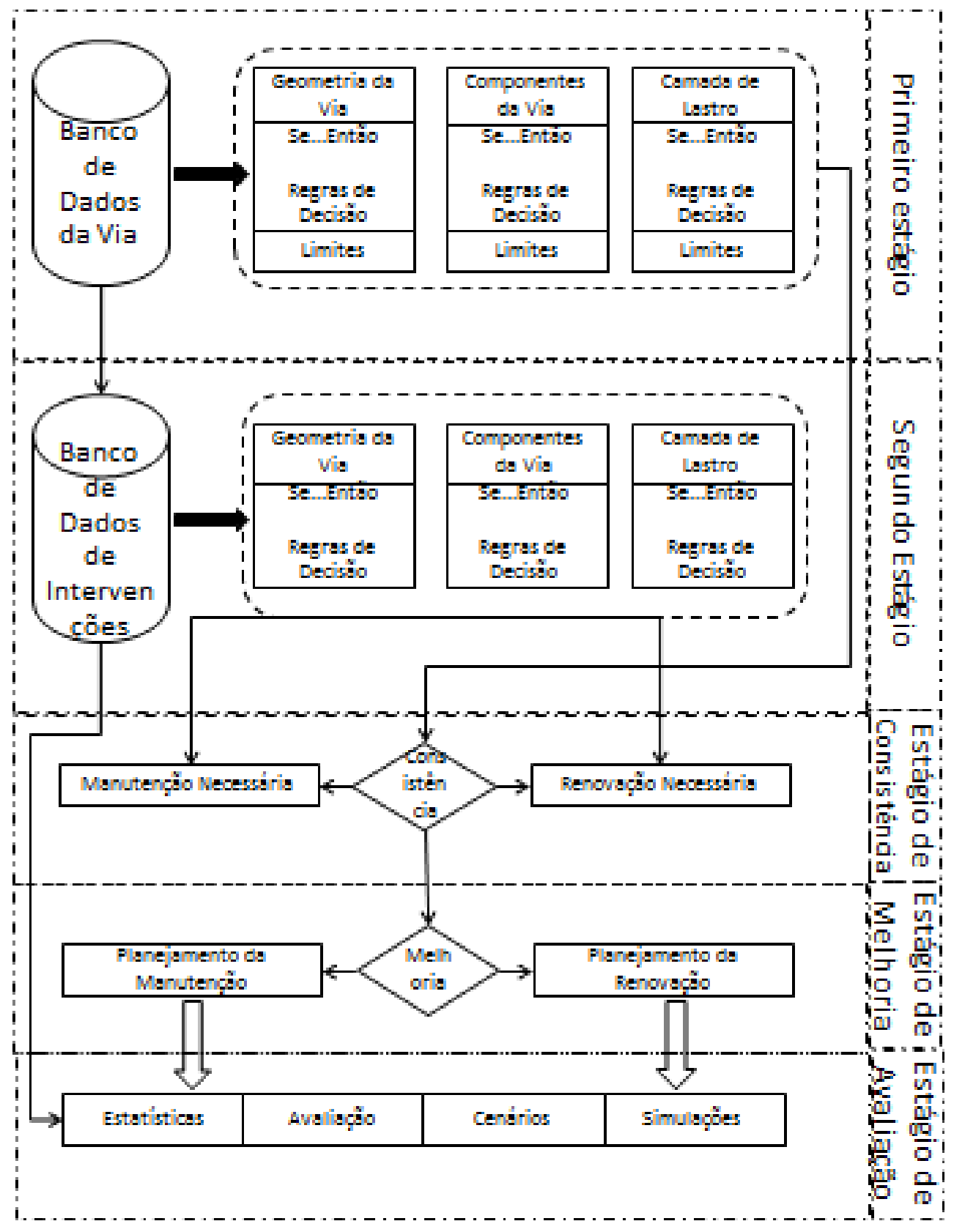

Figura 5.4 - Modelo lógico do DSS proposto. 
Os limites podem ser interdependentes: renovações podem ser agrupadas em tempo e lugar (agregação de renovações em seções de via adjacentes ou de componentes de infraestruturas diferentes). Além disso, é possível que a atividade de manutenção possa prejudicar a condição de outro componente (por exemplo, a qualidade do lastro pode diminuir como resultado da socaria da via).

\subsubsection{A composição das atividades de manutenção no sistema de suporte à decisão}

A partir de experiência acumulada, entrevistas com especialistas e pesquisa em material bibliográfico, os seguintes trabalhos de manutenção foram selecionados na formação de um sistema de suporte à decisão:

- Troca de Trilhos;

- Substituição de dormentes e fixação;

- Limpeza do lastro e/ou substituição do lastro;

- Socaria de via (nivelamento e alinhamento);

- Esmerilhamento de via;

- Medições e manutenções localizadas;

- Lubrificação de via.

Os parâmetros apresentados na Tabela 5.2 foram utilizados para envolver as regras para cada tipo manutenção. 0 sistema de suporte à decisão proposto calcula alguns dos parâmetros com base nos segmentos analisados. Estes dados são utilizados dentro das regras, no entanto, alguns dados intermediários podem ser produzidos no processo. Regras simples foram definidas para cada tipo de manutenção, usando os dados relevantes. Por exemplo: IF Track Data (1) $\geq$ Limit value (1) OR Track Data (2) $\geq$ Limit value(2) OR Track Data (3) $\geq$ Limit value (3) ... THEN Work type, Date. As incertezas decorrentes da falta de conhecimento sobre os valores limiares também foram eliminados. 
Tabela 5.2 - Indicadores de manutenção para pavimento ferroviário

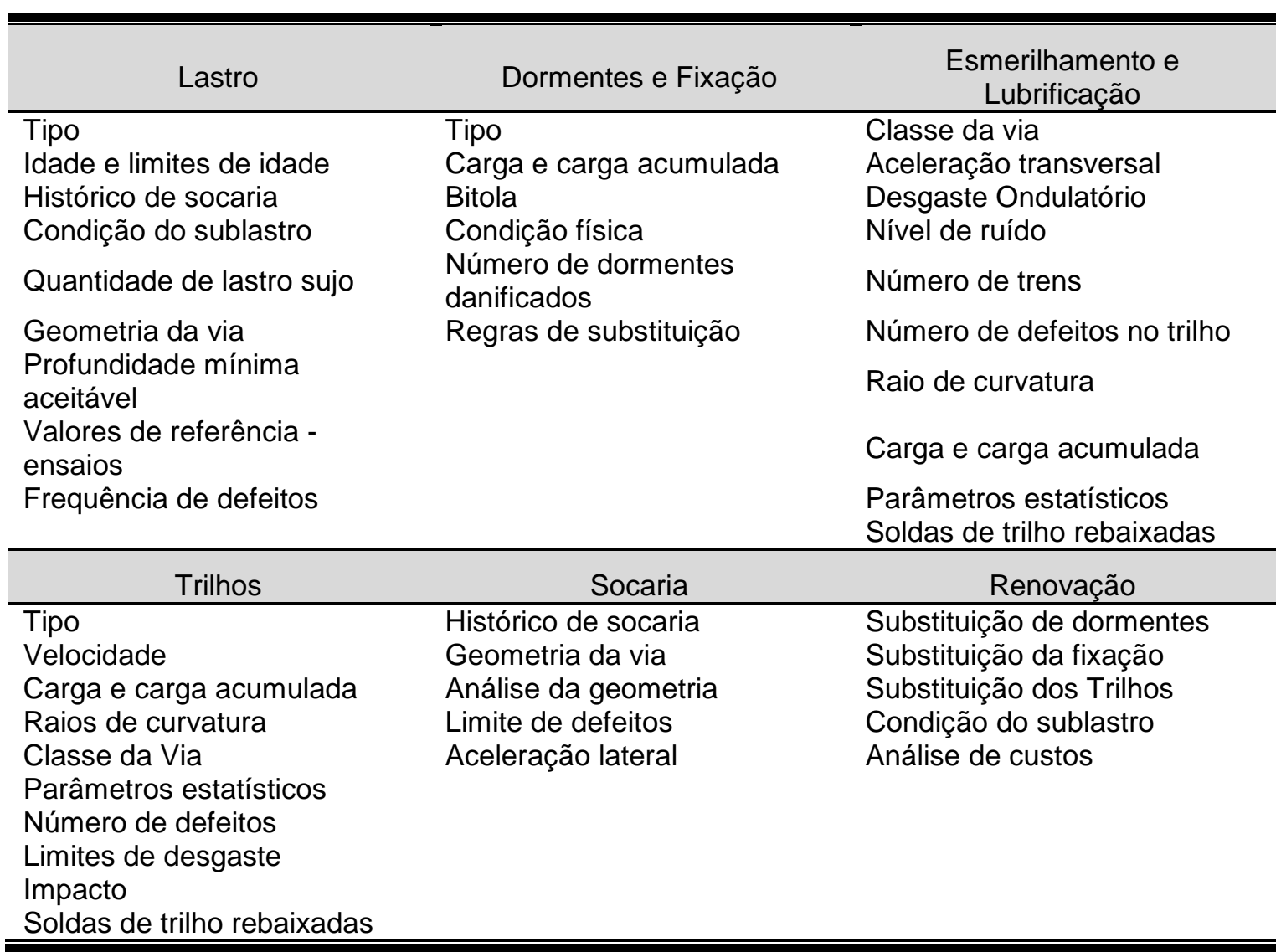

O primeiro estágio do sistema baseia-se em um número mínimo de dados. Os dados são avaliados no sistema de suporte à decisão (DSS) e a via é classificada em três classes de M\&R:

- $M \& R$ de classe I: as seções não requerem qualquer ação $M \& R$, os valores-limite estão abaixo do ponto de alerta. Estas secções são examinadas na fase de consistência;

- M\&R de classe II: as seções exigem operações regulares de M\&R, valores-limite estão entre alerta e intervenção (limite de manutenção e limite operacional);

- M\&R de classe III: as seções podem necessitar de manutenção corretiva e / ou operações de renovação porque os valores-limite são entre o limite de intervenção e o limite máximo (limite operacional). Essas seções são examinadas detalhadamente na segunda fase.

- M\&R de classe IV: o tráfego é proibido. As seções podem necessitar de manutenção corretiva e / ou operações de renovação, os valores excedem o limite operacional. Essas seções são examinadas detalhadamente na segunda fase. 
A segunda fase do sistema baseia-se em dados detalhados, que são valores limite, regras de decisão e modelos de degradação. Os dados de intervenções são analisados para determinar as ações necessárias de $M \& R$, levando em conta a urgência de cada uma das ações. Esta fase também propõe previsões de médio e longo prazo para ações de M\&R.

O estágio de consistência do sistema garante uma análise com base nas regras de decisão, e de coerência das ações no tempo e espaço para o ano seguinte planejado. As operações de manutenção não são programadas antes que a renovação não seja necessária.

O estágio de melhoria utiliza o resultado da fase de consistência e avalia a viabilidade técnico-econômica das operações de $M \& R$, levando em conta as restrições gerenciais e as de alocação de recursos. Este estágio permite ao usuário proceder ao planejamento das ações de $M \& R$ com base nas restrições técnicas (máquinas, pessoal e tempo) e restrições econômicas (recursos para M\&R) fornecidas pelo sistema.

Neste estudo, o sistema de suporte à decisão proposto calcula os custos das obras, considerando as equações dadas nos tópicos de custos do ciclo de vida (LCC). Durante o procedimento de melhoria, os diferentes tipos de manutenção e diferentes tipos de obras de renovação são reagrupados, devido a algumas restrições econômicas (como, por exemplo, substituição de dormentes e fixações é reagrupada com renovação da via ou vice-versa).

Além disso, a interação entre ações de M\&R são consideradas nesta fase, devido a algumas limitações técnicas (por exemplo, o esmerilhamento é realizado apenas depois do trabalho de substituição de dormentes e fixações).

A fase de avaliação do sistema fornece aos usuários a possibilidade de fazer a gestão global de operações de M\&R. Esta etapa permite fazer pleno uso dos dados da via e obter resultados com base em análises estatísticas: simulações aplicadas ao índice de qualidade da via, custos de ciclo de vida da via, orçamento, etc. 


\subsection{Desenvolvimento das Regras de Decisão}

\subsubsection{Descrição do modelo}

O modelo proposto utiliza dados completos de geometria de via e de componentes da via, como as camadas de lastro, trilhos e dormentes. As regras de decisão foram desenvolvidas com base em modelos de degradação, a opinião de especialistas e experiência acumulada. Componentes da geometria da via (trilhos, dormentes e camadas de lastro) e os seus valores-limite são descritos com base nos estudos conduzidos por Guler (2012), Zoeteman (2001b) e Zoeteman (2006).

Os dados de entrada e os produzidos pelo sistema são utilizados no cálculo dos parâmetros, no entanto, outros dados intermediários podem ser produzidos no processo. Regras simples são definidas utilizando os dados relevantes de acordo com o tipo de M\&R. Por exemplo: Se dado entrada $\geq$ valor limite, então, realizar a tarefa, na data.

Geralmente dados da via são extraídos de unidades básicas de seções, geralmente chamados de trechos de via analisados. 0 processo de segmentação é explicado na Figura 5.5. Medição, inspeções, e as obras realizadas na infraestrutura são obtidas para cada seção. Finalmente, a informação necessita ir agregando mais dados em outras seções a fim de obter uma avaliação da qualidade e as consequentes ações de M \& R necessárias (ESVELD, 2001). 


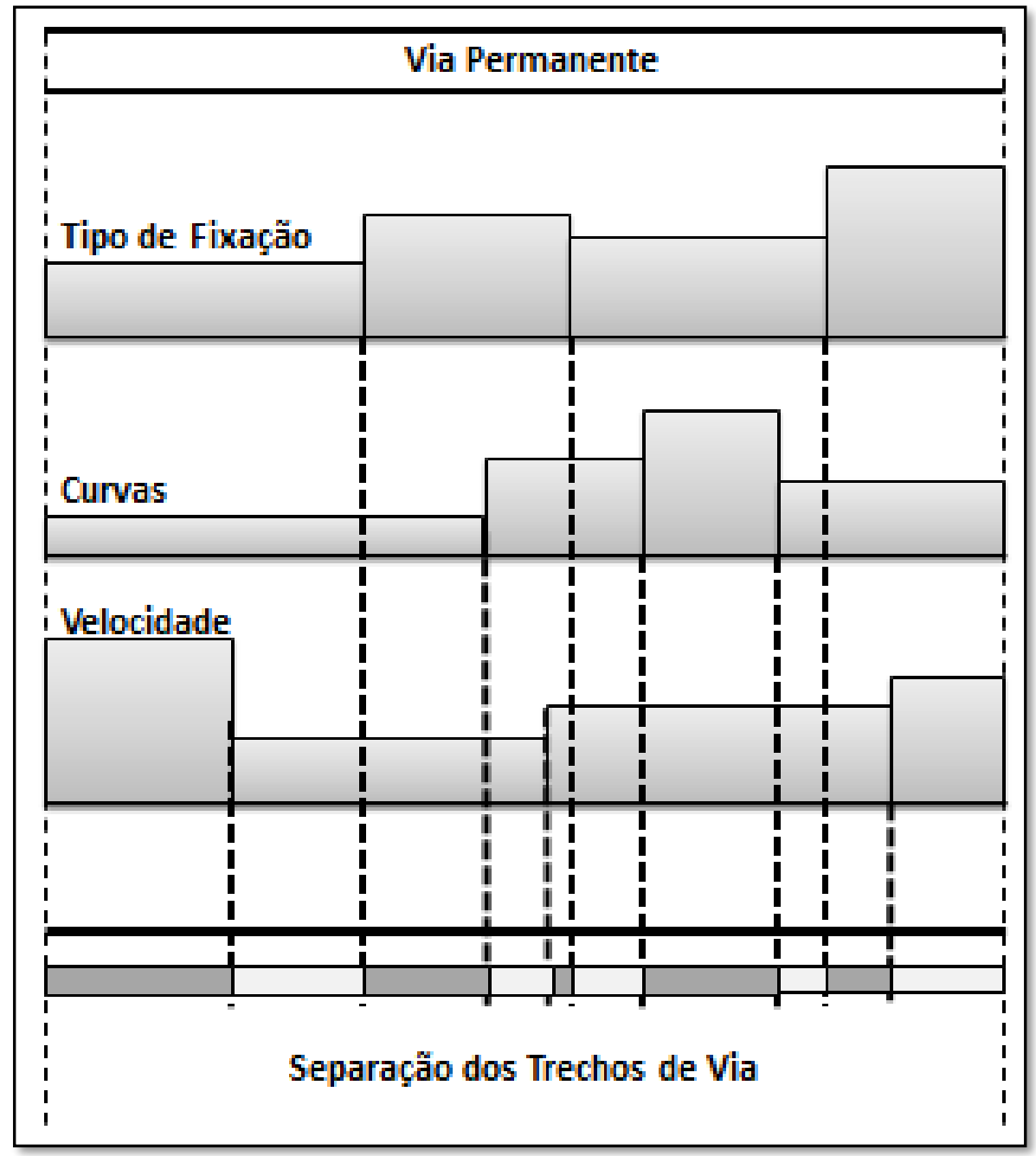

Figura 5.5 - modelo hipotético de separação de trechos de via (Fonte: o autor).

Indicadores relacionados com o conforto, confiabilidade e segurança da via devem ser calculados e controlados com valores limite pré-definidos. Qualquer violação dos valores-limite deve resultar em uma intervenção. Assim, três níveis principais foram considerados durante os procedimentos de desenvolvimento das regras: Limite de Alerta (AL), limite de intervenção (LI) e limite de ação imediata (LIA):

- Limite de Alerta (AL): 0 limite de alerta é um valor estabelecido com base no histórico de falhas que indica a necessidade de atuação dentro de um prazo também estabelecido pelos critérios da ferrovia. Por exemplo, em uma via com nivelamento longitudinal apresentando variação de $10 \mathrm{~mm}$ do valor de projeto. Se o AL é ultrapassado então as condições da geometria são analisadas e consideradas nas operações de manutenção previstas; 
- Limite de intervenção (LI): O limite de intervenção é o valor que obriga a atuação urgente no trecho que apresenta este alarme. Por exemplo, quando o valor de desgaste de um componente de AMV chega em seu limite a substituição do componente deve ser imediatamente planejada e realizada em um prazo que não exceda os limites de inspeção do trecho. Se o LI é excedido então manutenções corretivas são necessárias a fim de que o limite de uma ação imediata não seja alcançado antes da próxima inspeção;

- Limite de ação imediata (LIA): O limite de ação imediata indica que o trecho em avaliação excedeu todos os valores aceitáveis e uma ação imediata deve ser tomada. Se o LIA é excedido então são tomadas as medidas necessárias imediatas para trazer a condição geométrica da via para um nível aceitável.

Estes limites podem ser observados na Figura 5.1 - Degradação Hipotética de um Sistema, aonde o AL é o limite de manutenção (trecho em verde), LI o limite operacional (trecho em amarelo) e o LIA quando o extremo superior do limite operacional é excedido (trecho em vermelho).

Os modelos de degradação devem buscar a determinação do tempo em que cada um dos limites será excedido, de maneira a programar as ações de manutenção antecedendo estas ocorrências. No entanto a via permanente é um sistema complexo e a interação entre os componentes, a não homogeneidade dos materiais e os métodos construtivos com baixa qualidade podem levar a resultados não esperados, ocasionando o aparecimento de situações em que o LIA é alcançado, porém não desejado.

\subsubsection{Geometria de via}

Para calcular a condição geométrica da via a literatura apresenta índices, chamados de índice de qualidade de via. O Índice de Qualidade da Via (TQI) é uma representação numérica da capacidade da via de desempenhar a sua função de projeto. É uma tentativa de quantificar o estado das vias, ou seja, a distinção objetiva entre "bom" e "ruim". 
O índice de qualidade da via é caracterizado pelos desvios observados na geometria da via em termos de bitola, nivelamento, alinhamento, superelevação e torção. Na prática as irregulardades são medidas com carro controle, trólei de medição ou outros instrumentos manuais.

O carro controle é usado para medir a condição de irregularidade da via em condições de carga, enquanto que os outros dois tipos de instrumentos medem a via sem carga. $\mathrm{O}$ carro controle, além de monitorar parâmetros de irregularidades da geometria da via mede simultaneamente parâmetros de resposta da faixa de carregamento da roda como acelerações verticais e laterais. Contudo, existem instrumentos que simulam estes carregamentos por meio de um programa de computador fornecido com o instrumento de medição.

O método global de avaliação de qualidade é baseado em estatísticas de todos os valores de medição de parâmetros de qualidade de um segmento de um dado comprimento, que depende das práticas de gestão e de manutenção. Como estas estatísticas estão diretamente relacionadas com a qualidade de um segmento, elas são geralmente referidas como índice de qualidade da via. 0 segmento de via é parte do banco de dados do sistema e tem em suas características as informações de localização do trecho e data da medição, de mneira que seja possível comparar medições realizadas e verificar o desempenho deste trecho, inclusive avaliando a evolução do índice de qualidade da via.

Neste estudo será utilizado o método J, aplicado aos trechos analisados. Para tomar conhecimento de outros métodos de avaliação da geometria de via recomenda-se a leitura de Sadeghi (2010).

O método J, mostrado na equação 1, é uma aplicação de um índice somatório, com uma aplicabilidade em função da velocidade do trecho. Este método mostra-se adequado para o estudo, pois permite que trechos com comprimentos diferentes sejam avaliados, dependendo da característica de cada um deles, como trecho em curva, trecho em lastro, tercho em laje e demais características encontradas em uma via permanente de sistemas metroferroviários. Além disto, o índice é aplicável para aparelhos de mudança de via que, geralmente, são tratados de forma diferenciada na literatura.

$$
J=\frac{S_{z}+S_{y}+S_{w}+0,5 S_{e}}{3,5}
$$


Aonde:

- $S_{z}$ é o desvio padrão encontrado na bitola do trecho avaliado;

- $\quad$ y é o desvio padrão das irregularidades horizontais no trecho avaliado;

- $\quad S_{w}$ é o desvio padrão da torção no trecho avaliado;

- Se é o desvio padrão das irregularidades verticais no trecho avaliado.

Com o índice J calculado para cada trecho analisado, utiliza-se a Tabela 5.3 para avaliar a qualidade da geometria. A avaliação do índice J, e de sua evolução, permite estabelecer o desempenho da geometria e predizer o momento correto de realização da correção geométrica da via. Esta situação permite a programação da correção geométrica antes que a via atinja limites indesejados e seja necessária uma atuação corretiva.

Tabela 5.3 - Limites de J para trechos de via em função da velocidade (MADEJSKI; GRABCZYK, 2002).

\begin{tabular}{crrrrrr}
\hline Velocidade $(\mathrm{Km} / \mathrm{h})$ & 30 & 40 & 90 & 120 & 160 & 200 \\
Índice J & 12,0 & 11,0 & 6,2 & 4,0 & 2,0 & 1,4 \\
\hline
\end{tabular}

Atividades de M\&R na via sempre envolvem as substituições devido a quebras ou danos resultantes de cargas de tráfego, tempo e/ou defeitos de fabricação. Os seguintes dados são parte do banco de dados para monitorar o comportamento dos trilhos: generalidades, localização precisa do defeito na via, data, método de inspeção, características da via, características do trilho, características da solda de união de trilhos, código do defeito, ações tomadas e descrição do defeito.

\subsubsection{Trilhos}

Três definições de defeitos em trilhos foram especificadas: danificados, trincados e partidos. Esta especificação utiliza a experiência como referência, no entanto é possível ter uma definição documentada no manual UIC 712. Para as operações de $M \& R$, as 
seguintes expressões foram usadas para tornar as recomendações de fácil interpretação pelo pessoal de manutenção:

- Mantenha o trilho em regime de inspeção (AL);

- Substituição do trilho (LI);

- Proibição de tráfego e reparo imediato do trilho (LAI).

O reparo imediato consiste na instalação de uma tala de emergência para garantir a circulação de trens até que seja possível substituir o pedaço de trilho com o defeito identificado, geralmente uma trinca ou separação total do trilho.

As medições dos trilhos, e os valores limite de falha do trilho foram transferidos para o banco de dados do sistema. São eles: localização do ponto de medição de desgaste, desgaste vertical (mm) e lateral (mm), perfil do boleto, perfil no ponto de medição de bitola e desgaste ondulatório ( $\mathrm{mm}$ ). 0 desgaste ondulatório é um fenômeno observado nos trilhos quando temos as seguintes situações: aceleração, frenagem e efeito diferencial. Este fenômeno caracteriza-se pelo aparecimento de pequenas ondas ao longo do trilho, com frequência de $20 \mathrm{~mm}$ a $30 \mathrm{~mm}$ e com profundidade variando de $0,2 \mathrm{~mm}$ a $1,0 \mathrm{~mm}$.

Estudos anteriores mostraram que os defeitos de fadiga em trilhos seguem uma distribuição estatística da lei de Weibull (ZHAO; CHAN; BURROW, 2006). A distribuição de Weibull de dois parâmetros foi utilizada neste estudo para analisar os dados e prever a taxa de falha dos trilhos, pois tem a capacidade de fornecer uma razoável análise e previsibilidade das falhas (KUMAR, 2006).

A aplicação da distribuição de Weibull pode seguir um modelamento com base em estimadores de verossimilhança ou com a aplicação de papel apropriado para traçado do gráfico de Weibull. Os dois modos são eficientes, no entanto para a aplicação do método da verossimilhança é necessário o uso de programas de computador para a determinação dos parâmetros da distribuição. Este trabalho não tem em seus objetivos demonstrar a forma de cálculo para obtenção destes parâmetros, por outro lado a literatura possui várias publicações que abordam a determinação dos parâmetros e os métodos disponíveis, incluindo métodos iterativos de complexa aplicação e realização (LEWIS, 1996; MOUBRAY, 1997; KALLEN; VAN NOORTWIJK, 2005; KUNIEWSKI; VAN DER WEIDE; VAN NOORTWIJK, 2009; MERCIER; MEIER-HIRMER; ROUSSIGNOL, 2012). 
A função utilizada tem a seguinte forma:

$$
F(m)=1-\exp \left[-(m / \eta)^{\beta}\right]
$$

Aonde $m$ é o tempo, a carga acumulada, os ciclos, ou qualquer outro valor que seja considerado na avaliação da degradação, $\eta$ é o parâmetro de escala conhecido como vida característica e $\beta$ relaciona-se com a taxa de falha do componente estudado. Com os valores de $\eta$ e $\beta$ determinados é possível calcular o tempo médio entre falhas, dado pela equação 3.

$$
M T T F=\eta \Gamma[(\beta+1) / \beta]
$$

Por exemplo, suponha que o tempo de vida de um trilho obedeça a uma distribuição de Weibull com parâmetros $\eta=100.000$ horas e $\beta=0,5$ (estes valores são obtidos a partir da análise de dados de vida de trilhos utilizando-se os métodos citados para a determinação dos parâmetros $\eta$ e $\beta$ ).

O tempo médio de vida (MTTF) deste trilho é obtido a partir da equação (3) como:

$$
M T T F=100.000 \Gamma[(0,5+1) / 0,5]=200.000
$$

Ou seja, o trilho tem uma vida estimada de 200.000 horas, com base nos dados analisados e nos parâmetros calculados. Com esta informação é possível programar a manutenção deste trecho de via de maneira que o trilho seja substituído antes do final de sua vida.

\subsubsection{Dormentes}

Os dormentes são elementos importantes da via permanente. Na manutenção de via, a substituição de dormentes representa um custo significativo. Neste estudo decisões 
relacionadas com dormentes são baseadas em dados armazenados no banco de dados (idade, tipo, tonelagem, etc.), as medições de geometria e os resultados de uma avaliação visual de dormentes (YELLA; DOUGHERTY; GUPTA, 2009).

Existem duas possibilidades de defeitos em dormentes de concreto, classificados em rachaduras e defeitos de superfície. A classificação deste tipo de defeito em dormentes é particular para cada gestor. A convivência com os defeitos e o momento de substituição é determinada pelo fiscal que faz a inspeção do trecho. Geralmente o inspetor tem parâmetros definidos, estabelecidos em documentos internos de manutenção. Não obstante existem regras disponíveis da FRA (Federal Railroad Administration) e UIC (Union Internationale des Chemins de fer) para classificação de dormentes em função de defeitos.

Os estudos realizados em diferentes tipos de via mostrou que o desgaste e danos de ambos dormentes, madeira e concreto, era muito pequeno dentro de um tempo relativamente longo, mas crescem muito rápido no período final (LAKE; FERREIRA; MURRAY, 2000; R GUSTAVSON, 2002; YUN; FERREIRA, 2003; ZHAO; CHAN; BURROW, 2006; YELLA; RAHMAN; DOUGHERTY, 2010). Assim, este fenômeno é não linear.

As distribuições de probabilidade são utilizadas para modelar acontecimentos aleatórios para o qual o resultado é incerto, desta forma, a distribuição das probabilidades de falha em momentos diferentes pode ser modelada por uma distribuição de probabilidades. A função densidade de probabilidade (pdf), representada como $f(t)$ é uma função positiva com uma unidade como área (RAUSAND, 2004; STAPELBERG, 2009):

$$
f(t)=\int_{-\infty}^{\infty} f(t) d t
$$

A distribuição exponencial é utilizada com frequência em engenharia de confiabilidade para modelar o comportamento de ativos que tenham uma taxa de falhas estável. A função densidade de probabilidade (pdf) exponencial de um parâmetro é dada por:

$$
f(t)=\lambda e^{-\lambda t}
$$


0 valor de $\lambda$ é obtido a partir dos dados de falha dos dormentes. Este parâmetro é o inverso do tempo médio entre falhas de um determinado componente, neste caso os dormentes. A sua determinação é simples, o tempo de vida, desde a instalação até o aparecimento de falha, de cada um dos dormentes considerados no trecho analisado, deve ser registrado. Com a informação do tempo de vida individual calcula-se o tempo médio (MTTF) que é dado pela equação (6):

$$
M T T F=\frac{\sum_{i=i}^{n} T T F_{i}}{n}
$$

Aonde TTF é o tempo até a falha e MTTF é o tempo médio até a falha. Assim, $\lambda$ é dado pela equação (7):

$$
\lambda=\frac{1}{M T T F}
$$

A função probabilidade acumulada é dada pela equação (8):

$$
F(t)=1-e^{-\lambda t}
$$

Assim, a função confiabilidade pode ser escrita como mostrado na equação (9):

$$
R(t)=e^{-\lambda t}
$$

Com o uso da equação (9), sabendo qual o MTTF com base nos registros de manutenção, é possível estabelecer qual o nível de confiabilidade desejado e calcular o 
tempo em que este nível de confiabilidade é válido, ou determinar um intervalo de manutenção e verificar qual a confiabilidade alcançada.

$\mathrm{Na}$ prática as ações de manutenção são conjugadas e determina-se qual a confiabilidade alcançada para um determinado intervalo de tempo. Se esta confiabilidade não é aceitável estuda-se uma nova forma de intervenção, de maneira a atender as necessidades estabelecidas pela gestão da manutenção.

\subsubsection{Lastro}

O lastro tem um papel importante no desempenho da via em relação a controlar a rigidez de suporte, manutenção da geometria da via e drenagem. 0 termo geral para refere-se tanto ao lastro como as camadas de sublastro. Neste estudo, a Figura 5.6 foi considerada para a estrutura da via, durante o processo de coleta de dados.

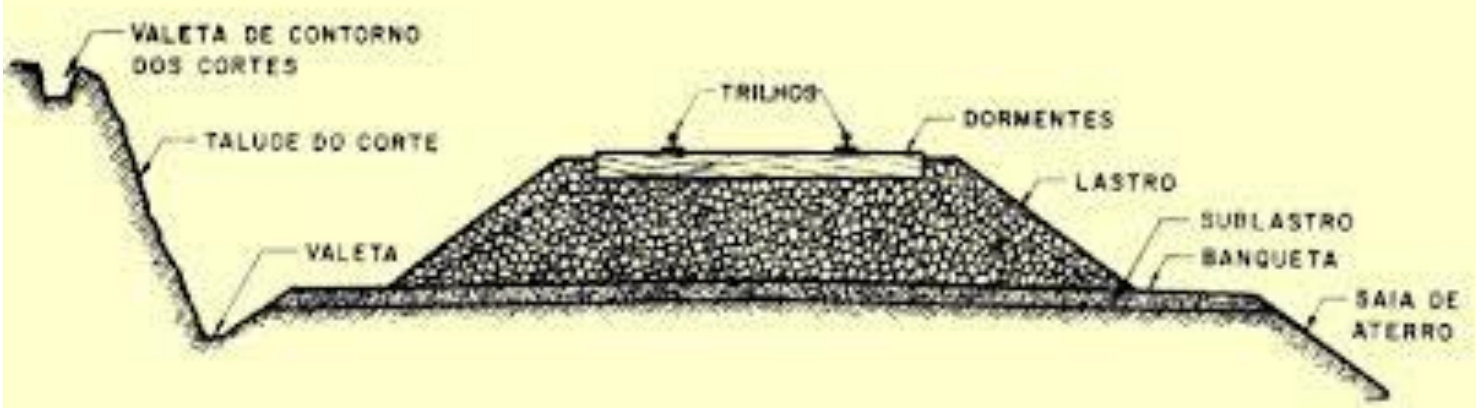

Figura 5.6 - Via permanente montada em lastro de pedra britada (Fonte: Brina, 1977).

O lastro é formado a partir de pedra britada (brita) e consiste de partículas variando em tamanhos de 20 a 63 milímetros. A boa qualidade do lastro indica que devem existir agregados bem graduados, mas a existência de uma grande quantidade de finos no lastro (material resultante do atrito entre as britas) pode resultar rapidamente em problemas de drenagem e nivelamento (BONNETT, 2005). 
O cálculo aplicado para a necessidade de socaria é com a utilização dos valores históricos de atuação de socaria, o tempo entre falhas (TTF). Aplicando-se a mesma técnica de confiabilidade, utilizada na predição de vida dos trilhos ou dormentes, é possível estabelecer o tempo médio de atuação da socaria e com esta informação estabelecer uma rotina de socaria. Dada a disponibilidade de dados históricos, este foi o método utilizado neste trabalho.

\subsubsection{Custo do ciclo de vida}

O custo do ciclo de vida (LCC) leva em conta todos os custos associados com o tempo de vida útil do sistema, tais como custos operacionais, de manutenção, de energia e impostos, além dos custos de capital (PATRA, 2009). O custo do ciclo de vida é uma ferramenta de engenharia para auxílio à decisão na concepção, aquisição e manutenção de grandes sistemas.

Neste estudo, trechos padrão de $200 \mathrm{~m}$ foram considerados para o cálculo dos custos. Mesmo que haja diferença no método construtivo, nas atuações de manutenção, e no tempo de vida dos componentes instalados em distintas configurações foi observado, para este caso em específico, que o " $m i x$ " de componentes, equipamentos e ações de manutenção necessárias para cada trecho de via acabam por levar a uma distribuição homogênea dos custos

O número de atividades de manutenção, para um determinado período, foi calculado considerando as cargas acumuladas e possíveis exceções definidas pela análise qualitativa dos dados disponíveis.

Ainda assim, um método tradicional de levantamento de custos deve ser considerado, para que sirva de referência para os eventuais utilizadores deste trabalho como base para aplicação prática. De tal feita, é apresentado o modelo abaixo, que considera todos os custos envolvidos na manutenção e renovação de uma via permanente.

Mesmo que os componentes da via estejam em boas condições, as estruturas podem ser parcialmente ou completamente danificadas por várias razões, tais como inundações, trincas, fadiga, etc. Nesta situação, é necessário reparar a estrutura danificada durante a atividade de manutenção. Portanto, um custo adicional foi somado ao custo 
total, considerando as estruturas na seção em manutenção. Os custos de M\&R foram determinados de acordo com as recomendações em Patra (2009). A formulação para a análise do custo do ciclo de vida é apresentada abaixo:

Custo de Esmerilhamento:

$$
R G C=\sum_{S=1}^{S} \sum_{i=1}^{R} \sum_{j=1}^{N-1} \frac{\left(C_{R G S}+\left(T_{R G i} C_{L} L_{i} n_{R G i}\right)+\left(T_{R G i} C_{E R G} L_{i} n_{R G i}\right)\right)\left(M / M_{R G i}\right)}{(1+r)^{j}}
$$

Custo de Lubrificação:

$$
R L C=\sum_{S=1}^{S} \sum_{i=1}^{R} \sum_{j=1}^{N-1} \frac{\left(C_{R L S}+\left(T_{R L i} C_{L} L_{i}\right)+\left(T_{R L i} C_{E R L} L_{i}\right)\right)\left(M / M_{R L i}\right)}{(1+r)^{j}}
$$

Custo de Substituição de Trilhos

$$
R R C=\sum_{S=1}^{S} \sum_{i=1}^{R} \sum_{j=1}^{N-1} \frac{\left(C_{R R S}+\left(C_{R} L_{i}\right)+\left(T_{R R i} C_{E} L_{i}\right)+\left(T_{R R i} C_{E R R} L_{i}\right)\right)\left(M / M_{R R i}\right)}{(1+r)^{j}}
$$

Custo de Socaria

$$
T A C=\sum_{S=1}^{S} \sum_{i=1}^{R} \sum_{j=1}^{N-1} \frac{\left(C_{T S}+\left(T_{T i} C_{L} L_{i}\right)+\left(C_{T i} C_{E T} L_{i}\right)\right)\left(M / M_{T i}\right)}{(1+r)^{j}}
$$

Custo de Substituição do Lastro

$$
B R C=\sum_{S=1}^{S} \sum_{i=1}^{R} \sum_{j=1}^{N-1} \frac{\left(C_{B R s}+\left(C_{R B} L_{i}\right)+\left(T_{B R i} C_{L} L_{i}\right)+\left(T_{B R i} C_{E B R} L_{i}\right)\right)\left(M / M_{B R i}\right)}{(1+r)^{j}}
$$


Custo de Limpeza do Lastro

$$
B C C=\sum_{S=1}^{S} \sum_{i=1}^{R} \sum_{j=1}^{N-1} \frac{\left(C_{B C S}+\left(T_{R B C i} L_{i} C_{L}\right)+\left(T_{B C i} C_{E B C} L_{i}\right)\right)\left(M / M_{B C i}\right)}{(1+r)^{j}}
$$

Custo de Substituição de Dormentes

$$
S R C=\sum_{S=1}^{S} \sum_{i=1}^{R} \sum_{j=1}^{N-1} \frac{\left(C_{S R S}+\left(C_{R S} L_{i}\right)+\left(T_{S R i} C_{L} L_{i}\right)+\left(T_{S R i} C_{E S R} L_{i}\right)\right)\left(M / M_{S R i}\right)}{(1+r)^{j}}
$$

Custo de Substituição de Fixações

$$
F R C=\sum_{S=1}^{S} \sum_{i=1}^{R} \sum_{j=1}^{N-1} \frac{\left(C_{F R S}+\left(C_{R F} L_{i}\right)+\left(T_{F R i} C_{L} L_{i}\right)+\left(T_{F R i} C_{E F R} L_{i}\right)\right)\left(M / M_{F R i}\right)}{(1+r)^{j}}
$$

Custo de Inspeção de Via

$$
T I C=\sum_{S=1}^{S} \sum_{j=1}^{N-1} \frac{\left(C_{T I S}+\left(T_{T I} C_{L} L\right)+\left(T_{T I} C_{E T I} L\right)\right)\left(M / M_{T I}\right)}{(1+r)^{j}}
$$

Siglas usadas:

- AfrCs = custo adicional de substituição das fixações, \$;

- $\quad$ C = índice de condição da via;

- $\mathrm{C}_{\mathrm{B}}=$ custo do lastro, $\$ / \mathrm{km}$;

- $\mathrm{C}_{\mathrm{BCs}}=$ custo adicional de limpeza do lastro, \$;

- $\mathrm{C}_{\mathrm{BRs}}=$ custo adicional de substituição do lastro, \$;

- $\mathrm{C}_{\mathrm{EBC}}=$ custo do equipamento para limpeza do lastro, $\$ / \mathrm{h}$;

- $\mathrm{C}_{\mathrm{EBR}}=$ custo do equipamento para troca do lastro, $\$ / \mathrm{h}$;

- $C_{E F R}=$ custo do equipamento para substituição da fixação, \$/h;

- $\mathrm{CERG}_{\mathrm{ERG}}$ custo do equipamento para esmerilhamento, $\$ / \mathrm{h}$; 
- $\mathrm{CERL}_{\mathrm{ER}}=$ custo de lubrificação, $\$ / \mathrm{h}$;

- $C_{E R R}=$ custo do equipamento para substituição de trilho, $\$ / h$;

- $\mathrm{CESR}_{\mathrm{ES}}=$ custo do equipamento para substituição de dormentes, $\$ / \mathrm{h}$;

- $\mathrm{C}_{\mathrm{ET}}=$ custo do equipamento de socaria, $\$ / \mathrm{h}$;

- CETI = custo do equipamento de inspeção de via, \$/h;

- $C_{F}=$ custo da fixação, $\$ / \mathrm{km}$;

- $\mathrm{C}_{\mathrm{L}}=$ custo médio da mão de obra, $\$ / \mathrm{h}$;

$-\mathrm{C}_{\mathrm{R}}=$ custo do trilho, $\$ / \mathrm{km}$;

- $\mathrm{C}_{\mathrm{RGs}}=$ custo adicional de esmerilhamento, \$;

- $\mathrm{C}_{\mathrm{RLs}}=$ custo adicional de lubrificação, \$;

- $\mathrm{C}_{\mathrm{RRs}}=$ custo adicional de substituição de trilhos, \$;

- C CSRs = custo adicional de substituição de dormentes, \$;

- $\mathrm{C}_{\mathrm{Ts}}=$ custo adicional de socaria, \$;

- $\quad C_{\text {TIs }}=$ custo adicional de inspeção de via, \$;

- $F(m)=$ distribuição acumulada de falhas;

- $\mathrm{f}(m)$ = função densidade;

- $\mathrm{k}$ = coeficiente de manutenção do lastro;

- $\mathrm{k}_{\mathrm{f}}=$ fator de ajuste de idade ou carga acumulada no lastro;

- $\mathrm{L}=$ comprimento total da seção de via, $\mathrm{km}$;

- $\mathrm{Li}_{\mathrm{i}}=$ comprimento da seção de via em manutenção, $\mathrm{km}$;

- $\quad$ l = número annual de socarias;

- $\mathrm{l}_{\mathrm{m}}=$ número médio annual de socarias;

- ls = limite admissível de socarias por ano;

- $\mathrm{M}=$ carga cumulada, ou idade;

- $M_{L}=$ carga acumulada limite;

- $\mathrm{M}_{\mathrm{BCi}}=$ intervalo para limpeza do lastro, em toneladas brutas acumuladas;

- $\mathrm{M}_{\mathrm{BRi}}=$ intervalo para substituição do lastro, em toneladas brutas acumuladas;

- $M_{\text {Fri }}=$ intervalo para substituição das fixações, em toneladas brutas acumuladas;

- $\mathrm{M}_{\mathrm{RGi}}=$ = intervalo para esmerilhamento da curva, em toneladas brutas acumuladas;

- MRLi = intervalo para lubrificação da via, em toneladas brutas acumuladas;

- $\mathrm{M}_{\mathrm{RRi}}=$ = intervalo para substituição do trilho, em toneladas brutas acumuladas;

- $\mathrm{M}_{\text {Sri }}=$ intervalo para substituição do lastro, em toneladas brutas acumuladas; 
- $\mathrm{M}_{\mathrm{TI}}=$ = intervalo para inspeção da via, em toneladas brutas acumuladas;

- $\mathrm{MTi}=$ = intervalo para socaria da via, em toneladas brutas acumuladas;

- $\mathrm{N}$ = período de vida da via em anos;

- $\quad \mathrm{n}_{\mathrm{RGi}}=$ número de passes de esmerilhamento na curva;

- $\quad \mathrm{R}=$ raio da curva;

- $R_{c}=$ identificação da curva;

- $\mathrm{R}_{\mathrm{e}}=$ substituição;

- $r=$ taxa de juros;

- $\quad$ S = número de estruturas;

- $\quad$ TBCi $=$ tempo médio de limpeza do lastro, $\mathrm{h}$.

Este trabalho conta com um capítulo específico para sugerir um sistema de informações geográficas e um banco de dados geográficos, que serão as ferramentas de armazenamento e visualização dos dados. Estas ferramentas servirão como parte do sistema de suporte a decisão, permitindo a visualização das estratégias de manutenção com base nos modelos de degradação e custo do ciclo de vida.

Com a apresentação da proposta de cálculo para a degradação dos componentes de via e dos custos envolvidos com cada uma das atividades de manutenção, temos um modelo que pode ser incorporado ao sistema de informações geográficas (SIG) e ao banco de dados geográfico. 


\section{O PROCESSO DECISÓRIO}

\subsection{Introdução}

Apesar da importância da tomada de decisões a preocupação com a formação de profissionais nesta área de conhecimento ainda é pequena. Assim, contamos com a experiência para acumular conhecimento tácito e qualitativo sobre decisões. No entanto, a experiência é, por vezes, ineficiente, e agrega, junto com as boas práticas, os maus hábitos (HAMMOND; KEENEY; RAIFFA, 2002).

A tomada de decisão é uma das tarefas difíceis da vida. A tomada de decisão verdadeira não ocorre quando se define exatamente o que fazer, mas quando ainda não é conhecido o que fazer (MCNAMEE; CELONA, 2001). Quando valores conflitantes devem ser equilibrados, situações complexas carecem de classificação e a incerteza é real, é quando o ponto de tomada de decisão é alcançado.

A análise de decisão é uma disciplina normativa, o que significa que ela descreve como as pessoas devem, logicamente, tomar decisões. Especificamente, corresponde como as pessoas tomam decisões em situações simples e mostra como esse comportamento deve, logicamente, ser estendido a situações mais complexas (WATSON, 1987). 


\subsection{A Filosofia da Decisão}

Como filosofia, a análise de decisão descreve de forma racional e coerente uma maneira de tomar decisões. Como tal, fornece aos decisores duas visões.

A primeira visão é que a incerteza é uma consequência do nosso conhecimento incompleto do mundo. Em alguns casos, a incerteza pode ser parcialmente ou completamente resolvida antes que as decisões sejam tomadas e os recursos comprometidos. No entanto, em muitos casos, a informação completa simplesmente não está disponível ou é dispendiosa de obter (em tempo, dinheiro ou outros recursos). Embora essa visão possa parecer clara, parece que existe uma tendência em negar a existência de incerteza, exceto, talvez, como algo a ser eliminado antes da ação a ser tomada.

A segunda ideia básica é que não há distinção entre boas decisões e bons resultados. Os bons resultados são o desejado, enquanto boas decisões é o que deve ser feito como forma de maximizar a probabilidade de ter bons resultados. Considerando a incerteza, somada a racionalidade limitada, uma boa decisão pode, por vezes, ter um resultado ruim. Esta situação deve considerar que no estabelecimento do problema e definição dos objetivos houve alguma falha, levando a um resultado indesejado. É comum na literatura a máxima de que é melhor uma decisão mediana sobre um problema bem formulado do que uma decisão ótima sobre um problema formulado com deficiências.

A tomada de decisão é um processo de escolha entre cursos alternativos de ação para atingir metas e objetivos. O ganhador do prêmio Nobel Herbert Simon (SIMON, 1997) escreveu que todo o processo de tomada de decisões gerenciais é sinônimo da prática de gestão. A tomada de decisão é o cerne de todas as funções gerenciais. Planejamento, por exemplo, envolve decidir o que deve ser feito? Quando? Como? Onde? Por quem? Outras funções de gestão, como a organização, implantação e controle dependem fortemente de tomada de decisões. 


\subsection{O Processo de Decisão}

A rápida mudança no ambiente corporativo exige um processo de tomada de decisão adequado para que o sucesso seja alcançado. Isso não significa apenas coleta e processamento de dados, mas também a tomada de decisões com o apoio de métodos (FORMAN; SELLY, 2002).

É fato comum a importância de informações relevantes na tomada de decisões. No entanto a simples coleta e análise de dados, seguida de avaliações e validação com objetivos não é suficiente para que o processo decisório alcance o sucesso. Já é um pensamento corrente que as decisões devem ser acompanhadas e que o seu curso deve ser permanentemente ajustado para alcançar os objetivos da corporação.

A conexão entre as decisões reside na forma de decidir, e não no que é decidido. Assim, de maneira a conseguir um sucesso razoável nas decisões o caminho é o de usar um processo de tomada de decisão que leva para a melhor solução com o mínimo de perda de tempo, energia, dinheiro e na medida.

\subsubsection{As etapas do processo de Decisão}

Um processo de decisão eficaz irá cumprir estes seis critérios:

- Concentra-se no que é importante;

- É lógico e consistente;

- Reconhece fatores subjetivos e objetivos e combina o pensamento analítico e intuitivo;

- Exige apenas a quantidade mínima de informações para resolver um problema em particular;

- Incentiva e orienta para a coleta de informações relevantes;

- É simples, confiável, fácil de usar e flexível. 
Uma abordagem de tomada de decisão que utiliza esses critérios pode ser aplicada em qualquer dimensão de decisão. À medida que o processo é utilizado as decisões tornam-se cada vez mais acertadas, dado o refinamento do processo.

Há oito elementos para a tomada de decisões eficaz, que seguem:

a. Foco no problema e sobre o que decidir.

A maneira como a decisão é modelada no início pode fazer toda a diferença. Para escolher bem, é necessário declarar os problemas de decisão com cuidado, reconhecendo a sua complexidade e evitando suposições não comprovadas e preconceitos de limitação de opção.

b. Especifique os objetivos.

A decisão levar a consecução de um objetivo. A decisão é um meio para um fim. Perguntar quais os interesses, valores, preocupações, medos e aspirações são os mais relevantes para atingir o objetivo é uma maneira clara de especifica-los. Pensando através de objetivos será mostrada a direção para a tomada de decisão.

c. Criar alternativas.

As alternativas representam os diferentes cursos de ação possíveis de escolha. Sem alternativas não há uma decisão a ser tomada. É importante a geração de alternativas de forma que haja possibilidade de escolha e, assim, a decisão não será melhor do que a melhor alternativa.

d. Entenda as consequências.

Avaliar as consequências de cada alternativa ajudará a identificar qual decisão que melhor atender aos objetivos. Trata-se de avaliar qual o nível de satisfação que cada uma das decisões propiciará.

e. Lidar com vantagens e desvantagens.

Os objetivos almejados podem ser conflitantes, de forma que é necessário encontrar um equilíbrio. Na maioria das decisões complexas, não há uma alternativa perfeita. Diferentes alternativas cumprem diferentes objetivos. A tarefa é escolher de forma inteligente entre as possibilidades. Para isso, é necessário definir prioridades, abordando a necessidade de compensações entre objetivos conflitantes.

f. Esclareça as incertezas. 
Decisões eficazes sempre remetem a um grau de incerteza, a julgar a probabilidade de resultados diferentes e avaliar seus possíveis impactos. A incerteza é parte integrante das decisões.

g. Avalie a tolerância ao risco.

Quando as decisões envolvem incertezas, e sempre envolvem, a consequência desejada pode não ser a única que realmente resulta. A percepção consciente de aceitar o risco vai fazer com que o processo de tomada de decisão seja mais fácil e eficaz, vai ajudar a escolher uma alternativa com o nível certo de risco.

h. Considerar as decisões conectadas.

O que é decidido hoje pode influenciar nas decisões futuras, da mesma forma que os objetivos futuros podem influenciar as decisões de hoje. Muitas decisões estão ligadas ao longo do tempo. A forma de lidar com as decisões que estejam conectadas ligadas é isolar e resolver problemas de curto prazo, enquanto são recolhidas as informações necessárias para as decisões futuras. Através desta sequência de ações os problemas, e as decisões, são depurados, permitindo que a decisão seja a mais adequada mesmo em um ambiente de incertezas.

\subsubsection{A incerteza e a engenharia de sistemas}

O tratamento da incerteza na análise, projeto, e tomada de decisão está passando por uma mudança de paradigma. Assim, a incerteza passa de uma estrutura probabilística para um quadro generalizado que inclui ambos os métodos, probabilísticos e não probabilísticos.

Atualmente, analistas, incluindo engenheiros e cientistas, reconhecem a presença de incerteza e tratam o assunto formalmente. Por exemplo, os engenheiros analisam a incerteza do modelo em muitos de seus campos de especialidade, tais como o desenvolvimento de códigos de construção, análise de riscos naturais (inundações, ventos e terremotos), tomada de decisão em despesas de manutenção de infraestrutura, segurança interna e de proteção de ativos e riscos ambientais. 
O interesse na incerteza vai continuar a aumentar à medida que o projeto de sistemas fica cada vez mais complexo, com o aparecimento de novas tecnologias, sistemas e materiais. Neste cenário as decisões são quase sempre críticas com consequências adversas. Além disso, as exigências políticas, sociais e financeiras aumentam, acrescentando novas dimensões de complexidade para atender às demandas da sociedade. As expectativas da sociedade aumentam, e a tolerância a erros diminui. 0 agregado desses fatores produz um ambiente que exige a consideração formal da incerteza na tomada de decisões em todos os níveis.

Problemas comuns exigem a tomada de decisões em condições de incerteza e falta de conhecimento. A falta de conhecimento pode ser relacionada com a definição de um problema, as metodologias de soluções alternativas e seus resultados, e da natureza dos resultados da solução. Com base nas tendências atuais, os analistas devem resolver problemas complexos com decisões tomadas em condições de recursos limitados, necessitando, portanto, aumento da dependência do tratamento adequado da incerteza e da utilização de opiniões de especialistas.

A complexidade de uma decisão pode aumentar substancialmente pela inclusão de incertezas, exigindo assim, em muitos casos, a dependência de peritos para lançar luz sobre a situação. A complexidade da nossa sociedade e sua base de conhecimento exigiu a especialização de seus membros para tornarem-se especialistas. Sabemos de nossas próprias experiências que os especialistas são valiosas fontes de informação e conhecimento, mas também podem estar errados em seus pontos de vista. As opiniões dos especialistas, portanto, podem ser consideradas como informação não fatual.

\subsubsection{Breve descrição de sistemas}

A definição e articulação de problemas de engenharia é uma tarefa crítica nos processos de análise e projeto, e pode ser realizada de forma sistemática dentro de uma estrutura de sistemas. A formulação adequada de um problema é muito mais essencial do que a sua solução. Os limites do sistema são desenhados com base na missão, metas e objetivos da análise, e da classe de desempenhos (incluindo falhas) em consideração. Uma visão generalizada de um sistema pode ser vista na Figura 6.1. 


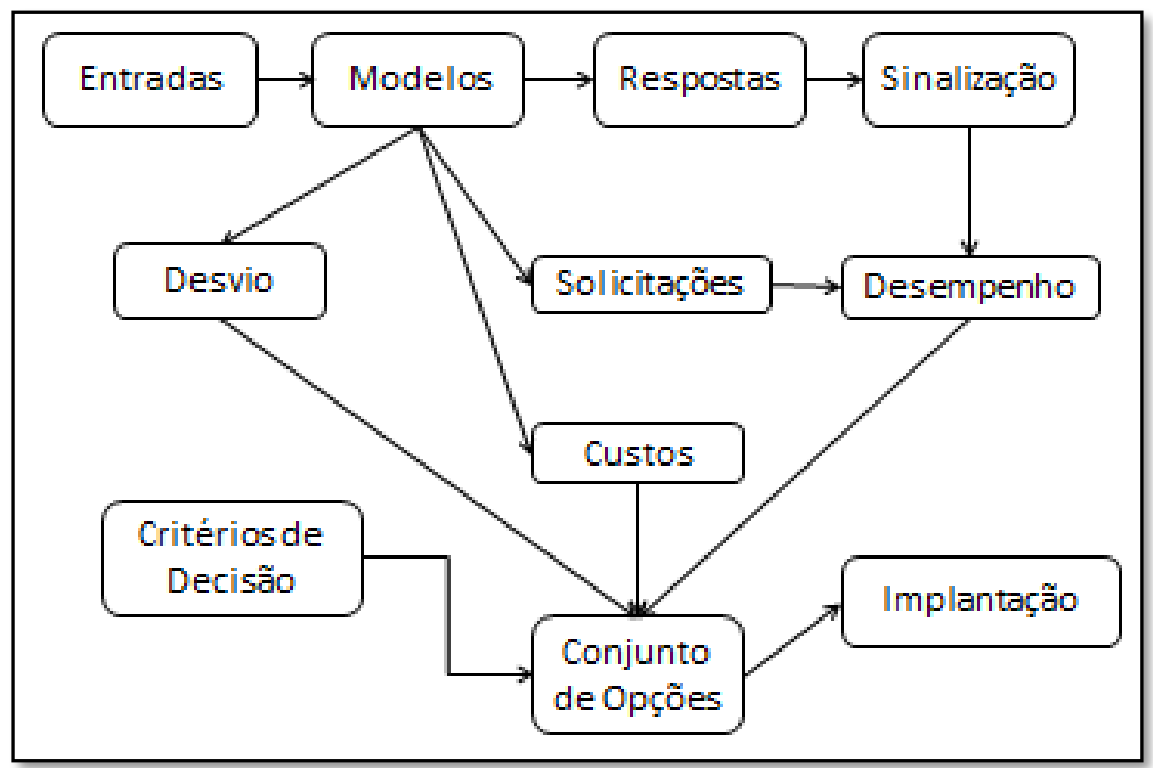

Figura 6.1 - Visão Geral de um Sistema. Adaptado de Patra (2009).

A formulação generalizada de sistemas permite o desenvolvimento de uma compreensão completa e abrangente da natureza de um problema, os fenômenos físicos subjacentes, os processos e atividades. A definição do sistema é, geralmente, o primeiro passo de um método formulado para atingir um conjunto de objetivos. Esta definição pode ser baseada em observações em diferentes níveis do sistema que são estabelecidos a partir destes objetivos. As observações podem ser sobre os diferentes elementos (ou componentes) do sistema, as interações entre estes elementos, bem como o comportamento esperado do sistema.

Cada nível de conhecimento que se obtém sobre um problema define um sistema para representa-lo. Como os níveis adicionais de conhecimento são adicionados aos anteriores, estes formam uma hierarquia das descrições do sistema.

Informalmente, o que é um sistema? 0 termo se origina da palavra grega systma, que significa um todo organizado. Um sistema pode ser definido como um grupo ou itens interdependentes interagindo regularmente que formam um todo unificado, tais como um sistema solar, ou o sistema de ferrovias. Todas as partes de um sistema estão relacionadas com o mesmo processo, procedimento ou estrutura geral, no entanto, são mutuamente diferentes e, muitas vezes, executam funções diferentes (SAGE; ARMSTRONG, 2000). 
Os sistemas são tradicionalmente agrupados em várias categorias:

- Os sistemas naturais, como por exemplo, sistemas fluviais e sistemas de energia;

- Sistemas feitos pelo Homem que podem ser incorporados nos sistemas naturais, como, por exemplo, sistemas de hidrelétricas e sistemas de navegação;

- Sistemas físicos que são feitos de componentes reais de ocupação do espaço, tais como automóveis e computadores;

- Sistemas conceituais que poderiam levar a sistemas físicos;

- Os sistemas estáticos sem qualquer atividade, tal qual pontes submetidas a cargas mortas;

- Sistemas dinâmicos, com, por exemplo, os sistemas de transporte;

- Sistemas fechados ou sistemas alimentados, tais como um processo de equilíbrio químico e sistemas logísticos, respectivamente.

De uma forma generalizada, estes conceitos básicos da tomada de decisão e da engenharia de sistemas foram levados em consideração na proposta do sistema de suporte a decisão descrita neste trabalho. 0 sistema de informações geográficas e o banco de dados geográfico sugeridos também foram avaliados sob esta perspectiva, de maneira que haja uma integração entre as diversas ferramentas de decisão e os princípios básicos que regem esta área do conhecimento. 


\section{INDICADORES}

Este capítulo pretende identificar e estudar os indicadores de desempenho de manutenção (MPI - do inglês Maintenance Performance Indicators) utilizados na indústria em geral e os relacionados à infraestrutura metroferroviária, qual a sua aplicação e analisar a sua utilidade na manutenção e no planejamento da infraestrutura.

O estudo possibilitará identificar e analisar os indicadores de manutenção. Fornecerá recomendações para a sua implantação, e como podem servir de elo para apoiar e conectar o processo de tomada de decisão na manutenção com relação a atendimento dos requisitos do cliente, necessidades do usuário, segurança, impacto ambiental e lucro. Também mostrará como os indicadores devem ter uma ligação direta com os objetivos e estratégias organizacionais.

\subsection{Histórico}

A evolução e utilização de indicadores de desempenho, em uma perspectiva mais ampla, começaram na década de 1880 nos EUA (AHREN, 2005). A evolução dos sistemas de gestão de contabilidade permitiu o conhecimento e manejo das informações relevantes, precisas e oportunas sobre as atividades internas de uma organização.

Desde o início, o uso destes sistemas poderia ter um olhar tal como a abordagem de um engenheiro para garantir uma boa alocação de recursos e utilização; ou seja, o foco foi colocado sobre as decisões de gestão e não no lucro relatado. A partir da década de 
1920, o uso destes sistemas declinou devido aos custos crescentes necessários para mantê-los em uso na medida que a empresa crescia. Ao mesmo tempo, a influência dos contabilistas foi aumentando, com um foco maior sobre o lucro reportado do que em decisões de gestão, ou seja, a abordagem do auditor. Durante o final da década de 1960 aumentou a necessidade de parâmetros para tomada de decisões de gestão de engenharia (HUSBAND, 1976).

Hoje, há um grande número de sistemas informatizados de gestão de manutenção disponíveis no mercado (vide capítulo sobre sistema de suporte à decisão). Alguns deles são aplicações dedicadas, enquanto outros são partes de soluções completas de negócios. Independente do sistema escolhido, uma questão importante é fazer a ponte entre os objetivos globais, as estratégias, e o sistema de medição de desempenho (ESPLING, 2007). Uma forma de conseguir isto é com o uso de diferentes modelos (LIYANAGE; KUMAR, 2002 ; LIYANAGE; KUMAR, 2003).

\subsection{Abordagem do Tema}

O sistema metroferroviário é um sistema complexo, usado para transporte de passageiros, onde as considerações políticas e sociais têm de ser levadas em conta; por exemplo, segurança e impacto ambiental, e as demandas públicas por transporte seguro, confiável e de baixo custo. Portanto, grandes investimentos e reinvestimentos são realizados para atualizar e atender os requisitos do sistema como, por exemplo, diminuição do intervalo entre trens, aumento da capacidade de passageiros transportados por trem e, em consequência, aumento da carga por eixo.

O planejamento futuro prevê novos investimentos, a fim de aumentar a capacidade da infraestrutura. Quando se olha para a rede metroferroviária como um todo, é importante manter a infraestrutura existente através de uma manutenção eficaz e eficiente, a fim de manter a capacidade de utilização e de segurança em níveis elevados, o máximo que seja possível.

A previsão das necessidades de recursos não será totalmente coberta com financiamento do governo; há uma necessidade de melhorias contínuas na área de manutenção da infraestrutura metroferroviária. 0 trabalho de manutenção da 
infraestrutura deve, então, ser realizado a partir de cinco perspectivas; segurança, as necessidades dos clientes, relação custo-benefício, os aspectos ambientais e desenvolvimento contínuo.

O desempenho da manutenção é uma das questões mais importantes no rol das atividades que regem a economia de atividades produtivas. No entanto, o desempenho é muitas vezes relegado, ignorado ou negligenciado por aqueles que influenciam os processos de produção (SINGH et al., 2014).

Levando em conta que a manutenção não só garante o desempenho e segurança da via, mas também cria um valor adicional no negócio, a manutenção deve ser tratada como parte integrante do negócio. A aplicação de uma visão holística no processo de manutenção tem o objetivo de cumprir os requisitos do cliente (KARLSSON, 2005).

Como as atividades de manutenção são multidisciplinares por natureza e com um grande número de entradas e saídas, o desempenho da produtividade da manutenção precisa ser medido e considerado de forma holística com uma abordagem integrada. Com o aumento da consciência de que a manutenção tem valor agregado, as organizações estão tratando a manutenção como parte integrante do negócio (LIYANAGE; KUMAR, 2003).

Processos de manutenção com custo-benefício adequado são necessários para atingir os objetivos orçamentais, enquanto um sistema eficiente é exigido pelos usuários do sistema. Ao atender as necessidades das partes interessadas de forma eficiente e eficaz, custos adequados, é possível manter a infraestrutura e material rodante em boas condições. Desse modo, será possível prolongar a vida útil esperada destes ativos.

É responsabilidade do gestor da infraestrutura definir os objetivos e estratégias de manutenção em geral, bem como realizar a avaliação final dos resultados e compará-lo com os objetivos e estratégias globais.

É necessário identificar, classificar e analisar todas as possíveis interrupções no processo, de modo que possam ser minimizadas, ou eliminadas, através de atividades eficazes e eficientes de manutenção. Decisões de manutenção devem ser tomadas racionalmente, com base em uma estratégia de manutenção cuidadosamente preparada e bem definida, considerando requisitos de diferentes partes interessadas.

Decisões de manutenção devem ser baseadas em dados confiáveis que refletem o status e as condições da infraestrutura, bem como os padrões de degradação dos ativos. 
Conhecer as tendências de degradação da condição de ativos possibilita a previsibilidade dos eventos. 0 processo de tomada de decisão pode ser apoiado por diferentes sistemas de apoio à decisão, se esses sistemas são suportados pelos dados e medidas necessárias.

A avaliação do desempenho da manutenção tornou-se um elemento essencial do pensamento estratégico dos gestores de ativos (BEN-DAYA, 2009; ÅHRÉN; PARIDA, 2009). Sem quaisquer medidas formais de desempenho, é difícil planejar, controlar e melhorar o processo de manutenção.

Uma questão-chave é verificar se as atividades de manutenção realizadas produzem os resultados esperados. Uma maneira de fazer isso é comparar a condição dos ativos antes e depois das atividades de manutenção em termos de indicadores técnicos, econômicos e organizacionais.

A manutenção eficiente e eficaz deve, também, proporcionar benefícios ambientais, a redução do número de interrupções da circulação de trens, aumento da segurança, etc. A junção destes fatores resulta em soluções de transporte competitivas e rentáveis para os passageiros e sociedade.

\subsection{Conteúdo Teórico}

\subsubsection{Manutenção}

O objetivo da manutenção e da gestão da manutenção é o de maximizar a disponibilidade de um dado sistema com custos mínimos, reduzindo a probabilidade de equipamento ou sistema apresentar falha (MOUBRAY, 1997; LIYANAGE; KUMAR, 2002; BEN-DAYA, 2009).

A gestão da manutenção pode, a partir de uma visão holística, ser descrita como a gestão dos recursos de manutenção disponíveis, ou seja, recursos humanos, financeiros, materiais, e informações, para garantir uma saída desejada em termos de alta integridade dos ativos (LIYANAGE; KUMAR, 2002). A gestão também inclui o gerenciamento de entradas inesperadas, bem como saídas indesejáveis.

A gestão da manutenção necessita de informações para o planejamento e controle 
do processo de manutenção. A informação precisa se concentrar na eficácia e eficiência do processo de manutenção, bem como na organização, cooperação e coordenação com outras unidades da organização.

Em uma organização que atende o transporte público de grandes populações o gerenciamento, gestão e o monitoramento da condição dos ativos requer uma série de dados das diferentes condições dos ativos. 0 tomador de decisão é dependente das informações da atual condição dos ativos, bem como saber os padrões de degradação de ativos; de maneira que possa projetar as condições futuras. Esta necessidade levou a evolução da manutenção.

A evolução da manutenção e da gestão da manutenção começou no período posterior a Segunda Guerra Mundial, quando então a política de manutenção dominante era a de "quebrou, consertou" (KELLY, 2006). Esta é chamada de a Primeira Geração da Manutenção (MOUBRAY, 1997).

Durante os anos 1960, as questões de segurança tornaram-se mais importantes, bem como a melhoria da eficiência do trabalho, assim uma estratégia de manutenção preventiva emergiu; isso é chamado de Segunda Geração de Manutenção (MOUBRAY, 1997). Esta mudança de estratégia também permitiu começar a controlar o desempenho de manutenção, os custos de produção e disponibilidade de ativos (AHREN, 2005).

A Terceira Geração da Manutenção (MOUBRAY, 1997), surgiu durante a década de 1970, com uma estratégia preventiva desenvolvida a níveis mais elevados devido aos avanços e as necessidades dos gestores em prever o valor futuro da manutenção; assim aconteceu a evolução de uma estratégia de manutenção baseada em condição (KELLY, 1997).

A evolução da manutenção atingiu hoje a Quarta Geração, em que a manutenção é encarada de um ponto de vista mais holístico (DUNN, 2003), com a integração do gerenciamento de ativos e operação do sistema. A manutenção não é mais vista apenas como despesa, ela também cria valor para o negócio (LIYANAGE; KUMAR, 2002; LIYANAGE; KUMAR, 2003).

A manutenção é necessária devido à falta de confiabilidade e perda da qualidade. A manutenção é uma "combinação de todas as ações técnicas, administrativas e de gestão durante o ciclo de vida de um produto, destinada a mantê-lo, ou restaurá-lo, para um 
estado em que ele pode executar a função desejada" (CEN, 2010).

A manutenção é muitas vezes encarada como um processo, ou seja, o estabelecimento de uma meta e estratégia, a criação de um programa, o planejamento, a execução e a análise de melhoria contínua (ciclo PDCA). As atividades de manutenção em si são realizadas tanto como manutenção corretiva depois de uma falha, ou manutenção preventiva para reduzir a probabilidade de avarias futuras (FAIZ; EDIRISINGHE, 2009).

Tradicionalmente, a manutenção preventiva é realizada com base no tempo. Uma abordagem de manutenção preditiva é frequentemente utilizada quando é possível monitorar o estado do equipamento, dando a oportunidade de executar a manutenção apenas quando existe a necessidade. Os benefícios desta estratégia são os intervalos de manutenção prolongada e custos de manutenção reduzidos (KELLY, 2006; CASTRO, 2009). Existem, porém, situações em que é mais rentável adotar uma estratégia de esperar o equipamento falhar. Esta estratégia é válida para equipamentos baratos cuja perda de função é fácil de detectar e que não tem qualquer efeito sobre o processo de produção.

A fim de acompanhar e avaliar a eficácia e eficiência, em curto e longo prazo, da gestão de manutenção e das atividades realizadas, bem como avaliar se o processo de manutenção suporta os objetivos gerais do negócio, o uso de indicadores é um requisito importante para o desempenho (WIREMAN, 2005). Na década de 1960, o foco principal era a economia, equipamentos e questões organizacionais (HUSBAND, 1976), mas hoje a saúde, segurança e questões ambientais são igualmente importantes (KUMAR, 2006).

O processo de tomada de decisão na manutenção pode ser apoiado por diferentes sistemas de apoio à decisão, desde que esse sistema seja alimentado pelo tipo certo de dados e informações necessárias. Dado que os indicadores corretos atendem a esta premissa, o processo de tomada de decisão torna-se mais eficaz e sistemático.

\subsubsection{Desempenho}

O conceito básico de desempenho estabelece uma função que envolve a capacidade, esforços, e oportunidade (SALMINEN, 2005; SINGH et al., 2014). Desempenho é a capacidade de uma organização em implantar uma estratégia escolhida e atingir os 
objetivos organizacionais (TSANG; JARDINE; KOLODNY, 1999).

O desempenho organizacional é o resultado do desempenho dos indivíduos e grupos. 0 desempenho pode ser analisado a partir de diferentes perspectivas, como o cliente, financeiro, processo empregado, segurança, ambiental, etc. (WIREMAN, 2005).

A medição do desempenho é o processo pelo qual uma organização afere o desempenho. As medidas são o conjunto de métricas usadas para quantificar a eficiência e eficácia das ações. A medição do desempenho inclui métricas financeiras e não financeiras, bem como métricas qualitativas, como as atitudes dos funcionários, e abrange os processos e resultados (SALMINEN, 2005).

A medição do desempenho na manutenção visa minimizar o custo de manutenção e, também, maximizar o desempenho geral de manutenção. Algumas das medidas de desempenho da manutenção são: disponibilidade, tempo médio entre falhas (MTBF, do inglês Medium Time Between Failures), frequência de falhas, índice de produção média e o tempo médio de reparo (MTTR, do inglês Medium Time To Repair).

O controle do desempenho assegura que os níveis orçados de manutenção estão sendo sustentados e que a saída planejada do processo é alcançada (KELLY, 1997). 0 desempenho é conectado tanto com a eficácia como com a eficiência.

A degradação do desempenho ao longo do tempo e acidentes são algumas das razões para a interrupção da operação, o que afeta a eficácia. Para alcançar maior oferta de usuários transportados, a gestão deve estar em condições de prever sua capacidade e de melhorá-la em um determinado momento.

O desempenho da manutenção e a política de segurança exercem um papel significativo na obtenção da eficácia operacional. Uma estratégia de manutenção e segurança adequados deve ser adaptada para atingir uma oferta mais eficiente.

A medição fornece a base para a organização avaliar o progresso em direção a seus objetivos pré-determinados, ajuda a identificar áreas forte e fraca, e permite decidir sobre as iniciativas futuras, com o objetivo de melhorar o desempenho organizacional. 0 processo de tomada de decisão deve considerar vários critérios, uma vez que ambos os fatores, econômicos e não econômicos, estão envolvidos (BLANCHARD; FABRYCKY, 2010; SAGE; ARMSTRONG, 2000). 


\subsubsection{Indicadores de desempenho}

A definição de indicador é abrangente, a literatura apresenta mais que uma forma de definição. As cinco definições abaixo tentam abranger as formas mais gerais:

- A definição técnica, que descreve o indicador como um dispositivo que mostra a forma como a pressão e volume dentro de um motor de êmbolo são alterados (AHREN, 2005);

- A definição química, que descreve uma substância que mostra a concentração de uma substância específica (BRITANNICA, 2003);

- A definição ecológica, dizendo que um organismo através da sua existência está mostrando certas condições existentes (BRITANNICA, 2003);

- A definição anatômica, dizendo que um indicador é o músculo que estende o dedo indicador (AHREN, 2005);

- A definição econômica, que define um indicador como uma medida estatística, que em combinação com outros indicadores são utilizados para determinar o estado geral da economia (EICHHORN, 2014).

Um indicador, assim, pode ser definido como um número que descreve o desempenho para uma atividade ou ocorrência específica. 0 número é normalmente relacionado com uma escala de medida fixa. Se os indicadores são estendidos para medir o desempenho, eles devem ser chamados de indicadores de desempenho.

A classificação dos indicadores de desempenho, segundo Allender (1997), é feita em sete grupos: eficiência, eficácia, produtividade, orçamento/lucro, qualidade de vida no trabalho, inovação e qualidade Os indicadores podem, posteriormente, ser agregados a um índice de desempenho.

Outras classificações de indicadores de desempenho podem ser encontradas, quando observadas as questões organizacionais de uma empresa. Uma forma de classificação pode ser feita considerando: estratégico, operacional, específico, comportamento, confiança e ética. 
Em termos gerais, os indicadores de desempenho são classificados como adiantados ou atrasado (tradução livre do inglês leading e lagging) (STRICOFF, 2000). Um indicador prospectivo (adiantado) é um indicativo do desempenho, ou seja, uma medida que pode alterar o desempenho dada a sua característica de mostrar se estamos no caminho certo ou não. A medida de resultado financeiro é uma medida em atraso, ou indicador retrospectivo.

Indicadores prospectivos e retrospectivos também podem se relacionar com a estratégia ou objetivos, e por isso é importante não misturar meios e fins (AHREN, 2005). Na elaboração e aplicação dos indicadores outras características importantes são:

- Indicadores sob medida: indicadores usados em comparações com líderes no quesito medido (benchmarking) (WIREMAN, 2005);

- Indicadores de longo ou curto prazo: quanto tempo as medidas têm de ser armazenadas;

- Indicadores com mudança rápida ou lenta: uma distinção importante na elaboração de cálculos de tendência para decidir se os indicadores mais rápidos ou lentos devem ser utilizados ou desenvolvidos.

Alguns dos conceitos utilizados na definição de métricas não são claros sobre o que medir, como comunicar o desempenho em toda a organização e alinhar o desempenho com objetivos e estratégias do negócio (MURTHY; ATRENS; ECCLESTON, 2002). Isso exige, essencialmente, criar os indicadores em uma estrutura top-down, de maneira a abranger todos os níveis corporativos, e agregar os indicadores medidos, tais como a disponibilidade, a confiabilidade, o tempo médio entre falhas, etc.

Esta prática deve, portanto, partir do chão de fábrica e seguir até os níveis estratégicos para auxiliar na tomada de decisões (TSANG, 2002). Assim, parece que existe a necessidade de identificar e analisar várias questões relacionadas com o desempenho de manutenção e de desenvolver um quadro para resolver os problemas e os desafios da gestão de manutenção, medição de desempenho de manutenção, medidas de desempenho e indicadores relacionados.

A fim de facilitar o desenvolvimento e implantação dos indicadores produtivos, há algumas questões básicas que devem ser levados em consideração, a saber: 
- Qual é o objetivo do indicador;

- O que o indicador suposto medirá;

- Como implantar o indicador;

- Quem é gestor do indicador;

- Quem deve usar o indicador.

Os indicadores escolhidos também devem ser escaláveis; isto é, deve ser possível utilizá-los de forma individual, ao mesmo tempo em que eles podem ser agregados e utilizados globalmente, ou vice-versa.

Uma vez que o processo de desenvolvimento para indicadores segue uma abordagem top-down, onde os objetivos gerais do negócio são o topo da pirâmide e os indicadores específicos a sua base (BEN-DAYA, 2009), a elaboração de relatórios e agregação de indicadores deve seguir uma perspectiva de baixo para cima (Figura 7.1). Essa abordagem também torna possível integrar o sistema de indicadores com outros sistemas de gestão de desempenho.

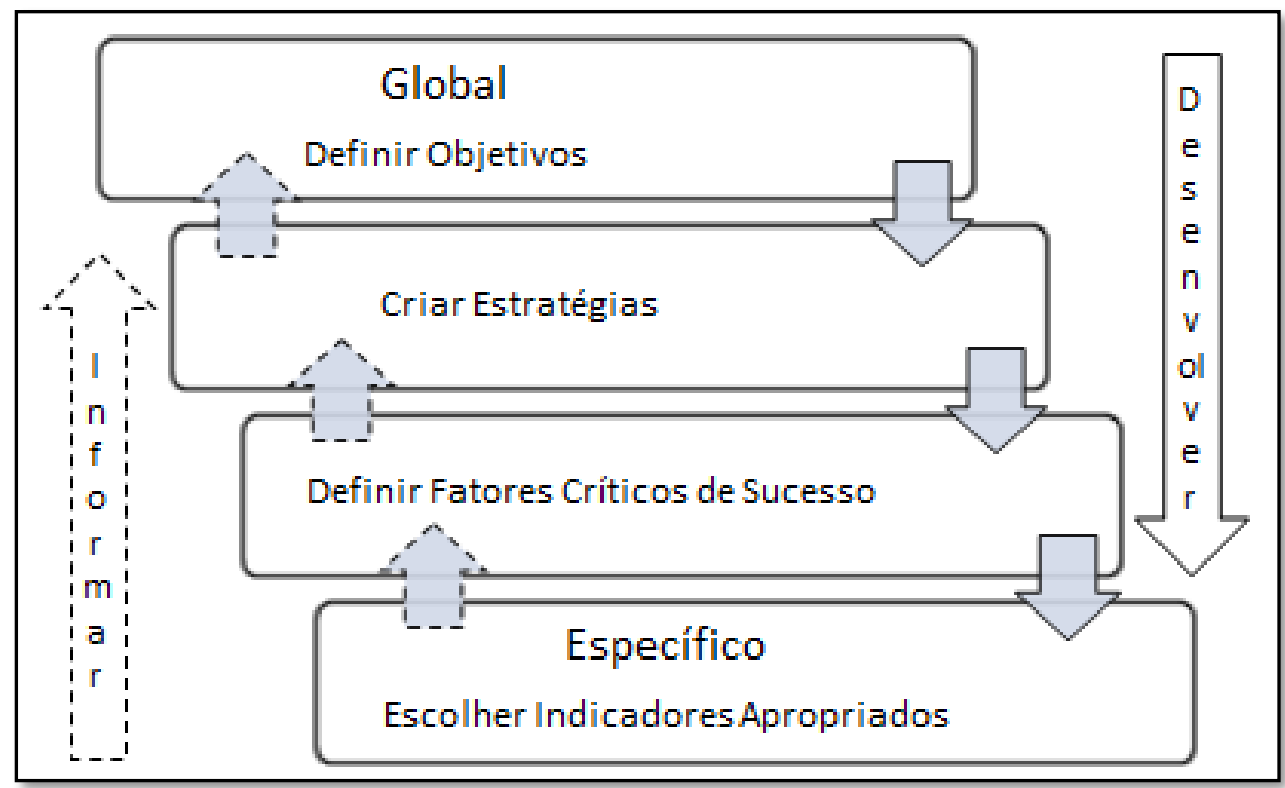

Figura 7.1 - Processo de desenvolvimento e informação de indicadores

Três modelos (ou sistemas) básicos são utilizados no desenvolvimento e implantação de indicadores. 
Em um sistema de indicadores horizontalmente agrupados, os indicadores são organizados em grupos lógicos independentes, abrangendo as perspectivas relacionadas ao processo de manutenção, tais como confiabilidade, manutenibilidade, manutenção preventiva, preditiva e corretiva, planejamento e programação da manutenção, gestão de materiais, treinamento, supervisão e produtividade.

Em um sistema verticalmente agregado os indicadores estão dispostos em uma estrutura piramidal, onde um grande número de indicadores em um nível inferior é agregado para cima na estrutura da pirâmide e, muitas vezes reduzida a um ou alguns indicadores a nível estratégico.

Um sistema que combina indicadores agrupados horizontalmente com os verticalmente agregados, cria grupos quasi independentes dispostos em uma estrutura horizontal ou vertical, sem agregação de indicadores entre os grupos, embora existam relações lógicas entre eles. Cada grupo é separado em um subsistema refletindo diferentes perspectivas de manutenção, tais como: economia, equipamentos, questões organizacionais, de saúde, segurança e meio ambiente.

\subsubsection{Indicadores de desempenho da manutenção}

Indicadores de desempenho da manutenção são utilizados para avaliar a eficácia da manutenção realizada. Eles podem comparar as condições reais com um conjunto específico de referência de requisitos e metas.

A medição do desempenho da manutenção é definida como "o processo de multidisciplinar de medir e justificar o valor criado pelo investimento em manutenção, e cuidar das necessidades do acionista da organização sob um olhar estratégico a partir da perspectiva global de negócios" (PARIDA, 2006).

Um indicador de manutenção é um produto de várias medidas (métricas) utilizadas para a medição do desempenho (WIREMAN, 2005). 0 indicador é equipado com linhas de base e metas realistas para facilitar os processos de prognóstico e diagnóstico, para justificar decisões associadas e as ações subsequentes, em níveis apropriados na organização, para criar valor no negócio (LIYANAGE; KUMAR, 2003).

Os indicadores de manutenção estão ligados à medição da disponibilidade de 
sistemas e equipamentos, custos e desperdícios, e ao aumento da utilização da capacidade, produtividade, qualidade, saúde e segurança.

Os indicadores podem ser usados para diferentes fins, tais como medir o desempenho financeiro, o desempenho do empregado, a satisfação do cliente, a saúde e segurança, a classificação ambiental, bem como a eficácia global do equipamento, de maneira que diferentes indústrias necessitam de diferentes indicadores.

O estabelecimento de uma conexão entre os principais indicadores ajuda a monitorar e controlar o desempenho do processo. Os indicadores a serem vinculados são selecionados de acordo com a estratégia de manutenção adotada, de maneira a permitir a sua integração com os objetivos principais.

A medição de desempenho da manutenção não é um conceito novo. 0 estabelecimento de indicadores de manutenção tornou-se uma parte importante da estratégia organizacional. Os indicadores devem considerar as questões dos requisitos de eficácia da manutenção total, tanto do ponto de vista interno como externo, para identificar os indicadores relevantes e, em seguida, alinha-los com os objetivos corporativos (AHLMANN, 2002).

Os indicadores de desempenho são uma ferramenta para alinhar os objetivos estratégicos dentro dos níveis hierárquicos de toda a organização. Assim, permite a visibilidade dos objetivos da empresa e os objetivos do nível estratégico para a média gerência no nível tático, e para toda a organização. Os indicadores, quando devidamente comunicados, podem servir como:

- Ferramenta de planejamento estratégico;

- Ferramenta de relatórios de gestão;

- Ferramenta de controle e monitoramento operacional;

- Ferramenta de apoio à gestão da mudança.

É importante que os conceitos utilizados na definição das métricas de manutenção sejam claros sobre o que deve ser medido, como comunicar o desempenho da manutenção em toda a organização, e alinhar o desempenho de manutenção com objetivos e estratégias organizacionais.

As oportunidades para monitorar e controlar todos os tipos de ativos é uma realidade, 
mas também uma fonte de sobrecarga de dados para os gestores, que muitas vezes é visível em termos de relatórios de desempenho redundantes (ÅHRÉN; PARIDA, 2009). Quando da tomada de decisão, o gestor não é capaz de levar em consideração mais do que cinco a oito parâmetros ao mesmo tempo (SAATY, 1980), o que enfatiza a importância de escolher bons indicadores para a tomada de decisão, mostrando que a agregação, muitas vezes, é necessária e benéfica.

A maneira tradicional de medir o desempenho com base em apenas resultados financeiros mostra-se inadequada e ineficiente, uma vez que todas as medidas refletem somente os resultados, sem permitir que haja correções no caminho escolhido, já que o indicador é fornecido somente após o fato ocorrido.

Algumas das medidas de desempenho da manutenção são:

- $\mathrm{A}($ disponibilidade $)=($ tempo previsto - tempo parado $) /$ tempo previsto;

- 0 tempo médio de reparo $(\mathrm{MTTR})$ = soma de tempo de reparo / número total de falhas;

- Tempo médio entre falhas $(\mathrm{MTBF})$ = número de horas / número operacional de falhas;

- Custo médio de reparo = custo de reparo das falhas / número de falhas;

- Custo de manutenção por hora = custo total de manutenção / total de homens $\mathrm{x}$ hora de manutenção;

- Utilização da Mão de Obra = tempo em trabalho / tempo total;

- Eficiência da Mão de Obra = tempo utilizado / planejado;

- Índice de custo de manutenção = custo total de manutenção / custo total de produção.

Vários fatores e questões devem ser considerados na medição do desempenho da manutenção. Alguns fatores, relevantes, que precisam ser considerados são:

- O valor criado pela manutenção: o fator mais importante do sistema de medição é o de medir o valor criado pelo processo de manutenção. Como gestor, é preciso saber que aquilo que está sendo feito é aquilo que é necessário para o negócio. Se o resultado da manutenção não está contribuindo ou criando valor para o negócio, ele precisa ser reestruturado. 
- Revisão da alocação de recursos: medir a eficácia da manutenção ajuda a determinar a exigência de investimento adicional e também o investimento feito. Alternativamente, tal medição de atividades também permite determinar se existe a necessidade de mudança e como fazê-lo de forma mais eficaz, utilizando os recursos alocados.

- Fatores de Segurança, Saúde e Meio Ambiente: é essencial compreender a contribuição da manutenção em relação às questões de saúde, segurança e meio ambiente. Um desempenho ineficiente pode levar a incidentes e acidentes (questão de segurança) e outros perigos, além das questões ambientais.

- Gestão do Conhecimento: Dado que a tecnologia está em mutação permanente, com novos sensores e tecnologia embarcada, tecnologias da informação, comunicação, inspeção baseada em condições como vibração, espectroscopia, termografia e outros, que substituem a manutenção preventiva pela preditiva, implica em uma abordagem sistemática para o crescimento do conhecimento na área específica de especialização.

- Novas tendências nas estratégias de operação e manutenção: as empresas precisam adotar uma nova estratégia de operação e manutenção em resposta rápida as demandas, bem como para a redução de perdas. Esta estratégia precisa ser continuamente revista e modificada.

- As alterações na estrutura organizacional: as organizações estão tentando seguir uma estrutura organizacional plana e compacta. Assim, existe uma necessidade de integrar o sistema de medição dentro da organização para proporcionar um retorno valioso para serviços de manutenção.

\subsection{Integração dos Indicadores}

A introdução de qualquer sistema de medição de desempenho requer um foco em áreas estratégicas críticas, determinadas pela natureza e interesses do negócio, requisitos e regulamentações públicas (LIYANAGE; KUMAR, 2003). As áreas estratégicas críticas variam de empresa para empresa, mas normalmente incluem áreas financeiras, de segurança, saúde e do meio ambiente, processos internos, competências, e, finalmente, relações internas e externas. 
Ao desenvolver um sistema de medição de desempenho, é importante que os objetivos globais sejam apoiados, o que significa uma abordagem top-down. A ligação direta entre os objetivos gerais e as medidas para operação e manutenção é em termos de retorno sobre investimentos (ROI) e de saúde, segurança e meio ambiente.

Competências adequadas, processos internos funcionais, e bons relacionamentos internos e externos estabelecem as bases da integridade do negócio. Portanto, a classificação dos indicadores em relação à área estratégica afetada pela sua medição deve permitir a criação de indicadores chave (KPI, do inglês Key Performance Indicator). 0 resultado final é um quadro, mostrando como os processos de operação e de manutenção contribuem para os objetivos globais da empresa ou da unidade de negócios.

Do ponto de vista da manutenção o KPI deve dar uma informação objetiva sobre a manutenção, por exemplo, a situação da manutenção preventiva: se foi realizada dentro do prazo, a logística de peças de reposição, o planejamento e acompanhamento. A fim de comparar e avaliar os diferentes KPI, eles devem refletir os resultados medidas semelhantes, como a confiabilidade dos ativos.

Há dois aspectos importantes que devem ser levadas em consideração quando KPIs são usados. 0 primeiro aspecto é que os dados de entrada podem ser inadequados, provocando um indicador errado e, então, decisões erradas com base no indicador. 0 outro aspecto é que as alterações nos sistemas, provavelmente, gerarão medidas de KPI alteradas.

Considerando que indicadores de desempenho mostram o desempenho, os KPIs são nada mais do que um indicador estratégico do desempenho. (WIREMAN, 2005). 0 principal objetivo é identificar possíveis áreas de melhoria dentro de uma estrutura organizacional.

Enquanto o processo de desenvolvimento de indicadores segue uma estrutura topdown, o sistema de comunicação dos indicadores segue um caminho inverso, conforme a Figura 7.1.

\subsubsection{Implantação de um sistema de indicadores}

É essencial compreender o processo de manutenção em detalhe antes de estudar 
as questões envolvidas no sistema de indicadores de manutenção, de modo que a implantação do sistema seja realizada sem dificuldades.

O processo de manutenção começa com os objetivos e estratégias de manutenção, que são derivadas da visão corporativa, das metas e objetivos gerais. Um programa de manutenção, com base nas metas e objetivos da manutenção, é dividido em tarefas. A execução das tarefas é realizada em horários e locais conforme especificação do plano de manutenção. A tarefa de manutenção pode ser reparo, substituição, adaptação, lubrificação, modificação ou inspeção.

Contudo, no ambiente corporativo, há um descompasso entre as expectativas das partes interessadas, as metas locais e os objetivos organizacionais e os recursos alocados para planejamento, programação e execução da manutenção e a sua comunicação através do registro e análise de dados. Há, então, a necessidade de mapear o processo de manutenção e identificar a lacuna entre o planejamento e execução da manutenção.

O maior desafio na implantação de um sistema de indicadores é o de medir o desempenho da manutenção em um caso real. A primeira tarefa da implantação envolve a execução do plano em implantar o sistema desenvolvido no lugar do sistema já existente. Em segundo lugar, significa operar com as medidas selecionadas e validar a garantia de que o sistema de medição de manutenção funciona em uma base do dia-a-dia.

Sem medidas formais de desempenho é difícil planejar, controlar e melhorar o processo de manutenção. 0 desempenho precisa ser medido para avaliar, controlar e melhorar as atividades de manutenção para garantir o cumprimento das metas e objetivos organizacionais.

As questões relacionadas com o sistema de indicadores são determinadas ao responder as perguntas:

- Que indicadores são relevantes para o negócio e relacionados com a manutenção?

- Como os indicadores são relacionados entre si e como eles alimentam os requisitos das partes interessadas?

- Os indicadores são medidos objetivamente? Como podem avaliar a eficiência e eficácia da organização?

- Os indicadores são um desafio e, ao mesmo tempo, possíveis de atingir?

- Os indicadores são conectados aos valores de referência do mercado? 
- Como são tomadas as decisões com base nos indicadores?

- Quais são as medições que provocam ações corretivas e preventivas?

- Quando e como é que se atualizam os indicadores?

Os indicadores precisam ser desenvolvidos com base nas respostas para as perguntas acima. Os dados relevantes precisam ser registrados e analisados em uma base regular e utilizados para o acompanhamento e controle de atividades preventivas e corretivas de manutenção e para tomada de decisão. Várias formas de acompanhamento dos indicadores, mostrando e registrando tendências, podem ser aplicadas para facilitar o processo de tomada de decisão.

Um exemplo de um sistema de indicadores de manutenção é apresentado na Figura 7.2. Os diferentes indicadores estão agrupados em uma estrutura piramidal. A ideia básica para o desenvolvimento e implantação do sistema de indicadores é começar com a base da pirâmide. Quando os indicadores de manutenção relacionados às manutenções preventivas são implantados e os gestores têm controle sobre esse processo, eles começam a implantar o próximo nível de indicadores.

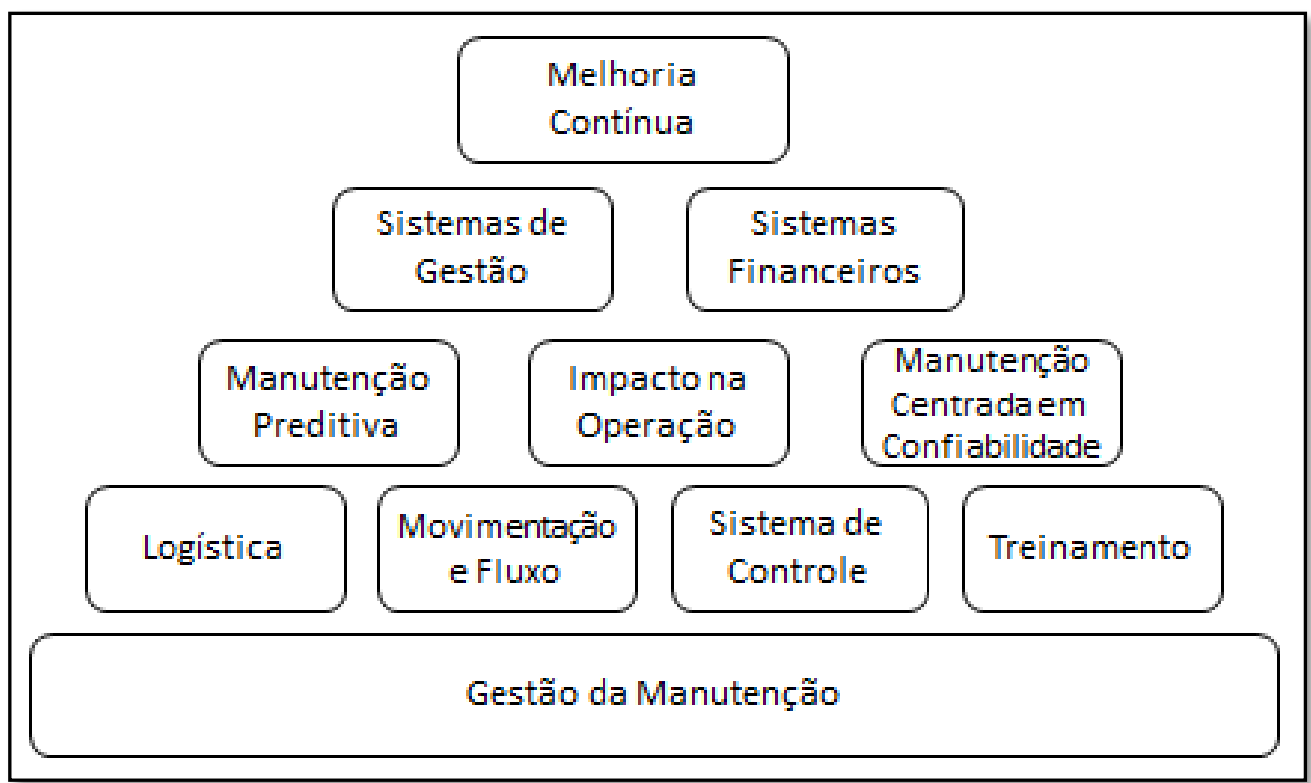

Figura 7.2 - Sistema de Gestão de Manutenção e Indicadores. Adaptado de WIREMAN (2005).

De maneira a ter uma aplicação bem-sucedida os diferentes grupos de indicadores devem ser pertencentes processos semelhantes. Como no exemplo, o desenvolvimento e 
implantação de indicadores de manutenção centrada em confiabilidade precisa de um programa implantado pelo mesmo processo. A conexão entre os diferentes grupos de indicadores não é tão forte, uma vez que os diferentes indicadores estão coletando dados necessários a partir dos diferentes programas.

Indicadores de manutenção são medidas de eficiência, eficácia, qualidade, pontualidade, segurança e produtividade, entre outros. Algumas das indústrias onde quadro de indicadores foi experimentado são: nuclear, petróleo e gás, transporte ferroviário, indústria de processo e de energia, entre outros. Uma abordagem distinta é utilizada para desenvolver o quadro de indicadores para diferentes indústrias.

\subsubsection{Desempenho global de equipamentos}

A efetividade geral do equipamento (OEE, do inglês Overall Effectiveness Equipment) é um indicador chave de desempenho (KPI, do inglês Key Performance Indicator) frequentemente utilizado na indústria de transformação para calcular a eficácia global do equipamento de um sistema de produção ou de partes dele.

O OEE foi apresentado como uma métrica no conceito de Manutenção Produtiva Total (TPM, do inglês Total Productive Maintenance). O OEE é uma medida de produtividade agregada que leva em consideração as seis grandes perdas que afetam a produtividade do equipamento em um sistema de produção. Estas perdas são divididas em três grupos principais de acordo com a disponibilidade, velocidade e qualidade.

A disponibilidade está relacionada com o tempo de inatividade em termos de falha do equipamento, instalação e ajustes. A taxa de velocidade ou desempenho está relacionada a pequenas paradas, juntamente com velocidade reduzida. Finalmente, a taxa de qualidade está relacionada com defeitos e rendimento reduzido. Para obter o OEE, simplesmente multiplica-se a disponibilidade do equipamento, a taxa de desempenho, e a taxa de qualidade. Normalmente, os valores que podem ser encontrados de OEE são de 30 a 95\% (AHLMANN, 2002).

A definição varia, bem como a aplicação do OEE nas diferentes indústrias e, portanto, é difícil identificar OEE ideais, bem como comparar os números $O E E$ entre diferentes empresas (STAMATIS, 2010). 
Geralmente, a disponibilidade é definida como a razão entre o tempo de funcionamento real e o pretendido. A taxa de desempenho é definida como a razão entre o tempo de produção real e o tempo de produção pretendida. Finalmente, a taxa de qualidade é dada como a razão entre os itens produzidos dentro dos padrões de qualidade esperados e a quantidade total de itens produzidos. A taxa de disponibilidade e desempenho, normalmente, é referida ao tempo de operação e de preparação ou o tempo planejado e a quantidade produzida.

A métrica de disponibilidade pode ser influenciada por fatores além do próprio equipamento, tais como operadores, instalações, a disponibilidade de material, programação da atividade, e demais variáveis relativas ao sistema como um todo. Assim, parece razoável considerar que a OEE reflete o desempenho do sistema de equipamentos integrados, e as suas interferências nos equipamentos individuais.

\subsubsection{Indicadores da indústria nuclear}

A importância da indústria nuclear para geração de energia, como uma fonte alternativa, mostra crescimento. Os organismos internacionais como a Agência Internacional de Energia Atômica (AIEA) têm participado ativamente e patrocinando o trabalho de desenvolvimento na área de indicadores para monitorar o desempenho de plantas nucleares de potência e a segurança operacional.

A operação segura das centrais nucleares é a meta da indústria nuclear. Um elevado nível de segurança resulta da integração do projeto adequado, segurança operacional e desempenho humano. Para ser eficaz, é necessária uma abordagem holística e integrada, de maneira a fornecer o quadro geral do desempenho e identificar os atributos de segurança para a operação de uma usina nuclear.

A evolução de um indicador específico, durante um período de tempo, pode fornecer um aviso prévio à administração para investigar as causas da mudança observada e comparar com o valor nominal. Cada planta precisa determinar os indicadores que melhor se adaptem às suas necessidades, que, por sua vez, dependem do desempenho projetado e da relação custo-benefício entre operação e manutenção.

Os parâmetros de desempenho incluem tanto a segurança como indicadores do 
desempenho econômico, com aspectos de segurança sendo primordiais. Para avaliar a segurança operacional um conjunto de ferramentas tais como aspecto das instalações, inspeção regulamentada, garantia de qualidade e auto avaliação são utilizados. Duas categorias de indicadores comumente aplicados são; indicadores baseados no risco e indicadores da cultura de segurança.

O desenvolvimento de indicadores começa com a identificação dos atributos de desempenho e de segurança operacionais. No âmbito de cada atributo, são estabelecidos indicadores globais para fornecer avaliação de aspectos relevantes do desempenho e da segurança e, no âmbito de cada indicador geral, os indicadores estratégicos são identificados. Os indicadores estratégicos são destinados a fazer a conexão entre os indicadores gerais e específicos.

Finalmente, um conjunto de indicadores específicos é identificado e desenvolvido para cada indicador estratégico de maneira a cobrir todos os aspectos de segurança relevantes. Os indicadores específicos são usados para medir o desempenho e identificar o seu declínio, assim a administração pode tomar decisões de ajuste (KUMAR; PARIDA, 2008).

\subsubsection{Indicadores da EFNMS}

Desde 2004, a Federação Europeia das Sociedades Nacionais de Manutenção (EFNMS, do inglês European Federation of National Maintenance Societies) realizou uma série de encontros resultando no estabelecimento de indicadores de manutenção para diferentes indústrias participantes das sociedades e sucursais nacionais.

Estes encontros tinham o objetivo de recolher os dados para apuração dos indicadores de manutenção das indústrias e também treinar os participantes na utilização dos indicadores. A sociedade de manutenção croata (HDO) acolheu o primeiro encontro sobre indicadores de manutenção para o setor alimentício e farmacêutico. 0 encontro foi organizado para treinar os gerentes de manutenção no uso de indicadores de manutenção ou indicadores chave de desempenho (KPIs) e criar uma compreensão de como interpretar o desempenho medido pelos indicadores.

Uma série de encontros setoriais é organizada para comparar os resultados 
individuais com o desempenho médio da manutenção no setor (benchmarking). Um dos objetivos dessas oficinas, além do cálculo dos indicadores, é aumentar a competência do gerente de manutenção, que entendem o mecanismo por trás dos indicadores.

Estes encontros resultaram no método para utilização dos indicadores e definiu o projeto de norma EN 15341. As versões iniciais da norma recomendam 71 indicadores para medir o desempenho da manutenção, e são divididos em econômicos, técnicos e organizacionais.

\subsubsection{Indicadores da indústria de óleo e gás}

O custo de manutenção e sua influência sobre o sistema de óleo e gás é alto e não deve ser ignorado. A indústria do petróleo utiliza indicadores de maneira extensiva devido a natureza competitiva dos negócios, além de medir a produtividade, segurança e questões ambientais. $\mathrm{O}$ objetivo do setor é o de ter operações seguras nas unidades de produção.

Um elevado nível de segurança é essencial a partir da integração de um bom projeto, segurança operacional e desempenho humano. Para ser eficaz, é necessária uma abordagem integrada para proporcionar a identificação dos atributos desejados na operação da unidade de produção de petróleo, e os de segurança. Um exemplo das diferentes categorias de indicadores é apresentada abaixo (KUMAR; ELLINGSEN, 2000):

- Produção

- Volume de óleo produzido $\left(\mathrm{Sm}^{3}\right)$.

- Produção planejada de petróleo $\left(\mathrm{Sm}^{3}\right)$.

- Volume de gás produzido $\left(\mathrm{Sm}^{3}\right)$.

- Produção planejada de gás $\left(\mathrm{Sm}^{3}\right)$.

- Volume Condensado Produzido $\left(\mathrm{Sm}^{3}\right)$.

- Produção planejada de Condensados $\left(\mathrm{Sm}^{3}\right)$.

- Integridade Técnica

- Manutenção preventiva (homens x hora).

- Manutenção corretiva (homens x hora).

- Quantidade de ordens de serviço corretivas. 
- Parâmetros de manutenção

- Manutenção de sistema de segurança (homens x hora).

- Manutenção de sistemas (homens x hora).

- Manutenção de outros sistemas (homens x hora).

- Total de manutenção (homens x hora).

- Produção Afetada

- Devido à manutenção $\left(\mathrm{Sm}^{3}\right)$.

- Devido à operação $\left(\mathrm{Sm}^{3}\right)$.

- Devido à perfuração / bem operações $\left(\mathrm{Sm}^{3}\right)$.

- Tempo à outras causas $\left(\mathrm{Sm}^{3}\right)$.

\subsubsection{Indicadores da indústria de manufatura e processos}

Medir o desempenho da manutenção tem atraído interesse da indústria de manufatura e de processo. As organizações desejam saber o retorno sobre o investimento com os gastos de manutenção e no cumprimento dos objetivos e estratégias do negócio. Sob um clima de mudanças tecnológicas, observado em vários segmentos, a implantação de um sistema de medição de desempenho adequado assegura que as ações estejam alinhadas com as estratégias e objetivos da organização.

Modelos equilibrados, holísticos e multicritérios de medição de desempenho, foram desenvolvidos e modificados com base em critérios de eficiência, eficácia, qualidade, oportunidade, segurança e produtividade. 0 objetivo foi o de alcançar a eficácia total de manutenção em uma usina de pelotização e em um setor de serviços de produção de energia da Suécia (PARIDA, 2006). Os indicadores desenvolvidos são:

- 0 tempo de inatividade (horas);

- Mudança ao longo do tempo;

- Tarefas de manutenção previstas;

- Tarefas não planejada;

- Número de novas ideias geradas;

- Melhoria na competência e formação;

- Qualidade alcançada; 
- Queixas dos funcionários;

- Custo de manutenção por tonelada.

Além disso, os indicadores identificados para compor o quadro multicritério hierárquico foram o custo de produção por tonelada, as tarefas de manutenção planejadas, os números de reclamações de qualidade, o número de acidentes, as queixas por SMS, e o impacto da qualidade.

\subsubsection{Indicadores da indústria de utilidades}

Os indicadores para a indústria de utilidades em um setor da energia terão variação como em outros setores industriais. Os indicadores identificados para uma organização do setor de energia da Europa são:

1. A satisfação do cliente: a satisfação do cliente é uma das exigências principais das partes interessadas para a organização. Dado que seu cliente está relacionado com o fornecimento de energia, duração e interrupções, a satisfação do cliente e os indicadores relacionados são retirados do IEEE Power \& Energy Society et al., (2012): 1.1. DEC (índice de duração média de interrupção no sistema), somatório da duração das interrupções aos clientes com relação ao número total de clientes atendidos;

1.2. CAIDI (índice de duração média de interrupção ao cliente), somatório da duração das interrupções ao cliente em relação ao número total de clientes com fornecimento interrompido;

1.3. CSI (índice de satisfação do cliente), obtidos por meio de pesquisa com o cliente.

2. Custo relacionado: o custo ou resultado financeiro é outro dos requisitos principais para qualquer organização. Uma vez que o custo total de manutenção tem de ser controlado e a margem de lucro tem de seguir uma regra do Governo, dois indicadores são recomendados:

2.1. 0 custo total de manutenção; 
2.2. A margem de lucro.

3. Indicadores da planta e processo: os indicadores relacionados a planta ou ao processo também são importantes para uma visão geral do negócio. 0 tempo de inatividade na geração e distribuição de energia, bem como a classificação de eficácia global equipamentos (OEE) de geração são os indicadores sugeridos:

3.1. Tempo de inatividade;

3.2. OEE (Overall Equipment Effectiveness $=$ disponibilidade $\times$ velocidade $\times$ qualidade $)$.

4. Indicadores de realização da manutenção: os indicadores relacionados com as tarefas de manutenção são sugeridos abaixo:

4.1. Número de paradas não planejadas (quantidade e tempo);

4.2. Número de trabalhos de emergência;

4.3. Custo dos estoques.

5. Relacionados com a aprendizagem, crescimento e inovação: os indicadores relacionados com a aprendizagem e crescimentos, importantes para as organizações baseadas no conhecimento são:

5.1. Número de novas ideias geradas;

5.2. Melhoria nas habilidades através de treinamento.

6. Saúde, segurança e meio ambiente: indicadores da sociedade, muito relevantes para qualquer organização hoje, são:

6.1. Número de acidentes;

6.2. Número de reclamações de SMS.

7. Satisfação dos funcionários: os funcionários são os mais importantes ativos de uma organização e sua motivação, capacitação e prestação de contas será um fator favorável para atingir a meta organizacional:

7.1. Nível de satisfação dos funcionários. 


\subsection{Indicadores de Ferrovias}

\subsubsection{Indicadores na Bankvert (Suécia)}

A operação e manutenção ferroviária devem fornecer um serviço satisfatório para os usuários, e ao mesmo tempo atender às exigências das autoridades reguladoras. Hoje, um dos requisitos para os gestores de infraestrutura é o de realizar as atividades de manutenção com baixo custo, com um sistema de transporte pontual e eficaz em termos de custos. Os indicadores de desempenho de manutenção identificados por Ahren (2005) são apresentados abaixo:

- Capacidade de utilização da infraestrutura;

- Limite de capacidade da infraestrutura;

- Horas de atrasos de trem devido à infraestrutura;

- Número de comboios de mercadorias adiados devido à infraestrutura;

- Número de interrupções devido à infraestrutura;

- Padrão de classificação da via;

- Custo de manutenção por quilômetro de via;

- Volume de tráfego;

- Número de acidentes envolvendo veículos de transporte ferroviário;

- Número de acidentes em passagens de nível;

- Consumo de energia por área;

- Utilização de materiais perigosos ao ambiente;

- O uso de materiais não renováveis;

- Número total de falhas de funcionamento.

\subsubsection{Indicadores na Rede Ferroviária Italiana (RFI)}

A fim de melhorar as atividades de manutenção realizadas, a RFI decidiu planejar a manutenção com antecedência de dois anos. Para isto foi preparada uma ferramenta de 
simulação de manutenção, com base em técnicas de simulação de Monte Carlo. A ferramenta requer informações sobre a via, em termos de taxa de falha, tempo de reparo, os atrasos devido a falhas, o preço, os custos de reparação, e os custos de manutenção preventiva.

Os resultados da simulação são baseados em um modelo híbrido de confiabilidade, disponibilidade e manutenibilidade e o custo do ciclo de vida para cada objeto de uma via específica para os próximos 15 anos (AHREN, 2005). Usando a ferramenta de simulação, diferentes estratégias de manutenção podem ser testadas, encontrando a melhor opção a um custo mínimo. Além disso, oito diferentes indicadores são apresentados para validar e acompanhar os resultados simulados. Estes são:

- Disponibilidade;

- Número de falhas esperadas;

- Número de ações de manutenção preventiva;

- Número de inspeções;

- Número de ações de manutenção corretiva;

- 0 tempo de inatividade devido à manutenção preventiva;

- 0 tempo de inatividade devido às inspeções;

- 0 tempo de inatividade devido à manutenção corretiva.

\subsubsection{Indicadores na Queensland Rail (Austrália)}

A Queensland Rail utiliza o conceito de Balanced Scorecard (BSC) para acompanhar o desempenho. Os indicadores principais são os apresentados na Tabela 7.1.

Tabela 7.1 - Indicadores da Queensland Rail

\begin{tabular}{ll}
\hline \hline Área de Resultados & KPI \\
\hline Segurança & Prejuízo para baixo a taxa tempo \\
& Taxa de frequência de tempo perdido \\
& Acidentes com afastamento \\
& Acidentes transgressão Públicas
\end{tabular}


Acidentes em passagens de nível

Públicas

Incêndios florestais

\begin{tabular}{ll}
\hline Confiabilidade do Ativo & \begin{tabular}{l} 
Atrasos devido ocorrência na via \\
Descarrilamentos causados por \\
infraestrutura \\
Defeitos em trilhos - quantidade / km \\
MTBF Equipamentos \\
MTTR Equipamentos \\
\hline Desempenho da Manutenção \\
Manutenção Corretiva em Dormentes \\
Esmerilhamento Corretivo \\
Inspeção de via - Programação \\
Urgente \\
Porcentagem de manutenção \\
programada realizada
\end{tabular} \\
\hline Controle de Custos & Inventário de Ativos \\
\hline \hline
\end{tabular}

\subsection{Indicadores Sugeridos para Gestão de Via Permanente}

Diferentes estruturas de indicadores para monitorar, controlar e avaliar o desempenho da manutenção estão em uso por diferentes indústrias. As indústrias estão trabalhando no sentido de desenvolver quadros específicos para a sua organização e de identificar os indicadores mais adequados.

Organizações, como a Agência Internacional de Energia Atômica (AIEA), já desenvolveram e publicaram indicadores de segurança para usinas nucleares. A Sociedade de Manutenção e Profissionais de Confiabilidade (SMRP) e a Federação Europeia das Sociedades Nacionais de Manutenção (EFNMS) estão organizando grupos de trabalho e oficinas para identificar e selecionar indicadores para as indústrias. A ABRAMAN (Associação Brasileira de Manutenção) incentiva a adoção de indicadores baseados em confiabilidade dos ativos. Além disso, uma série de indústrias iniciaram projetos de investigação em colaboração com universidades para identificar indicadores adequados ao seu setor específico.

Diferentes indústrias utilizam abordagens diferentes para desenvolver o quadro 
de indicadores, assim como adotam indicadores por exigências dos interessados. Os indicadores específicos são necessários, mas indicadores globais devem existir para que sejam integrados com os objetivos globais das organizações.

Apesar da pluralidade de indicadores encontrados, um termo comum a todos os setores é a busca de eficiência e eficácia, alinhamento com os objetivos globais e atendimento do interesse do cliente. No setor metroferroviário esta generalidade também acontece. Não é possível a sobrevivência de um negócio sem que haja esta integração.

Assim, os indicadores que serão utilizados neste trabalho, mesmo que de forma reduzida, abrangendo somente alguns equipamentos da via permanente, serão pautados pela necessidade generalizada de medir o desempenho com base na eficiência e eficácia dos processos e alinhamento com os objetivos globais.

O controle e avaliação do desempenho de uma via permanente necessita de indicadores para sinalizar quais são as ações de manutenção que devem ser tomadas. Os indicadores servem para indicar ações imediatas, ações no futuro e para verificar se o que foi realizado colaborou para que os objetivos da organização fossem alcançados.

Assim, indicadores que levam em conta a degradação dos ativos, cumprimento de metas contratadas com os operadores do sistema, verificação da eficiência e eficácia das ações de manutenção e qualidade do trabalho realizado são fundamentais no estabelecimento de um programa de manutenção. A utilização acertada dos indicadores permite que os objetivos corporativos sejam alcançados e, ao mesmo tempo, criam um ambiente para que haja melhoria contínua do processo.

Neste trabalho os indicadores utilizados serão em número reduzido, contudo servirão como base para mostrar a total aplicabilidade do modelo para controlar e avaliar o desempenho de uma via permanente. De uma forma generalista, o controle pode ser estendido para toda a infraestrutura, desde que haja o cuidado de observar todas as variáveis envolvidas neste processo.

Os índices de degradação mostrados no capítulo sobre Sistemas de Suporte a Decisão serão utilizados em conjunto com o banco de dados geográfico e com o sistema de informações geográficas para gerar os indicadores. Considerações de comportamento dos equipamentos com base no MTBF e MTTR também serão utilizadas para compor os indicadores globais. 


\section{SISTEMA DE INFORMAÇÕES GEOGRÁFICAS E GERENCIADOR DE BANCO DE DADOS}

Este capítulo pretende apresentar, em linhas gerais, a escolha de um programa de computador para manipular dados espaciais e um sistema gerenciador de banco de dados que seja compatível com dados espaciais. Como premissa deste trabalho os programas de computador escolhidos devem ser livres e de código aberto.

\subsection{Breve Descrição do Conceito de Livre e Código Aberto}

Uma breve introdução ao movimento de código aberto pode ser explicada como uma tentativa mundial para promover um estilo de desenvolvimento de programas de computador com código aberto, o que de certa forma é alinhado com o já aceito modelo utilizado nas ciências, o de compartilhamento do conhecimento. Esta é uma forma de manter os avanços científicos, na área de software, abertos e disponíveis para qualquer um, de maneira a criar um ambiente de melhoria contínua.

Um breve histórico do início deste movimento remete a Richard (STALLMAN, 1985), originário dos laboratórios do MIT (Massachusetts Institute of Technology). Insatisfeito com a situação que se apresentava na época, aonde programadores e 
companhias de software protegiam os programas de computador desenvolvidos, fechando o acesso ao código fonte, Stallman iniciou o projeto GNU em 1983.

O objetivo deste projeto era o de desenvolver um pacote completo de programas de computador, incluindo um sistema operacional baseado em Unix, livre e aberto para qualquer um, e sem ter nenhum componente que fosse propriedade de alguém. Para proteger esta liberdade foi criado um novo tipo de licença, GPL (do inglês General Public License) e foi criada a FSF (Free Software Foundation) para suportar financeiramente o projeto GNU. O objetivo de Stallman, ao estabelecer o projeto GNU, não foi o de criar programas de computador sofisticados, mas o de alertar a sociedade de que o compartilhamento do conhecimento e ajuda aos demais é a pedra angular de uma sociedade ética.

O termo "free", na língua inglesa, pode ser entendido de duas formas. Uma das formas é utilizada para identificar alguma coisa que é gratuita, ou seja, livre de custos. Outra forma de uso do termo é relativa à liberdade, como liberdade de imprensa. Observase que as duas maneiras de uso do termo diferem entre si, no entanto, algumas vezes, a utilização do termo é negligenciada quando o assunto é relativo a programas de computador. A forma utilizada para o termo, no caso de programas de computador, é referente à liberdade de uso da licença, e que deve atender as seguintes premissas:

- Liberdade de utilizar o programa de computador para qualquer propósito (educacionais negócios, etc....);

- Liberdade de estudar e adaptar o programa para suas necessidades específicas;

- Liberdade para distribuir o programa e as alterações realizadas, e;

- Liberdade de melhorar o programa e disponibilizar estes melhoramentos para a sociedade (http://www.gnu.org/philosophy/free-sw.html).

As licenças GPL e LGPL, provavelmente, são as mais conhecidas. A diferença entre elas é que um programa com licença GPL não pode ser adicionado a um programa proprietário, enquanto a licença LGPL permite este tipo de combinação. Basicamente, podemos dizer que uma biblioteca (plug-in ou extensão), sob a licença GPL, não pode ser adicionada a um programa proprietário. A licença LGPL permite esta forma de 
distribuição, ou seja, uma biblioteca pode ser adicionada a um programa proprietário. A biblioteca GDAL/OGR é um exemplo desta modalidade. (DONNELLY, 2010).

Tabela 8.1 - Diferenças Entre as Licenças FOSS

\begin{tabular}{llll}
\hline \hline Licença & $\begin{array}{l}\text { Pode ser } \\
\text { Combinado com } \\
\text { Software } \\
\text { Proprietário }\end{array}$ & $\begin{array}{l}\text { Modificações } \\
\text { podem ser } \\
\text { realizadas sem } \\
\text { retornar a } \\
\text { sociedade }\end{array}$ & $\begin{array}{l}\text { Mudanças podem } \\
\text { ser realizadas sob } \\
\text { uma licença } \\
\text { diferente }\end{array}$ \\
\hline GPL & Não & Não & Não \\
LGPL & Sim & Não & Não \\
BSD (BSD, Mozilla, & Sim & Sim & Sim (limitado no \\
MIT) & Sim & Sim & Sim \\
Domínio Público & - & Não & Não \\
Licença Proprietária & - & & \\
\hline \hline
\end{tabular}

O desenvolvimento de programas de computador livres e de código aberto tem registrado um crescimento acelerado nos últimos anos. A variedade de programas FOSS (Free and Open Source Software - FOSS) que podem ser encontrados para computadores pessoais vão desde processadores de texto (OpenOffice.org), navegadores para internet (Mozilla Firefox), desenho (Inkscape), tratamento de imagens (GIMP) até aplicações científicas (R Projetc, SciLab).

Com o objetivo de criar padronização nos dados espaciais, foi criado nos anos 2000 o OpenGIS Consórcio (OGC, http://www.opengeospatial.org) como um braço do W3C (World Wide Web Consortium). O OGC elegeu todos os institutos e organizações importantes do setor, como IBM, Microsoft, Oracle, ESRI, MIT, Stanford University, entre outros, para serem integrantes do consórcio. Desde então o OGC publicou os padrões para a Geographic Markup Language (GML), Web Map Services (WMS) e Web Feature Services (WFS) para estabelecer um padrão na maneira de manipular dados geográficos. (CHEN et al., 2010).

Assim, a comunidade que estava envolvida com software aberto voltado a informação geográfica entendeu que deveria ser criado um órgão para representar esta 
vertente. Desta forma, em 2006, é criado o Open Source Geospatial Foundation (OSGeo, www.osgeo.org), para oferecer um ponto de contato entre todos os envolvidos com informações geográficas.

Nos últimos anos o mundo do software livre e aberto direcionado a sistemas de informação geográfica tem recebido mudanças significativas. 0 sítio da internet FreeGis.org lista 356 projetos relacionados à GIS. (STEINIGER; BOCHER, 2009). No domínio do GIS o aparecimento e disseminação de programas com a filosofia FOSS4G (Free and Open Source Software for GIS) parecem seguir um caminho de sucesso. Este aparente sucesso pode ser avaliado por quatro indicadores:

- Número de projetos iniciados nos últimos dois anos: 20 novos projetos foram adicionados à lista de projetos existentes no sítio FreeGis.org;

- Crescimento do suporte financeiro dado por organizações governamentais para a fundação de projetos FOSS;

- Taxa de downloads de FOSS GIS desktop;

- Crescente utilização do PostGis como banco de dados espacial (RAMSEY, 2007).

Uma vantagem observada na utilização de software livre e de código aberto é de que esta prática facilita a estrutura de distribuição do software nas organizações, já que não existem custos relativos à sua aquisição. Os demais custos de implantação e treinamento existiriam mesmo com um software proprietário (por exemplo, ArcGIS da ESRI).

O fato de o software ter um código aberto cria condições que facilitam o desenvolvimento de ferramentas específicas, quais sejam: (i) desenvolvimento dentro da organização; (ii) ação isolada de um estudioso do assunto; ou (iii) utilização de soluções pré-existentes desenvolvidas pela base de usuários do software.

Assim, a adoção de um software livre e de código aberto, desde que obedecidas algumas premissas básicas na sua escolha, mostra-se como alternativa viável para utilização em sistemas que envolvam informações geográficas. 


\subsection{O Processo de Escolha}

Uma escolha, de qualquer natureza, é um processo decisório que pode ser decomposto em etapas. A decomposição de um problema em etapas é uma das primeiras lições aprendidas na área de análise das decisões e, portanto, o processo de escolha de um determinado sistema, para gerenciamento de informações, sendo um processo decisório, pode ser avaliado sob a ótica da análise da decisão.

A análise da decisão fornece ferramentas adequadas para que o processo de escolha seja conduzido de uma maneira organizada, ou em etapas. As etapas podem ser decompostas em mais ou menos fases (HAMMOND; KEENEY; RAIFFA, 2002); (BAZERMAN; MOORE, 2010)(CLEMEN; REILLY, 2000) (MCNAMEE; CELONA, 2001) (GOMES; GOMES; ALMEIDA, 2009). A finalização de cada uma das etapas do processo de escolha fortalece a decisão a ser tomada.

A decomposição tem o objetivo de facilitar a análise do problema e chegar a uma solução que seja adequada com base em um objetivo comum, que pode ser melhor solução financeira, ou economia de tempo, ou aumento de eficiência, ou aumento de eficácia, etc...

A análise conduzida para a escolha de um programa de computador para manipular dados espaciais relativos a um pavimento ferroviário não foge a esta regra. 0 problema a ser analisado é o da escolha de um programa de computador (software) para análise de dados espacialmente distribuídos relativos a um pavimento ferroviário.

\subsection{Definição de SIG}

Programas de computador utilizados para visualizar, criar, gerenciar e analisar dados espaciais são classificados genericamente como Sistemas de Informação Geográfica (SIG) ou da sigla em inglês GIS (Geographic Information System) (STEINIGER; WEIBEL, 2009).

Sistemas de Informação Geográfica podem ser definidos, de uma forma simples, como uma coleção integrada de dados e procedimento computacionais para visualizar e 
organizar dados com posições espaciais definidas com o propósito de realizar análises geográficas e criação de mapas relativos a essas análises (DONNELLY, 2010).

Definições mais amplas de SIG incorporam as ideias da comunidade usuária de tais ferramentas, que as utiliza na solução de problemas e no compartilhamento de conhecimento adquirido. A versatilidade do SIG permitiu que as fronteiras da geografia e das ciências da terra fossem transpostas e a utilização deste sistema fosse aplicada nas mais diversas áreas do conhecimento (sociologia, marketing, planejamento urbano, etc....).

Uma designação abrangente de um SIG envolve dizer que, além da criação de mapas, o SIG pode servir como "front-end" para banco de dados espaciais e conduzir análises raster em imagens geradas por satélite. Esta característica é reforçada pela disponibilidade de pacotes FOSS4G que podem ser utilizados para acesso a um conjunto de dados espaciais na web para análises complexas.

Em qualquer conjunto de dados relativos a informação geográfica temos a possibilidade de encontrar dois tipos de representação: raster e vetorial.

Em uma representação raster uma malha regular de células é usada, aonde cada célula é um registro com valores que descrevem o ponto. Arquivos raster são comumente utilizados para representar variáveis que são contínuas no espaço, como elevação do terreno ou a cobertura do solo.

Os modelos representados com dados vetoriais são utilizados para mostrar dados espacialmente discretos, aonde cada objeto é representado por uma geometria (ponto, linha ou polígono), e por valores que descrevem propriedades não espaciais do objeto, chamados atributos, definidos em uma tabela. Assim, uma construção pode ser representada, por exemplo, por um retângulo (geometria) e ter acoplado dois campos que descrevem o ano da construção e o proprietário. (STEINIGER; HAY, 2009).

Os SIGs disponíveis na versão FOSS4G estão preparados para lidar com conjunto de dados raster ou vetorial, contudo este trabalho envolve a utilização de dados vetoriais. A utilização de dados raster será, se eventualmente utilizada, uma maneira de mostrar o sistema de transportes inserido no contexto urbano, no entanto nenhuma operação geográfica envolvendo dados raster será procedida. 


\subsubsection{Critérios de avaliação do SIG}

Como já abordado, programas de computador que lidam com dados espacialmente distribuídos são conhecidos como SIG. Os SIGs estão inseridos em famílias, de acordo com as tarefas específicas executadas por cada um deles, porém as funcionalidades básicas são comuns a todos. As famílias de SIGs podem ser assim discriminadas (STEINIGER; BOCHER, 2009): (i) Desktop GIS; (ii) Sistemas Gerenciadores de Banco de Dados Espacial; (iii) Software para aplicações geográficas na Internet; (iv) SIG Móvel; (v) Extensões; (vi) Bibliotecas, Plug-ins e APIs para SIGs; (vii) SIG para tratamento de imagens; (viii) Análise Exploratória de Dados Espaciais. A Figura 8.1 (STEINIGER; HUNTER, 2012) mostra tal "constelação" de soluções.

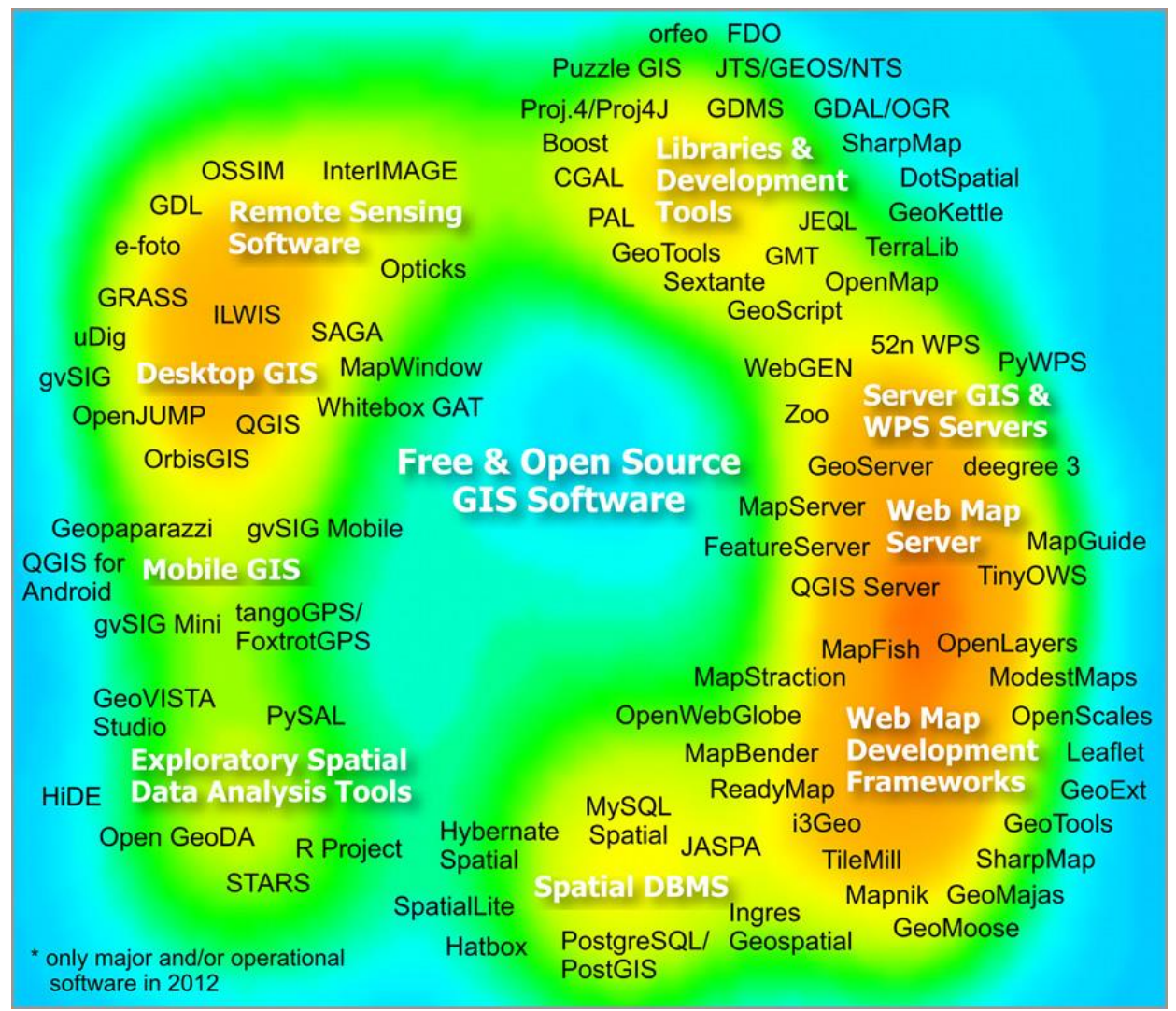

Figura 8.1 - Distribuição das Soluções em SIG 
Os critérios de avaliação de um SIG devem levar em conta o conjunto de ferramentas disponível para a realização de tarefas rotineiras na utilização do SIG. Estas tarefas são assim classificadas: (a) visualização e exploração dos dados; (b) criação de dados; (c) edição de dados; (d) armazenamento dos dados; (e) integração de dados de diferentes fontes; (f) consulta de dados para seleção de conjunto específico de dados; (g) análise dos dados com criação de novas de informações; (h) transformação de dados (mudança de coordenadas); (i) criação de mapas, talvez a mais visual e simples maneira de analisar um conjunto de dados de forma espacial.

0 conjunto de características apresentadas na Tabela 8.2 é produto de uma avaliação conduzida por STEINIGER; HUNTER (2012). Algumas alterações foram consideradas, em face ao atual panorama da comunidade SIG e das recentes melhorias implantadas em diversos programas de computador e ferramentas de análise (QGis, R Project, Gvsig, PostGre/PostGis, I3Geo, MapServer, etc...).

As tabelas 8.2 e 8.3 apresentam os critérios de seleção de um software:

Tabela 8.2 - Critérios de Seleção de Software

\begin{tabular}{lll}
\hline \hline & Critério & Legenda \\
\hline \multirow{2}{*}{$\begin{array}{c}\text { Avaliação a } \\
\text { longo Termo }\end{array}$} & Fível do Usuário & $\begin{array}{l}\text { Iniciante, usuário avançado, expert, } \\
\text { desenvolvedor. }\end{array}$ \\
& Tipo de Dados & Edição de Dados, Junção de Dados, \\
& Plataforma de desenvolvimento & Análises, Visualização. \\
& Critério & Raster, Vetor, Voxel (volumetric pixel). \\
\hline & Funcionalidade Python, MS .Net. \\
\hline \multirow{3}{*}{$\begin{array}{c}\text { Critério de } \\
\text { Avaliação }\end{array}$} & Documentação & Critério \\
& Modular & Suporte a Padrões OGC. \\
& Comunidade de Usuários & Equipe de Desenvolvimento Transparente. \\
& Usabilidade & Comunidade desenvolvedora. \\
\hline \hline
\end{tabular}

A Tabela 8.2 indica as características estudadas por (STEINIGER; HUNTER, 2012) nos software GRASS, Qgis, Gvsig, OpenJump e Udig. 
Esta tabela é um a ferramenta para avaliação inicial destes software para a seleção daquele que atenda às necessidades do projeto. Entenda-se que estas funcionalidades não são os únicos critérios a serem analisados. A facilidade de uso, a estabilidade do software, a velocidade de processamento das operações, a comunidade usuária do software, existência de documentação e suporte ao desenvolvimento são, também, critérios muito importantes para esta seleção.

Com base na Tabela 1 (HSU; OBE, 2008; OBE; HSU, 2009) do ANEXO A e nas considerações sobre demais critérios avaliados, mostrados na tabela 2 do ANEXO A, a árvore de critérios na Figura 8.1 mostra quais são todos os critérios a serem utilizados em uma avaliação para a escolha de um software que seja adequado ao projeto apresentado.

Observe-se que a escolha aqui apresentada pode, e deve sofrer alterações sempre que um novo processo de escolha se inicia. A evolução tecnológica, as necessidades imediatas, as características intrínsecas de cada projeto, a experiência de cada um que está envolvido no processo de escolha, e demais condições de contorno levam a escolhas diferentes, para situações diferentes.

Tabela 8.3 - Critérios de Escolha - Necessidades de um SIG (adaptado de Steiniger; Hunter (2012).

\begin{tabular}{|c|c|c|c|c|c|c|c|c|}
\hline \multirow[b]{2}{*}{ Tipo de SIG } & \multicolumn{8}{|c|}{ Tarefas Exigidas } \\
\hline & $\begin{array}{l}\text { Visualização } \\
\text { e Exploração }\end{array}$ & $\begin{array}{l}\text { Criação } \\
\text { de } \\
\text { Dados }\end{array}$ & Edição & Armazenamento & Integração & Análise & Transformação & $\begin{array}{l}\text { Criação } \\
\text { de } \\
\text { Mapas }\end{array}$ \\
\hline Visualizador & घ & & & घ & & & & घ \\
\hline Editor & - & - & - & - & & & $\square$ & - \\
\hline $\begin{array}{l}\text { Análises } \\
\text { Profissionais }\end{array}$ & - & - & - & घ & - & - & घ & - \\
\hline $\begin{array}{l}\text { Remote Sensing } \\
\text { Software } \\
\text { (Tratamento de } \\
\text { Imagens) }\end{array}$ & - & $\square$ & - & घ & $\square$ & - & - & घ \\
\hline $\begin{array}{l}\text { Ferramentas de } \\
\text { Análise }\end{array}$ & - & & $\square$ & घ & $\square$ & घ & - & घ \\
\hline $\begin{array}{l}\text { Banco de Dados } \\
\text { Espacial }\end{array}$ & - & - & - & - & - & $\square$ & - & $\square$ \\
\hline $\begin{array}{l}\text { Servidor de } \\
\text { Mapas Web }\end{array}$ & - & $\square$ & $\square$ & & & & - & - \\
\hline $\begin{array}{l}\text { Servidor de } \\
\text { mapas GIS/ } \\
\text { Servidor de } \\
\text { mapas WPS }\end{array}$ & घ & & & घ & & 口 & च & घ \\
\hline
\end{tabular}


A similaridade entre os programas avaliados é alta, de maneira que em uma escolha normal o desempate seria pela questão de custos envolvidos. Por serem programas de computador livres e de código aberto existem os custos de implantação e manutenção, mas não existem os custos de aquisição e renovação de licenças, que geralmente são os custos significativos. Desta forma, persiste a situação de empate.

Entretanto, a existência de uma base sólida de usuários, documentação disponível e financiadores confiáveis para os projetos FOSS4G servem como qualificadores do programa de computador, para que seja adotado com um nível de confiança adequado.

A base de usuários e os financiadores podem ser enxergados como garantia da perpetuação dos programas de computador; a existência de documentação permite que os usuários tenham material de treinamento disponível para aprofundar-se na utilização do programa escolhido.

Assim, com base nas tabelas apresentadas, na árvore de critérios e nos demais qualificadores envolvendo número de usuários, documentação disponível e financiadores do projeto, a escolha recaiu sobre o software QGis, por apresentar o melhor conjunto de qualificadores dentro do processo de escolha no exato momento da escolha. Mudanças temporais de escolha podem mudar esta escolha devido a velocidade com que novas ferramentas e funcionalidades são atribuídas a estes softwares.

\subsection{Escolha do Sistema Gerenciador de Banco de Dados}

Por definição, Banco de Dados é uma coleção de dados inter-relacionados (ELMASRI; NAVATHE, 2011).

Sistema de Gerenciamento de Banco de dados (SGBD) é uma coleção de dados inter-relacionados e um conjunto de programas para acessá-los permitindo ao usuário criar e manter o banco de dados (DATE; VIEIRA, 2004; GUIMARÃES, 2003).

Um SGBD é uma forma de armazenar dados e gerir informações para a posterior recuperação ou atualização dessas informações por um usuário. Este sistema deve evitar 
perdas de dados por falhas no sistema, acessos não autorizados e anomalias de dados. (HARRINGTON, 2002).

A escolha de um Sistema Gerenciador de Banco de dados (SGBD) seguirá os mesmos passos da escolha do SIG, porém com critérios específicos para um banco de dados. Da mesma forma o processo de escolha nãos será apresentado de maneira detalhada.

\subsubsection{Definição de banco de dados}

Um banco de dados é criado e mantido por sistema gerenciador de banco de dados (SGDB), que é uma coleção de programas que permite aos usuários criar e manter um banco de dados. O SGDB é, portanto, um sistema de software de propósito geral que facilita os processos de definição, construção, manipulação e compartilhamento de banco de dados ente vários usuários e aplicações (ELMASRI; NAVATHE, 2011).

A definição de um banco de dados implica em especificar os tipos, as estruturas e as restrições para os dados a serem armazenados.

Ainda, o sistema de banco de dados consiste na manutenção de registros por computador, ou seja, um sistema cujo principal objetivo é manter as informações e tornálas disponíveis quando estas são solicitadas (GUIMARÃES, 2003).

A utilização de um SGBD implica na definição de um único repositório de dados, mantido e que pode ser acessado por vários usuários. As principais características de abordagem de um banco de dados são (FLEMING; HALLE, 1989):

- Natureza auto descritiva do sistema de banco de dados;

- Isolamento entre os programas, os dados, e a abstração;

- Independência de dados;

- Suporte para as múltiplas visões dos dados;

- Compartilhamento de dados e processamento de transações de multiusuários.

Uma característica fundamental dos bancos de dados é que eles provêm um nível de abstração, escondendo detalhes de armazenamento que não são necessários para a 
maioria dos usuários de banco de dados. 0 modelo de dados é a ferramenta principal utilizada para garantir esta abstração (ELMASRI; NAVATHE, 2011).

Um modelo de dados é um conjunto de conceitos usado para descrever a estrutura do banco de dados e as restrições que o banco deve garantir. Existem três conjuntos de modelos de dados: (i) o conceitual, que expõe a composição dos dados de forma abstrata sem se incomodar com a prática; (ii) o físico, que apresenta formas físicas de implantação; (iii) o de implementação (um grupo com peculiaridades dos dois primeiros) (HARRINGTON, 2002).

\subsubsection{O modelo relacional}

No modelo relacional a representação dos dados é feita através de tabelas, cada uma delas com sua própria denominação. Estas tabelas se relacionam através de um elemento comum, chamada de chave primária, que atenda às restrições impostas pelo próprio modelo, garantindo a integridade dos dados. (GUIMARÃES, 2003).

O princípio básico do modelo relacional é o princípio da informação: toda informação é representada por valores em relações.

\subsubsection{Restrições do modelo relacional}

- Regras de Integridade: 0 termo integridade de dados refere-se ao formato como os dados são armazenados, ou seja, duas entradas inconsistentes podem gerar arquivos com falha na integridade.

As restrições de integridade consistem em tentar impedir que o usuário entre com dados com formatos diferentes daqueles exigidos pelo campo; garanta que as mudanças realizadas no banco de dados não violem as regras estabelecidas no SGBD. (HOFFER; VENKATARAMAN; TOPI, 2012). 
- Visões: Consiste em uma forma que o SGBD utiliza para gerar uma tabela virtual com resultados oriundos de outras tabelas fisicamente existentes no banco de dados.

As visões são úteis como uma forma de segurança dos dados, não deixando usuários acessarem informações sem permissão; permite que usuários com diferentes permissões vejam uma mesma informação de forma diferente e são úteis para simplificar consultas em um banco de dados (HOFFER; VENKATARAMAN; TOPI, 2012).

O modelo relacional apresenta as seguintes restrições (ELMASRI; NAVATHE, 2011):

a) Restrições de Domínio: especifica que o valor de cada atributo A deve ser um valor atômico do domínio dom(A).

b) Restrições de chave: por definição, todos os elementos de um conjunto são distintos. Consequentemente, todas as linhas em uma relação devem também ser distintas. Isto significa que não devem existir duas linhas com a mesma combinação de valores para todos os atributos.

c) Restrição de nulo: pode ser especificado se valor nulo pode ou não ser permitido.

d) Restrição de Integridade Referencial: a restrição de integridade referencial envolve duas relações distintas, ou dois atributos distintos de uma relação. Por exemplo, supondo um relacionamento entre duas entidades "trilhos" e "soldas", onde soldas estão ligadas a um trilho, podemos supor que haja na relação das soldas um atributo contendo o código do seu trilho. A restrição de integridade referencial define que este atributo "código do trilho" deve corresponder ao valor da chave primária que identifica o trilho utilizado na solda, ou caso não esteja ligada a um trilho, este valor seja nulo. Não é possível este atributo conter algum valor diferente dos que estão na chave primária da relação dos trilhos.

\subsubsection{Fatores determinantes na escolha de um banco de dados}

A escolha de um banco de dados segue as mesmas premissas anteriormente abordadas na escolha do SIG, porém existem características que devem ser observadas 
para que o banco de dados responda as necessidades definidas no projeto. Um conjunto de fatores é apresentado por Harrington (2002):

a) Controle de redundância: o banco de dados deve ser capaz de garantir que os dados não tenham duplicidade. Desta forma, não seria possível incluir dois registros com o mesmo código (integridade de entidade). Também não seria possível excluir um registro que tivesse relacionamento com outras tabelas (integridade referencial). A base do modelo relacional está contida nesta integridade.

b) Compartilhamento de dados: a informação deve estar disponível para qualquer número de usuários de maneira rápida, concomitante e segura.

c) Controle de acesso: é importante saber quem fez e o que fez no banco de dados.

d) Cópias de Segurança (back-up): deve haver rotinas específicas para realizar cópias de segurança dos dados armazenados.

e) Suporte às Transações: as transações são originadas em qualquer operação com os dados armazenados. Realizar o controle sobre essas transações, garantindo a integridade das informações armazenadas é uma necessidade para os bancos de dados. 0 mínimo controle necessário é o bloqueio por linha, ou seja, cada alteração bloqueará apenas uma linha no banco de dados. Com isso, há uma maior disponibilidade da informação armazenada.

f) Suporte à programação: algumas operações continuam sendo mais rápidas se forem realizadas diretamente no banco de dados. Com isso, o banco de dados deve possuir uma linguagem de programação que permita realizar rotinas específicas diretamente sobre ele. Muitas regras de negócio são executadas diretamente no banco de dados. Por exemplo, emitir um relatório toda vez que o desgaste limite em um equipamento estiver próximo, ou criar uma tarefa automaticamente quando o tempo de manutenção do equipamento estiver próximo do vencimento.

g) Recuperação: o banco de dados deve ser dotado de ferramentas de geração de backup automático.

h) Desempenho: 0 desempenho do banco de dados pode ser melhorado com técnicas de ajuste realizadas diretamente no banco. Deve ser verificada a disponibilidade de ferramentas que permitam realizar estes ajustes. 
i) Escalabilidade: é necessário saber os limites do banco de dados. Geralmente existem mecanismos de junção de banco de dados, criando condições necessárias para o adequado armazenamento e a cesso dos dados.

\subsubsection{Escolha do SGBD}

Dentre os softwares livres para gerenciamento de banco de dados que tenham possibilidade de lidar com dados geográficos temos as seguintes opções: PostgreSQL e a sua extensão PostGIS, MySQL e o SQLite com a extensão SpatiaLite.

O SQLite é um SGBD que não tem características de acesso múltiplo, de fato o SQLite é uma excelente opção para dispositivos móveis ou aplicações satndalone para posterior transferência de dados para um SGBD que seja preparado para lidar com múltiplos acessos e tenha a robustez suficiente para manter a integridade dos dados.

Assim, a comparação será entre o PostgreSQL e o MySQL. As características de cada um dos SGBD são apresentadas na Tabela 3 (HSU; OBE, 2008) do ANEXO A.

Os SGBD avaliados diferem em questões técnicas, existe superioridade por parte do PostgreSQL. Mesmo com os custos de implantação e manutenção semelhantes para ambos a questão técnica aponta para um desempate pendendo para o PostgreSQL.

O MySQL possui uma comunidade usuária muito maior que a do PostgreSQL, uma vez que é largamente utilizado em aplicações web, fazendo sempre dupla com a linguagem de programação PHP para aplicações que envolvam manipulação de dados na web.

Mesmo com a existência de uma base sólida de usuários, o MySQL não é a escolha da comunidade usuária de informações espaciais e, neste nicho específico, o PostgreSQL+PostGIS acaba por ser a escolha de muitas aplicações, inclusive para aplicações web.

Desta forma, com uma base de usuários crescente, existência de documentação disponibilizada aos usuários, crescente utilização em aplicações dedicadas e também na web, uma base de desenvolvedores sólida, o PostgreSQL foi a escolha natural para o projeto em curso. 


\section{EXEMPLO DE APLICAÇÃO NUMÉRICA}

\subsection{Definição}

A aplicação numérica aqui apresentada enquadra-se em um estudo de caso. 0 estudo de caso contribui para compreendermos melhor os fenômenos individuais, os processos organizacionais e políticos da sociedade. É uma ferramenta utilizada para entendermos a forma e os motivos que levaram a determinada decisão. 0 estudo de caso é uma estratégia de pesquisa que compreende um método que abrange abordagens específicas de coletas e análise de dados (YIN, 2002).

Este método é útil quando o fenômeno a ser estudado é amplo e complexo e não pode ser estudado fora do contexto onde ocorre naturalmente. Ele é um estudo empírico que busca determinar ou testar uma teoria.

Os casos podem ser reais ou fictícios. Os reais exigem muito cuidado na atribuição de declarações, que devem ser devidamente documentadas. Casos fictícios dão mais liberdade ao autor, mas isso não significa que possam abordar situações irreais. 0 caso posto como fictício deve, de fato, expressar situações que possam ser vividas e possíveis de acontecer.

Um caso não é um documento histórico nem um texto puramente descritivo. Ele deve ser capaz de suscitar questões para debate e ter elementos que permita tomada de posição e definição de cursos de ação. 
É uma investigação que trata de uma situação específica, procurando encontrar as características e o que há de essencial nela. Esse estudo pode ajudar na busca de novas teorias e questões que servirão como base para futuras investigações.

A vocação do estudo de caso é tentar esclarecer decisões a serem tomadas. Ele investiga um fenômeno contemporâneo partindo do seu contexto real, utilizando de múltiplas fontes de evidências. Os estudos de caso podem ser:

- Exploratórios: quando se quer encontrar informações preliminares sobre o assunto estudado.

- Descritivos: cujo objetivo é descrever o estudo de caso.

- Analíticos: quando se quer produzir novas teorias que irão construir ou desenvolver que irão ser confrontadas com as existentes, proporcionando avanços do conhecimento.

É preciso ter diferentes visões do assunto estudado, pois serão a base para orientar as discussões sobre a aceitação ou não das alternativas encontradas.

\subsubsection{Desenvolvimento}

Uma vez definidos o tema e o foco para o caso, que devem estar conectados ao objetivo geral do trabalho desenvolvido, é necessário a coleta de dados, que devem garantir a veracidade e a fidedignidade das informações geradas.

Perguntas de caráter descritivo, do tipo "o que", "quem", "como" e "onde”, e, principalmente "como", serão o foco das pesquisas, que fornecerão informações para o relato e para o alinhamento entre questões teóricas e o caso em questão.

Perguntas de caráter explicativo, do tipo "por quê", fornecerão subsídios para os objetivos da aprendizagem.

Essa é uma orientação geral sobre a organização a ser feita. 0 tipo de questionamento dependerá do tema abordado e do conhecimento prévio de informações. 


\subsection{O Estudo de Caso Objeto do Trabalho}

\subsubsection{Características}

O exemplo de aplicação numérica apresentado é realizado na linha vermelha do Metrô de São Paulo. Este sistema conta com as seguintes características:

- Via permanente:

- Bitola de $1600 \mathrm{~mm}$;

- Assentada em lastro de pedra brita;

- Dormentes de concreto com espaçamento de 0,65m;

- Fixação do tipo SKL-3;

- Trilhos TR57;

- Palmilha polimérica entre o dormente e trilho;

- Trilhos continuamente soldados.

- Material Rodante

- Taxa de aceleração: $0,9 \mathrm{~m} / \mathrm{s}^{2}$;

- Taxa de frenagem: $0,7 \mathrm{~m} / \mathrm{s}^{2}$;

- Taxa de frenagem de emergência: $1,2 \mathrm{~m} / \mathrm{s}^{2}$;

- Velocidade máxima: $100 \mathrm{~km} / \mathrm{h}$;

- Perfil de roda AAR-G29;

- Carga por eixo: 14 ton;

- Trens com 6 carros, totalizando 24 eixos.

- Operação do Sistema

- Intervalo entre trens: 105 seg no horário de pico;

- Média de usuários: 1,6 milhão/dia;

- Número médio de viagens diárias realizadas: 1008;

- Número de trens em circulação no pico: 47. 
Esta operação promove o acúmulo de aproximadamente 90 milhões de toneladas brutas transportadas anualmente (MTBT, ou em inglês MGT, Million Gross Tons). Esta tonelagem acumulada compara-se a marcas alcançadas em ferrovias de transporte de carga chamadas "Heavy Haul”. Estas ferrovias geralmente transportam minério, as cargas por eixo estão entre 35 e 40 ton/eixo, a velocidade dos trens está entre $20 \mathrm{~km} / \mathrm{h}$ a 70 $\mathrm{km} / \mathrm{h}$ e os comboios utilizam quatro locomotivas puxando comboios de até 300 vagões.

A diferença do sistema estudado com uma ferrovia de carga é o intervalo entre trens, usualmente denominado "headway". Enquanto na ferrovia de carga o intervalo é de vários minutos, não sendo incomum intervalo de 30 a 40 minutos entre trens, no sistema estudado temos um intervalo entre trens, no horário de pico, de 105 segundos.

Vale citar que existe uma tendência europeia de trens de carga com intervalo reduzido, de 3 a 4 minutos, circulando a velocidades altas, em torno de $160 \mathrm{~km} / \mathrm{h}$, em comboios puxados por uma locomotiva, com número reduzido de vagões (em geral 32 vagões), para mitigar o problema de ruído.

\subsubsection{A Locação da Via Permanente}

A locação da via estudada é mostrada na Figura 9.1a e 9.1b, que contempla a porção Leste-Oeste da cidade de São Paulo.

A divisão da via permanente foi realizada em trechos de 200 metros. Esta divisão foi utilizada pois é uma extensão de via que pode ser atendida em uma única ação de manutenção, bem como seus múltiplos, para o caso aqui estudado. Outras vias podem ter como característica trechos de 150 metros, ou 225 metros, ou 300 metros, dependendo do tamanho da equi8pe de manutenção, recursos disponíveis e tempo disponível para a manutenção. 


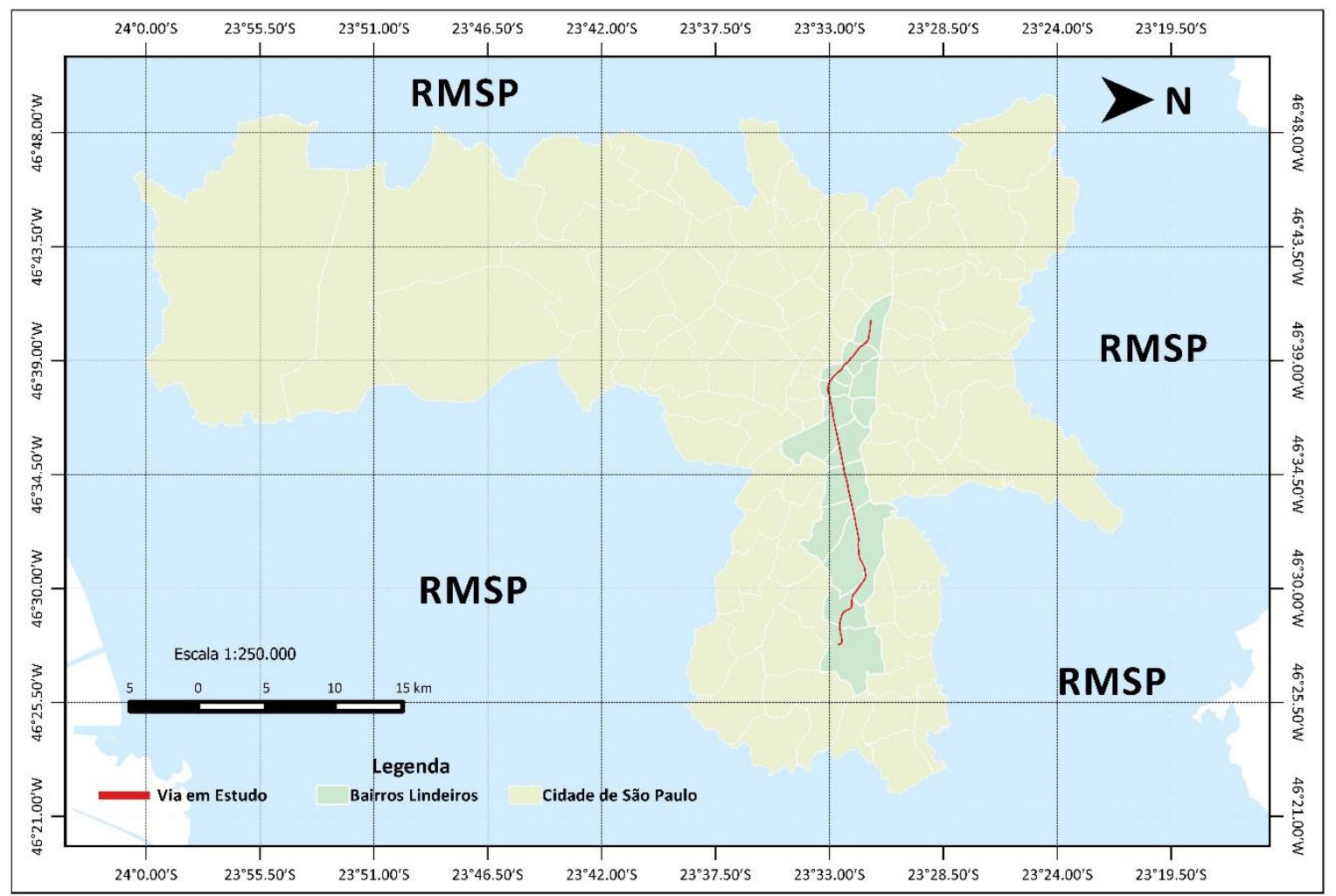

Figura 9.1a - Locação da via permanente estudada.

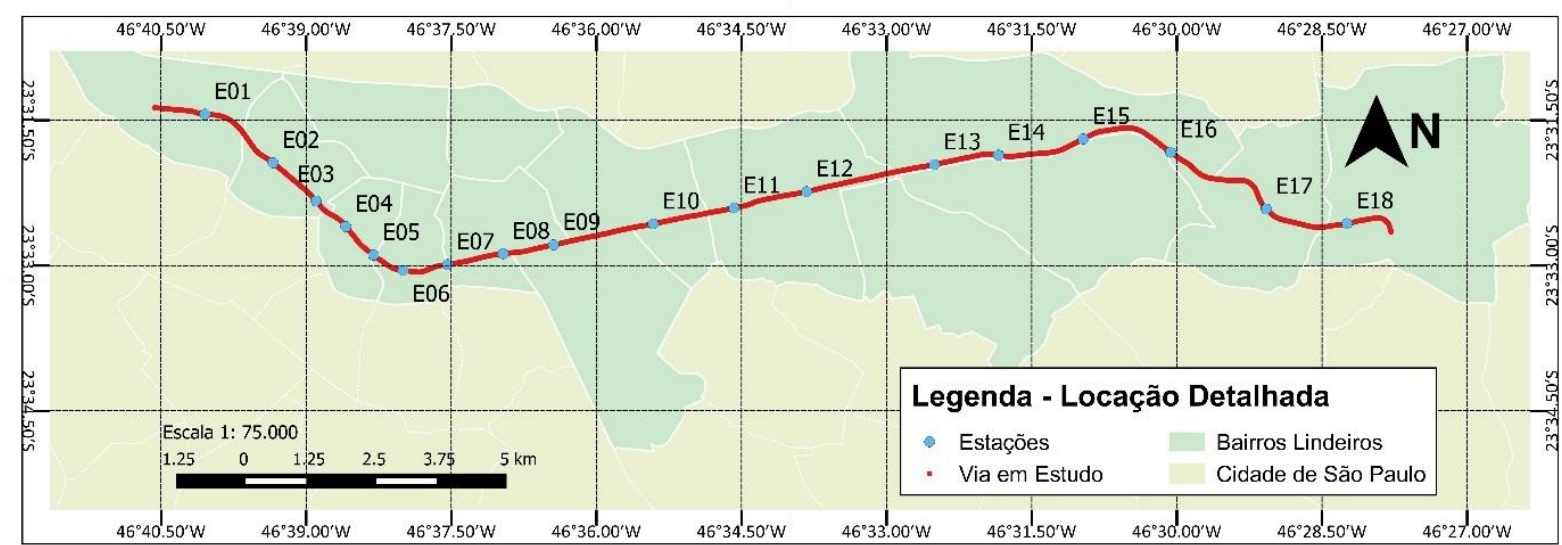

Figura 9.1b - Locação da via permanente - Posição Detalhada.

Por exemplo, a substituição de trilhos em um trecho de 200 metros é o limite que a equipe de manutenção consegue realizar no período noturno de manutenção.

Para a ação de socaria de via o limite, dependendo das condições geométricas da via, é de 600 metros. As equipes de socaria trabalham, então, com trechos de 200, 400 e 
600 metros, de acordo com a condição do trecho, de maneira que inicie e termine a ação de socaria em uma única jornada de trabalho.

O esmerilhamento de via utiliza o mesmo processo, no entanto, dependendo do valor do desgaste ondulatório encontrado, os trechos podem ser mais extensos. Utiliza-se a regra prática de considerar que a cada passagem do trem esmerilhador (equipamento utilizado para eliminar o desgaste ondulatório), com uma velocidade de operação de 5 $\mathrm{km} / \mathrm{h}$, remove-se uma camada de $1 \cdot 10^{-3} \mathrm{~mm}(0,001 \mathrm{~mm})$. No item que contempla o desgaste ondulatório haverá uma explicação um pouco mais detalhada dos tempos e custos envolvidos nesta operação.

\subsubsection{Limitação do Estudo de Caso}

O estudo de caso é limitado na medida em que é aplicado apenas em um tipo de configuração da via (Figuras 3.2a e 5.6), ou seja, a via permanente é montada sobre lastro de pedra britada, com uso de dormentes.

Ainda que a linha vermelha do Metrô SP possua 1/3 de seu trecho construída em laje de concreto, com utilização de fixação direta observou-se, ao longo do estudo, que os custos, ainda que com distribuição temporal diferente, ao final de períodos mais extensos, são compatíveis, tanto para a via em lastro como para a via em laje de concreto.

Esta descoberta permitiu que houvesse tranquilidade em aplicar as formulações da via em lastro na via em laje de concreto, desde que guardadas as proporções.

A aplicação de todas as formulações apresentadas no capítulo 5 não será realizada. Contudo a potencialidade do uso das ferramentas de confiabilidade, disponibilidade, manutenibilidade e segurança e de custo do ciclo de vida será explorada nesta aplicação numérica, demonstrando uma forma racional de uso, ainda que em um formato básico.

A utilização destes conceitos permite que decisões eficazes e eficientes sejam tomadas, e esta é premissa que foi seguida no estudo de caso.

A aplicação numérica considera somente as atividades de manutenção preventiva e preditiva, não considerando as atividades corretivas. 
Observe-se que se o estudo de comportamento da via e dos componentes for adequadamente conduzido temos a tendência da mitigação da manutenção corretiva. 0 entendimento cada vez maior do comportamento, associado a um número cada vez maior de dados disponíveis permite que as previsões sejam cada vez mais acertadas.

A incerteza residirá apenas quando da utilização de materiais de qualidade diferente daquela usual. Os materiais com qualidade superior tendem a durar mais enquanto os materiais de qualidade inferior devem falhar em um período de tempo menor do que ao usualmente previsto.

A mudança do comportamento da operação do sistema também é uma variável que afeta diretamente a previsão conduzida.

O intervalo entre trens menor, por exemplo, aumenta a tonelagem bruta acumulada e, em consequência, os equipamentos tendem a apresentar os defeitos em um período de tempo menor, ainda que com a mesma tonelagem acumulada.

O inverso também afeta o comportamento, o limite da tonelagem acumulada, com um intervalo maior entre trens, vai demorar mais a chegar, e, assim, os equipamentos tendem a durar por um intervalo de tempo maior.

\subsection{Dados Utilizados}

Como já referenciado, a via foi dividida em trechos de 200 metros. No entanto, temos o registro de cada um dos fenômenos abordados na aplicação numérica a cada 4 metros. Isto significa que temos um banco de dados com mais de 13.000 linhas de registro.

As estruturas dos bancos de dados são mostradas no ANEXO A, Figuras 1 e 2. 0 ANEXO A também contém o dicionário de dados e os scripts em linguagem SQL (do inglês Structured Query Language) para a geração dos bancos de dados.

A linguagem SQL é um padrão para banco de dados, no entanto existem bancos de dados que não seguem este padrão. A linguagem, através de procedimentos estruturados, permite a manipulação dos dados armazenados, realização de consultas, geração de relatórios, operações de criação e alteração das tabelas e operações geográficas. 0 banco 
de dados sugerido neste trabalho, o PostgreSQL+PostGis, é compatível com a linguagem SQL.

Na aplicação numérica o comportamento da via foi avaliado a partir dos seguintes dados:

- Periodicidade de troca de trilhos;

- Periodicidade de troca de dormentes;

- Periodicidade na socaria da via;

- Periodicidade de inspeção da via;

- Evolução do desgaste de trilhos;

- Evolução do desgaste ondulatório;

- Comportamento da geometria da via;

- Custo de manutenção da via.

Cada um destes fenômenos foi estudado a partir dos conceitos da confiabilidade, utilizando o tempo médio entre falhas como parâmetro para determinação das equações de vida de cada um deles.

A única exceção é com relação a inspeção de vias, que é realizada em períodos fixos de sete dias, ou seja, a cada sete dias toda a via é inspecionada e todos os desvios e defeitos encontrados são registrados para posterior atuação corretiva ou, dependendo do grau de severidade, na próxima manutenção preventiva

Os tempos médios entre falhas foram obtidos a partir de um banco de dados que contém todas as atuações de manutenção realizadas nos últimos 10 anos, a carga acumulada, as falhas ocorridas e os dados de inspeção da via.

\subsection{Resultados Obtidos}

Os resultados são apresentados na forma de mapas temáticos, gerados a partir do sistema de informações geográficas escolhido, o QGis, tendo como base de dados o PostgreSQL+PostGIS. 
O comportamento dos componentes da via foi avaliado utilizando o software Weibul++ 7.0, da ReliaSoft . Com este software é possível determinar a curva típica e os parâmetros que determinam o tempo de vida mediano dos componentes estudados, com base nos dados de manutenção e inspeção.

Para os dados utilizados nesta aplicação prática o resultado mostrou que uma curva típica do padrão Weibull, de dois parâmetros, seria aplicável em todos os casos. Os parâmetros são o fator de forma $\beta$ e a vida característica $\eta$. Avaliações um pouco mais rigorosas apontaram para uma distribuição log-normal para algumas situações, mas a distribuição de Weibull é conhecida pela sua flexibilidade e facilidade de aplicação, de maneira que esta distribuição foi a escolhida para todos os componentes.

A forma simplificada da equação de Weibull para a confiabilidade é descrita na equação 19:

$$
R(t)=e^{-\left(\frac{t}{\eta}\right)^{\beta}}
$$

t = Variável escolhida (tempo, ciclos, tonelagem, etc...);

$\beta=$ Fator de forma;

$\eta=$ Vida característica.

Esta equação permite, a partir de um valor estabelecido de confiabilidade (R), calcular a variável escolhida, com o uso dos parâmetros.

Cada um dos estudos individuais mostrará quais foram os parâmetros utilizados e qual a forma de utilização da equação de Weibull.

\subsubsection{Desgaste dos Trilhos}

O contato roda trilho provoca o desgaste do trilho, principalmente em curvas. Este desgaste é diretamente associado a tonelagem bruta acumulada no trilho, de maneira que quanto mais carga o trilho receber maior será o desgaste. 
O desgaste deve ser verificado pois a capacidade de carga do trilho diminui conforme a diminuição da área do boleto do trilho. Além disso elevados níveis de desgaste podem contribuir para que ocorram descarrilamentos.

Os limites de manutenção adotados nesta aplicação prática são de desgaste máximo de $12 \mathrm{~mm}$. 0 desgaste é medido na lateral do boleto (cabeça do trilho), a 45ㅜㅡ, e na parte superior, a $90^{\circ}$, como mostra a figura 9.2.

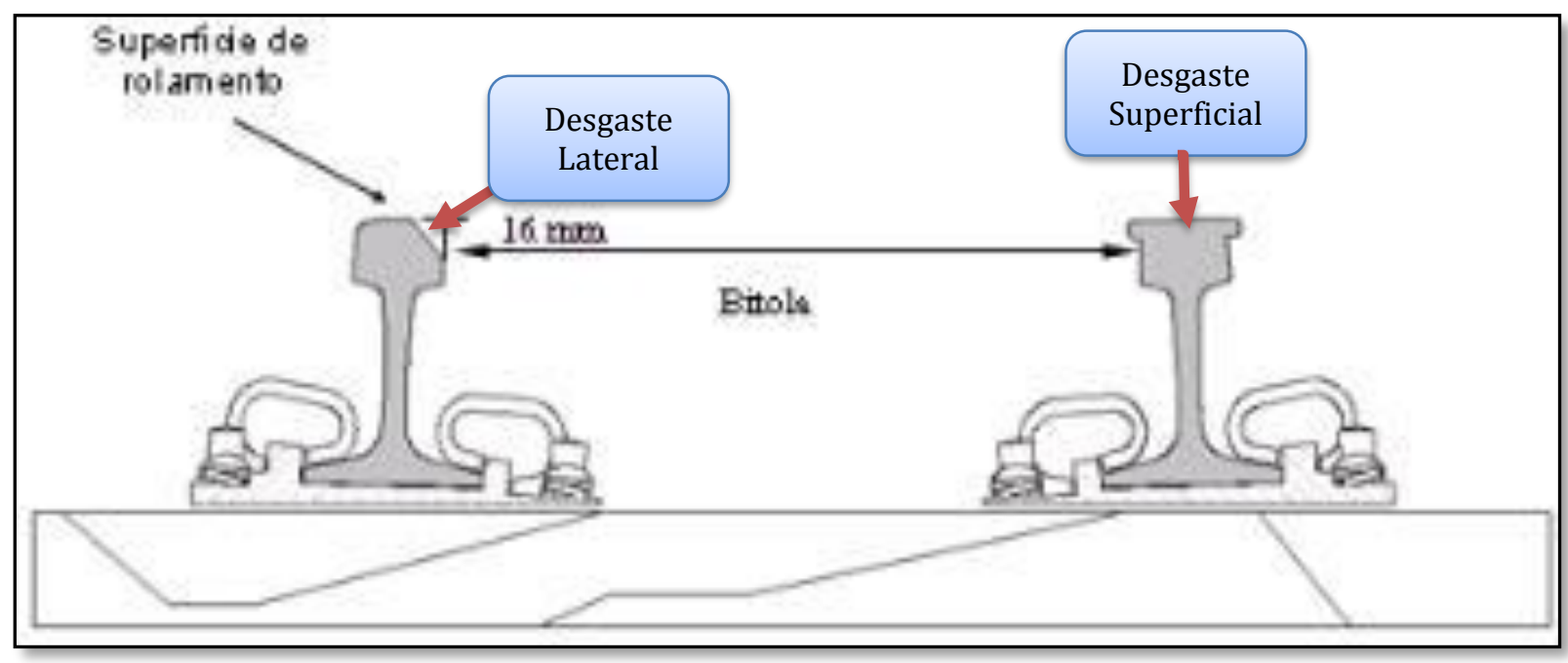

Figura 9.2 - Modos de Desgaste de Trilhos

Para o cálculo dos parâmetros e, consequentemente, determinação da equação de Weibull para o desgaste de trilhos, foram utilizados todos os dados disponíveis. Os dados utilizados neste caso foram os dados de tempo de vida dos trilhos. Este tempo é o tempo em que um trilho permaneceu na via permanente desde a sua instalação até o final de sua vida devido ao desgaste limite.

Obviamente que dentro destes tempos também houveram trilhos que foram substituídos por outros motivos além do desgaste, promovendo um erro na determinação do tempo ótimo de troca.

Uma maneira de mitigar a substituição de trilhos que ainda estejam em condições de uso é a de fazer um acompanhamento do desgaste destes trilhos em inspeções regulares. Uma inspeção a cada 6 meses nas curvas e a cada 2 anos nas retas é uma boa 
prática para verificar se o planejamento sugerido pelo sistema de informações geográficas está adequado.

Também é possível incluir a inspeção de desgaste de trilhos na inspeção geral de vias, que inspeciona toda a via em um intervalo de 7 dias, verifica diversos parâmetros e registra os defeitos e desvios encontrados. Neste caso a inspeção geral de vias facilita a realização da inspeção de desgaste, mas os prazos sugeridos de inspeção a cada 6 meses para curvas e 2 anos para retas deve ser mantido.

Não é recomendado utilizar somente o desgaste de trilhos como referência para a substituição dos trilhos pois existem outros defeitos, que ocorrem ao longo da vida do sistema, e exigem a substituição dos trilhos. Um planejamento que não leve este detalhe em consideração pode colocar em risco a segurança do sistema.

Nesta aplicação prática a forma da equação para substituição de trilhos segue o seguinte padrão: $R(t)=e^{-\left(\frac{t}{\eta}\right)^{\beta}}$, os valores calculados de $\eta$ e $\beta$ são, respectivamente, 11,9 e 7.352, e adotando um nível de confiabilidade de 90\%, a equação é escrita da seguinte maneira: $0,9=e^{-\left(\frac{t}{7352}\right)^{11,9}}$. Com essa equação podemos determinar o tempo médio entre substituições de trilhos. Com este valor calculado e com a data da última substituição do trilho em cada um dos trechos de 4 metros podemos prever a próxima data de substituição.

Neste caso a regra de agrupar por 200 metros utiliza a data mais próxima do conjunto de datas para estabelecer a data da próxima substituição. Ou seja, em cada 200 metros temos 50 datas, pois temos um registro a cada 4 metros, e o sistema escolhe a data mais próxima para colocar no planejamento.

Deve ser levado em conta que a prática de inspeções regulares para verificar se o planejamento aponta para uma ação que realmente deve ser realizada é importante, pois isto significa alocação adequada dos recursos disponíveis.

Outro fator que não deve ser desconsiderado é de que a equação que determina o tempo médio de troca de trilhos é dinâmica. A cada nova entrada de registros no banco de dados os parâmetros são novamente calculados, promovendo um ajuste da realidade da via permanente com o modelo implementado no sistema de informações geográficas.

Com os dados disponíveis foi gerado o mapa apresentado na Figura 9.3. 
0 mapa não responde a todas as perguntas, mas permite que o gestor de via permanente tenha uma visão ampla dos trabalhos a serem desenvolvidos ao longo do tempo, aonde serão realizados, e uma ideia da extensão dos trabalhos. Estas informações ajudam na determinação dos recursos e do tempo em que será necessário permanecer em cada um dos locais para a realização das substituições, ajudando na alocação de máquinas, materiais e mão de obra.

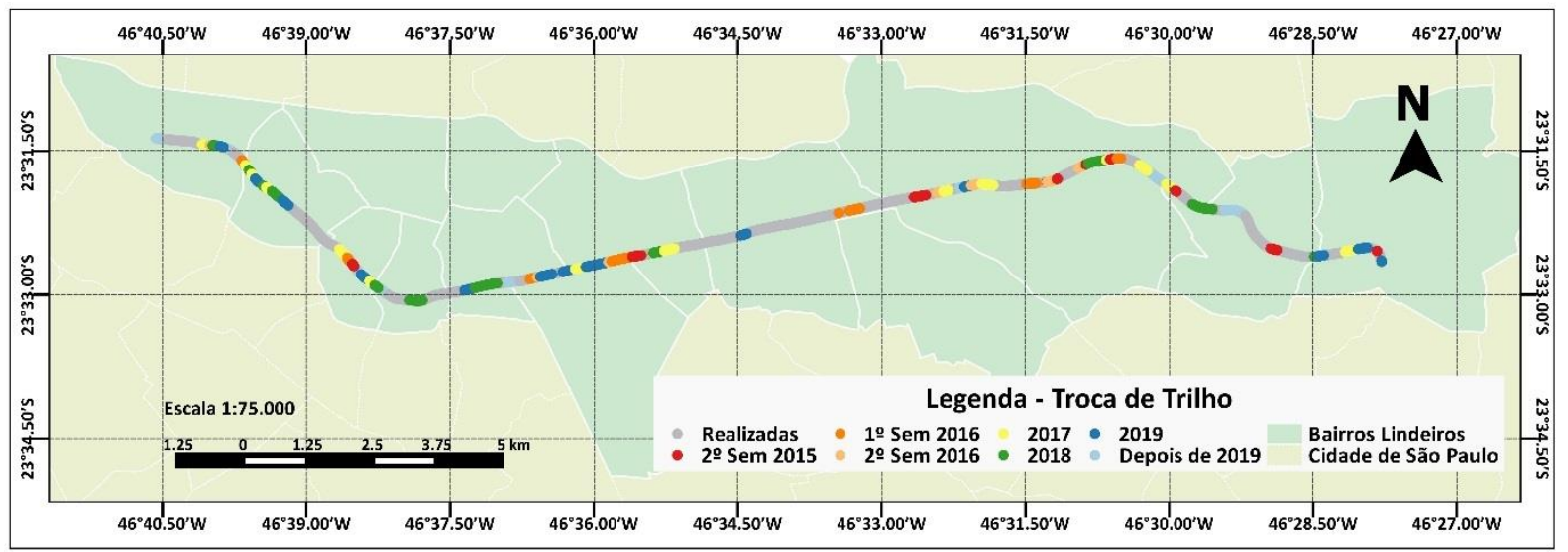

Figura 9.3 - Previsão de Trocas de Trilho.

Outro ponto em que o mapa de substituição de trilhos auxilia na gestão da via permanente é na determinação das inspeções de desgaste e condição dos trilhos, de maneira a verificar se o apontado no mapa de fato corresponde ao estado da prática na via permanente. As inspeções devem ser prioritariamente realizadas nos pontos em que as substituições de trilho estão mais próximas. As inspeções podem postergar as substituições de trilhos em função dos parâmetros ajustados que já foram discutidos neste capítulo.

Para completar o mapa as informações de custo das substituições de trilhos são apresentadas na Tabela 9.2, de forma que a gestão da via permanente tenha condições de ajustar o orçamento anual com as necessidades apresentadas no mapa, e determinadas pelo modelo implementado no sistema de informações geográficas. 
Tabela 9.2a - Previsão orçamentária de troca de trilho

\begin{tabular}{rrrrrrr}
\hline \hline Estação & $\mathbf{2 0 1 5}$ & $\mathbf{2 0 1 6}$ & $\mathbf{2 0 1 7}$ & $\mathbf{2 0 1 8}$ & $\mathbf{2 0 1 9}$ & $\mathbf{2 0 2 0}$ \\
\hline E01 & $9.729,61$ & $6.867,48$ & $9.822,31$ & $10.128,36$ & $8.739,83$ & $11.159,34$ \\
E02 & $3.731,87$ & $6.651,10$ & $3.911,27$ & $5.071,11$ & $6.788,02$ & $3.376,00$ \\
E03 & $3.008,39$ & $4.052,65$ & $4.268,62$ & $3.549,19$ & $3.065,59$ & $3.494,71$ \\
E04 & $1.790,99$ & $3.067,43$ & $1.300,81$ & $3.050,20$ & $2.943,80$ & $3.436,54$ \\
E05 & $3.498,92$ & $2.919,38$ & $3.190,96$ & $3.090,72$ & $3.015,93$ & $2.740,14$ \\
E06 & $4.854,67$ & $2.904,50$ & $3.200,76$ & $2.692,58$ & $4.412,93$ & $4.390,92$ \\
E07 & $2.878,96$ & $3.993,91$ & $4.027,67$ & $5.261,23$ & $6.387,47$ & $6.496,07$ \\
E08 & $4.281,75$ & $6.615,60$ & $5.294,16$ & $5.376,09$ & $5.402,76$ & $4.910,95$ \\
E09 & $7.406,80$ & $6.782,12$ & $9.029,47$ & $7.116,64$ & $8.461,11$ & $7.437,01$ \\
E10 & $9.761,26$ & $6.107,83$ & $10.886,48$ & $8.423,97$ & $10.250,77$ & $9.542,01$ \\
E11 & $8.196,10$ & $7.104,84$ & $9.082,82$ & $9.005,77$ & $7.172,97$ & $7.261,52$ \\
E12 & $10.511,73$ & $10.825,58$ & $8.078,72$ & $10.167,10$ & $10.686,61$ & $9.899,87$ \\
E13 & $11.078,18$ & $7.724,81$ & $8.954,72$ & $10.227,07$ & $8.974,47$ & $10.693,59$ \\
E14 & $5.555,17$ & $4.417,65$ & $8.965,65$ & $7.568,90$ & $7.549,51$ & $7.752,92$ \\
E15 & $8.121,76$ & $9.186,65$ & $7.649,86$ & $9.057,63$ & $8.179,37$ & $9.439,30$ \\
E16 & $10.131,44$ & $8.680,83$ & $11.100,81$ & $8.258,53$ & $8.213,23$ & $8.454,03$ \\
E17 & $9.027,67$ & $7.619,54$ & $9.035,67$ & $8.865,41$ & $7.025,33$ & $7.957,30$ \\
E18 & $8.755,17$ & $9.373,33$ & $8.245,09$ & $9.517,18$ & $7.284,91$ & $8.051,74$ \\
\hline Total & $122.320,44$ & $114.895,22$ & $126.045,84$ & $126.427,67$ & $124.554,60$ & $126.493,95$ \\
\hline \hline
\end{tabular}

Tabela 9.2b - Previsão de quantidades (metragem) de troca de trilho.

\begin{tabular}{lrrrrrr}
\hline \hline Estação & $\mathbf{2 0 1 5}$ & $\mathbf{2 0 1 6}$ & $\mathbf{2 0 1 7}$ & $\mathbf{2 0 1 8}$ & $\mathbf{2 0 1 9}$ & $\mathbf{2 0 2 0}$ \\
\hline E01 & 189,66 & 133,87 & 191,47 & 197,43 & 170,37 & 217,53 \\
E02 & $\mathbf{7 2 , 7 5}$ & 129,65 & $\mathbf{7 6 , 2 4}$ & 98,85 & 132,32 & 65,81 \\
E03 & 58,64 & 79,00 & 83,21 & 69,19 & 59,76 & 68,12 \\
E04 & 34,91 & 59,79 & 25,36 & 59,46 & 57,38 & 66,99 \\
E05 & 68,21 & 56,91 & 62,20 & 60,25 & 58,79 & 53,41 \\
E06 & 94,63 & 56,62 & 62,39 & 52,49 & 86,02 & 85,59 \\
E07 & 56,12 & 77,85 & 78,51 & 102,56 & 124,51 & 126,63 \\
E08 & 83,47 & 128,96 & 103,20 & 104,80 & 105,32 & 95,73 \\
E09 & 144,38 & 132,21 & 176,01 & 138,73 & 164,93 & 144,97 \\
E10 & 190,28 & 119,06 & 212,21 & 164,21 & 199,82 & 186,00 \\
E11 & 159,77 & 138,50 & 177,05 & 175,55 & 139,82 & 141,55 \\
E12 & 204,91 & 211,03 & 157,48 & 198,19 & 208,32 & 192,98 \\
E13 & 215,95 & 150,58 & 174,56 & 199,36 & 174,94 & 208,45 \\
E14 & 108,29 & 86,11 & 174,77 & 147,54 & 147,16 & 151,13 \\
E15 & 158,32 & 179,08 & 149,12 & 176,56 & 159,44 & 184,00 \\
E16 & 197,49 & 169,22 & 216,39 & 160,99 & 160,10 & 164,80 \\
E17 & 175,98 & 148,53 & 176,13 & 172,82 & 136,95 & 155,11 \\
E18 & 170,67 & 182,72 & 160,72 & 185,52 & 142,01 & 156,95 \\
\hline Total & 2384,41 & 2239,67 & 2457,03 & 2464,48 & 2427,97 & 2465,77 \\
\hline \hline
\end{tabular}




\subsubsection{Desgaste Ondulatório}

0 desgaste ondulatório é um fenômeno que ocorre em curvas e em região de frenagem e aceleração. Este tipo de desgaste é caracterizado por uma corrugação que aparece na cabeça do trilho (boleto), conforme mostra a Figura 9.4.

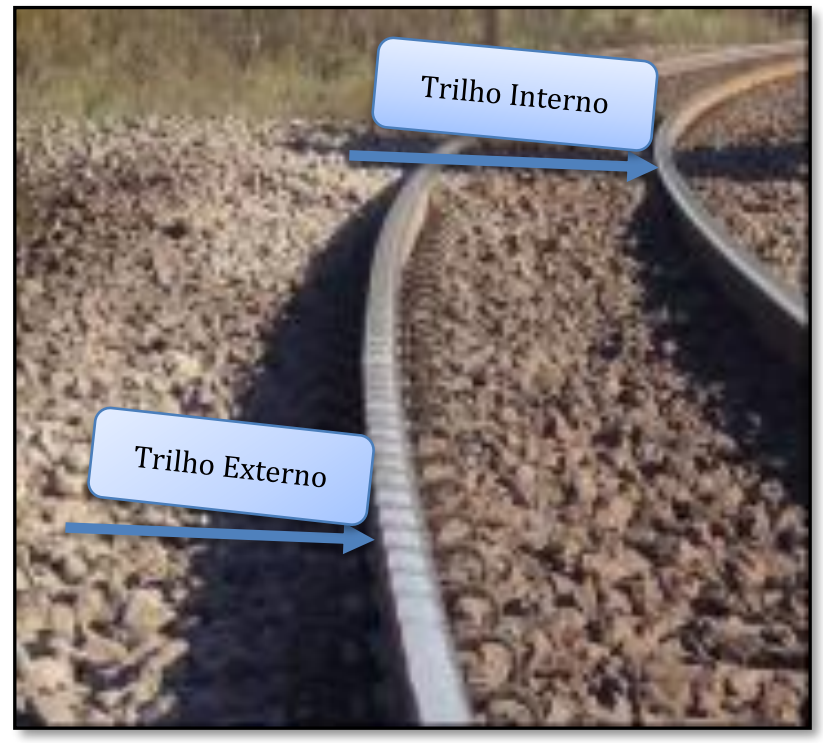

Figura 9.4 - Desgaste ondulatório

O conjunto eixo e roda dos trens é uma peça única, as rodas são solidárias ao eixo, de maneira que a rotação das duas rodas é sempre a mesma. Nos automóveis este problema é resolvido com o uso de diferenciais, que permitem que as rodas girem em velocidades diferentes.

Soma-se a isto que em regiões de curva o trilho externo é maior que o trilho interno da curva. Esta diferença no comprimento dos trilhos faz com que as rodas tentem ajustar a velocidade tangencial, provocando um escorregamento da roda externa. Este escorregamento é o principal motivador do desgaste ondulatório.

Este fenômeno é prejudicial para a via e para o material rodante e, portanto, precisa ser tratado com esmerilhamento de via. 0 desgaste ondulatório produz uma vibração com a passagem do trem.

Esta vibração possibilita a soltura das fixações; acelera processos de fadiga dos trilhos e dormentes; provoca movimentação do lastro, causando pontos de recalque; acelera o processo de degradação das palmilhas instaladas entre o trilho e dormente; 
produz frequências de vibração indesejadas nos sistemas do trem, causando soltura de peças.

A Figura 9.5a mostra o perfil da via com os níveis de desgaste ondulatório e a Figura 9.5b apresenta a programação de esmerilhamento. A Tabela 9.3a mostra a previsão orçamentária, enquanto a tabela 9.3b apresenta as metragens a serem esmerilhadas.

Foi considerado que o metro do esmerilhamento tem um custo aproximado de $\mathrm{R} \$$ 50,00. De fato, as operadoras europeias trabalham com um custo aproximado de $€ 16,00$ o metro de trilho esmerilhado.

Ainda assim a literatura não tem estes valores comprovados, de maneira que este valor foi adotado com base em conversas com representantes de operadoras europeias. Neste custo estão inclusos todos os materiais necessários, mão de obra, depreciação do equipamento e custos de manutenção do equipamento de esmerilhamento.

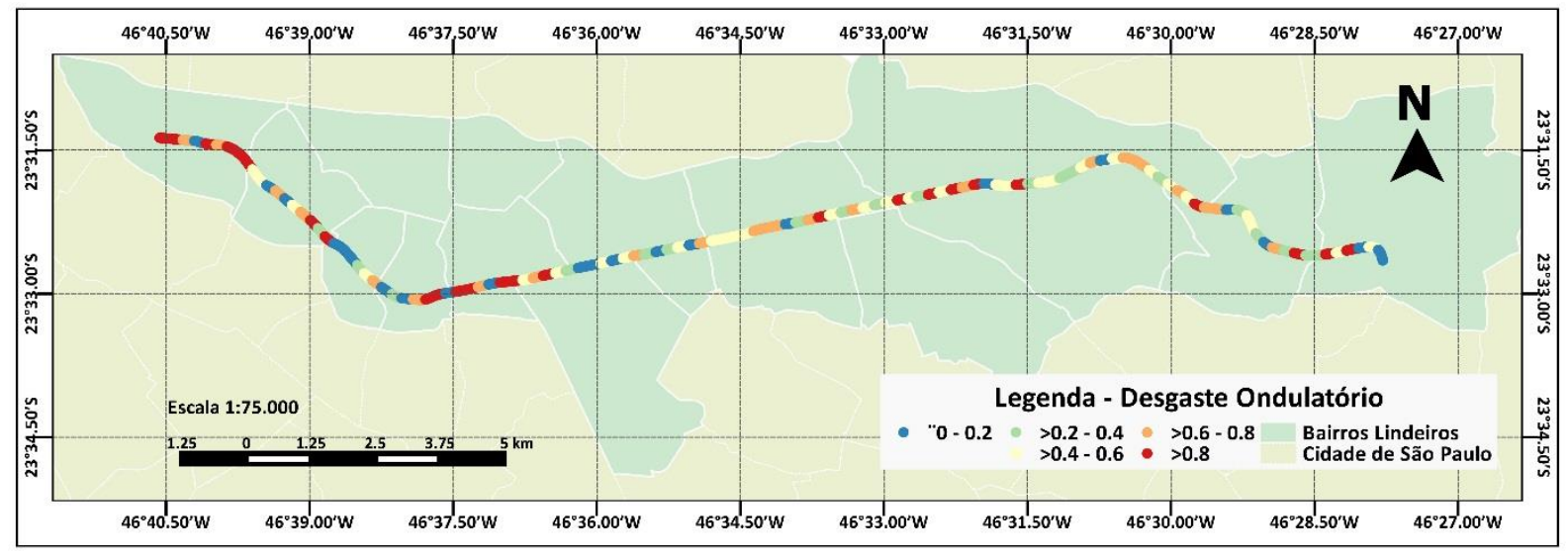

Figura 9.5a - Níveis do Desgaste ondulatório

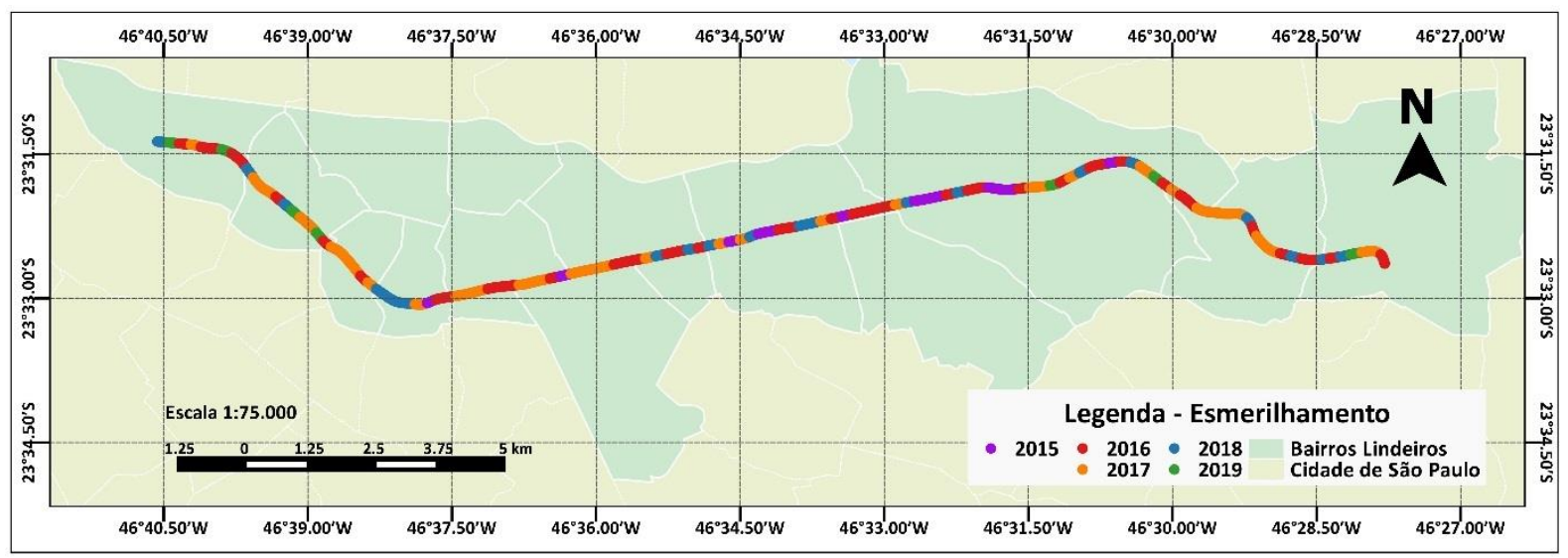

Figura 9.5b - Planejamento do Esmerilhamento 
Tabela 9.3a - Previsão orçamentária de Esmerilhamento de Trilhos.

\begin{tabular}{|c|c|c|c|c|c|c|c|}
\hline Estação & 2015 & 2016 & 2017 & 2018 & 2019 & & 2020 \\
\hline E01 & - & $50.169,25$ & $22.998,05$ & $8.652,50$ & & - & - \\
\hline E02 & - & $12.547,10$ & $22.077,55$ & $6.923,90$ & & - & - \\
\hline E03 & - & $13.314,95$ & $11.255,05$ & $6.411,25$ & & - & - \\
\hline E04 & - & 67,50 & $21.944,30$ & - & & - & - \\
\hline E05 & - & $13.696,30$ & $13.421,35$ & - & & - & - \\
\hline E06 & - & $1.498,10$ & $30.566,90$ & - & & - & - \\
\hline E07 & - & $23.603,20$ & $18.353,90$ & - & & - & - \\
\hline E08 & - & $26.780,80$ & $18.919,20$ & - & & - & - \\
\hline E09 & $8.902,40$ & $21.061,45$ & $36.700,60$ & - & & - & - \\
\hline E10 & - & $51.530,30$ & $25.426,20$ & - & & - & - \\
\hline E11 & $11.893,20$ & $26.917,80$ & $27.402,30$ & - & & - & - \\
\hline E12 & $5.785,10$ & $54.332,55$ & $27.688,25$ & - & & - & - \\
\hline E13 & - & $57.144,35$ & $25.703,55$ & - & & - & - \\
\hline E14 & $8.760,85$ & $35.988,25$ & $18.296,70$ & - & & - & - \\
\hline E15 & - & $50.197,65$ & $16.924,00$ & $8.408,85$ & & - & - \\
\hline E16 & - & $35.875,10$ & $43.457,95$ & - & & - & - \\
\hline E17 & - & $26.312,85$ & $45.418,90$ & - & & - & - \\
\hline E18 & 578,80 & $29.512,75$ & $41.670,10$ & - & & - & 274,30 \\
\hline Total & $35.920,35$ & $530.550,25$ & $468.224,85$ & $30.396,50$ & & - & 274,30 \\
\hline
\end{tabular}

Tabela 9.3b - Previsão de Quantidades (metragem) de Esmerilhamento de Trilhos.

\begin{tabular}{|c|c|c|c|c|c|c|}
\hline Estação & 2015 & 2016 & 2017 & 2018 & 2019 & 2020 \\
\hline E01 & 0,00 & 1003,39 & 459,96 & 173,05 & 0,00 & 0,00 \\
\hline E02 & 0,00 & 250,94 & 441,55 & 138,48 & 0,00 & 0,00 \\
\hline E03 & 0,00 & 266,30 & 225,10 & 128,23 & 0,00 & 0,00 \\
\hline E04 & 0,00 & 1,35 & 438,89 & 0,00 & 0,00 & 0,00 \\
\hline E05 & 0,00 & 273,93 & 268,43 & 0,00 & 0,00 & 0,00 \\
\hline E06 & 0,00 & 29,96 & 611,34 & 0,00 & 0,00 & 0,00 \\
\hline E07 & 0,00 & 472,06 & 367,08 & 0,00 & 0,00 & 0,00 \\
\hline E08 & 0,00 & 535,62 & 378,38 & 0,00 & 0,00 & 0,00 \\
\hline E09 & 178,05 & 421,23 & 734,01 & 0,00 & 0,00 & 0,00 \\
\hline E10 & 0,00 & 1030,61 & 508,52 & 0,00 & 0,00 & 0,00 \\
\hline E11 & 237,86 & 538,36 & 548,05 & 0,00 & 0,00 & 0,00 \\
\hline E12 & 115,70 & 1086,65 & 553,77 & 0,00 & 0,00 & 0,00 \\
\hline E13 & 0,00 & 1142,89 & 514,07 & 0,00 & 0,00 & 0,00 \\
\hline E14 & 175,22 & 719,77 & 365,93 & 0,00 & 0,00 & 0,00 \\
\hline E15 & 0,00 & 1003,95 & 338,48 & 168,18 & 0,00 & 0,00 \\
\hline E16 & 0,00 & 717,50 & 869,16 & 0,00 & 0,00 & 0,00 \\
\hline E17 & 0,00 & 526,26 & 908,38 & 0,00 & 0,00 & 0,00 \\
\hline E18 & 11,58 & 590,26 & 833,40 & 0,00 & 0,00 & 5,49 \\
\hline Total & 718,41 & 10611,01 & 9364,50 & 607,93 & 0,00 & 5,49 \\
\hline
\end{tabular}




\subsubsection{Troca de Dormentes}

Os dormentes são parte da superestrutura que compõe a via permanente. É através dos dormentes que a carga aplicada ao trilho, no contato roda-trilho, é distribuída em forma de cone para o lastro. A Figura 9.6 mostra a distribuição de carga nos dormentes.

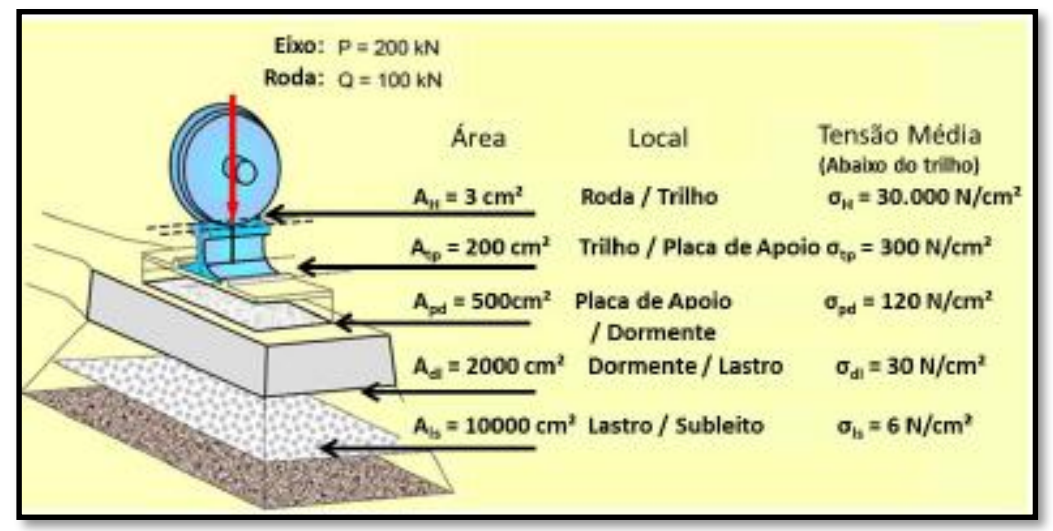

Figura 9.6 - Cargas Padrão na Via Permanente (Adaptado de ESVELD, 2001).

A troca de dormentes é a atividade que concorre com a troca de trilho em recursos financeiros necessários para ser realizada. Os volumes necessários, em geral, são altos. 0 planejamento financeiro é essencial para a atividade possa iniciar e terminar. A Figura 9.7 mostra a necessidade de substituição de dormentes ao longo de um período e a Tabelas 9.4a e $9.4 \mathrm{~b}$ apresentam os valores envolvidos e quantidades envolvidas.

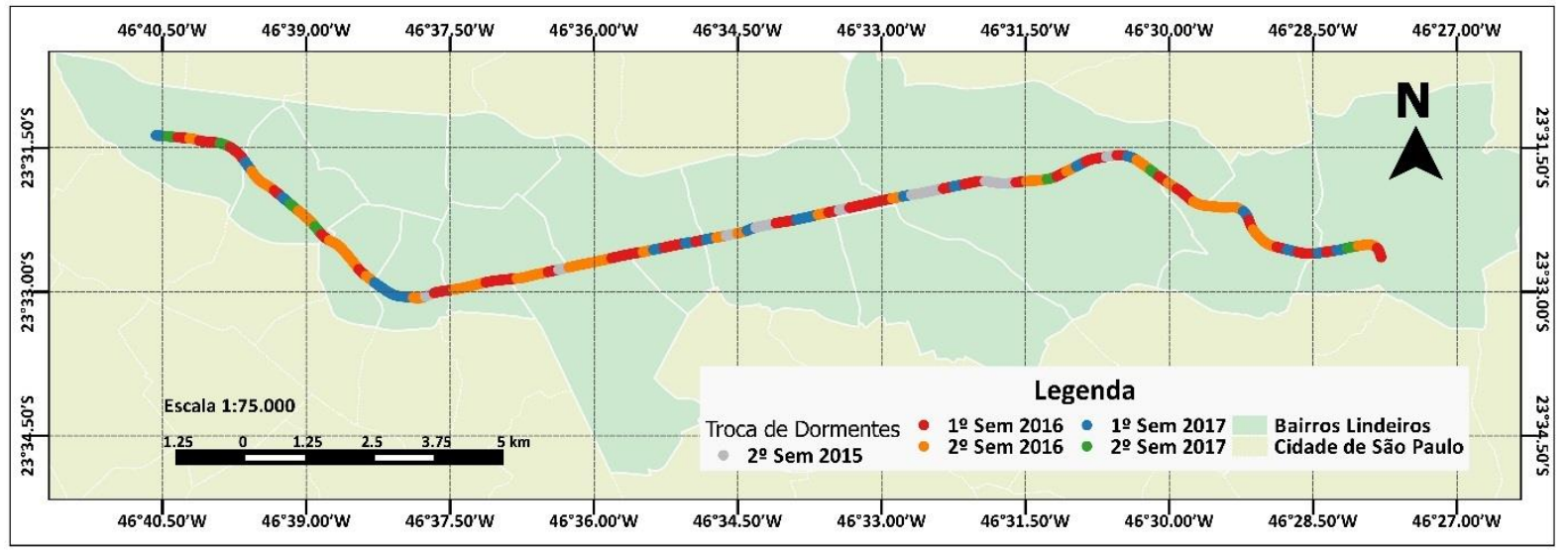

Figura 9.7 - Substituição de Dormentes ao Longo do Tempo. 
Tabela 9.4a - Previsão Orçamentária Para Troca de Dormentes.

\begin{tabular}{ccccccc}
\hline \hline Estação & $\mathbf{2 0 1 5}$ & $\mathbf{2 0 1 6}$ & $\mathbf{2 0 1 7}$ & $\mathbf{2 0 1 8}$ & $\mathbf{2 0 1 9}$ & $\mathbf{2 0 2 0}$ \\
\hline E01 & $11.760,00$ & $17.640,00$ & $16.170,00$ & $26.460,00$ & $27.930,00$ & $31.850,00$ \\
E02 & $3.920,00$ & $8.820,00$ & $13.230,00$ & $12.250,00$ & $12.250,00$ & $23.030,00$ \\
E03 & $3.920,00$ & $6.860,00$ & $11.270,00$ & $7.840,00$ & $14.700,00$ & $13.230,00$ \\
E04 & $3.430,00$ & $3.430,00$ & $6.370,00$ & $7.840,00$ & $6.860,00$ & $15.680,00$ \\
E05 & $3.430,00$ & $7.350,00$ & $8.330,00$ & $9.310,00$ & $7.840,00$ & $12.250,00$ \\
E06 & $3.920,00$ & $4.410,00$ & $5.390,00$ & $5.390,00$ & $7.350,00$ & $14.700,00$ \\
E07 & $4.900,00$ & $5.390,00$ & $10.290,00$ & $10.290,00$ & $13.230,00$ & $14.700,00$ \\
E08 & $3.920,00$ & $7.350,00$ & $6.860,00$ & $9.310,00$ & $16.660,00$ & $14.210,00$ \\
E09 & $7.840,00$ & $10.290,00$ & $13.230,00$ & $18.620,00$ & $23.030,00$ & $28.420,00$ \\
E10 & $9.310,00$ & $9.310,00$ & $20.090,00$ & $18.620,00$ & $20.580,00$ & $24.010,00$ \\
E11 & $6.370,00$ & $8.330,00$ & $13.230,00$ & $21.560,00$ & $19.600,00$ & $27.440,00$ \\
E12 & $5.390,00$ & $14.700,00$ & $17.150,00$ & $24.500,00$ & $24.500,00$ & $33.810,00$ \\
E13 & $7.350,00$ & $13.230,00$ & $14.700,00$ & $19.110,00$ & $24.500,00$ & $30.380,00$ \\
E14 & $4.410,00$ & $12.250,00$ & $12.250,00$ & $15.680,00$ & $14.210,00$ & $24.010,00$ \\
E15 & $10.780,00$ & $10.780,00$ & $13.720,00$ & $24.990,00$ & $24.500,00$ & $25.480,00$ \\
E16 & $9.800,00$ & $13.720,00$ & $20.090,00$ & $28.420,00$ & $28.910,00$ & $37.730,00$ \\
E17 & $8.820,00$ & $12.740,00$ & $18.620,00$ & $30.380,00$ & $25.480,00$ & $38.220,00$ \\
E18 & $7.840,00$ & $15.680,00$ & $10.780,00$ & $20.580,00$ & $29.400,00$ & $28.420,00$ \\
\hline Total & $\mathbf{1 1 7 . 1 1 0 , 0 0}$ & $\mathbf{1 8 2 . 2 8 0 , 0 0}$ & $\mathbf{2 3 1 . 7 7 0 , 0 0}$ & $\mathbf{3 1 1 . 1 5 0 , 0 0}$ & $\mathbf{3 4 1 . 5 3 0 , 0 0}$ & $\mathbf{4 3 7 . 5 7 0 , 0 0}$ \\
\hline \hline
\end{tabular}

Tabela 9.4b - Previsão de Quantidades de Dormentes para Substituição.

\begin{tabular}{ccccccc}
\hline \hline Estação & $\mathbf{2 0 1 5}$ & $\mathbf{2 0 1 6}$ & $\mathbf{2 0 1 7}$ & $\mathbf{2 0 1 8}$ & $\mathbf{2 0 1 9}$ & $\mathbf{2 0 2 0}$ \\
\hline E01 & 24 & 36 & 33 & 54 & 57 & 65 \\
E02 & 8 & 18 & 27 & 25 & 25 & 47 \\
E03 & 8 & 14 & 23 & 16 & 30 & 27 \\
E04 & 7 & 7 & 13 & 16 & 14 & 32 \\
E05 & 7 & 15 & 17 & 19 & 16 & 25 \\
E06 & 8 & 9 & 11 & 11 & 15 & 30 \\
E07 & 10 & 11 & 21 & 21 & 27 & 30 \\
E08 & 8 & 15 & 14 & 19 & 34 & 29 \\
E09 & 16 & 21 & 27 & 38 & 47 & 58 \\
E10 & 19 & 19 & 41 & 38 & 42 & 49 \\
E11 & 13 & 17 & 27 & 44 & 40 & 56 \\
E12 & 11 & 30 & 35 & 50 & 50 & 69 \\
E13 & 15 & 27 & 30 & 39 & 50 & 62 \\
E14 & 9 & 25 & 25 & 32 & 29 & 49 \\
E15 & 22 & 22 & 28 & 51 & 50 & 52 \\
E16 & 20 & 28 & 41 & 58 & 59 & 77 \\
E17 & 18 & 26 & 38 & 62 & 52 & 78 \\
E18 & 16 & 32 & 22 & 42 & 60 & 58 \\
\hline Total & $\mathbf{2 3 9}$ & $\mathbf{3 7 2}$ & $\mathbf{4 7 3}$ & $\mathbf{6 3 5}$ & $\mathbf{6 9 7}$ & $\mathbf{8 9 3}$ \\
\hline \hline
\end{tabular}




\subsubsection{Inspeção de Via}

A inspeção de via é uma atividade de vital importância. É na inspeção que são identificados os equipamentos com nível de degradação acima do esperado.

$\mathrm{Na}$ rotina de inspeção é previsto o registro das informações sobre os equipamentos, no banco de dados, e assim é possível calcular o tempo médio entre falhas, os tempos de manutenção, a disponibilidade dos equipamentos e demais indicadores, levando a uma manutenção cada vez mais eficiente e eficaz.

A inspeção quase não utiliza materiais, ela é praticada por profissionais treinados em enxergar defeitos que não são tão visíveis para os demais profissionais que trabalham na via permanente. Assim, o custo desta atividade é menor do que as demais atividades de manutenção, havendo gasto praticamente somente com mão de obra.

Alguns equipamentos auxiliam na realização da inspeção, para levantamento da geometria de via, medição de desgastes do trilho, desgaste ondulatório e ultrassom, mas o custo dos equipamentos é diluído ao longo de anos, de maneira que não interferem significativamente no custo da atividade.

Dado que os resultados da inspeção são muito valiosos, ela é praticada com muito mais frequência que as demais. A partir da atividade de inspeção são coletados os dados para verificação do comportamento do desgaste dos trilhos, desgaste ondulatório, condição dos dormentes, condição da fixação e geometria, que por sua vez são informações fundamentais no estabelecimento dos programas de troca de trilhos, esmerilhamento de vias, troca de dormentes e socaria de vias.

O planejamento da inspeção de via é mostrado na Figura 9.8. De uma forma geral, a atividade de inspeção é a mais dinâmica entre as atividades que um gestor de via permanente deve gerenciar, assim a base de dados deve ser atualizada constantemente para que as programações de inspeção sejam realizadas no prazo. Da mesma forma, uma previsão orçamentária é gerada para esta atividade de inspeção (Tabela 9.5), contudo ela é apenas informativa, já que a mão de obra necessária está sempre disponível para a atividade, já prevista no orçamento geral da manutenção de gastos com mão de obra. 


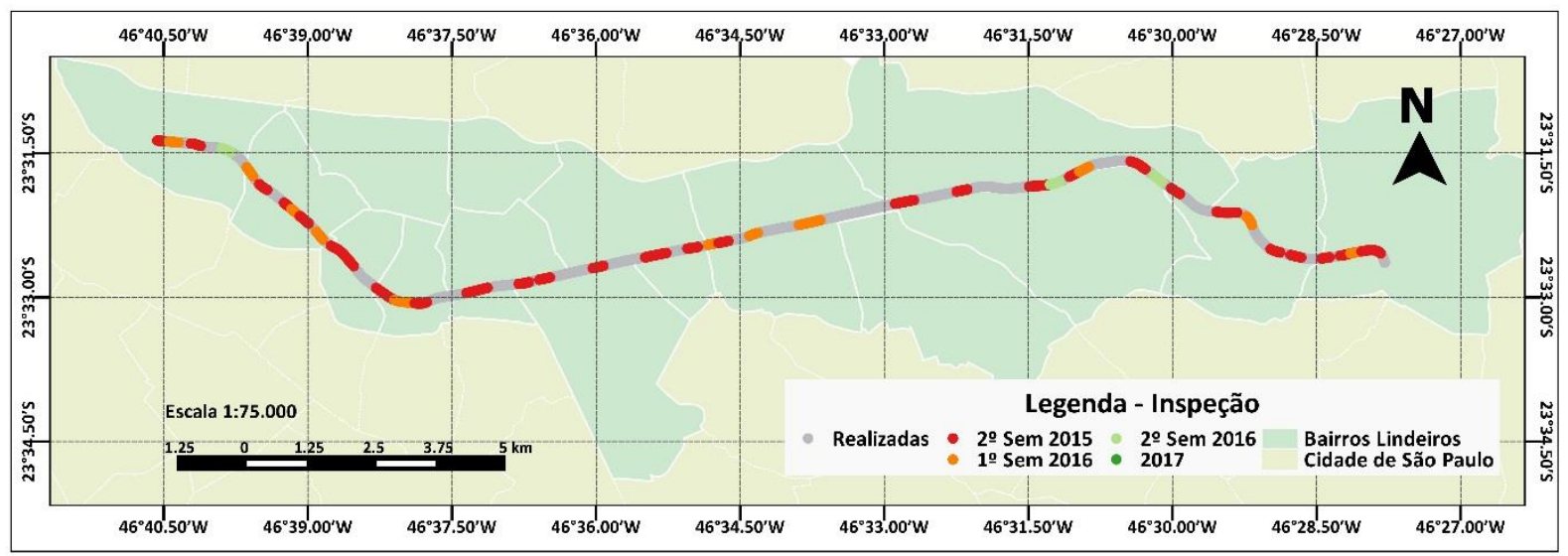

Figura 9.8 - Planejamento Macro de Inspeção de Via

Tabela 9.5 - Previsão Orçamentária Para Inspeção de Vias

\begin{tabular}{crrrrrr}
\hline \hline Estação & \multicolumn{1}{l}{$\mathbf{2 0 1 5}$} & \multicolumn{1}{l}{$\mathbf{2 0 1 6}$} & \multicolumn{1}{l}{$\mathbf{2 0 1 7}$} & \multicolumn{1}{c}{$\mathbf{2 0 1 8}$} & \multicolumn{1}{c}{$\mathbf{2 0 1 9}$} & \multicolumn{1}{c}{$\mathbf{2 0 2 0}$} \\
\hline E01 & $5.635,35$ & $5.653,38$ & $5.664,69$ & $5.672,62$ & $5.690,77$ & $5.702,16$ \\
E02 & $6.221,32$ & $6.241,23$ & $6.253,71$ & $6.262,47$ & $6.282,51$ & $6.295,07$ \\
E03 & $9.076,50$ & $9.105,54$ & $9.123,75$ & $9.136,53$ & $9.165,76$ & $9.184,10$ \\
E04 & $3.064,34$ & $3.074,14$ & $3.080,29$ & $3.084,60$ & $3.094,47$ & $3.100,66$ \\
E05 & $2.839,08$ & $2.848,16$ & $2.853,86$ & $2.857,85$ & $2.867,00$ & $2.872,73$ \\
E06 & 940,01 & 943,02 & 944,90 & 946,23 & 949,25 & 951,15 \\
E07 & $9.642,49$ & $9.673,34$ & $9.692,69$ & $9.706,26$ & $9.737,32$ & $9.756,79$ \\
E08 & $5.709,08$ & $5.727,35$ & $5.738,80$ & $5.746,84$ & $5.765,23$ & $5.776,76$ \\
E09 & $5.585,97$ & $5.603,84$ & $5.615,05$ & $5.622,91$ & $5.640,91$ & $5.652,19$ \\
E10 & $11.357,58$ & $11.393,92$ & $11.416,71$ & $11.432,69$ & $11.469,28$ & $11.492,21$ \\
E11 & $13.642,59$ & $13.686,25$ & $13.713,62$ & $13.732,82$ & $13.776,77$ & $13.804,32$ \\
E12 & $14.636,32$ & $14.683,15$ & $14.712,52$ & $14.733,12$ & $14.780,26$ & $14.809,82$ \\
E13 & $23.785,64$ & $23.861,76$ & $23.909,48$ & $23.942,95$ & $24.019,57$ & $24.067,61$ \\
E14 & $22.043,98$ & $22.114,52$ & $22.158,75$ & $22.189,77$ & $22.260,78$ & $22.305,30$ \\
E15 & $5.824,85$ & $5.843,49$ & $5.855,17$ & $5.863,37$ & $5.882,13$ & $5.893,90$ \\
E16 & $22.447,52$ & $22.519,35$ & $22.564,39$ & $22.595,98$ & $22.668,28$ & $22.713,62$ \\
E17 & 480,51 & 482,05 & 483,02 & 483,69 & 485,24 & 486,21 \\
E18 & $10.575,85$ & $10.609,69$ & $10.630,91$ & $10.645,79$ & $10.679,86$ & $10.701,22$ \\
\hline Total & $\mathbf{1 7 3 . 5 0 8 , 9 6}$ & $\mathbf{1 7 4 . 0 6 4 , 1 9}$ & $\mathbf{1 7 4 . 4 1 2 , 3 2}$ & $\mathbf{1 7 4 . 6 5 6 , 5 0}$ & $\mathbf{1 7 5 . 2 1 5 , 4 0}$ & $\mathbf{1 7 5 . 5 6 5 , 8 3}$ \\
\hline \hline
\end{tabular}

Outras informações são geradas pela inspeção de vias. A medição do desgaste de trilhos, por exemplo, é uma informação que permite ao gestor da via permanente ter uma ideia do comportamento da via em termos de desgaste e observar comportamentos que não sejam usuais. A inspeção de desgaste de trilhos deve seguir uma rotina de inspeção das curvas, preferencialmente, a cada 6 meses e nos trechos em reta a cada 2 anos. A figura 9.9 mostra o resultado da inspeção de desgaste de trilhos. 


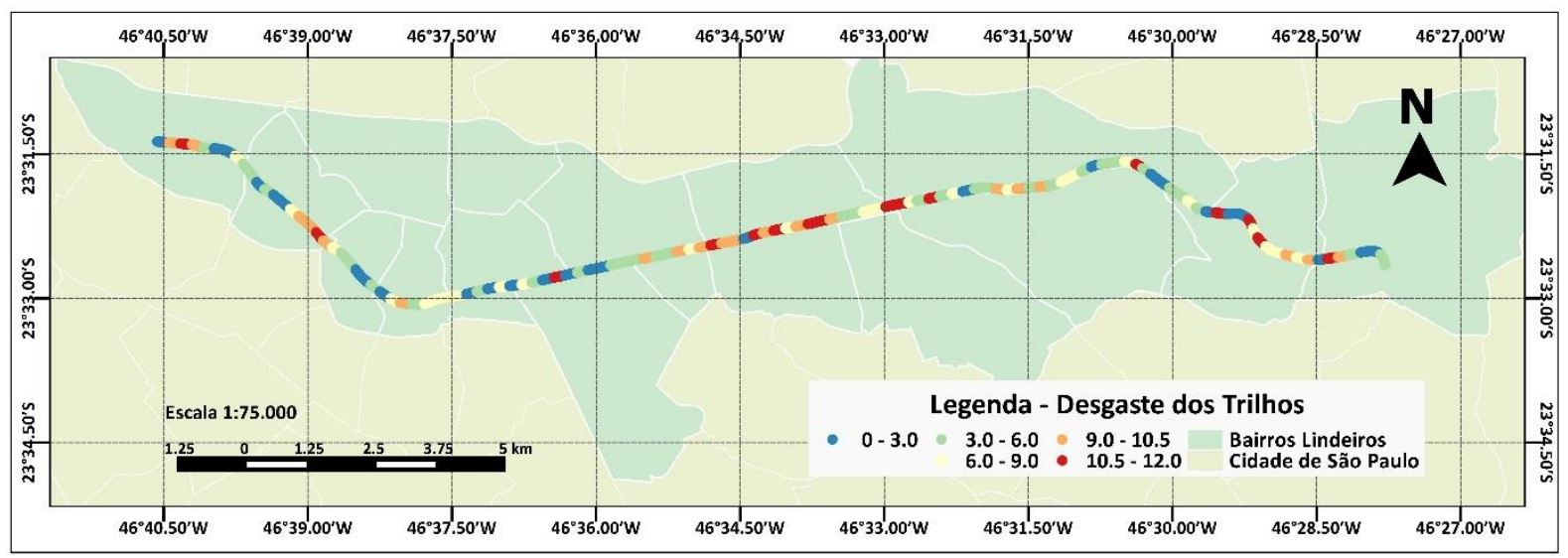

Figura 9.9 - Mapa com o desgaste dos trilhos ao longo da via.

Outro resultado apresentado pela inspeção é o mapa do desgaste ondulatório, já mostrado na Figura 9.5a.

Para a realização da correção geométrica da via é necessário que haja um referencial que indique quais são os pontos da via que devem ser priorizados. Este referencial é geralmente denominado Índice de Qualidade de Via, e é o resultado da inspeção dos parâmetros geométricos da via. Os parâmetros medidos nesta inspeção são: bitola, nivelamento, alinhamento e torsão.

Após a coleta de dados é gerado um mapa que aponta quais são os trechos de via prioritários em função do índice. Neste trabalho utiliza-se o índice J, que é uma composição dos parâmetros de via medido a cada 4 metros, mostrado no capítulo 5.6.2.

O índice é calculado levantando o valor de cada um dos parâmetros a cada 4 metros e após isto calculando o desvio padrão para o trecho padrão de 200 metros. Este índice mostra, de uma maneira simplista, aonde existem os maiores desvios, e, portanto, aonde deve ser priorizada a correção geométrica. A Figura 9.10 mostra o mapa gerado com estes dados. 


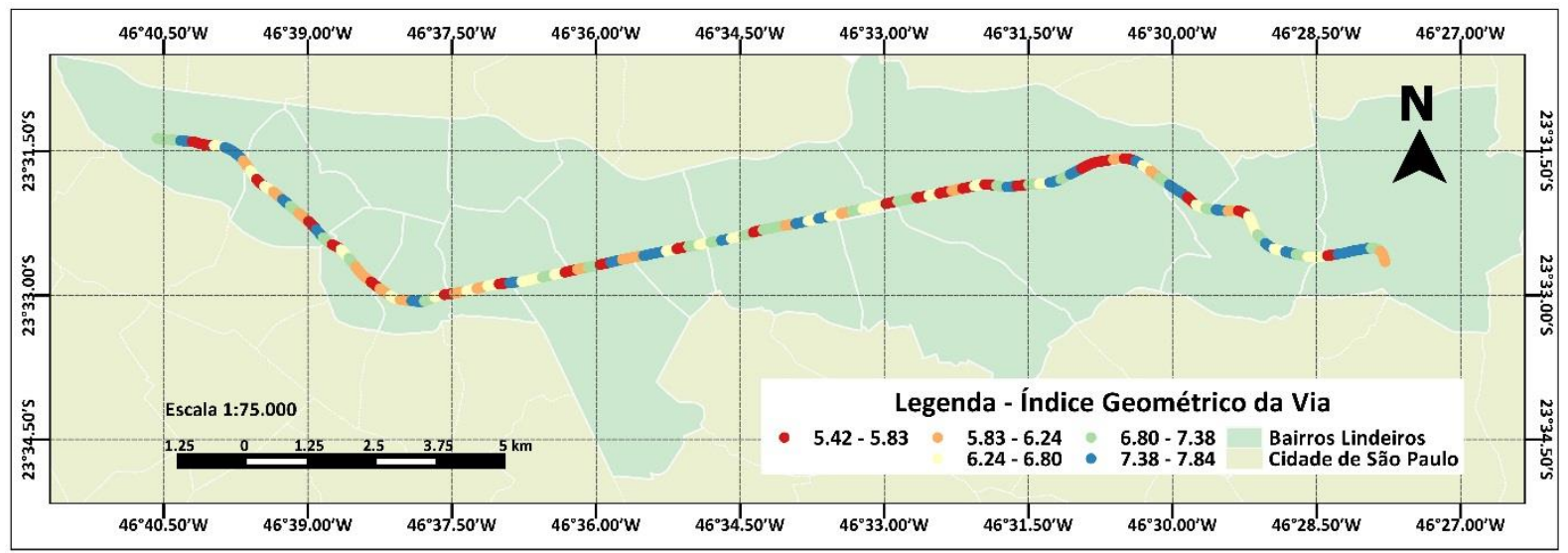

Figura 9.10 - Mapa com o índice geométrico da via.

\subsubsection{Correção Geométrica da Via - Socaria de Via}

A correção geométrica de uma via instalada em lastro de pedra britada necessita de intervenções para que a sua geometria seja restabelecida. A passagem de trens, associada a intempéries, problemas de drenagem e qualidade dos materiais acaba por interferir na geometria da via, mudando as suas características principais de bitola, nivelamento, alinhamento e torsão.

Esta mudança de característica é prejudicial para a via e para o material rodante, uma vez que os parâmetros de via são os dados de entrada para determinar qual o regime operacional que será adotado em cada trecho. Com a mudança das características geométricas o comportamento do sistema já não segue o padrão inicialmente estabelecido, promovendo baixa eficiência e, em casos extremos, acidentes e descarrilamentos.

A atuação da inspeção de vias, no levantamento de dados geométricos, contribui para a formatação de um planejamento de socaria de via que estabelece os prazos para a atuação e o orçamento previsto. No orçamento estão inclusos os gastos com mão de obra, materiais e depreciação dos equipamentos.

Ainda que haja um planejamento, baseado nos tempos entre falhas obtidos no banco de dados, por vezes é necessária uma atuação corretiva, o que acaba por gerar um novo planejamento, por conta de adiantamento de socaria de via em trechos programados. 
O planejamento é mostrado na Figura 9.11 e o orçamento na tabela 9.6.

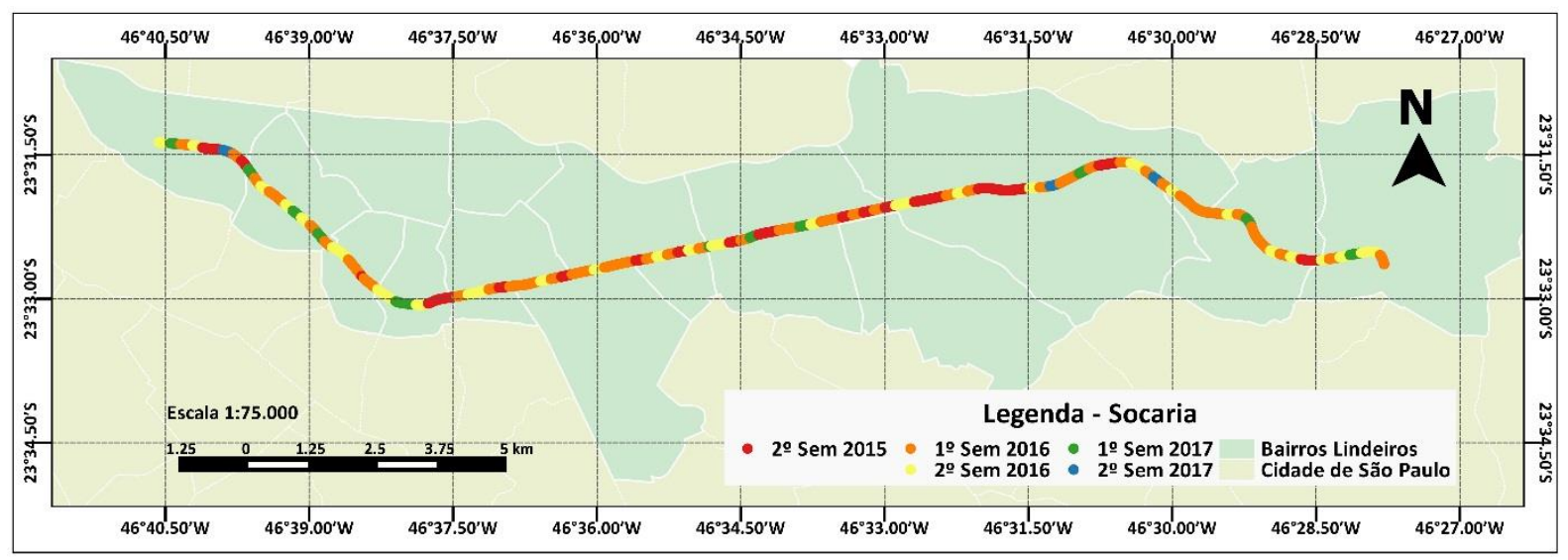

Figura 9.11 - Previsão de correção da geometria de via.

Tabela 9.6 - Previsão Orçamentária da Socaria de Vias.

\begin{tabular}{rrrrrrr}
\hline \hline Estação & $\mathbf{2 0 1 5}$ & $\mathbf{2 0 1 6}$ & $\mathbf{2 0 1 7}$ & $\mathbf{2 0 1 8}$ & $\mathbf{2 0 1 9}$ & $\mathbf{2 0 2 0}$ \\
\hline E01 & $17.361,67$ & $33.499,12$ & $19.100,35$ & $35.365,90$ & $19.891,45$ & $36.578,42$ \\
E02 & $22.041,10$ & $10.155,62$ & $24.248,41$ & $10.721,55$ & $25.252,73$ & $11.089,14$ \\
E03 & $13.426,39$ & $10.777,12$ & $14.770,97$ & $11.377,69$ & $15.382,76$ & $11.767,77$ \\
E04 & $12.398,49$ & $4.611,96$ & $13.640,13$ & $4.868,97$ & $14.205,08$ & $5.035,90$ \\
E05 & $15.710,30$ & $5.217,55$ & $17.283,61$ & $5.508,31$ & $17.999,46$ & $5.697,16$ \\
E06 & $23.230,84$ & $1.212,56$ & $25.557,30$ & $1.280,13$ & $26.615,83$ & $1.324,02$ \\
E07 & $13.948,96$ & $19.104,43$ & $15.345,88$ & $20.169,04$ & $15.981,48$ & $20.860,54$ \\
E08 & $13.640,33$ & $22.462,63$ & $15.006,34$ & $23.714,38$ & $15.627,87$ & $24.527,43$ \\
E09 & $23.311,71$ & $29.131,24$ & $25.646,26$ & $30.754,60$ & $26.708,48$ & $31.809,03$ \\
E10 & $30.939,30$ & $29.338,24$ & $34.037,71$ & $30.973,14$ & $35.447,49$ & $32.035,06$ \\
E11 & $15.210,22$ & $31.413,62$ & $16.733,45$ & $33.164,18$ & $17.426,52$ & $34.301,21$ \\
E12 & $21.043,07$ & $48.659,23$ & $23.150,43$ & $51.370,81$ & $24.109,27$ & $53.132,06$ \\
E13 & $19.534,70$ & $46.252,64$ & $21.491,00$ & $48.830,11$ & $22.381,11$ & $50.504,25$ \\
E14 & $6.868,08$ & $43.714,76$ & $7.555,89$ & $46.150,81$ & $7.868,84$ & $47.733,09$ \\
E15 & $12.862,24$ & $40.629,98$ & $14.150,33$ & $42.894,12$ & $14.736,41$ & $44.364,75$ \\
E16 & $23.344,88$ & $33.329,07$ & $25.682,76$ & $35.186,36$ & $26.746,48$ & $36.392,73$ \\
E17 & $44.221,78$ & $10.963,48$ & $48.650,37$ & $11.574,44$ & $50.665,37$ & $11.971,27$ \\
E18 & $31.341,68$ & $24.017,57$ & $34.480,39$ & $25.355,97$ & $35.908,50$ & $26.225,30$ \\
\hline Total & $360.435,74$ & $444.490,83$ & $396.531,57$ & $469.260,53$ & $412.955,12$ & $485.349,13$ \\
\hline \hline
\end{tabular}




\subsubsection{Orçamento Consolidado}

Com a apropriação da previsão orçamentária para cada uma das atividades, o gestor da via permanente tem a possibilidade de agregar estas previsões em um único relatório, que vai orienta-lo na realização dos trabalhos e possibilitar a formação de estratégias de trabalho de acordo com a disponibilidade financeira. Muitas vezes alguns trabalhos precisam ser postergados por conta de restrições orçamentárias, e saber quando e qual atividade será envolvida é fundamental para que o nível de serviço seja mantido. A tabela 9.7 apresenta o orçamento geral gerado nesta aplicação numérica.

Tabela 9.7 - Previsão Orçamentária Generalizada.

\begin{tabular}{rrrrrrr}
\hline \hline Estação & $\mathbf{2 0 1 5}$ & $\mathbf{2 0 1 6}$ & $\mathbf{2 0 1 7}$ & $\mathbf{2 0 1 8}$ & $\mathbf{2 0 1 9}$ & $\mathbf{2 0 2 0}$ \\
\hline E01 & $49.891,97$ & $117.644,50$ & $79.212,24$ & $91.906,25$ & $67.107,51$ & $91.489,55$ \\
E02 & $37.987,56$ & $48.110,10$ & $71.893,86$ & $44.046,31$ & $54.344,37$ & $45.665,78$ \\
E03 & $31.102,60$ & $46.361,73$ & $53.059,86$ & $40.286,43$ & $44.017,21$ & $39.618,08$ \\
E04 & $21.678,80$ & $15.955,17$ & $47.058,21$ & $20.538,32$ & $28.738,80$ & $29.162,29$ \\
E05 & $27.422,14$ & $33.653,27$ & $46.852,54$ & $22.483,95$ & $33.397,90$ & $25.082,33$ \\
E06 & $35.642,57$ & $12.581,80$ & $67.438,06$ & $11.804,82$ & $41.779,64$ & $23.805,50$ \\
E07 & $32.969,83$ & $63.983,72$ & $59.947,73$ & $48.349,43$ & $48.884,86$ & $55.422,33$ \\
E08 & $29.929,91$ & $72.611,71$ & $54.759,70$ & $47.134,02$ & $46.457,39$ & $52.153,44$ \\
E09 & $57.161,76$ & $76.636,49$ & $95.237,75$ & $66.067,85$ & $68.541,12$ & $77.449,90$ \\
E10 & $66.791,06$ & $111.073,53$ & $107.905,14$ & $74.129,79$ & $83.442,40$ & $82.380,39$ \\
E11 & $59.865,50$ & $91.399,65$ & $85.208,20$ & $82.465,97$ & $61.961,24$ & $86.841,22$ \\
E12 & $63.206,06$ & $149.214,72$ & $95.268,10$ & $106.419,41$ & $80.013,15$ & $117.151,68$ \\
E13 & $67.903,07$ & $152.505,11$ & $99.733,60$ & $107.791,83$ & $84.860,98$ & $121.586,33$ \\
E14 & $50.724,30$ & $120.939,43$ & $74.207,90$ & $95.794,44$ & $56.083,30$ & $106.108,49$ \\
E15 & $42.100,94$ & $121.741,46$ & $62.549,28$ & $96.245,99$ & $57.842,01$ & $90.422,01$ \\
E16 & $71.352,42$ & $118.947,03$ & $129.063,01$ & $99.048,94$ & $91.100,91$ & $109.987,07$ \\
E17 & $67.565,34$ & $62.351,00$ & $127.227,78$ & $56.228,77$ & $87.558,90$ & $63.055,49$ \\
E18 & $63.955,47$ & $94.400,74$ & $110.387,09$ & $71.386,26$ & $87.320,43$ & $78.145,75$ \\
\hline Total & $\mathbf{8 7 7 . 2 5 1 , 2 9}$ & $\mathbf{1 . 5 1 0 . 1 1 1 , 1 8}$ & $\mathbf{1 . 4 6 7 . 0 1 0 , 0 6}$ & $\mathbf{1 . 1 8 2 . 1 2 8 , 7 9}$ & $\mathbf{1 . 1 2 3 . 4 5 2 , 1 3}$ & $\mathbf{1 . 2 9 5 . 5 2 7 , 6 2}$ \\
\hline \hline
\end{tabular}




\subsection{Resultados Comentados}

Os resultados obtidos a partir da utilização das ferramentas de banco de dados e sistema de informações geográficas mostram grande potencial para a gestão deste tipo de ativo.

O fornecimento do cronograma de atividades juntamente com o orçamento permite que o gestor defina a ação de manutenção mais adequada, já que a ferramenta entrega as informações, mas a decisão é de responsabilidade do gestor.

A visualização individualizada de cada mapa não mostra a totalidade dos recursos disponíveis. A atividade de manutenção, no ambiente gráfico do sistema de informações geográficas, permite a sobreposição de imagens, a visualização simultânea de mais de uma atividade de manutenção e pesquisas geográficas para delimitar um trecho da via que apresente características específicas.

As possibilidades de configuração das ferramentas também é outro item facilitador para gerar informação e possibilitar a tomada de decisão com um grau de certeza elevado. 


\section{CONCLUSÃO}

\subsection{Considerações Iniciais}

O desenvolvimento do assunto relativo a gerência de pavimentos aplicado a uma infraestrutura metroferroviária não é trivial. Responder de forma simples e didática incorre em certa generalização, o que pode levar a perder o foco no problema específico.

Um sistema de gerência de pavimentos tem muitas variáveis, algumas que podem ser controladas, mas outras totalmente sem controle. Assim, com esta multiplicidade, existe uma limitação na capacidade de gerar soluções e enxergar alternativas para a solução de problemas. A isto se denomina racionalidade limitada (BAZERMAN; MOORE, 2008; CLEMEN; REILLY, 2000).

No desenvolvimento do trabalho muitos problemas foram enfrentados e cada uma das soluções demandou um estudo, ainda que não específico, mas direcionado. A abordagem ampla do trabalho, se por um lado justifica-se para entregar um modelo que seja aplicável, por outro lado tem a dificuldade das tantas variáveis encontradas, e nem sempre modeláveis.

No que diz respeito a modelos, o entendimento de modelo neste trabalho é de um sistema que tenta explicar o comportamento de uma pequeníssima parte do universo. No caso aqui estudado, avalia-se o comportamento de uma via permanente metroferroviária exposta aos carregamentos diários e quais são as ações de manutenção necessárias para que este ativo tenha a sua vida prolongada ao máximo com o mínimo custo. 
Os resultados obtidos são baseados na suposição de que a taxa de degradação dos segmentos de via segue um conjunto de equações que foram determinadas ao longo do trabalho. No entanto, devido à deterioração dos componentes da via, a taxa de degradação pode aumentar ao longo do tempo.

O estudo utiliza um modelo que consiste de parâmetros diretos e quantitativos de custos. Parâmetros de custos indiretos, tais como o efeito da baixa qualidade da via sobre a taxa de degradação de outros componentes, não são considerados.

Modelos de degradação de infraestrutura são relações matemáticas entre uma variável dependente e um conjunto de variáveis casuais, incluindo atributos de projeto, carregamento do tráfego, fatores ambientais, idade e histórico de manutenção.

O principal desafio no desenvolvimento de modelos precisos de degradação para as instalações de infraestrutura é que a condição, muitas vezes, é medida em uma escala discreta.

No entanto, a própria degradação da instalação é um processo contínuo. Por exemplo, o desgaste do trilho é feito de forma gradual e ao longo de um período. Além disso, na fase inicial, os processos de degradação ocorrem em escala microscópica ou o nível abaixo da superfície.

Assim, o processo não é observado diretamente ao passo que estão sendo observados indicadores de desempenho. Portanto, é necessário que no desenvolvimento de modelos discretos de degradação o estado estocástico seja levado em conta para que ambos os comportamentos, contínuo e discreto, sejam levados em conta.

A quantidade de variáveis de entrada que não são controláveis leva a uma simplificação do sistema, de maneira a possibilitar o controle das variáveis, ou, ao menos, ter resultados que sejam comparáveis com os resultados passados, considerando que existe um conjunto de dados similares e condições de contorno similares.

O problema da simplificação é que o sistema pode recair em um modelo muito simplista e acabar por não explicar nada. É neste contexto que a exigência de avaliações constantes e rigorosas no conjunto de dados e nos modelos acaba por tornar o trabalho de desenvolvimento não trivial. 


\subsection{Benefícios da Abordagem Adotada}

A infraestrutura metroferroviária é um sistema complexo. Um aspecto importante da infraestrutura é que os ativos têm uma longa vida útil. Consequentemente, uma vez que eles estão instalados, é muito difícil modificar o projeto inicial. Por conseguinte, o desempenho da infraestrutura depende das decisões de manutenção e de renovação tomadas durante o seu ciclo de vida.

Sistemas urbanos são, geralmente, operados em áreas urbanas densas, o que resulta em linhas com uma porcentagem alta de curvas, ou curvas com raios pequenos (menores que $300 \mathrm{~m}$ ), aumentando o desgaste de rodas e trilhos e, também, a probabilidade de descarrilamento.

Os sistemas urbanos têm a característica de operar com várias frotas de material rodante, com suspensões diferentes. Esta diversidade causa um comportamento diferente de cada frota e, em consequência, um resultado observado na via também diferente. A mudança do perfil da frota, com a inclusão ou exclusão de trens do conjunto que forma a frota, leva a comportamentos diferentes da via permanente, em termos de degradação.

As crescentes exigências de eficiência estão criando um ambiente de mudança para a gestão de infraestrutura. Para garantir os melhores resultados em longo prazo para os sistemas metroferroviários, os efeitos das decisões devem ser avaliados de forma sistemática.

O contato roda-trilho é o ponto de encontro do veículo com a via e, da mesma forma, dos operadores do sistema com os responsáveis pela manutenção da infraestrutura de via permanente. A interação entre a roda e o trilho é um elemento não linear complexo nos sistemas sobre trilhos.

A degradação da geometria de via é um fenômeno complexo que ocorre sob o efeito de cargas dinâmicas e é normalmente calculado como uma função do tráfego em milímetros de desgaste por milhões de toneladas transportadas, ou função do tempo em milímetros de desgaste em um ano (ESVELD, 2001).

O gerente de infraestrutura, que é o responsável pela manutenção, renovação e modernização da infraestrutura, tem um papel claramente definido e é desafiado com o 
crescente aumento da necessidade de desempenho do sistema. Devido ao aumento dos custos de operação e manutenção, os gestores de infraestrutura são obrigados a aperfeiçoar seu orçamento, enquanto a confiabilidade e disponibilidade tem que ser aumentada sem pôr em perigo a segurança do tráfego.

A gestão de ativos tem um papel importante no controle do desempenho e rentabilidade das empresas que operam estes ativos. Os efeitos das políticas de gestão de ativos podem ser julgados em termos de seu impacto sobre o valor do ativo e de como o nível de serviço e de segurança exigidos podem ser alcançados de maneira mais econômica. À medida que as redes de infraestrutura envelhecem a qualidade de serviço exigido aumenta. Portanto, o gerenciamento de ativos torna-se importante na manutenção e melhoria de redes.

Em geral, a estrutura de gestão de ativos considera dados da condição dos ativos para avaliar o estado atual e prever a degradação do ativo. Em seguida, o nível exigido de serviço precisa ser conhecido e as possibilidades de a rede ficar aquém de alcançar este nível de serviço precisam ser analisadas.

Usando a experiência e a aplicação de diferentes políticas de manutenção, as rotinas de inspeção e renovação de ativos são avaliadas, aperfeiçoando as atividades do ciclo de vida para alcançar o desempenho esperado da rede. A análise é realizada em diferentes níveis de organização - nível de ativos, nível de rede e até mesmo no nível de gestão da organização.

Uma abordagem sistêmica é necessária para garantir que os níveis estabelecidos para o desempenho sejam alcançados. Uma vez que, no cenário atual, a maioria das decisões de manutenção e renovação está baseada na experiência passada e na estimativa de especialistas, uma abordagem que utilize os custos do ciclo de vida parece ser adequada.

As decisões eficientes têm o objetivo de atingir as metas estabelecidas para o sistema. A estimativa apropriada das metas para a infraestrutura é importante, uma vez que isto influencia diretamente a estratégia de manutenção, bem como o investimento de manutenção durante um período de tempo. A Figura 10.1 ilustra os parâmetros em diferentes níveis de hierarquia. A hierarquia de objetivos foi dividida em três níveis, ou seja, o nível de infraestrutura, nível de sistema e nível de componente. 


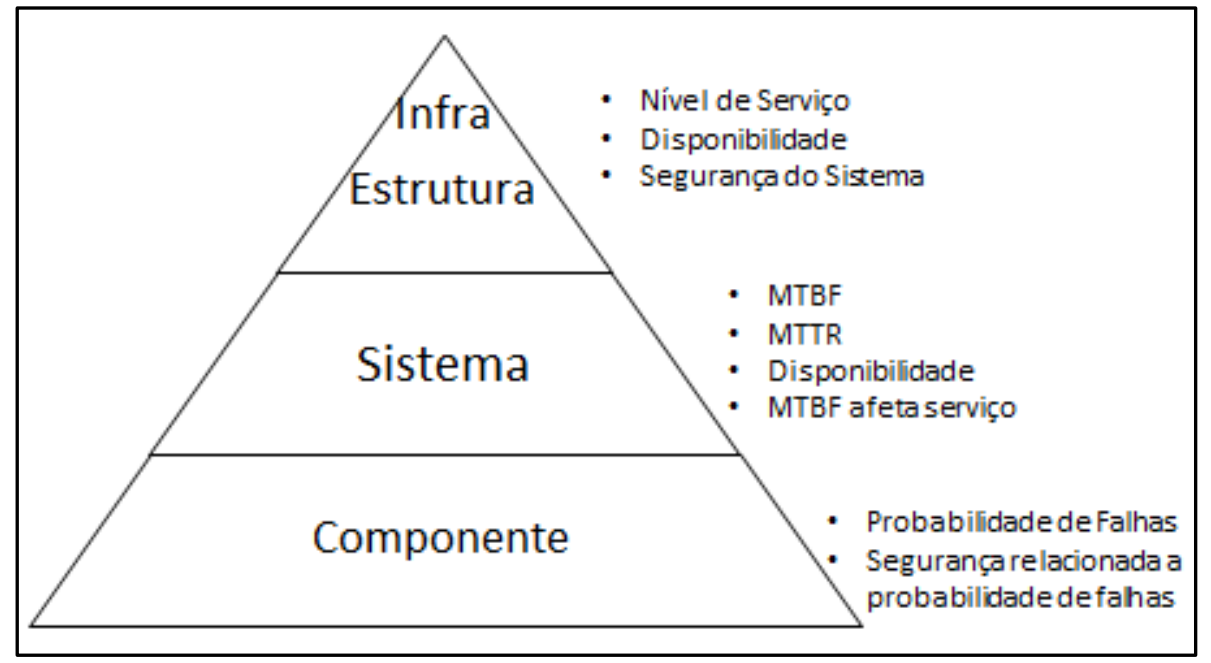

Figura 10.1 - Hierarquia dos parâmetros de controle

Os objetivos a serem alcançados indicam as características no nível de infraestrutura, as características técnicas no nível do sistema, e as características de falha no nível do componente. Assim, as metas de disponibilidade e de segurança são geralmente estimadas no nível de infraestrutura, ao passo que as metas de confiabilidade e manutenção são estimadas em níveis hierárquicos mais baixos.

Isto requer a estimativa de metas de disponibilidade e de segurança para atingir o nível de qualidade exigido pela infraestrutura. A relação entre a disponibilidade, capacidade e pontualidade vai ajudar os gestores de infraestrutura a identificar a meta de disponibilidade para a seção específica.

\subsection{Limitações}

A prática deve apoiar-se na teoria, e não desafia-la. 0 conjunto de ferramentas desenvolvido mostrou que é possível alcançar o objetivo de realizar manutenções planejadas usando computador e sistemas de medição como forma de organizar as atividades relativas a conservação do ativo.

No caso de uma gestão eficiente do ciclo de vida, a política de manutenção arcaica deve ser substituída por uma política que representa um equilíbrio ideal entre 
manutenção e renovação. A aplicação de novas regras e valores-limite com base em resultados e dados medidos na via permanente concorre para a melhora do conjunto de ferramentas.

A abordagem por um conjunto de ferramentas que permite uma avaliação preliminar dos custos e desempenho, em longo prazo, de diferentes alternativas de decisão mostra-se, então, um caminho para a decisão eficiente e eficaz.

Mesmo com as incertezas relacionadas com as condições operacionais, e esta seja, talvez, a maior variável a ser considerada, percebe-se a necessidade de tecnologias inovadoras de manutenção, bem como que haja a confiabilidade dos dados históricos de manutenção. Estas ferramentas auxiliam a explorar os custos do ciclo de vida de diferentes estratégias de manutenção e testar a robustez de diferentes estratégias. No entanto, devem ser levados em conta os requisitos de desempenho da infraestrutura. Uma previsão do desempenho confiável continua a ser difícil em sua fase de concepção.

Usar um sistema para explorar os custos do ciclo de vida auxilia na compreensão dos mecanismos que influenciam o desempenho da infraestrutura. Fornecer as informações sobre os prováveis custos de ciclo de vida para as diversas estratégias de manutenção contribui para melhorar a qualidade e transparência das decisões que estão sendo tomadas, ainda que a eficácia dependa da participação (ativa) de intervenientes e da disponibilidade de conhecimentos técnicos.

A eliminação da causa raiz de falhas pode ser benéfica para o gestor da infraestrutura, reduzindo os custos de manutenção e aumentando a disponibilidade da via. Em contraste, a redução do custo de capital necessário para corrigir a causa raiz de falhas pode resultar em custos de manutenção elevados anos mais tarde para compensar as deficiências da via. Isso pode ser evitado se a análise do custo do ciclo de vida for utilizada para selecionar uma ação de manutenção adequada e não a de baixo custo.

Um desenvolvimento do conceito de ferramentas de suporte poderia incidir sobre o uso de análise de incerteza. Distribuições probabilísticas dos resultados podem aumentar ainda mais a visão sobre os custos do ciclo de vida e tempos de falha.

Outros avanços podem ser obtidos pela integração de métodos para a manutenção baseada em condição. 0 modelo é uma ferramenta que permite decisões com base no risco de operações medidas pela idade e condições do equipamento. Esse tipo de solução pode 
permitir um controle equilibrado dos custos de manutenção, mantendo os níveis de segurança e de serviços necessárias.

O aperfeiçoamento da manutenção deve considerar a realização da estimativa da taxa de degradação e as consequências desta degradação, explicadas em termos de custo. Obtendo o conhecimento sobre a degradação é possível determinar os intervalos ótimos de inspeção e manutenção.

A execução da manutenção após o limite pode resultar em menor eficiência da manutenção. Isto significa que a qualidade inicial da via não pode ser obtida e mais do que uma operação de manutenção de rotina será necessária para atingir a qualidade inicial da via. No entanto, realizar a manutenção com frequência acima do adequado causará uma taxa de degradação maior (JOVANOVIC; EVREN; GULER, 2011).

Com a degradação do ativo, aumentam os custos de manutenção, assim, é necessário encontrar o nível ideal da condição dos ativos que seja o equilíbrio entre a manutenção e a degradação. Na gestão de ativos a falta de investimento em manutenção da rede não é imediatamente percebida, mas tais decisões podem causar aumentos consideráveis na despesa necessária no futuro.

A regulação das redes de infraestrutura continua a ser importante. É improvável que a necessidade de gerenciamento de ativos diminua no futuro. A capacidade de coletar dados da condição dos ativos, e outras informações, está aumentando por meio de novas técnicas de medição e de tecnologias sem fio. Portanto, a modelagem dos dados tem que lidar com quantidades de informação cada vez maiores, incluindo-se dados incorretos e, em alguns casos, a falta de dados.

Com o aumento da quantidade de informações nas bases de dados, as curvas de degradação podem ser ajustadas para ativos individuais e, obviamente, uma questão de decisão eficaz em termos de custos para gerenciar altos níveis de investimento será sempre desejável.

A sustentabilidade das redes de infraestrutura em termos de custo, bem como os recursos aplicados, terá de ser abordada na tomada de decisões de gestão de ativos, melhorando o desempenho da rede a partir do ponto de vista técnico, econômico e de sustentabilidade. A incorporação das questões ambientais no processo de gestão, a fim de minimizar os efeitos negativos sobre a sociedade e meio ambiente, o uso de recursos 
naturais, a geração de ruído, e demais prejuízos a sociedade, também deverão ser levados em conta.

O uso de sistemas integrados, como é proposto neste trabalho, de um SIG e de um banco de dados geográfico, mostra-se, então, como uma solução que pode ajudar no gerenciamento dos ativos, recolhendo as informações da via por meio de sistemas de controle ou por entrada de dados.

Com um volume cada vez maior de dados o processamento necessita de ferramentas adequadas e que forneçam respostas rápidas e confiáveis. Um sistema que permite a visualização dos dados de maneira gráfica é um avanço em relação aos tradicionais relatórios.

Além destas funcionalidades, o avanço computacional destas ferramentas permite consultas que não eram possíveis a pouco tempo atrás. Estas consultas são estreitamente ligadas com os sistemas de suporte a decisão, na medida em que permitem decisões cada vez mais refinadas.

\subsection{Proposições Para Estudos Futuros}

O estabelecimento de um elo entre a engenharia de sistemas e os sistemas de gerência de pavimentos é uma das contribuições deste trabalho, ainda que não faça parte de seus objetivos.

Oferecer uma forma organizada de escolha de um sistema de informações geográficas e de um banco de dados relacional geográfico também pode ser considerado uma contribuição, além de atender a um dos objetivos deste trabalho.

Devido a diversidade de práticas adotadas entre os operadores não é tarefa trivial estabelecer um conjunto de regras universais para serem aplicadas a todos os sistemas de transporte.

O estudo sobre indicadores e a respectiva seleção dos que são parte do estudo de caso pode ajudar as operadoras de sistemas metroferroviários a iniciar um processo de definição de indicadores. 0 estudo de caso mostrou que os indicadores são válidos e indicam um caminho para definição das ações de manutenção. 
Assim, as sugestões para trabalhos futuros podem considerar as seguintes linhas de pesquisa:

1. A continuação do desenvolvimento, verificação e implantação de indicadores para a gestão da infraestrutura metroferroviária encontra base em uma área específica de interesse, que são os parâmetros relacionados com os indicadores e RAMS metroferroviário (confiabilidade, disponibilidade, facilidade de manutenção e de segurança);

2. Automatizar o processo de captura de dados necessário e informações quantitativas e qualitativas, gerir e transformar os dados do modelo, para validação da mudança de requisitos ao longo do tempo são desafios a serem considerados, assim como a posterior modelagem matemática e simulação dos indicadores para atender às necessidades futuras do setor metroferroviário;

3. A proposta de um estudo de benchmarking, a ser realizado para comparar os indicadores entre diferentes infraestruturas ou setores a partir de perspectivas mais amplas, utilizando o modelo da Figura 10.2, também deve ser encarado como um trabalho para contribuir com os sistemas metroferroviários;

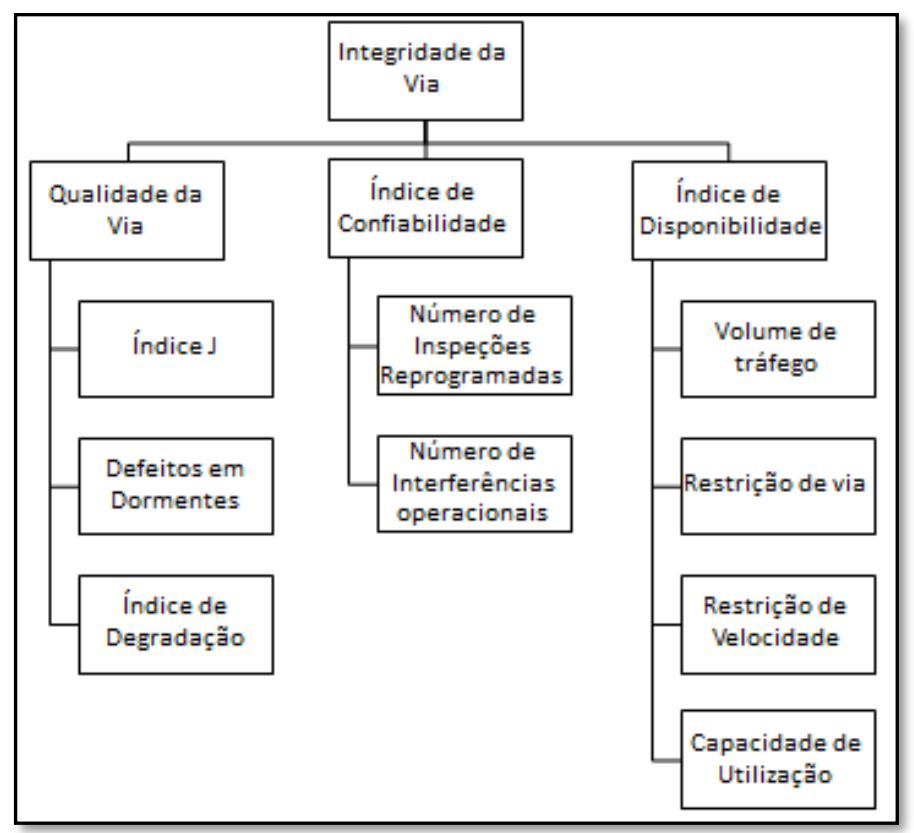

Figura 10.2 - Modelo para composição de indicador para Benchmarking

4. Desenvolver indicadores para gerenciar e entender o processo de manutenção terceirizado para o mercado aberto, ou seja, quais são os indicadores que podem ser usados para gerir a ligação entre o contratado e contratante; 
5. Realização de pesquisas futuras para identificar e compreender quais são as áreas de transporte metroferroviário mais estratégicas do ponto de vista de manutenção, bem como identificar e compreender as relações com base em indicadores adequados;

6. Desenvolver um modelo de monitoramento e avaliação da eficiência global do sistema metroferroviário, o chamado modelo de eficiência geral do equipamento. Este modelo é encarado como uma poderosa ferramenta de gestão para muitas indústrias, tais como processos e indústrias transformadoras;

7. O desenvolvimento de um modelo de custo global para especificar limites de manutenção de baixo custo que considera todos os parâmetros da via, incluindo degradação da via e fatores de custo indiretos, tais como o efeito da má qualidade da via sobre as taxas de degradação de outros componentes;

8. O desenvolvimento de um conjunto de medidas, a fim de identificar o equipamento de alta importância no que diz respeito aos seus efeitos sobre o desempenho global do sistema de transporte, pode ser outro caminho relevante para pesquisa;

9. Utilizar funcionalidades dos bancos de dados geográficos para publicar os mapas temáticos com acesso facilitado por navegadores. Avaliar os avanços dos bancos de dados geográficos e da possibilidade de desconexão do banco de dados do sistema de informações geográficas na geração dos mapas mais simples;

10. Desenvolver um sistema básico de consulta de indicadores de desempenho de via permanente, com uma apresentação geográfica, para uso exclusivo na web, com acesso por qualquer dispositivo móvel. 


\section{BIBLIOGRAFIA}

AHLMANN, H. From traditional practice to the new understanding: the significance of the Life Cycle Profit concept in the management of industrial enterprises. In: MAINTENANCE MANAGEMENT \& MODELLING CONFERENCE. International Foundation for Reseach in Maintenance, 2002.

AHREN, T. A Study of Maintenance Performance Indicators for the Swedish Railroad System. Licenciate-Lulea, Sweden: Lulea University of Technology, ago. 2005.

ÅHRÉN, T.; PARIDA, A. Maintenance performance indicators (MPIs) for benchmarking the railway infrastructure: A case study. Benchmarking: An International Journal, v. 16, n. 2, p. 247-258, 2009.

ALLENDER, H. D. Objectives matrix provides information balance. Water Engineering \& Management, v. 144, n. 9, p. 30-33, 1997.

ANDREWS, J. System reliability modelling: The current capability and potential future developments. Proceedings of the Institution of Mechanical Engineers, Part C: Journal of Mechanical Engineering Science, v. 223, n. 12, p. 2881-2897, 1 dez. 2009. ASCHER, H. Repairable systems reliability: modeling, inference, misconceptions and their causes. New York: M. Dekker, 1984.

ASIEDU, Y.; GU, P. Product life cycle cost analysis: State of the art review. International Journal of Production Research, v. 36, n. 4, p. 883-908, Abril de 1998.

BARROS, L. L. The optimization of repair decision using life-cycle cost Parameters. IMA Journal of Management Mathematics, v. 9, n. 4, p. 403-413, 1 out. 1998. 
BAZERMAN, M. H.; MOORE, D. A. Judgment in Managerial Decision Making. 7 edition ed. Hoboken, NJ: Wiley, 2008.

BAZERMAN, M.H., M. H.; MOORE, D. Processo decisório. Rio de Janeiro: Elsevier, 2010. BEN-DAYA, M. Handbook of maintenance management and engineering. London: Springer, 2009.

BLANCHARD, B. S.; FABRYCKY, W. J. Systems Engineering and Analysis. 5 edition ed. Boston: Prentice Hall, 2010.

BLISCHKE, W. R.; MURTHY, D. N. P. (EDS.). Case studies in reliability and maintenance. Hoboken, NJ: John Wiley, 2003.

BONNETT, C. F. Practical Railway Engineering. 2. ed. Singapore: World Scientific Publishing Company, 2005.

BRITANNICA, I. E. (ED.). Encyclopedia Britannica. 15 edition ed. Chicago: Encyclopedia Britannica Inc, 2003.

BURSTEIN, F.; HOLSAPPLE, C. Handbook on Decision Support Systems 1: Basic Themes. [s.l.] Springer Science \& Business Media, 2008.

CASTRO, I. T. A model of imperfect preventive maintenance with dependent failure modes. European Journal of Operational Research, v. 196, n. 1, p. 217-224, 1 jul. 2009.

CEN. EN 13306:2010-12, 2010. Disponível em:

<http://www.beuth.de/en/standard/din-en-13306/126908059>. Acesso em: 25 ago. 2014.

CENELEC. EN 50126 (1999) The Specification and Demonstration of Reliability, Availability, Maintainability and Safety (RAMS) for Railway Applications. Brussel, Belgium, 1999. Acesso em: 15 fev. 2014.

CHEETHAM, A.; BECK, B. INTEGRATION OF A PAVEMENT MANAGEMENT SYSTEM AND A GEOGRAPHIC INFORMATION SYSTEM IN SOUTH CAROLINATransportation Research Board Conference Proceedings. Anais... In: THIRD INTERNATIONAL CONFERENCE ON MANAGING PAVEMENTS. 1994. Disponível em: <http://trid.trb.org/view/390725>. Acesso em: 16 jun. 2012. 
CHEN, D. et al. Assessment of open source GIS software for water resources management in developing countries. Journal of Hydro-environment Research, v. 4, n. 3, p. 253264, out. 2010.

CLEMEN, R. T.; REILLY, T. Making Hard Decisions with DecisionTools. 1. ed. Pacific Grove, CA: Duxbury/Thomson Learning, 2000.

COOPER, D. R.; SCHINDLER, P. S. Business research methods. Boston: McGraw-Hill Irwin, 2006.

DANE, F. C. Research Methods. Pacific Grove, Calif.: Brooks/Cole Pub Co, 1990.

DATE, C. J.; VIEIRA, A., LIFSCHITZ, SERGIO. Introdução a sistemas de bancos de dados. Rio de Janeiro: Campus, 2004.

DHILLON, B. S. Engineering maintainability: how to design for reliability and easy maintenance. Houston, Tex: Gulf Pub. Co, 1999.

DONNELLY, F. P. Evaluating open source GIS for libraries. Library Hi Tech, v. 28, n. 1, p. 131-151, 2010.

DUNN, S. The Fourth Generation of Maintenance. In: CONFERENCE PROCEEDINGS OF INTERNATIONAL CONFERENCE OF MAINTENANCE SOCIETIES (ICOM 2003). Perth, Australia: 2003. Disponível em: <http://www.plant-

maintenance.com/articles/4th_Generation_Maintenance.pdf>. Acesso em: 28 maio. 2014 EICHHORN, W. (ED.). Measurement in economics: theory and applications of economics indices. Physica Springer, 2014.

ELHANDI, H. M. A. GIS, A TOOL FOR PAVEMENT MANAGEMENT. Master-Stockholm: Royal Institute of Technology (KTH), fev. 2009.

\section{ELLINGHAM, I.; FAWCETT, W. New Generation Whole-Life Costing: Property and} Construction Decision-Making Under Uncertainty. 1 edition ed. London New York: Routledge, 2006.

ELMASRI, R.; NAVATHE, S. Fundamentals of database systems. Boston: AddisonWesley, 2011.

ESPLING, U. MAINTENANCE STRATEGY FOR A RAILWAY INFRASTRUCTURE IN A REGULATED ENVIRONMENT. Doutorado - Lulea, Sweden: Lulea University of Technology, jul. 2007. 
ESVELD, C. Modern railway track. 2nd. ed. Zaltbommel: Esveld, 2001.

EUROPEAN RAIL RESEARCH INSTITUTE et al. CRMA - Cost, Reliability, Maintenance, and Availability. NL, Brussels: European Rail Research Institute, 28 jan. 2000.

Disponível em: <http://cordis.europa.eu/transport/src/crmarep.htm\#1>. Acesso em: 18 fev. 2012.

FAIZ, R. B.; EDIRISINGHE, E. A. Decision Making for Predictive Maintenance in Asset Information Management. Interdisciplinary Journal of Information, Knowledge, and Management, v. 4, p. 62, 2009.

FAZIO, A. E.; PRYBELLA, R. DEVELOPMENT OF AN ANALYTICAL APPROACH TO TRACK MAINTENANCE PLANNING. Transportation Research Record, n. 744, 1980.

FERREIRA, L.; MURRAY, M. H. Modelling rail track deterioration and maintenance: current practices and future needs. Transport Reviews, v. 17, n. 3, p. 207-221, jul. 1997.

FLANAGAN. Life Cycle Costing Theory and Practice. Oxford; Boston: Blackwell Science Inc, 1989.

FLEMING, C. C.; HALLE, B. VON. Handbook of Relational Database Design. 1 edition ed. Reading, Mass.: Addison-Wesley Professional, 1989.

FLINTSCH, G. W. et al. Pavement management applications using geographic information systems. Washington, D.C.: Transportation Research Board, National Research Council, 2004.

FORMAN, E. H.; SELLY, M. A. Decision by Objectives. 1st edition ed. River Edge, N. J: World Scientific Pub Co Inc, 2002.

GOMES, L. F. A. M.; GOMES, C. F. S.; ALMEIDA, A. T. DE. Tomada de decisão gerencial: enfoque multicritério. São Paulo: Atlas, 2009.

GORMAN, M.; KANET, J. Formulation and Solution Approaches to the Rail Maintenance Production Gang Scheduling Problem. Journal of Transportation Engineering, v. 136, n. 8, p. 701-708, 2010.

GRIMES, G. A.; BARKAN, C. P. L. Cost-Effectiveness of Railway Infrastructure Renewal Maintenance. Journal of Transportation Engineering, v. 132, n. 8, p. 601-608, 1 ago. 2006. 
GUIMARÃES, C. C. Fundamentos de bancos de dados modelagem, projeto de linguagem SQL. Campinas: Ed. da Unicamp, 2003.

GULER, H. A Decision Support System for Railway Track Maintenance and Renewal Management. Journal of Computing in Civil Engineering, n. ja, p. 162, 2012.

GULER, H.; AKAD, M.; ERGUN, M. Railway Asset Management System in Turkey: A GIS ApplicationFIG Working Week 2004. Anais...Athens, Greece: maio 2004Disponível em: <http://www.fig.net/pub/athens/papers/ts20/TS20_3_Guler_et_al.pdf>

HAAS, R. C. G.; HUDSON, W. R.; ZANIEWSKI, J. P. Modern pavement management. Original ed ed. Malabar, Fla: Krieger Pub. Co, 1994.

HALFAWY, M.; DRIDI, L.; BAKER, S. Integrated Decision Support System for Optimal Renewal Planning of Sewer Networks.

HAMMOND, J. S.; KEENEY, R. L.; RAIFFA, H. Smart Choices: A Practical Guide to Making Better Decisions. São Paulo, SP: Crown Business, 2002.

HARRINGTON, J. L. Relational Database Design Clearly Explained, Second Edition. 2 edition ed. New York: Morgan Kaufmann, 2002.

HOFFER, J. A.; VENKATARAMAN, R.; TOPI, H. Modern Database Management. 11 edition ed. Boston: Prentice Hall, 2012.

HSU, L.; OBE, R. Cross Compare of SQL Server, MySQL, and PostgreSQL - Postgres OnLine Journal. Disponível em:

<http://web.archive.org/web/20110728074921/http://www.postgresonline.com/jour nal/index.php?/archives/51-Cross-Compare-of-SQL-Server,-MySQL,-andPostgreSQL.html>. Acesso em: 22 abr. 2014.

HUANG, Y. H. Pavement analysis and design. Upper Saddle River, NJ: Pearson/Prentice Hall, 2004.

HUSBAND, T. M. Maintenance Management and Terotechnology. Farnborough: Saxon House, 1976.

IBRAHEEM, A. T. Applying Geographic Information System (GIS) for Maintenance Strategy Selection. Engineering, v. 04, n. 01, p. 44-54, 2012.

IEEE POWER \& ENERGY SOCIETY et al. IEEE 1366. New York: Institute of Electrical and Electronics Engineers, 2012. 
IMPROVERAIL. IMPROVERAIL - IMPROVEd tools for RAILway capacity and accesS management. [s.l.] TIS.PT, dez. 2003. Disponível em: <http://www.transportresearch.info/Upload/Documents/200607/20060727_145926_44007_IMPROVERAIL_F inal_Report.pdf>. Acesso em: 2 dez. 2014.

INTERNATIONAL GULF CONFERENCE ON ROADS; AL-QADI, I. L. Efficient transportation and pavement systems characterization, mechanisms, simulation, and modeling : proceedings of the 4th International Gulf Conference on Roads, Doha, Qatar, 10-13 November 2008. Leiden, the Netherlands; Boca Raton: CRC Press, 2009.

JO, J. et al. Integrated Decision Support for Roadway Safety Analysis. Journal of Computing in Civil Engineering, v. 25, n. 1, p. 50-56, 2011.

JOVANOVIC, S. Railway track quality assessment and related decision making2004 IEEE International Conference on Systems, Man and Cybernetics. Anais... In: 2004 IEEE INTERNATIONAL CONFERENCE ON SYSTEMS, MAN AND CYBERNETICS. Outubro de 2004.

JOVANOVIC, S.; EVREN, G.; GULER, H. Modelling railway track geometry deterioration. Proceedings of the ICE - Transport, v. 164, n. 2, p. 65-75, 1 maio de 2011.

KALLEN, M. J.; VAN NOORTWIJK, J. M. Optimal maintenance decisions under imperfect inspection. Reliability Engineering \& System Safety, v. 90, n. 2-3, p. 177-185, nov. 2005.

KARLSSON, V. An overall view of maintenance. European Railway Review, v. issue 3, 23 maio de 2005.

KELLY, A. Maintenance Strategy. 1 edition ed. Oxford ; Boston: ButterworthHeinemann, 1997.

KELLY, A. Strategic maintenance planning. Amsterdam; Oxford: Elsevier ButterworthHeinemann, 2006.

KUMAR, S. A Study of the Rail degradation Process to Predict Rail Breaks. Licenciate-Lulea, Sweden: Lulea University of Technology, dez. 2006. 
KUMAR, U. Development and Implementation of Maintenance Performance Measurement System: Issues and Challenges. In: MATHEW, J. et al. (Eds.). . Engineering Asset Management. [s.l.] Springer London, 2006. p. 738-743.

KUMAR, U.; AKERSTEN, P. A. Availability and Maintainability. In: Encyclopedia of Quantitative Risk Analysis and Assessment. [s.l.] John Wiley \& Sons, Ltd, 2008. KUMAR, U.; ELLINGSEN, H. Development and implementation of maintenance performance indicators for the Norwegian oil and gas industry. In: PROCEEDINGS OF THE 14TH INTERNATIONAL MAINTENANCE CONGRESS (EURO MAINTENANCE 2000). 2000

KUMAR, U.; PARIDA, A. Maintenance Performance Measurement (MPM) System. In: Complex System Maintenance Handbook. Springer Series in Reliability Engineering. [s.l.] Springer London, 2008. p. 459-478.

KUNIEWSKI, S. P.; VAN DER WEIDE, J. A. M.; VAN NOORTWIJK, J. M. Sampling inspection for the evaluation of time-dependent reliability of deteriorating systems under imperfect defect detection. Reliability Engineering \& System Safety, v. 94, n. 9, p. 1480-1490, Setembro 2009.

LARSSON, D. A Study of the Track Degradation Process Related to Changes in Railway Traffic. Trabalho de Conclusão de Curso-Suécia: Luleå University of Technology JvtC - Luleå Railway Research Centre Division of Operation and Maintenance Engineering, Dezembro 2004.

LEVITT, J. Handbook of Maintenance Management. 2 edition ed. New York, NY: Industrial Press, Inc., 2009.

LEWIS, E. Introduction to reliability engineering. 2nd ed. ed. New York: J. Wiley, 1996.

LI, Z.; SINHA, K. Methodology for Multicriteria Decision Making in Highway Asset Management. Transportation Research Record: Journal of the Transportation Research Board, v. 1885, n. -1, p. 79-87, 1 jan. 2004.

LIBERTIN. Libertin - Light Rail Thematic Network. Karlsruhe, DE: TransportTechnologie-Consult Karlsruhe GmbH (TTK), fev. 2005. Disponível em: 
<http://www.libertin.info/pdf/Final_public_report_libertin.pdf>. Acesso em: 2 dez. 2014

LIYANAGE, J. P.; KUMAR, U. Process of maintenance performance management and its imperatives within the offshore petroleum industry: Part II: The principles of value based maintenance performance management. SMRP Solutions, n. 2, 2002.

LIYANAGE, J. P.; KUMAR, U. Towards a value-based view on operations and maintenance performance management. Journal of Quality in Maintenance Engineering, v. 9, n. 4, p. 333-350, dez. 2003.

MADEJSKI, J.; GRABCZYK, J. Continuous geometry measurement for diagnostics of tracks and switches. International Conference on Switches: Switch to Delft, 2002.

MADU, C. N. Strategic value of reliability and maintainability management.

International Journal of Quality \& Reliability Management, v. 22, n. 3, p. 317-328, 1 abr. 2005.

MAGEL, E. et al. Control of Rolling Contact Fatigue of Rails. In: AREMA CONFERENCE PROCEEDINGS. 2004. Acesso em: 18 set. 2013

MARKESET, T.; KUMAR, U. Dimensioning of product support: issues, challenges, and opportunities. Reliability and Maintainability, 2004 Annual Symposium - RAMS. Anais... In: RELIABILITY AND MAINTAINABILITY, 2004 ANNUAL SYMPOSIUM - RAMS. jan. 2004 MCNAMEE, P.; CELONA, J. Decision Analysis for the Professional. Menlo Park, Calif.: SmartOrg, 2001.

MERCIER, S.; MEIER-HIRMER, C.; ROUSSIGNOL, M. Bivariate Gamma wear processes for track geometry modelling, with application to intervention scheduling. Structure and Infrastructure Engineering, v. 8, n. 4, p. 357-366, 2012.

MOUBRAY, J. Reliability-Centered Maintenance Second Edition. 2 Revised edition ed. New York: Industrial Press, Inc., 1997.

MURTHY, D. N. P.; ATRENS, A.; ECCLESTON, J. A. Strategic maintenance management. Journal of Quality in Maintenance Engineering, v. 8, n. 4, p. 287-305, 1 dez. 2002. NUTT, P. C.; WILSON, D. C. Handbook of Decision Making. [s.l.] John Wiley \& Sons, 2010. 
ÖBERG, J. Track deterioration of ballasted tracks: marginal cost models for different railway vehicles. [s.l.] Rail Vehicles, Aeronautical and Vehicle engineering, Royal Institute of Technology, 2006.

PARIDA, A. Development of a Multi-criteria Hierarchical Framework for Maintenance Performance Measurement. 2006.

PATRA, A. P. Maintenance decision support models for railway infrastructure using RAMS \& LCC analyses. Luleå: Division of Operation and Maintenane Engineering, Luleå University of Technology, 2009.

PUTALLAZ, Y.; RIVIER, R. Strategic maintenance and renewal policy of a railway corridors, taking into account the value of capacity. In: WORLD CONFERENCE ON RAIL RESEARCH, WCRR 03. Edinburgh: set. 2003. Disponível em: <http://infoscience.epfl.ch/record/126092>. Acesso em: 28 jun. 2014 RAMSEY, P. The State of Open Source GIS. [s.l.] Refractions Research, 15 set. 2007. RAUSAND, M. System reliability theory: models, statistical methods, and applications. 2nd ed ed. Hoboken, NJ: Wiley-Interscience, 2004.

RICHARDSON, R. J.; PERES, J. A. DE S. Pesquisa social: métodos e técnicas. São Paulo: Atlas, 1999.

ROUSE, W. B.; SAGE, A. P. Handbook of systems engineering and management. 2nd. ed. Hoboken, N.J.: John Wiley \& Sons, 2009.

RUBIN, A.; BABBIE, E. R. Research Methods for Social Work, 8th Edition. 8th edition ed. Belmont, CA: Brooks/Cole Cengage Learning, 2013.

SAATY, T. L. The Analytic Hierarchy Process. 1. ed. New York: McGraw Hill, 1980. SADEGHI, J. Development of Railway Track Geometry Indexes Based on Statistical Distribution of Geometry Data. Journal of Transportation Engineering, v. 136, n. 8, p. 693-700, 2010.

SAGE, A. P.; ARMSTRONG, J. E. Introduction to systems engineering. 1st. ed. New York: Wiley, 2000.

SALMINEN, J. Measuring performance and determining success factors of construction sites. Espoo: Helsinki University of Technology, 2005. 
SHAHIN, M. Y. Pavement management for airports, roads, and parking lots. 2nd. ed. New York: Springer, 2005.

SHEN, Y.; GRIVAS, D. Decision-Support System for Infrastructure Preservation. Journal of Computing in Civil Engineering, v. 10, n. 1, p. 40-49, 1996.

SHYR, F. Y. Combining Laboratory and Field Data in Rail Fatigue Analysis. [s.l.] Massachusetts Institute of Technology, 1993.

SIMON, H. A. Administrative Behavior, 4th Edition. 4 Sub edition ed. New York: Free Press, 1997.

SINGH, Y. et al. Investigation of Contemporary Performance Measurement Systems for Production Management of Renovation Projects. Journal of Construction Engineering, v. 2014, 2014.

STALDER, O. THE LIFE CYCLE COSTS (LCC) OF ENTIRE RAIL NETWORKS. AN INTERNATIONAL COMPARISON. RAIL INTERNATIONAL, v. 32, abr. 2001.

STALLMAN, R. The GNU manifesto. Dr. Dobb's Journal of Software Tools, v. 10, n. 3, p. 30-35, 1985.

STAMATIS, D. H. The OEE Primer: Understanding Overall Equipment Effectiveness, Reliability, and Maintainability. 1 Pap/Cdr edition ed. Boca Raton, FL: Productivity Press, 2010.

STAPELBERG, R. F. Handbook of Reliability, Availability, Maintainability and Safety in Engineering Design. London: Springer London, 2009.

STEINIGER, S.; BOCHER, E. An overview on current free and open source desktop GIS developments. International Journal of Geographical Information Science, v. 23, n. 10, p. 1345-1370, out. 2009.

STEINIGER, S.; HAY, G. J. Free and open source geographic information tools for landscape ecology. Ecological Informatics, v. 4, n. 4, p. 183-195, set. 2009.

STEINIGER, S.; HUNTER, A. J. S. The 2012 free and open source GIS software map - A guide to facilitate research, development, and adoption. Computers, Environment and Urban Systems, 2012.

STEINIGER, S.; WEIBEL, R. GIS Software - A description in 1000 words, 8 maio 2009. Disponível em: 
<http://ufpr.dl.sourceforge.net/project/mentaer.u/pubs/gissoftware_steiniger2008.pdf >. Acesso em: 16 nov. 2012.

STRICOFF, R. S. Safety performance measurement: Identifying prospective indicators with high validity. Professional Safety, v. 45, n. 1, p. 36-39, 2000.

SUMSER, J. A guide to empirical research in communication: rules for looking. Thousand Oaks, Calif: Sage Publications, 2001.

SWANSON, L. Linking maintenance strategies to performance. International Journal of Production Economics, v. 70, n. 3, p. 237-244, 18 abr. 2001.

TSANG, A. H. C. Strategic dimensions of maintenance management. Journal of Quality in Maintenance Engineering, v. 8, n. 1, p. 7-39, 1 mar. 2002.

TSANG, A. H. C.; JARDINE, A. K. S.; KOLODNY, H. Measuring maintenance performance: a holistic approach. International Journal of Operations \& Production Management, v. 19, n. 7, p. 691-715, 1999.

TURBAN, E.; DELEN, D. Decision Support and Business Intelligence Systems. 9 edition ed. Boston: Prentice Hall, 2010.

UZARSKI, D. R.; DARTER, M. I.; THOMPSON, M. R. DEVELOPMENT OF CONDITION INDEXES FOR LOW-VOLUME RAILROAD TRACKAGE. Transportation Research Record, n. 1381, 1993.

UZARSKI, D.; MCNEIL, S. Technologies for Planning Railroad Track Maintenance and Renewal. Journal of Transportation Engineering, v. 120, n. 5, p. 807-820, 1994. WATSON, S. R. Decision synthesis: the principles and practice of decision analysis. Cambridge [Cambridgeshire] ; New York: Cambridge University Press, 1987.

WIREMAN, T. Developing Performance Indicators for Managing Maintenance. $2 \mathrm{Cdr}$ edition ed. [s.l.] Industrial Press, Inc., 2005.

YEHIA, S. et al. A decision support system for concrete bridge deck maintenance. Advances in Engineering Software, v. 39, n. 3, p. 202-210, mar. 2008. YELLA, S.; DOUGHERTY, M.; GUPTA, N. K. Condition monitoring of wooden railway sleepers. Transportation Research Part C: Emerging Technologies, v. 17, n. 1, p. 3855, Fevereiro de 2009. 
YELLA, S.; RAHMAN, A. S.; DOUGHERTY, M. Pattern recognition for classifying the condition of wooden railway sleepers 2010 International Conference on Multimedia Computing and Information Technology (MCIT). Anais... In: 2010 INTERNATIONAL CONFERENCE ON MULTIMEDIA COMPUTING AND INFORMATION TECHNOLOGY (MCIT). mar. 2010

YIN, R. K. Case Study Research: Design and Methods, 3rd Edition. 3rd edition ed. Thousand Oaks, Calif: SAGE Publications, Inc, 2002.

ZAALBERG, H. Economising Track Renewal and Maintenance with ECOTRACK, Conference on Cost Effectiveness and Safety Aspects of Railway Track, ERRI and UIC. Anais... 1998.

ZAREMBSKI, A. M. Development and Implementation of Integrated Maintenance Planning Systems. Transportation Research Board Annual Meeting. Anais...Washington, D.C.: 1998.

ZHAO, J.; CHAN, A. H. C.; BURROW, M. P. N. Reliability analysis and maintenance decision for railway sleepers using track condition information. Journal of the Operational Research Society, v. 58, n. 8, p. 1047-1055, 5 jul. 2006.

ZIO, E.; MARELLA, M.; PODOFILLINI, L. Importance measures-based prioritization for improving the performance of multi-state systems: application to the railway industry. Reliability Engineering \& System Safety, v. 92, n. 10, p. 1303-1314, out. 2007. ZOETEMAN, A. Asset maintenance management: state of the art in the European railways. International Journal of Critical Infrastructures, v. 2, n. 2/3, p. 171, 2006. ZOETEMAN, A. Life Cycle Analysis for managing rail Infrastructure. European Journal of Transport and Infrastructure Research, v. 1, n. 4, p. 23, nov. 2001 b. ZOETEMAN, A. Life cycle cost analysis for managing rail infrastructure. EJTIR, v. 1, n. 4, p. 391-413, 2001a.

ZORITA, A. et al. Determination and Optimization of the Maintenance Frequencies in the Overhead Contact Line System. Journal of Transportation Engineering, v. 136, n. 11, p. 964-972, 2010. 


\section{ANEXO A}

Tabela 1 - Critérios de Escolha - Necessidades de um SIG (adaptado de Steiniger; Hunter (2012).

\begin{tabular}{|c|c|c|c|c|c|c|c|c|}
\hline \multirow[b]{2}{*}{ Tipo de SIG } & \multicolumn{8}{|c|}{ Tarefas Exigidas } \\
\hline & $\begin{array}{l}\text { Visualização e } \\
\text { Exploração }\end{array}$ & $\begin{array}{l}\text { Criação de } \\
\text { Dados }\end{array}$ & Edição & Armazenamento & Integração & Análise & Transformação & $\begin{array}{l}\text { Criação } \\
\text { de } \\
\text { Mapas }\end{array}$ \\
\hline Visualizador & $\mathbf{\square}$ & & & $\mathbf{\square}$ & & & & a \\
\hline Editor & घ & घ & घ & घ & & & $\square$ & घ \\
\hline Análises Profissionais & - & - & - & - & - & - & - & - \\
\hline $\begin{array}{l}\text { Remote Sensing Software } \\
\text { (Tratamento de Imagens) }\end{array}$ & घ & $\square$ & - & - & $\square$ & - & घ & घ \\
\hline Ferramentas de Análise & - & & $\square$ & - & $\square$ & - & - & - \\
\hline Banco de Dados Espacial & - & - & - & - & - & $\square$ & - & $\square$ \\
\hline Servidor de Mapas Web & - & $\square$ & $\square$ & & & & - & - \\
\hline $\begin{array}{l}\text { Servidor de mapas GIS/ Servidor de } \\
\text { mapas WPS }\end{array}$ & a & & & ! & & घ & - & - \\
\hline
\end{tabular}

- Funcionalidade Padrão; $\square-$ Funcionalidade Opcional. 
Tabela 2 - Características dos SIGs analisados Adaptado de Steiniger; Bocher (2009).

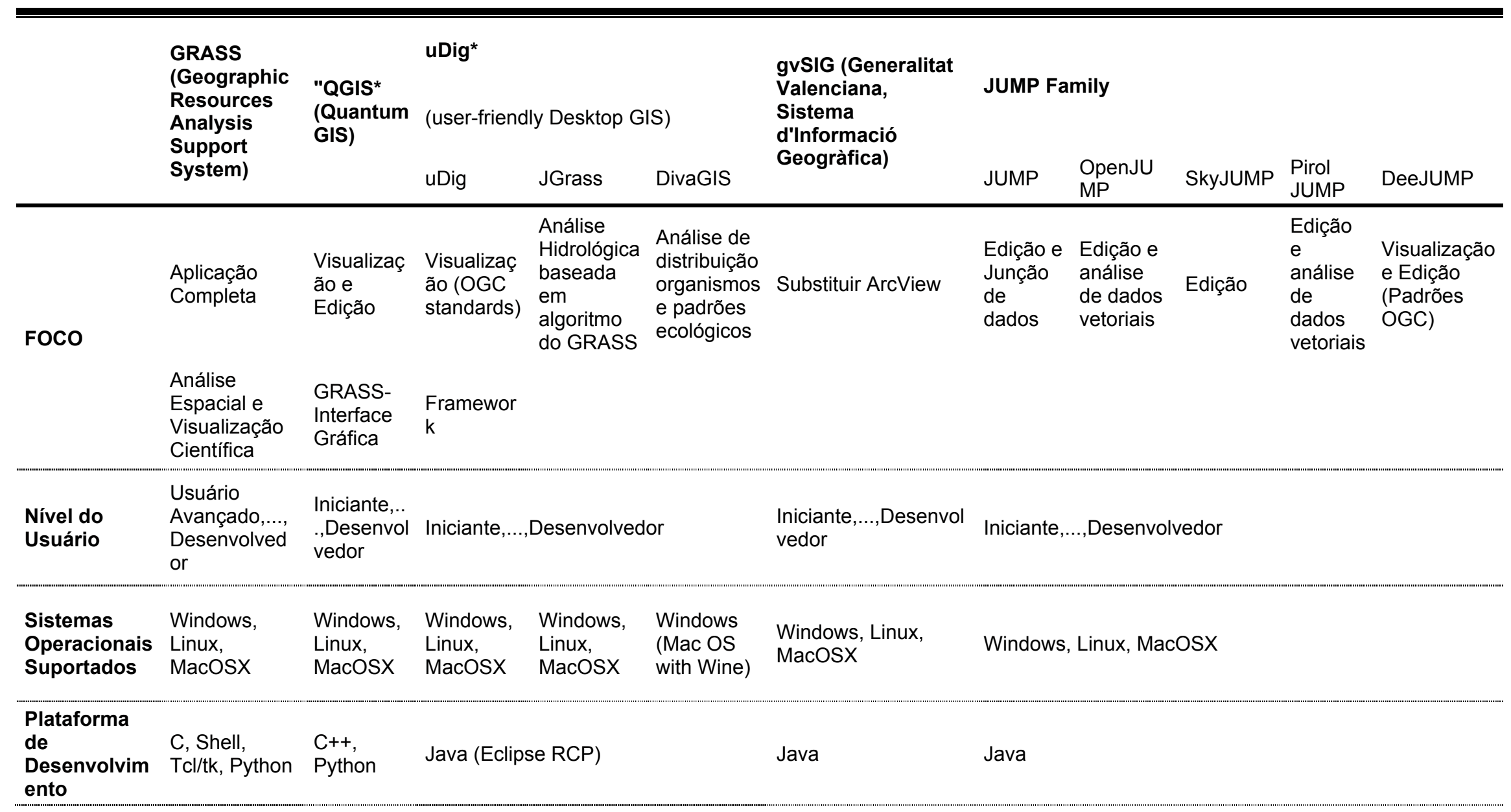




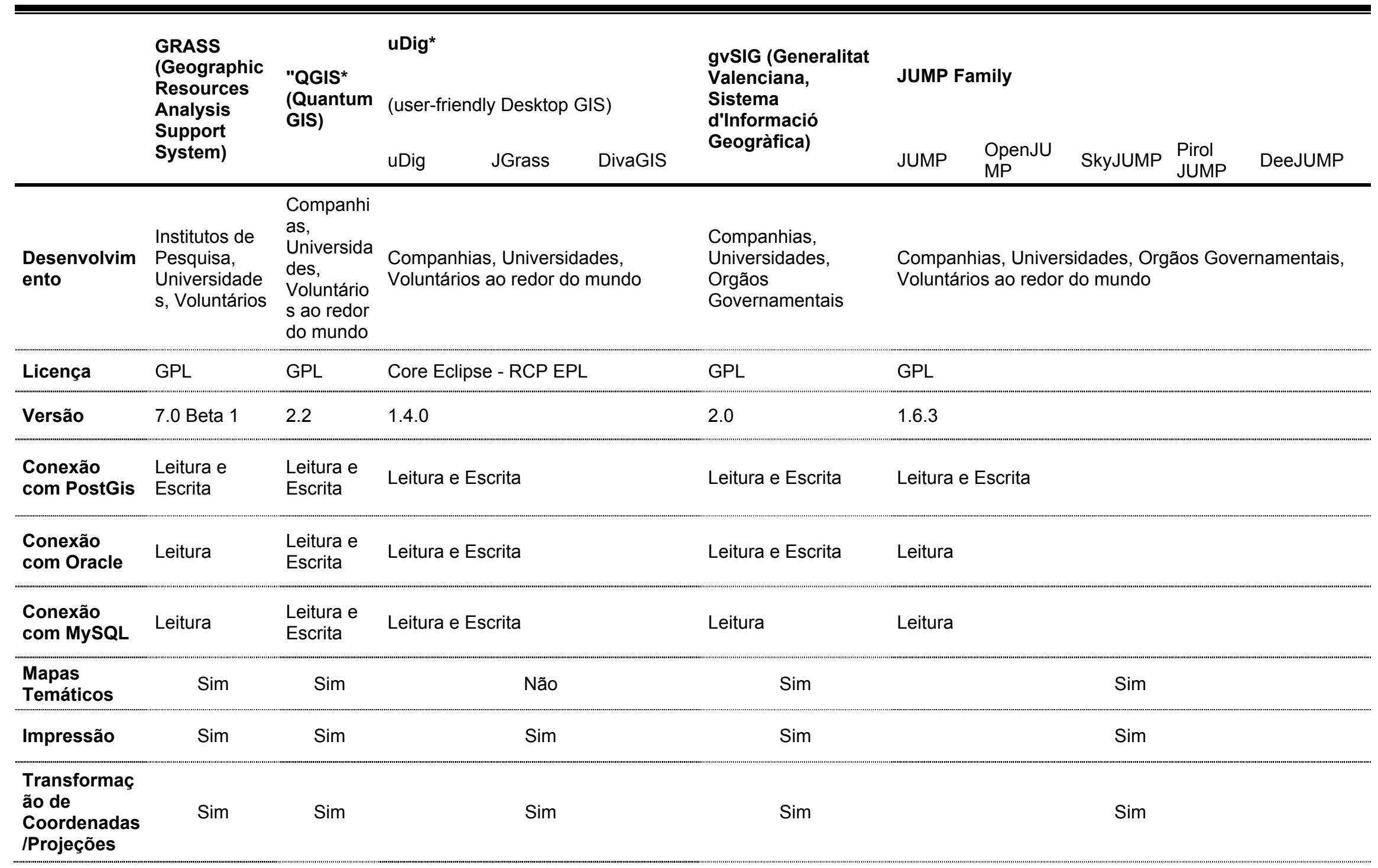




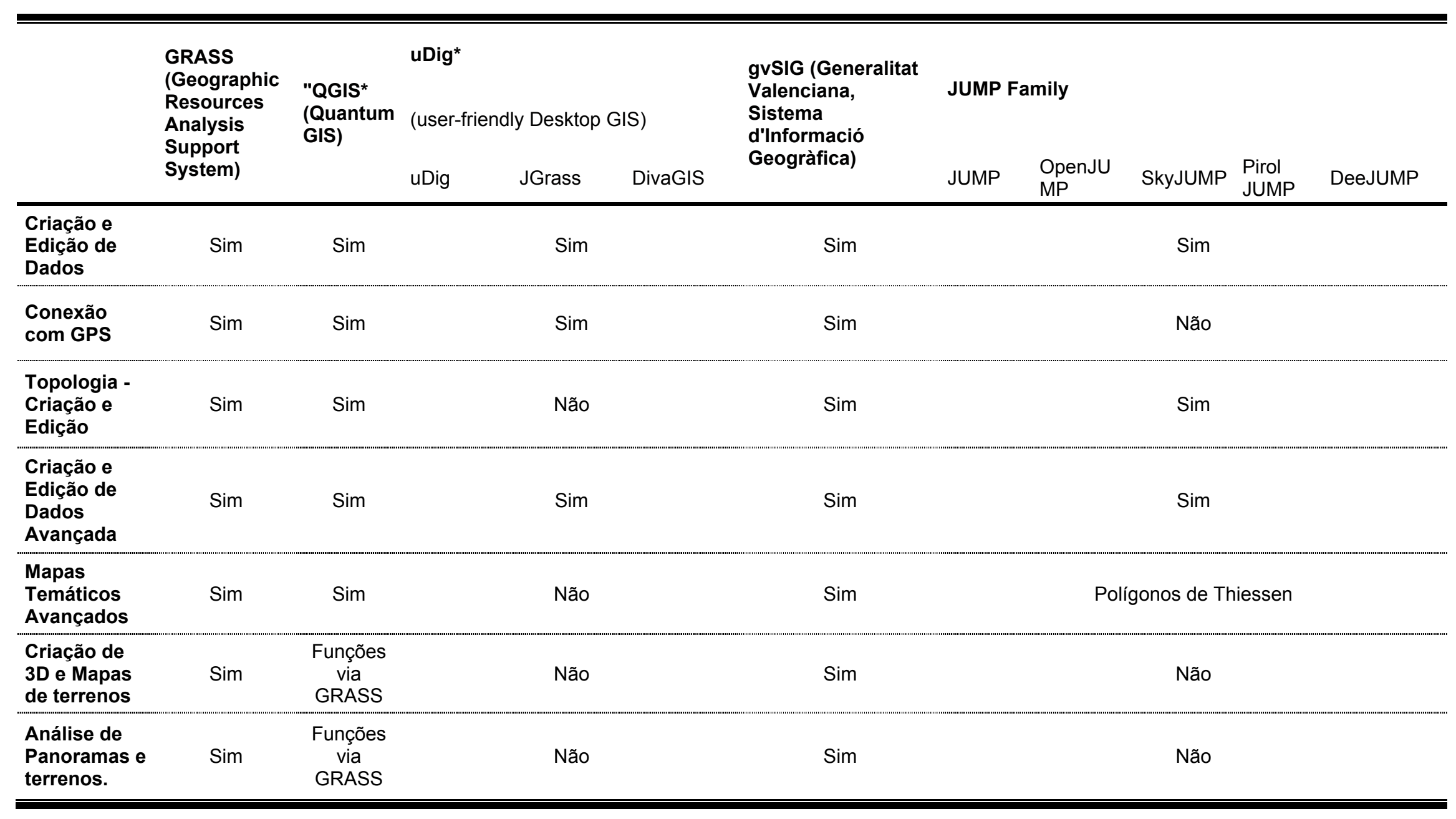


Tabela 3 - Características de Bancos de Dados (Adaptado de Hsu; Obe (2008))

\begin{tabular}{|c|c|c|}
\hline Características & MySQL & PostgreSQL + PostGIS \\
\hline Plataformas & $\begin{array}{l}\text { Tem uma distribuição de arquivos binários para a maioria } \\
\text { das plataformas suportadas. Trabalha melhor em plataforma } \\
\text { Windows em comparação ao PostgreSQL. É executado } \\
\text { como uma aplicação nativa do Windows. }\end{array}$ & $\begin{array}{l}\text { Possui distribuição para todas as plataformas, com exceção } \\
\text { de NextStep e Ultrix. }\end{array}$ \\
\hline Licença & $\begin{array}{l}\text { Comercial Open Source (COSS). É um software livre, mas } \\
\text { não de código aberto. }\end{array}$ & $\begin{array}{l}\text { FLOSS( PostgreSQL está sob licença BSD enquanto o } \\
\text { PostGIS está sob licença GPL código aberto. Pode ser usado } \\
\text { para propósitos comerciais, mas se alguma alteração for } \\
\text { realizada ela deve voltar para a comunidade). }\end{array}$ \\
\hline Aderência aos padrões SQL & $\begin{array}{l}\text { Usa SQL92 como sua base. Funciona em inúmeras } \\
\text { plataformas. Pode construir consultas e juntarem-se tabelas } \\
\text { de bancos de dados diferentes. Suportam uniões à direita e } \\
\text { a esquerda usando ANSI e conexão ODBC. }\end{array}$ & $\begin{array}{l}\text { Está preparado para quase todo o conjunto de instruções } \\
\text { SQL92/99 e os recursos de orientação a objeto destes } \\
\text { conjuntos. Trabalha com rotinas complexas em diversas } \\
\text { operações. Não está preparado para selecionar dados de } \\
\text { bancos diferentes. }\end{array}$ \\
\hline Velocidade & $\begin{array}{l}\text { Rápido com instruções SELECT simples e complexas, mas } \\
\text { precisa mudar o padrão do banco de dados para realizar } \\
\text { instruções de UPDATE. Trabalha com conexões em alta } \\
\text { velocidade, referendando-o para aplicações web. }\end{array}$ & $\begin{array}{l}\text { É lento em algumas situações, mas pode ser melhorado com } \\
\text { codificação de operações armazenadas (stored procedures). }\end{array}$ \\
\hline Estabilidade & $\begin{array}{l}\text { Realiza as tarefas perfeitamente, mesmo em ambientes com } \\
\text { muito tráfego de dados. Desconexões e quebras dos dados } \\
\text { são raras. Possui uma base de usuários grande o suficiente } \\
\text { para testar o código exaustivamente. }\end{array}$ & $\begin{array}{l}\text { A estabilidade é adequada para um banco de dados que se } \\
\text { compromete a lidar com grandes volumes de dados. }\end{array}$ \\
\hline Integridade dos Dados & $\begin{array}{l}\text { Possui somente as propriedades básicas para integridade } \\
\text { referencial. }\end{array}$ & $\begin{array}{l}\text { Suporta integridade referencial em operação simples e } \\
\text { complexa. }\end{array}$ \\
\hline
\end{tabular}




\begin{tabular}{|c|c|c|}
\hline Características & MySQL & PostgreSQL + PostGIS \\
\hline Segurança & Excelente controle de acesso baseado em usuário ou tabela. & $\begin{array}{l}\text { Excelente controle de acesso baseado em rede, identificação, } \\
\text { etc... }\end{array}$ \\
\hline \multirow{3}{*}{ Recursos de Administração } & $\begin{array}{l}\text { Possui triggers e stored procedures em um nível muito } \\
\text { básico. }\end{array}$ & $\begin{array}{l}\text { Possui triggers e stored procedures que podem ser escritas } \\
\text { em C, Perl, Python, e tcl. }\end{array}$ \\
\hline & $\begin{array}{l}\text { Tem uma interface de administração poderosa, com } \\
\text { recursos de backup, recuperação de arquivos corrompidos e } \\
\text { demais recursos necessários a uma boa administração do } \\
\text { banco. }\end{array}$ & Tem uma interface adequada para administrar os dados. \\
\hline & & $\begin{array}{l}\text { Tem características para criar tabelas com mesmo nome em } \\
\text { espaços diferentes. }\end{array}$ \\
\hline Alteração de Tabelas & $\begin{array}{l}\text { Tem todas as opções para alterar tabelas sem a } \\
\text { necessidade de bloquear o banco de dados. }\end{array}$ & $\begin{array}{l}\text { Tem todas as opções para alterar tabelas sem a necessidade } \\
\text { de bloquear o banco de dados. }\end{array}$ \\
\hline $\begin{array}{l}\text { Travamento e Suporte a Acesso } \\
\text { Múltiplo }\end{array}$ & Possui mecanismos de travamento de tabelas & $\begin{array}{l}\text { Possui um mecanismo avançado, superior ao de softwares } \\
\text { comerciais. }\end{array}$ \\
\hline Objetos Grandes & $\begin{array}{l}\text { Tem recursos para lidar com grandes objetos no banco, mas } \\
\text { a função de indexação é prejudicada. }\end{array}$ & $\begin{array}{l}\text { Tem o recurso de linhas que permitem armazenamento de } \\
\text { grandes objetos. }\end{array}$ \\
\hline Transformação de Dados & OGR2OGR, shp2mysql.pl script & $\begin{array}{l}\text { shp2pgsql, OGR2OGR, QuantumGIS SPIT, SHP loader for } \\
\text { PostGIS }\end{array}$ \\
\hline $\begin{array}{l}\text { Drivers disponíveis para } \\
\text { componentes espaciais }\end{array}$ & GDAL C++, SharpMap via OGR, AutoCAD FDO & $\begin{array}{l}\text { SharpMap.Net, JDBC postgis.jar included with postgis, JTS } \\
\text { etc. tons for Java, GDAL C++, AutoCad FDO beta support }\end{array}$ \\
\hline $\begin{array}{l}\text { SIG Livre e de código abertos } \\
\text { compatíveis }\end{array}$ & GvSig & OpenJump, QuantumGIS, GvSig, uDig \\
\hline Funções Espaciais & Poucas funções verdadeiramente espaciais & Mais de 300 funções e operadores espaciais. \\
\hline
\end{tabular}


Características

\section{Suporte a Geodésia}

Tipos de Geometrias Suportadas
MySQL

Não

Geometrias 2D e pode armazenar 3D, mas sem funções

para manipula-las. As funções são Polygon, Point,

LineString, MultiPoint, MultiPolygon,MultiLineString,

GeometryCollection

\section{Capacidade de transformar}

referências espaciais

Funções de entrada de geometrias

Cruzamentos e interseções

$$
\text { Não }
$$

GeomFromText(), GeomFromWKB()

MBRIntersects()* somente em bounding box (as referências

das geometrias devem ser as mesmas),não possui

intersecção.

MBRContains(), MBREqual(), MBROverlaps,

Relacionamentos não agregados

MBRTouches(), MBRWithin(), referência espacial deve ser a

mesma.

Centroid(), Dimension(), EndPoint(), Envelope(),

ExteriorRing(), GeomtryN(), GeometryType(),

InteriorRingN(), IsClosed(), IsRing(), NumPoints(), PointN(),

SRID(), StartPoint()
PostgreSQL + PostGIS

Não

Geometrias 2D, algumas 3D e 4D e suporte a curvatruras. As funçõs suportadas são: Polygon, Point, LineString, MultiPoint, MultiPolygon, MultiLineString, GeometryCollection,

CircularString, CompoundCurve, CurvePolygon, MultiCurve, MultiSurface

Sim

ST_GeomFromText(), ST_GeomFromWKB()

ST_Intersects(), ST_Intersection() (referência espacial deve ser a mesma)

ST_Contains(), ST_Disjoint(), ST_Difference(), ST_Equals(),

ST_Overlaps(), ST_Relate(), ST_SymDifference(),

ST_Touches(), ST_Within() referência espacial deve ser a mesma.

ST_Affine(), ST_Boundary(), ST_Buffer() (2 variants similar to STBuffer() and BufferWithTolerance()), ST_Centroid(),

ST_ConvexHull(), ST_Dimension(), ST_EndPoint(),

ST_ExteriorRing(), ST_GeometryN(), ST_GeometryType(),

ST_InteriorRingN(), ST_IsClosed(), ST_IsEmpty(),ST_IsRing(), ST_ISSimple(), ST_NumGeometries(),ST_NumPoints() (only applies to linestrings), ST_NPoints() - returns num vertexes regardless of geometry type, ST_PointN(), ST_Simplify(), 


\begin{tabular}{|c|c|c|}
\hline Características & MySQL & PostgreSQL + PostGIS \\
\hline & & $\begin{array}{l}\text { ST_StartPoint(), ST_SRID(),ST_Translate(), ST_Union(), } \\
\text { various MakeLine,MakePolygon, buildarea etc. }\end{array}$ \\
\hline Funções de medida & Area(), GLength(), Distance() & $\begin{array}{l}\text { ST_Area(), } \\
\text { ST_Distance_Spheroid(), ST_Length_Spheriod (as u nidadres } \\
\text { das funções non-sphere, non-spheriod functions units estão } \\
\text { em referência espacial, sphere and spheroid estão em metros } \\
\text { mas só é aplicável para pontos) e equivaklentes para } \\
\text { geometrias 3D }\end{array}$ \\
\hline Referência linear & Nenhuma & $\begin{array}{l}\text { ST_Line_Interpolate_point(), } \\
\text { ST_line_locate_point(), } \\
\text { ST_locate_between_measures() }\end{array}$ \\
\hline Agregação Espacial & Nenhuma & $\begin{array}{l}\text { ST_Extent(), ST_Collect(), ST_Union(), ST_Accum(), } \\
\text { ST_MakeLine(), ST_Polygonize() }\end{array}$ \\
\hline
\end{tabular}




\section{Dicionário de Dados - Banco de Dados de Falhas}

\begin{tabular}{|c|c|c|c|c|c|c|c|}
\hline $\begin{array}{l}\text { tabAMV } \\
\text { ColumnName }\end{array}$ & DataType & PrimaryKey & NotNull & Flags & Default Value & Comment & AutoInc \\
\hline idAMV & VARCHAR(8) & PK & $\mathrm{NN}$ & & & & AI \\
\hline tabRegiao_idRegiao & INTEGER & & $\mathrm{NN}$ & UNSIGNED & & & \\
\hline AberturaAMV & $\operatorname{VARCHAR}(4)$ & & NN & & & & \\
\hline CodEstoque & $\operatorname{VARCHAR(15)}$ & & NN & & & & \\
\hline Fabricante & $\operatorname{VARCHAR(15)}$ & & NN & & & & \\
\hline CustoAMV & DOUBLE & & $\mathrm{NN}$ & ZEROFILL & & & \\
\hline geomLocal & MULTIPOINT & & NN & & & & \\
\hline dataCadastroAMV & DATE & & & & & & \\
\hline IndexName & IndexType & Columns & & & & & \\
\hline PRIMARY & PRIMARY & idAMV & & & & & \\
\hline tabAMV_FKIndex1 & Index & tabRegiao_idRegiao & & & & & \\
\hline
\end{tabular}

\begin{tabular}{|c|c|c|c|c|c|c|c|}
\hline ColumnName & DataType & PrimaryKey & NotNull & Flags & Default Value & Comment & AutoInc \\
\hline idFalha & INTEGER & PK & NN & UNSIGNED & & & AI \\
\hline tabEquipeManut_idtEquipeManut & INTEGER & & NN & UNSIGNED & & & \\
\hline tabEquip_idEquip & INTEGER & & NN & UNSIGNED & & & \\
\hline tabTrechoVia_idTrechoVia & INTEGER & & NN & UNSIGNED & & & \\
\hline tabAMV_idAMV & $\operatorname{VARCHAR}(8)$ & & NN & & & & \\
\hline tabVia_idVia & INTEGER & & NN & UNSIGNED & & & \\
\hline
\end{tabular}




\begin{tabular}{|c|c|c|c|c|c|c|}
\hline tabTipoManut_idManut & INTEGER & & NN & UNSIGNED & & \\
\hline tabReparo_idReparo & INTEGER & & NN & UNSIGNED & & \\
\hline tabDefeitos_idDefeito & INTEGER & & $\mathrm{NN}$ & UNSIGNED & & \\
\hline dataFalha & DATE & & & & & \\
\hline horaFalha & TIME & & & & & \\
\hline geomInicioFalha & GEOMETRY & & & & & \\
\hline geomFimFalha & GEOMETRY & & & & & \\
\hline IndexName & IndexType & Columns & & & & \\
\hline PRIMARY & PRIMARY & idFalha & & & & \\
\hline tabManutReal_FKIndex1 & Index & tabDefeitos_idDefeito & & & & \\
\hline tabManutReal_FKIndex2 & Index & tabReparo_idReparo & & & & \\
\hline tabManutReal_FKIndex3 & Index & tabTipoManut_idManut & & & & \\
\hline tabManutReal_FKIndex4 & Index & tabVia_idVia & & & & \\
\hline tabManutReal_FKIndex5 & Index & tabAMV_idAMV & & & & \\
\hline tabManutReal_FKIndex6 & Index & tabTrechoVia_idTrechoVia & & & & \\
\hline tabManutReal_FKIndex7 & Index & tabEquip_idEquip & & & & \\
\hline tabManutReal_FKIndex8 & Index & tabEquipeManut_idtEquipeManut & & & & \\
\hline $\begin{array}{l}\text { tabCargaAMV } \\
\text { ColumnName }\end{array}$ & DataType & PrimaryKey & NotNull & Flags & Default Value & AutoInc \\
\hline idCargaAMV & INTEGER & PK & NN & UNSIGNED & & AI \\
\hline tabAMV_idAMV & $\operatorname{VARCHAR}(8)$ & & NN & & & \\
\hline CargaAMV & DOUBLE & & & & & \\
\hline DataCargaAMV & DATE & & & & & \\
\hline
\end{tabular}




\begin{tabular}{lll} 
IndexName & IndexType & Columns \\
\hline PRIMARY & PRIMARY & idCargaAMV \\
\hline tabCargaAMV_FKIndex1 & Index & tabAMV_idAMV
\end{tabular}

\section{tabCargaVia}

ColumnName

\begin{tabular}{llll}
\hline idCargaVia & INTEGER & PK & NN \\
\hline tabTrechoVia_idTrechoVia & INTEGER & & NN \\
\hline Carga & DOUBLE & \\
\hline DataCarga & DATE & \\
\hline IndexName & IndexType & Columns \\
\hline PRIMARY & PRIMARY & idCargaVia \\
\hline tabCargaVia_FKIndex1 & Index & tabTrechoVia_idTrechoVia \\
\hline
\end{tabular}

\section{tabDefeitos}

ColumnName

DataType

idDefeito

INTEGER

PrimaryKey

NotNull

Flags

Default Value

Comment

AutoInc

DescDefeito VARCHAR(45)

dataCadDef DATE

\section{IndexName}

IndexType

PRIMARY PRIMARY

\section{Columns}

NN UNSIGNED

UNSIGNED

\section{tabEquip}




\begin{tabular}{|c|c|c|c|c|c|c|}
\hline ColumnName & DataType & PrimaryKey & NotNull & Flags & Default Value & AutoInc \\
\hline idEquip & INTEGER & PK & NN & UNSIGNED & & AI \\
\hline descEquip & VARCHAR(45) & & & & & \\
\hline dataCadEquip & DATE & & & & & \\
\hline CustoEquipamento & DOUBLE & & NN & ZEROFILL & & \\
\hline IndexName & IndexType & Columns & & & & \\
\hline PRIMARY & PRIMARY & idEquip & & & & \\
\hline
\end{tabular}

\section{tabEquipeManut}

\begin{tabular}{|c|c|c|c|c|c|c|}
\hline ColumnName & DataType & PrimaryKey & NotNull & Flags & Default Value Comment & AutoInc \\
\hline idtEquipeManut & INTEGER & PK & NN & UNSIGNED & & AI \\
\hline descEquipeManut & VARCHAR(45) & & NN & & & \\
\hline CustoEquipe & DOUBLE & & NN & ZEROFILL & & \\
\hline dataCadEqManut & DATE & & NN & & & \\
\hline IndexName & IndexType & Columns & & & & \\
\hline PRIMARY & PRIMARY & idtEquipeManut & & & & \\
\hline
\end{tabular}

\begin{tabular}{|c|c|c|c|c|c|c|c|}
\hline ColumnName & DataType & PrimaryKey & NotNull & Flags & Default Value & Comment & AutoInc \\
\hline idInspVia & INTEGER & PK & NN & UNSIGNED & & & AI \\
\hline tabAMV_idAMV & $\operatorname{VARCHAR}(8)$ & & NN & & & & \\
\hline tabTrechoVia_idTrechoVia & INTEGER & & NN & UNSIGNED & & & \\
\hline tabTipoInsp_idTipoInsp & INTEGER & & NN & UNSIGNED & & & \\
\hline DataInsp & DATE & & & & & & \\
\hline
\end{tabular}




\begin{tabular}{lll} 
IndexName & IndexType & Columns \\
\hline PRIMARY & PRIMARY & idInspVia \\
\hline tabInspVia_FKIndex1 & Index & tabTipoInsp_idTipoInsp \\
\hline tabInspVia_FKIndex2 & Index & tabTrechoVia_idTrechoVia \\
\hline tabInspVia_FKIndex3 & Index & tabAMV_idAMV \\
\hline
\end{tabular}

\section{tabLinhas}

ColumnName

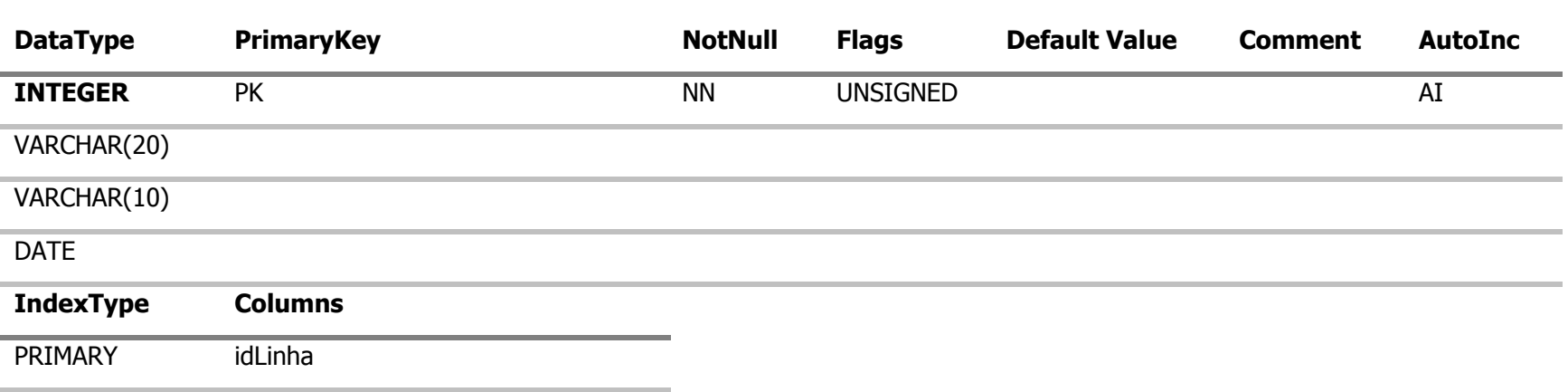

\section{tabRegiao \\ ColumnName}

idRegiao

DataType

INTEGER

PrimaryKey

NotNull

Flags

Default Value

Comment

\begin{tabular}{llll}
\hline DescRegiao & INTEGER & PK & UN \\
\hline CodRegiao & VARCHAR(45) & \\
\hline DataCadastroRg & VARCHAR(3) & \\
\hline IndexName & DATE & \\
\hline PRIMARY & IndexType & Columns \\
\hline
\end{tabular}




\begin{tabular}{|c|c|c|c|c|c|c|c|}
\hline ColumnName & DataType & PrimaryKey & NotNull & Flags & Default Value & Comment & AutoInc \\
\hline idReparo & INTEGER & PK & $\mathrm{NN}$ & UNSIGNED & & & AI \\
\hline descReparo & VARCHAR(45) & & & & & & \\
\hline dataCadRep & DATE & & & & & & \\
\hline IndexName & IndexType & Columns & & & & & \\
\hline PRIMARY & PRIMARY & idReparo & & & & & \\
\hline
\end{tabular}

\begin{tabular}{|c|c|c|c|c|c|c|c|}
\hline ColumnName & DataType & PrimaryKey & NotNull & Flags & Default Value & Comment & AutoInc \\
\hline idTipoInsp & INTEGER & PK & NN & UNSIGNED & & & AI \\
\hline DescTipoInsp & $\operatorname{VARCHAR}(20)$ & & & & & & \\
\hline CustoInsp & DOUBLE & & & & & & \\
\hline DataCadInsp & DATE & & & & & & \\
\hline IndexName & IndexType & Columns & & & & & \\
\hline PRIMARY & PRIMARY & idTipoInsp & & & & & \\
\hline $\begin{array}{l}\text { tabTipoManut } \\
\text { ColumnName }\end{array}$ & DataType & PrimaryKey & NotNull & Flags & Default Value & Comment & AutoInc \\
\hline idManut & INTEGER & PK & NN & UNSIGNED & & & AI \\
\hline TipoManut & $\operatorname{VARCHAR}(20)$ & & & & & & \\
\hline CustoManut & DOUBLE & & NN & ZEROFILL & & & \\
\hline dataCadastroManut & DATE & & NN & & & & \\
\hline
\end{tabular}




\begin{tabular}{lll} 
IndexName & IndexType & Columns \\
\hline PRIMARY & PRIMARY & idManut
\end{tabular}

\section{tabTrechoVia}

ColumnName

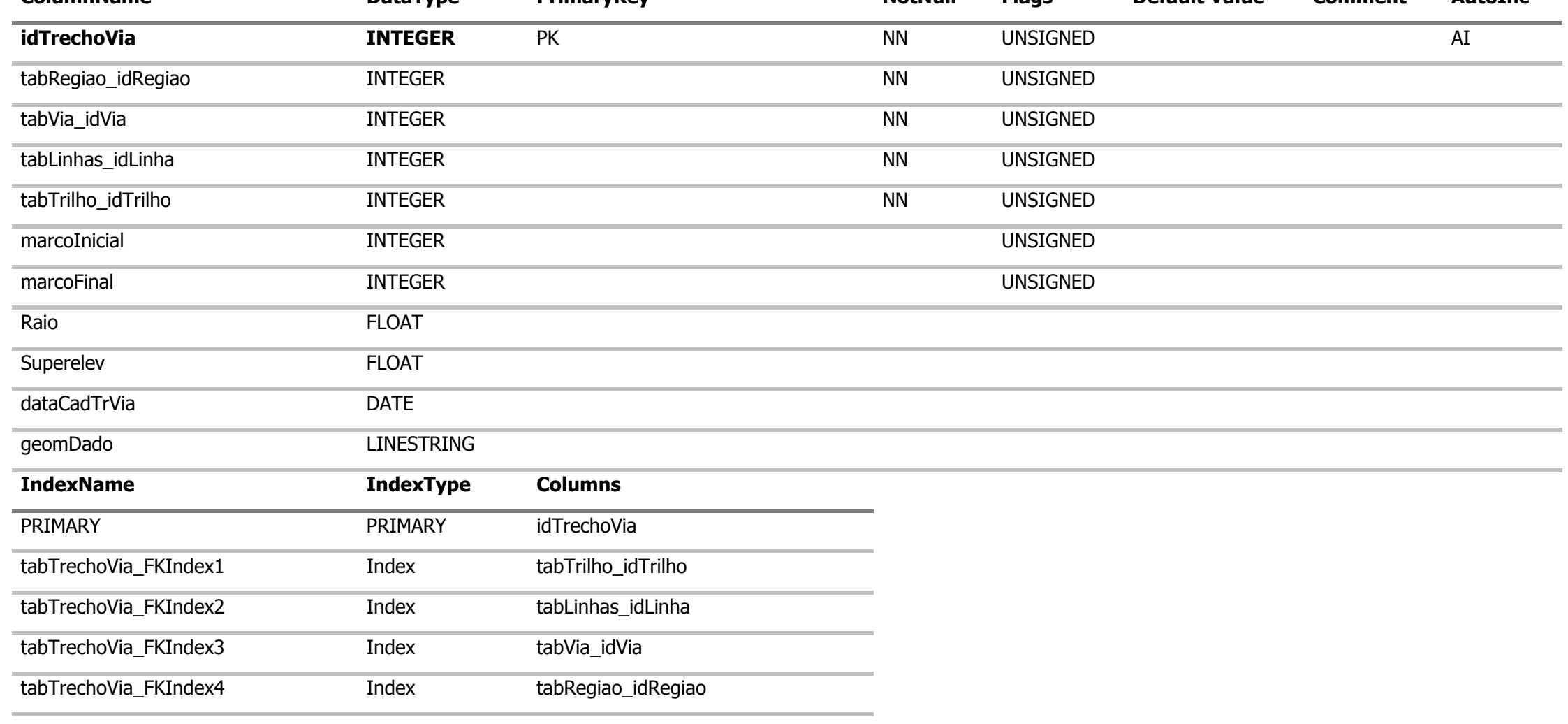




\section{tabTrilho}

ColumnName

DataType

PrimaryKey

NotNull

Flags

Default Value

Comment AutoInc

idTrilho

INTEGER

NN

UNSIGNED

AI

TipoTrilho VARCHAR(20) NN

DurezaTrilho INTEGER NN

FabricanteTrilho $\operatorname{VARCHAR}(20) \quad$ NN

CustoTrilho DOUBLE NN

DataCadastroTr DATE

DATE

NN

\section{IndexName}

IndexType

Columns

PRIMARY

PRIMARY

idTrilho

\section{tabVia}

ColumnName

idVia

DataType

PrimaryKey

NotNull

Flags

Default Value

Comment

AutoInc

DescVia

NN

UNSIGNED

AI

dataCadVia

IndexName DATE

PRIMARY IndexType Columns PRIMARY idVia 


\section{Dicionário de Dados - Banco de Dados de Manutenção}

\begin{tabular}{|c|c|c|c|c|c|c|c|}
\hline $\begin{array}{l}\text { tabAMV } \\
\text { ColumnName }\end{array}$ & DataType & PrimaryKey & NotNull & Flags & Default Value & Comment & AutoInc \\
\hline idAMV & VARCHAR(8) & PK & NN & & & & AI \\
\hline tabRegiao_idRegiao & INTEGER & & NN & UNSIGNED & & & \\
\hline AberturaAMV & $\operatorname{VARCHAR}(4)$ & & NN & & & & \\
\hline CodEstoque & VARCHAR(15) & & $\mathrm{NN}$ & & & & \\
\hline Fabricante & VARCHAR(15) & & $\mathrm{NN}$ & & & & \\
\hline CustoAMV & DOUBLE & & $\mathrm{NN}$ & ZEROFILL & & & \\
\hline geomLocal & MULTIPOINT & & $\mathrm{NN}$ & & & & \\
\hline dataCadastroAMV & DATE & & & & & & \\
\hline IndexName & IndexType & Columns & & & & & \\
\hline PRIMARY & PRIMARY & idAMV & & & & & \\
\hline tabAMV_FKIndex1 & Index & tabRegiao_idRegiao & & & & & \\
\hline
\end{tabular}

\begin{tabular}{|c|c|c|c|c|c|c|c|}
\hline ColumnName & DataType & PrimaryKey & NotNull & Flags & Default Value & Comment & AutoInc \\
\hline idManutReal & INTEGER & PK & NN & UNSIGNED & & & AI \\
\hline tabEquipeManut_idtEquipeManut & INTEGER & & NN & UNSIGNED & & & \\
\hline tabEquip_idEquip & INTEGER & & NN & UNSIGNED & & & \\
\hline tabTrechoVia_idTrechoVia & INTEGER & & NN & UNSIGNED & & & \\
\hline tabAMV_idAMV & $\operatorname{VARCHAR}(8)$ & & NN & & & & \\
\hline tabVia_idVia & INTEGER & & NN & UNSIGNED & & & \\
\hline
\end{tabular}




\begin{tabular}{|c|c|c|c|c|c|c|c|}
\hline tabTipoManut_idManut & INTEGER & & NN & UNSIGNED & & & \\
\hline tabReparo_idReparo & INTEGER & & NN & UNSIGNED & & & \\
\hline tabDefeitos_idDefeito & INTEGER & & $\mathrm{NN}$ & UNSIGNED & & & \\
\hline DataManReal & DATE & & & & & & \\
\hline horaManReal & TIME & & & & & & \\
\hline geomInicioManReal & GEOMETRY & & & & & & \\
\hline geomFimManReal & GEOMETRY & & & & & & \\
\hline IndexName & IndexType & Columns & & & & & \\
\hline PRIMARY & PRIMARY & idManutReal & & & & & \\
\hline tabManutReal_FKIndex1 & Index & tabDefeitos_idDefeito & & & & & \\
\hline tabManutReal_FKIndex2 & Index & tabReparo_idReparo & & & & & \\
\hline tabManutReal_FKIndex3 & Index & tabTipoManut_idManut & & & & & \\
\hline tabManutReal_FKIndex4 & Index & tabVia_idVia & & & & & \\
\hline tabManutReal_FKIndex5 & Index & tabAMV_idAMV & & & & & \\
\hline tabManutReal_FKIndex6 & Index & tabTrechoVia_idTrechoVia & & & & & \\
\hline tabManutReal_FKIndex7 & Index & tabEquip_idEquip & & & & & \\
\hline tabManutReal_FKIndex8 & Index & tabEquipeManut_idtEquipeManut & & & & & \\
\hline $\begin{array}{l}\text { tabCargaAMV } \\
\text { ColumnName }\end{array}$ & DataType & PrimaryKey & NotNull & Flags & Default Value & Comment & AutoInc \\
\hline idCargaAMV & INTEGER & PK & NN & UNSIGNED & & & AI \\
\hline tabAMV_idAMV & $\operatorname{VARCHAR}(8)$ & & NN & & & & \\
\hline CargaAMV & DOUBLE & & & & & & \\
\hline DataCargaAMV & DATE & & & & & & \\
\hline
\end{tabular}




\begin{tabular}{lll} 
IndexName & IndexType & Columns \\
\hline PRIMARY & PRIMARY & idCargaAMV \\
\hline tabCargaAMV_FKIndex1 & Index & tabAMV_idAMV \\
\hline
\end{tabular}

\section{tabCargaVia}

ColumnName

\begin{tabular}{|c|c|c|c|c|c|}
\hline DataType & PrimaryKey & NotNull & Flags & Default Value & AutoInc \\
\hline INTEGER & PK & NN & UNSIGNED & & AI \\
\hline INTEGER & & NN & UNSIGNED & & \\
\hline \multicolumn{6}{|l|}{ DOUBLE } \\
\hline \multicolumn{6}{|l|}{ DATE } \\
\hline IndexType & Columns & & & & \\
\hline PRIMARY & idCargaVia & & & & \\
\hline Index & tabTrechoVia_idTrechoVia & & & & \\
\hline
\end{tabular}

\section{tabDefeitos}

ColumnName

idDefeito

DataType

PrimaryKey

NotNull Flags

Default Value

Comment

AutoInc

DescDefeito INTEGER PK

NN

UNSIGNED

dataCadDef

VARCHAR(45)

IndexName

DATE

PRIMARY

IndexType

Columns

PRIMARY

idDefeito

\section{tabEquip}




\begin{tabular}{|c|c|c|c|c|c|c|c|}
\hline ColumnName & DataType & PrimaryKey & NotNull & Flags & Default Value & Comment & AutoInc \\
\hline idEquip & INTEGER & PK & NN & UNSIGNED & & & AI \\
\hline descEquip & VARCHAR(45) & & & & & & \\
\hline dataCadEquip & DATE & & & & & & \\
\hline CustoEquipamento & DOUBLE & & NN & ZEROFILL & & & \\
\hline IndexName & IndexType & Columns & & & & & \\
\hline PRIMARY & PRIMARY & idEquip & & & & & \\
\hline $\begin{array}{l}\text { tabEquipeManut } \\
\text { ColumnName }\end{array}$ & DataType & PrimaryKey & NotNull & Flags & Default Value & Comment & AutoInc \\
\hline idtEquipeManut & INTEGER & PK & NN & UNSIGNED & & & AI \\
\hline descEquipeManut & VARCHAR(45) & & NN & & & & \\
\hline CustoEquipe & DOUBLE & & NN & ZEROFILL & & & \\
\hline dataCadEqManut & DATE & & NN & & & & \\
\hline IndexName & IndexType & Columns & & & & & \\
\hline PRIMARY & PRIMARY & idtEquipeManut & & & & & \\
\hline
\end{tabular}

\begin{tabular}{llllll}
$\begin{array}{l}\text { tabInspVia } \\
\text { ColumnName }\end{array}$ & DataType & PrimaryKey & NotNull & Flags & Default Value \\
\hline idInspVia & INTEGER & PK & NN & UNSIGNED \\
\hline tabAMV_idAMV & VARCHAR(8) & & NN & \\
\hline tabTrechoVia_idTrechoVia & INTEGER & NN & UNSIGNED \\
\hline tabTipoInsp_idTipoInsp & INTEGER & NN & UNSIGNED \\
\hline DataInsp & DATE & & & \\
\hline
\end{tabular}




\begin{tabular}{lll} 
IndexName & IndexType & Columns \\
\hline PRIMARY & PRIMARY & idInspVia \\
\hline tabInspVia_FKIndex1 & Index & tabTipoInsp_idTipoInsp \\
\hline tabInspVia_FKIndex2 & Index & tabTrechoVia_idTrechoVia \\
\hline tabInspVia_FKIndex3 & Index & tabAMV_idAMV \\
\hline
\end{tabular}

\section{tabLinhas}

ColumnName

DataType

PrimaryKey

NotNull

Flags

Default Value

Comment

AutoInc

idLinha

INTEGER

PK

NN

UNSIGNED

AI

DescLinha

VARCHAR(20)

CorLinha $\operatorname{VARCHAR}(10)$

DataCadLinha DATE

IndexName IndexType

Columns

PRIMARY

PRIMARY

idLinha

\section{tabRegiao}

ColumnName

idRegiao

DataType

INTEGER

PrimaryKey

NotNull

Flags

Default Value

Comment

AutoInc

DescRegiao VARCHAR(45)

CodRegiao VARCHAR(3)

DataCadastroRg

DATE

IndexName

IndexType

PRIMARY

PRIMARY

Columns

PRIMARY idRegiao


tabReparo

ColumnName

DataType

PrimaryKey

NotNull

Flags

Default Value

Comment

AutoInc

idReparo

INTEGER

PK

NN

UNSIGNED

AI

descReparo

VARCHAR(45)

dataCadRep

DATE

PRIMARY

IndexType

Columns

PRIMARY

idReparo

tabTipoInsp

ColumnName

DataType

PrimaryKey

NotNull Flags

Default Value

Comment

AutoInc

idTipoInsp

INTEGER

NN

UNSIGNED

AI

DescTipoInsp

$\operatorname{VARCHAR}(20)$

CustoInsp DOUBLE

DataCadInsp DATE

IndexName IndexType Columns

PRIMARY PRIMARY idTipoInsp

\section{tabTipoManut}

ColumnName

DataType

PrimaryKey

NotNull Flags

Default Value

Comment

AutoInc

idManut

INTEGER

NN

UNSIGNED

AI

TipoManut

VARCHAR(20)

CustoManut

DOUBLE

NN

ZEROFILL

dataCadastroManut

DATE

NN 


\begin{tabular}{lll} 
IndexName & IndexType & Columns \\
\hline PRIMARY & PRIMARY & idManut
\end{tabular}

\section{tabTrechoVia}

\begin{tabular}{|c|c|c|c|c|c|c|}
\hline ColumnName & DataType & PrimaryKey & NotNull & Flags & Default Value Comment & AutoInc \\
\hline idTrechoVia & INTEGER & PK & NN & UNSIGNED & & AI \\
\hline tabRegiao_idRegiao & INTEGER & & NN & UNSIGNED & & \\
\hline tabVia_idVia & INTEGER & & NN & UNSIGNED & & \\
\hline tabLinhas_idLinha & INTEGER & & NN & UNSIGNED & & \\
\hline tabTrilho_idTrilho & INTEGER & & NN & UNSIGNED & & \\
\hline marcoInicial & INTEGER & & & UNSIGNED & & \\
\hline marcoFinal & INTEGER & & & UNSIGNED & & \\
\hline Raio & FLOAT & & & & & \\
\hline Superelev & FLOAT & & & & & \\
\hline dataCadTrVia & DATE & & & & & \\
\hline geomDado & LINESTRING & & & & & \\
\hline IndexName & IndexType & Columns & & & & \\
\hline PRIMARY & PRIMARY & idTrechoVia & & & & \\
\hline tabTrechoVia_FKIndex1 & Index & tabTrilho_idTrilho & & & & \\
\hline tabTrechoVia_FKIndex2 & Index & tabLinhas_idLinha & & & & \\
\hline tabTrechoVia_FKIndex3 & Index & tabVia_idVia & & & & \\
\hline tabTrechoVia_FKIndex4 & Index & tabRegiao_idRegiao & & & & \\
\hline
\end{tabular}

\section{tabTrilho}




\begin{tabular}{|c|c|c|c|c|c|c|c|}
\hline ColumnName & DataType & PrimaryKey & NotNull & Flags & Default Value & Comment & AutoInc \\
\hline idTrilho & INTEGER & PK & $\mathrm{NN}$ & UNSIGNED & & & AI \\
\hline TipoTrilho & $\operatorname{VARCHAR}(20)$ & & $\mathrm{NN}$ & & & & \\
\hline DurezaTrilho & INTEGER & & $\mathrm{NN}$ & & & & \\
\hline FabricanteTrilho & VARCHAR(20) & & $\mathrm{NN}$ & & & & \\
\hline CustoTrilho & DOUBLE & & $\mathrm{NN}$ & ZEROFILL & & & \\
\hline DataCadastroTr & DATE & & $\mathrm{NN}$ & & & & \\
\hline IndexName & IndexType & Columns & & & & & \\
\hline PRIMARY & PRIMARY & idTrilho & & & & & \\
\hline $\begin{array}{l}\text { tabVia } \\
\text { ColumnName }\end{array}$ & DataType & PrimaryKey & NotNull & Flags & Default Value & Comment & AutoInc \\
\hline idVia & INTEGER & PK & $\mathrm{NN}$ & UNSIGNED & & & AI \\
\hline DescVia & $\operatorname{VARCHAR}(8)$ & & & & & & \\
\hline dataCadVia & DATE & & & & & & \\
\hline IndexName & IndexType & Columns & & & & & \\
\hline PRIMARY & PRIMARY & idVia & & & & & \\
\hline
\end{tabular}




\section{Script SQL Para Criação do Banco de Dados de Falhas}

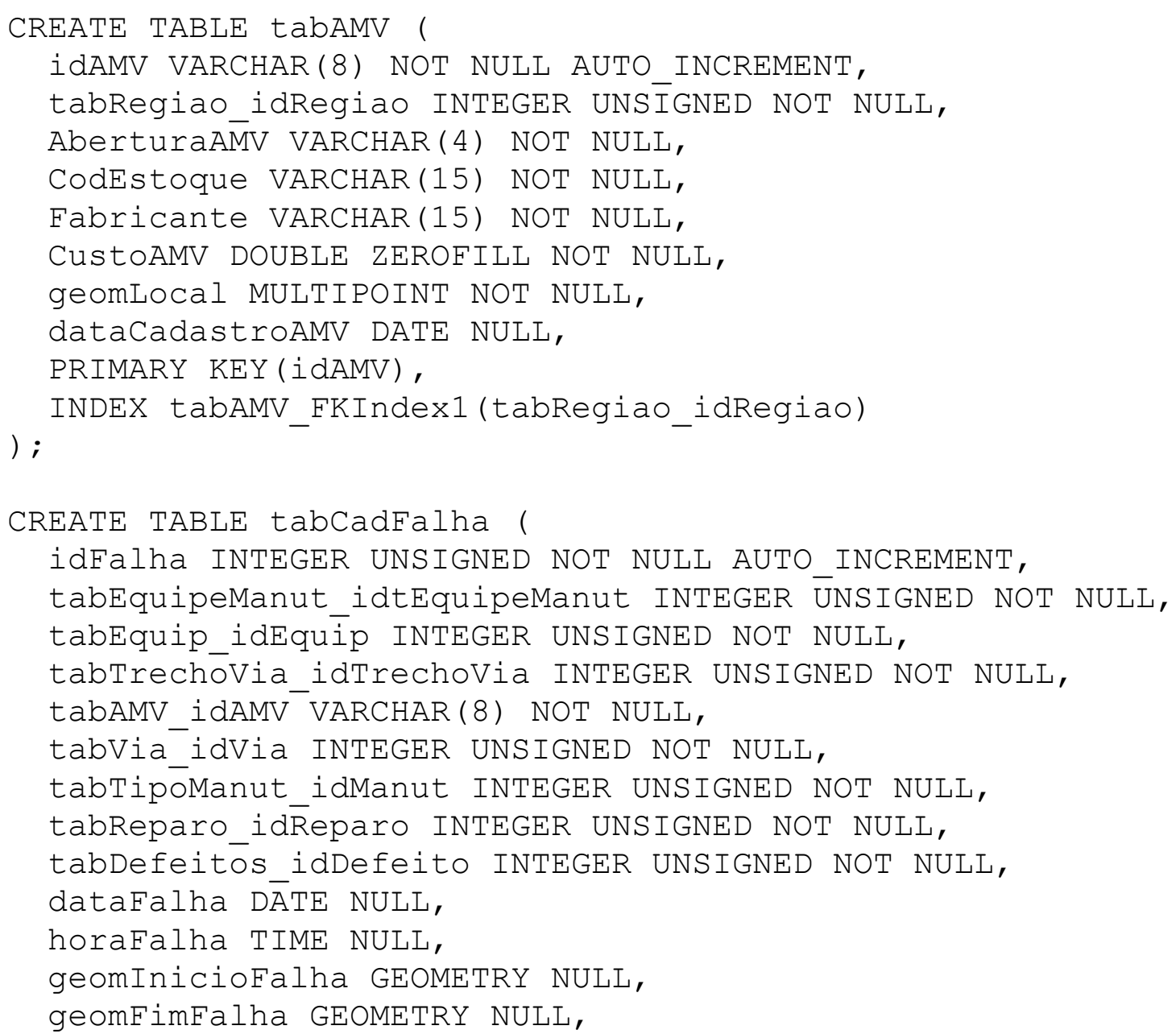




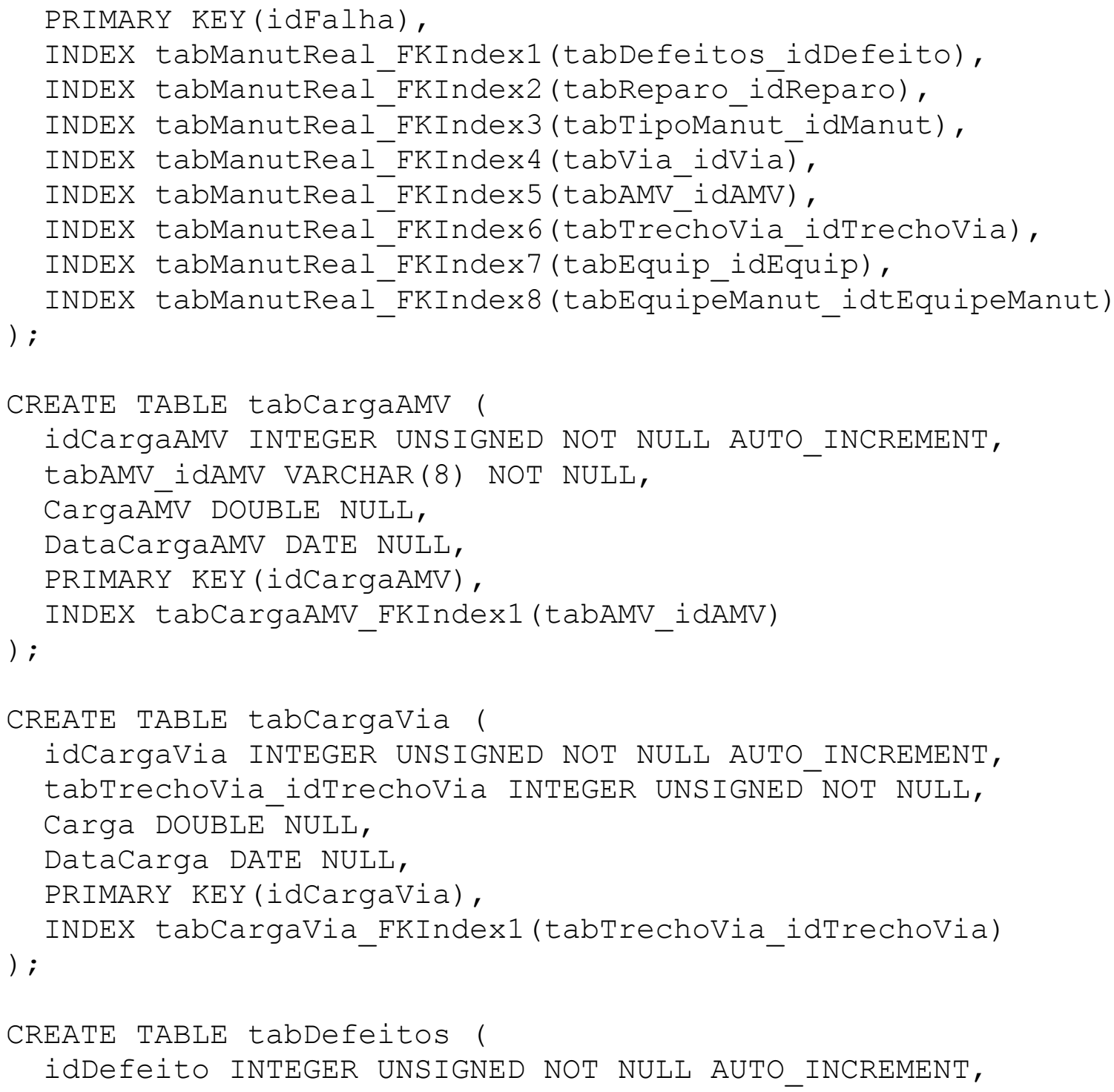


DescDefeito VARCHAR ( 45 ) NULL,

dataCadDef DATE NULL,

PRIMARY KEY (idDefeito)

);

CREATE TABLE tabEquip (

idEquip INTEGER UNSIGNED NOT NULL AUTO_INCREMENT, descEquip VARCHAR (45) NULL,

dataCadEquip DATE NULL,

CustoEquipamento DOUBLE ZEROFILL NOT NULL,

PRIMARY KEY (idEquip)

) ;

CREATE TABLE tabEquipeManut (

idtequipeManut INTEGER UNSIGNED NOT NULL AUTO_INCREMENT, descEquipeManut VARCHAR(45) NOT NULL,

CustoEquipe DOUBLE ZEROFILL NOT NULL,

dataCadEqManut DATE NOT NULL,

PRIMARY KEY (idtEquipeManut)

) ;

CREATE TABLE tabInspVia (

idInspVia INTEGER UNSIGNED NOT NULL AUTO INCREMENT, tabAMV idAMV VARCHAR(8) NOT NULL,

tabTrechoVia idTrechoVia INTEGER UNSIGNED NOT NULL, tabTipoInsp ìdTipoInsp INTEGER UNSIGNED NOT NULL, DataInsp DAT̄E NULL, PRIMARY KEY (idInspVia),

INDEX tabInspVia_FKIndex1 (tabTipoInsp_idTipoInsp), INDEX tabInspVia FKIndex2 (tabTrechoVia idTrechoVia), INDEX tabInspVia_FKIndex3 (tabAMV_idAMV) 


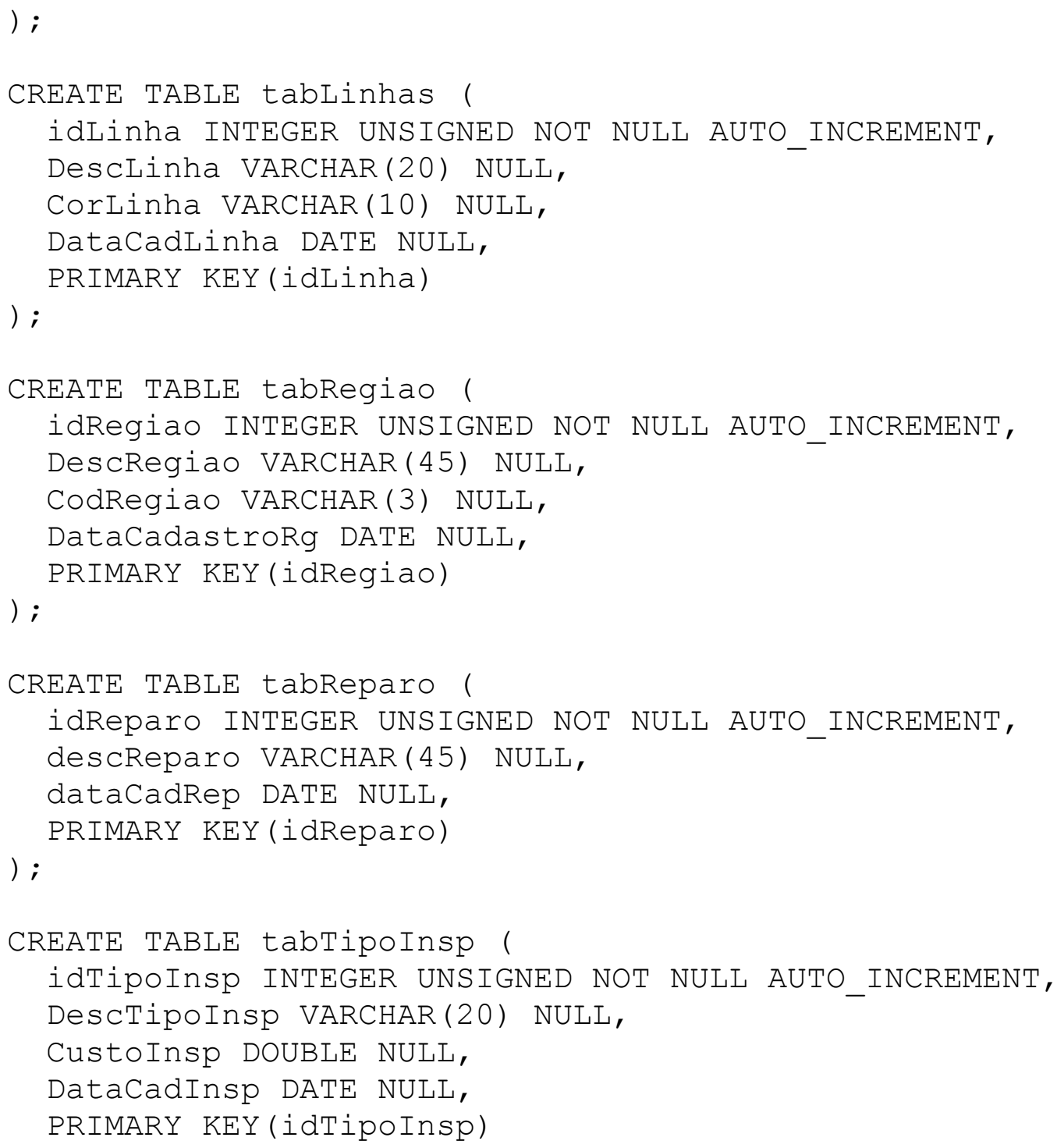


) ;

CREATE TABLE tabTipoManut (

idManut INTEGER UNSIGNED NOT NULL AUTO_INCREMENT,

TipoManut VARCHAR(20) NULL,

Customanut DOUBLE ZEROFILL NOT NULL,

dataCadastroManut DATE NOT NULL,

PRIMARY KEY (idManut)

) ;

CREATE TABLE tabTrechoVia (

idTrechoVia INTEGER UNSIGNED NOT NULL AUTO_INCREMENT, tabRegiao_idRegiao INTEGER UNSIGNED NOT NULL, tabVia idVia INTEGER UNSIGNED NOT NULL,

tabLinhas_idLinha INTEGER UNSIGNED NOT NULL, tabTrilho idTrilho INTEGER UNSIGNED NOT NULL, marcoInicial INTEGER UNSIGNED NULL, marcoFinal INTEGER UNSIGNED NULL,

Raio FLOAT NULL,

Superelev FLOAT NULL, dataCadTrVia DATE NULL, geomDado LINESTRING NULL, PRIMARY KEY(idTrechoVia),

INDEX tabTrechoVia_FKIndexl (tabTrilho_idTrilho), INDEX tabTrechoVia FKIndex2 (tabLinhas idLinha), INDEX tabTrechoVia_FKIndex3 (tabVia idV̄ia), INDEX tabTrechoVia_FKIndex4 (tabRegíao_idRegiao) ) ;

CREATE TABLE tabTrilho ( idTrilho INTEGER UNSIGNED NOT NULL AUTO_INCREMENT, 
TipoTrilho VARCHAR(20) NOT NULL, DurezaTrilho INTEGER NOT NULL,

FabricanteTrilho VARCHAR(20) NOT NULL, CustoTrilho DOUBLE ZEROFILL NOT NULL,

DataCadastroTr DATE NOT NULL,

PRIMARY KEY(idTrilho)

) ;

CREATE TABLE tabVia (

idVia INTEGER UNSIGNED NOT NULL AUTO_INCREMENT, DescVia VARCHAR (8) NULL,

dataCadVia DATE NULL,

PRIMARY KEY(idVia)

); 


\section{Script SQL Para Criação do Banco de Dados de Manutenção Realizada}

CREATE TABLE TABAMV (

IdAMV VARCHAR(8) NOT NULL AUTO INCREMENT,

tabRegiao idRegiao INTEGER UNSĪGNED NOT NULL,

AberturaAM $\bar{M}$ VARCHAR (4) NOT NULL,

CodEstoque VARCHAR(15) NOT NULL,

Fabricante VARCHAR(15) NOT NULL,

CustOAMV DOUBLE ZEROFILL NOT NULL,

geomLocal MULTIPOINT NOT NULL,

dataCadastroAMV DATE NULL,

PRIMARY KEY(idAMV),

) ;

INDEX tabAMV_FKIndex1(tabRegiao_idRegiao)

CREATE TABLE tabCadManut (

idManutReal INTEGER UNSIGNED NOT NULL AUTO INCREMENT,

tabEquipeManut idtEquipeManut INTEGER UNSIḠNED NOT NULL,

tabEquip_idEquip INTEGER UNSIGNED NOT NULL,

tabTrechoVia idTrechoVia INTEGER UNSIGNED NOT NULL,

tabAMV idAMV VARCHAR (8) NOT NULL,

tabVia_idVia INTEGER UNSIGNED NOT NULL,

tabTipoManut idManut INTEGER UNSIGNED NOT NULL,

tabReparo idReparo INTEGER UNSIGNED NOT NULL,

tabDefeitōs_idDefeito INTEGER UNSIGNED NOT NULL,

DataManReal DATE NULL,

horaManReal TIME NULL,

geomInicioManReal GEOMETRY NULL,

geomFimManReal GEOMETRY NULL,

PRIMARY KEY (idManutReal),

INDEX tabManutReal FKIndexl(tabDefeitos idDefeito),

INDEX tabManutReal_FKIndex2 (tabReparo_idReparo),

INDEX tabManutReal FKIndex3 (tabTipoManut idManut)

INDEX tabManutReal FKIndex4 (tabVia idVia),

INDEX tabManutReal FKIndex5 (tabAMV idAMV), 
INDEX tabManutReal FKIndex6(tabTrechoVia idTrechoVia),

INDEX tabManutReal_FKIndex7 (tabEquip_idEquip), ;

INDEX tabManutReal_EKIndex8 (tabEquipeManut_idtEquipeManut)

CREATE TABLE tabCargaAMV (

idCargaAMV INTEGER UNSIGNED NOT NULL AUTO INCREMENT,

tabAMV_idAMV VARCHAR(8) NOT NULL,

CargaĀ̄ DOUBLE NULL,

DataCargaAMV DATE NULL,

PRIMARY KEY(idCargaAMV)

INDEX tabCargaAMV_FKIndex1 (tabAMV_idAMV)

CREATE TABLE tabCargaVia (

idCargaVia INTEGER UNSIGNED NOT NULL AUTO_INCREMENT, tabTrechoVia idTrechoVia INTEGER UNSIGNED NOT NULL,

Carga DOUBLE ${ }^{-}$NULL,

DataCarga DATE NULL,

PRIMARY KEY(idCargaVia),

INDEX tabCargaVia_FKIndex1 (tabTrechoVia_idTrechoVia)

) ;

CREATE TABLE tabDefeitos (

idDefeito INTEGER UNSIGNED NOT NULL AUTO_INCREMENT, DescDefeito VARCHAR (45) NULL,

dataCadDef DATE NULL,

PRIMARY KEY(idDefeito)

;

CREATE TABLE tabEquip (

idEquip INTEGER UNSIGNED NOT NULL AUTO INCREMENT,

descEquip VARCHAR (45) NULL,

dataCadEquip DATE NULL,

CustoEquipamento DOUBLE ZEROFILL NOT NULL,

PRIMARY KEY(idEquip)

) ; 
CREATE TABLE tabEquipeManut (

idtEquipeManut INTEGER UNSIGNED NOT NULL AUTO_INCREMENT, descEquipeManut VARCHAR (45) NOT NULL,

CustoEquipe DOUBLE ZEROFILL NOT NULL,

dataCadEqManut DATE NOT NULL,

PRIMARY KEY(idtEquipeManut)

) ;

CREATE TABLE tabInspVia (

idInspVia INTEGER UNSIGNED NOT NULL AUTO_INCREMENT, tabAMV_idAMV VARCHAR(8) NOT NULL,

tabTrechoVia idTrechoVia INTEGER UNSIGNED NOT NULL,

tabTipoInsp_idTipoInsp INTEGER UNSIGNED NOT NULL,

DataInsp DATE NULL,

PRIMARY KEY(idInspVia),

INDEX tabInspVia_FKIndex1 (tabTipoInsp idTipoInsp),

INDEX tabInspVia_FKIndex2 (tabTrechoViāidTrechoVia), INDEX tabInspVia_FKIndex3 (tabAMV_idAMV)

)

CREATE TABLE tabLinhas (

idLinha INTEGER UNSIGNED NOT NULL AUTO INCREMENT,

DescLinha VARCHAR (20) NULL,

CorLinha VARCHAR(10) NULL,

DataCadLinha DATE NULL

PRIMARY KEY(idLinha)

) ;

CREATE TABLE tabRegiao (

idRegiao INTEGER UNSIGNED NOT NULL AUTO_INCREMENT, DescRegiao VARCHAR (45) NULL,

CodRegiao VARCHAR(3) NULL,

DataCadastroRg DATE NULL,

PRIMARY KEY(idRegiao)

); 
CREATE TABLE tabReparo (

idReparo INTEGER UNSIGNED NOT NULL AUTO_INCREMENT, descReparo VARCHAR (45) NULL,

dataCadRep DATE NULL,

PRIMARY KEY(idReparo)

) ;

CREATE TABLE tabTipoInsp (

idTipoInsp INTEGER UNSIGNED NOT NULL AUTO_INCREMENT, DescTipoInsp VARCHAR(20) NULL,

CustoInsp DOUBLE NULL,

DataCadInsp DATE NULL,

PRIMARY KEY(idTipoInsp)

);

CREATE TABLE tabTipoManut (

idManut INTEGER UNSIGNED NOT NULL AUTO INCREMENT,

TipoManut VARCHAR(20) NULL,

CustoManut DOUBLE ZEROFILL NOT NULL,

dataCadastroManut DATE NOT NULL,

PRIMARY KEY(idManut)

) ;

CREATE TABLE tabTrechoVia (

idTrechoVia INTEGER UNSIGNED NOT NULL AUTO_INCREMENT, tabRegiao idRegiao INTEGER UNSIGNED NOT NULL, tabVia idVia INTEGER UNSIGNED NOT NULL,

tabLinh̄as_idLinha INTEGER UNSIGNED NOT NULL,

tabTrilho idTrilho INTEGER UNSIGNED NOT NULL,

marcoInicíal INTEGER UNSIGNED NULL,

marCoFinal INTEGER UNSIGNED NULL,

Raio FLOAT NULL,

Superelev FLOAT NULL,

dataCadTrVia DATE NULL,

geomDado LINESTRING NULL,

PRIMARY KEY(idTrechoVia),

INDEX tabTrechoVia_FKIndex1 (tabTrilho_idTrilho), 
INDEX tabTrechoVia FKIndex2 (tabLinhas idLinha) INDEX tabTrechoVia_FKIndex3 (tabVia_idVia),

INDEX tabTrechoVia_FKIndex4 (tabRegía_idRegiao)

) ;

CREATE TABLE tabTrilho (

idTrilho INTEGER UNSIGNED NOT NULL AUTO INCREMENT,

TipoTrilho VARCHAR(20) NOT NULL,

DurezaTrilho INTEGER NOT NULL,

FabricanteTrilho VARCHAR(20) NOT NULL,

CustoTrilho DOUBLE ZEROFILL NOT NULL,

DataCadastroTr DATE NOT NULL,

PRIMARY KEY(idTrilho)

);

CREATE TABLE tabVia (

idVia INTEGER UNSIGNED NOT NULL AUTO INCREMENT,

DescVia VARCHAR (8) NULL

dataCadVia DATE NULL,

PRIMARY KEY(idVia)

) ; 
Figura 1 - Modelo ER do Banco de Dados de Falhas

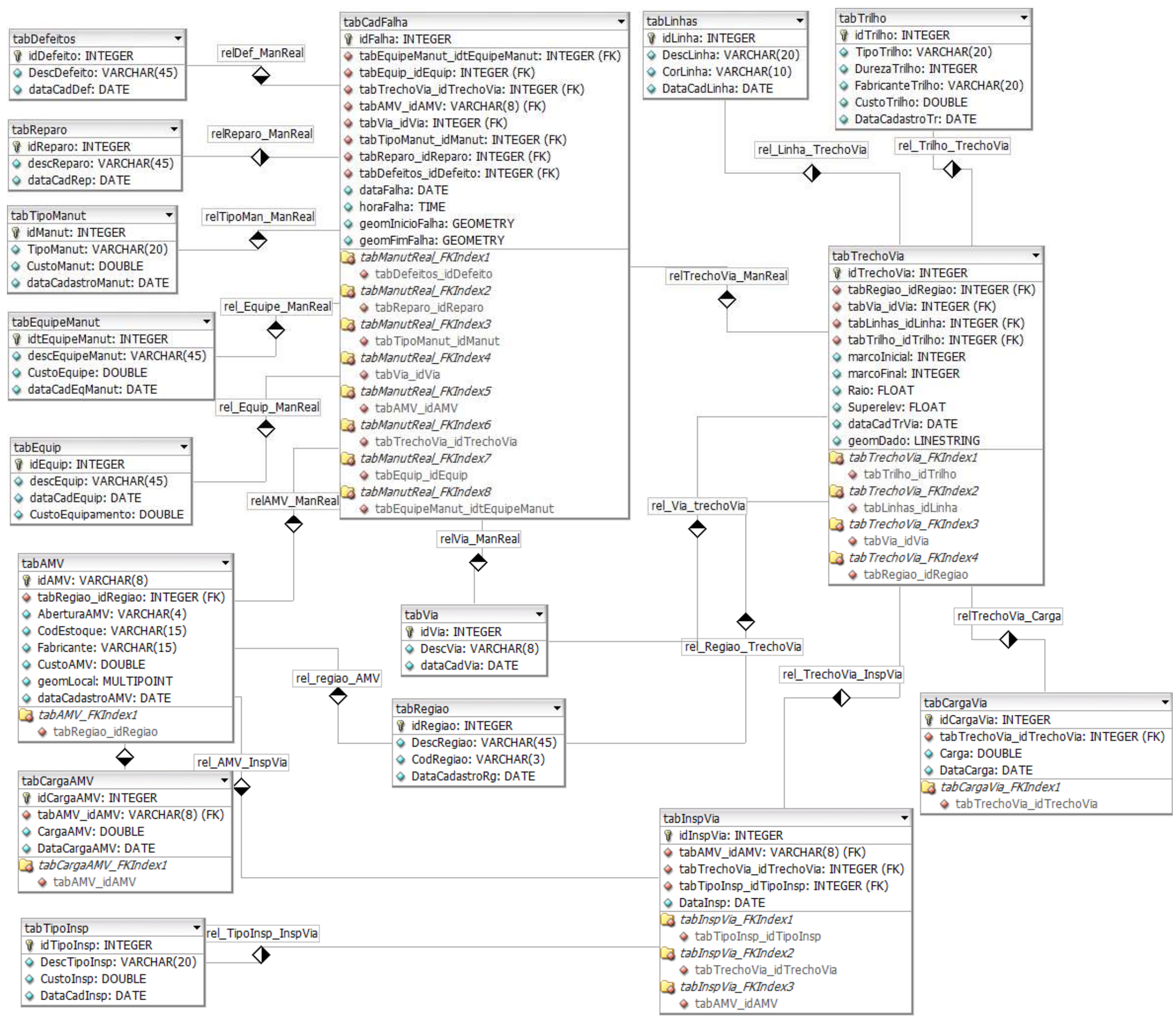


Figura 2 - Modelo ER do Banco de Dados de Manutenção Realizada

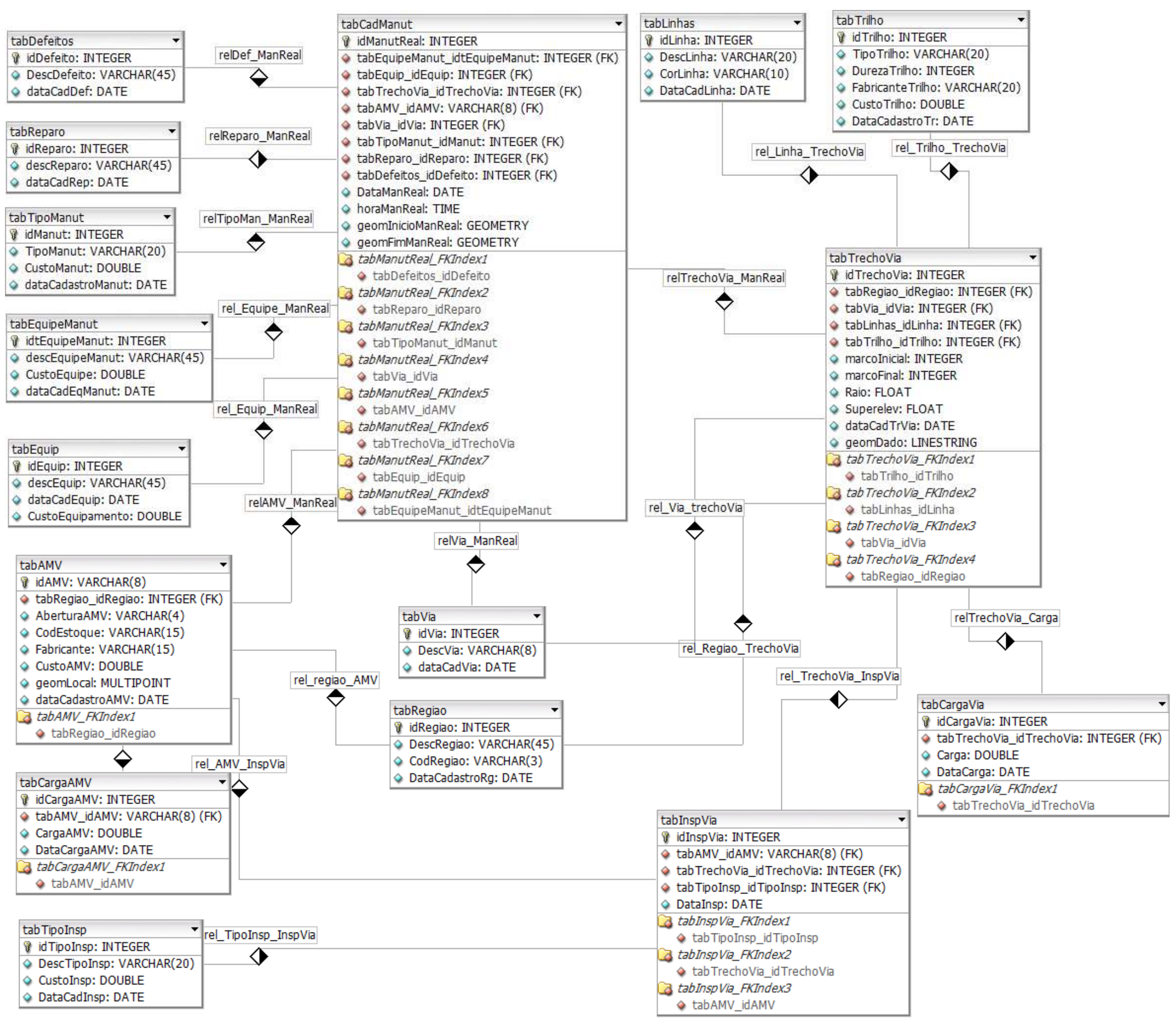

